NUREG/CR-6189

SAND94-0407

\title{
A Simplified Model of Aerosol Removal by Natural Processes in Reactor Containments
}

Prepared by

D. A Powers, K. E. Washington/SNL

S. B. Burson/NRC

J. L. Sprung/SNL

Sandia National Laboratories

Operated by

Sandia Corporation

Prepared for

U.S. Nuclear Regulatory Commission

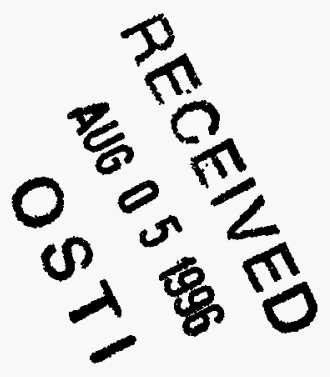

MASTER 


\section{AVAILABILITY NOTICE}

Availability of Reference Materials Cited in NRC Publications

Most documents cited in NRC publications will be available from one of the following sources:

1. The NRC Public Document Room, 2120 L Street, NW., Lower Level, Washington, DC 20555-0001

2. The Superintendent of Documents, U.S. Government Printing Office, P. O. Box 37082, Washington, DC 20402-9328

3. The National Technical Information Service, Springfield, VA 22161-0002

Although the listing that follows represents the majority of documents cited in NRC publications, it is not intended to be exhaustive.

Referenced documents avallable for inspection and copying for a fee from the NRC Public Document Room include NRC correspondence and internal NRC memoranda; NRC bulletins, circulars, information notices, inspection and investigation notices; licensee event reports; vendor reports and correspondence; Commission papers; and applicant and licensee documents and correspondence.

The following documents in the NUREG series are available for purchase from the Government Printing Office: formal NRC staff and contractor reports, NRC-sponsored conference proceedings, international agreement reports, grantee reports, and NRC booklets and brochures. Also available are regulatory guides, NRC regulations in the Code of Federal Regulations, and Nuclear Regulatory Commission Issuances.

Documents available from the National Technical Information Service include NUREG-series reports and technical reports prepared by other Federal agencies and reports prepared by the Atomic Energy Commission, forerunner agency to the Nuclear Regulatory Commission.

Documents available from public and special technical libraries include all open literature items, such as books, journal articles, and transactions. Federal Register notices. Federal and State legislation, and congressional reports can usually be obtained from these libraries.

Documents such as theses, dissertations, foreign reports and translations, and non-NRC conference proceedings are avallable for purchase from the organization sponsoring the publication cited.

Single copies of NRC draft reports are available free, to the extent of supply, upon written request to the Office of Administration, Distribution and Mail Services Section, U.S. Nuclear Regulatory Commission, Washington, DC 20555-0001.

Copies of industry codes and standards used in a substantive manner in the NRC regulatory process are maintained at the NRC Library. Two White Flint North, 11545 Rockville Pike, Rockville, MD 20852-2738, for use by the public. Codes and standards are usually copyrighted and may be purchased from the originating organization or, if they are American National Standards, from the American National Standards Institute, 1430 Broadway, New York, NY 10018-3308.

\section{DISCLAIMER NOTICE}

This report was prepared as an account of work sponsored by an agency of the United States Government. Neither the United States Government nor any agency thereof, nor any of their employees, makes any warranty, expressed or implied, or assumes any legal liability or responsibility for any third party's use, or the results of such use, of any information, apparatus, product, or process disclosed in this report, or represents that its use by such third party would not infringe privately owned rights. 


\section{A Simplified Model of Aerosol Removal by Natural Processes in Reactor Containments}

Manuscript Completed: October 1995

Date Published: July 1996

Prepared by

D. A. Powers, K. E. Washington/SNL

S. B. Burson/NRC

J. L. Sprung/SNL

Sandia National Laboratories

Albuquerque, NM 87185

J. H. Schaperow, NRC Project Manager

Prepared for

Division of Systems Technology

Office of Nuclear Regulatory Research

U.S. Nuclear Regulatory Commission

Washington, DC 20555-0001

NRC Job Code L2035 


\section{DISCLAIMER}

Portions of this document may be illegible in electronic image products. Images are produced from the best available original document. 


\section{DISCLAIMER}

This report was prepared as an account of work sponsored by an agency of the United States Government. Neither the United States Government nor any agency thereof, nor any of their employees, makes any wartanty, express or implied, or assumes any legal liability or responsibility for the accuracy, completeness, or usefulness of any information, apparatus, product, or process disclosed, or represents that its use would not infringe privately owned rights. Reference herein to any specific commercial product, process, or service by trade name, trademark, manufac. turer, or otherwise does not necessarily constitute or imply its endorsement, recommendation, or favoring by the United States Government or any agency thereof. The views and opinions of authors expressed herein do not necessarily state or reflect those of the United States Government or any agency thereof. 


\begin{abstract}
Simplified formulae are developed for estimating the aerosol decontamination that can be achieved by natural processes in the containments of pressurized water reactors and in the drywells of boiling water reactors under severe accident conditions. These simplified formulae were derived by correlation of results of Monte Carlo uncertainty analyses of detailed models of aerosol behavior under accident conditions. Monte Carlo uncertainty analyses of decontamination by natural aerosol processes are reported for $1000,2000,3000$, and $4000 \mathrm{MW}$ (th) pressurized water reactors and for 1500,2500 , and $3500 \mathrm{MW}$ (th) boiling water reactors. Uncertainty distributions for the decontamination factors and decontamination coefficients as functions of time were developed in the Monte Carlo analyses by considering uncertainties in aerosol processes, material properties, reactor geometry and severe accident progression. Phenomenological uncertainties examined in this work included uncertainties in aerosol coagulation by gravitational collision, Brownian diffusion, turbulent diffusion and turbulent inertia. Uncertainties in aerosol deposition by gravitational settling, thermophoresis, diffusiophoresis, and turbulent diffusion were examined. Electrostatic charging of aerosol particles in severe accidents is discussed. Such charging could affect both the coagulation and deposition of aerosol particles. Electrostatic effects are not considered in most available models of aerosol behavior during severe accidents and cause uncertainties in predicted natural decontamination processes that could not be taken in to account in this work.
\end{abstract}

Median (50 percentile), 90 and 10 percentile values of the uncertainty distributions for effective decontamination coefficients were correlated with time and reactor thermal power. These correlations constitute a simplified model that can be used to estimate the decontamination by natural aerosol processes at three levels of conservatism. Example applications of the simplified model are described. 


\section{Table of Contents}

Page

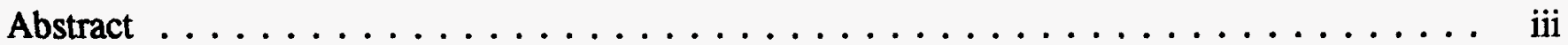

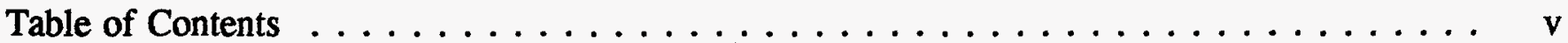

List of Figures $\ldots \ldots \ldots \ldots \ldots \ldots \ldots \ldots \ldots \ldots \ldots \ldots \ldots \ldots \ldots \ldots \ldots$ viii

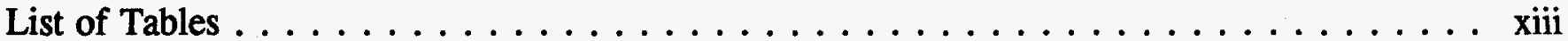

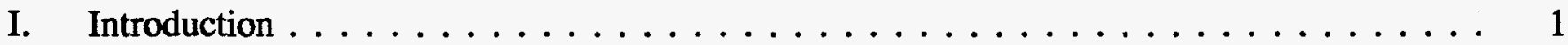

II. Physical and Chemical Phenomena That Affect Aerosol Behavior in Reactor Containments . . . . . . . . . . . . . . . . . . . 8

A. Aerosol Dynamic Equation . . . . . . . . . . . . . . . . 8

B. Aerosol Growth by Coagulation $\ldots \ldots \ldots \ldots \ldots \ldots \ldots \ldots$

1. The Coagulation Kernel $\ldots \ldots \ldots \ldots \ldots \ldots \ldots \ldots$

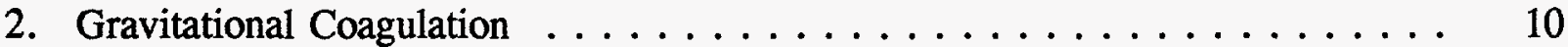

3. Brownian Coagulation $\ldots \ldots \ldots \ldots \ldots \ldots \ldots \ldots \ldots \ldots \ldots \ldots \ldots$

4. Turbulent Diffusion Coagulation $\ldots \ldots \ldots \ldots \ldots \ldots \ldots \ldots \ldots \ldots$

5. Turbulent Inertial Coagulation $\ldots \ldots \ldots \ldots \ldots \ldots \ldots \ldots \ldots \ldots$

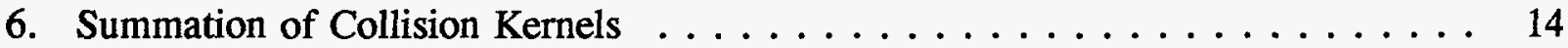

C. Aerosol Growth by Condensation $\ldots \ldots \ldots \ldots \ldots \ldots \ldots \ldots \ldots \ldots$

1. Condensation in the Free Molecular Regime . . . . . . . . . . . . 18

2. Condensation in the Continuum Regime . . . . . . . . . . . . 25

3. Condensation in the Transition Regime $\ldots \ldots \ldots \ldots \ldots \ldots \ldots$

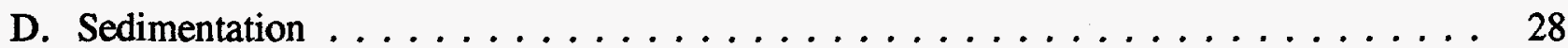

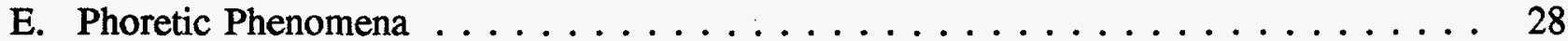

1. Diffusiophoresis . . . . . . . . . . . . . . . . . 29

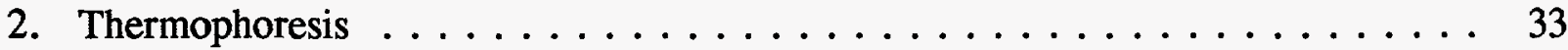

F. Diffusive Deposition of Aerosols . . . . . . . . . . . . . . . . . . . . . 34

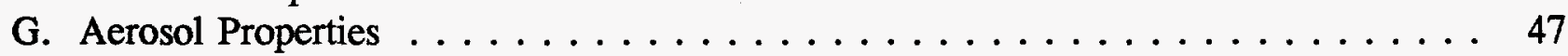

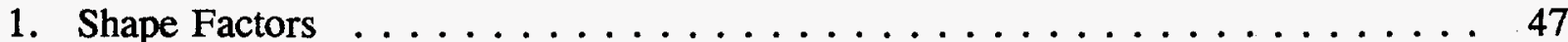

2. Slip Correction Factor $\ldots \ldots \ldots \ldots \ldots \ldots \ldots \ldots \ldots \ldots$

3. Hygroscopicity . . . . . . . . . . . . . . . . 52

4. Thermal Conductivity .................... 55

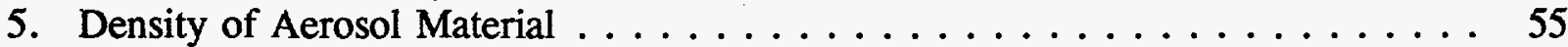

6. Accommodation Coefficients . . . . . . . . . . . . . . 58 
H. Thermophysical Properties of the Gas Phase $\ldots \ldots \ldots \ldots \ldots \ldots$

1. The Diffusion Coefficient of Steam $\ldots \ldots \ldots \ldots \ldots \ldots \ldots \ldots$

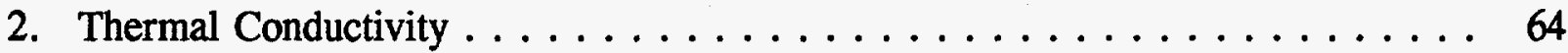

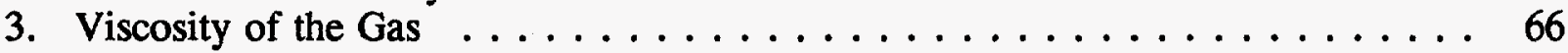

I. Effects of Radioactivity on Aerosol Behavior . . . . . . . . . . . . . . . . 69

1. Charging of Radioactive Aerosol Particles . . . . . . . . . . . . . . . . 69

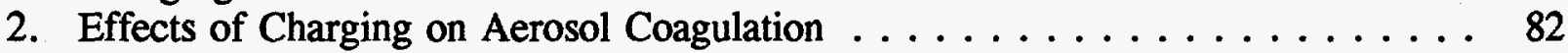

3. Effect of Charging on Aerosol Particle Deposition . . . . . . . . . . 83

4. Neglect of Charging Effects . . . . . . . . . . . . . . . 85

III. Uncertainties in the Prediction of Aerosol Behavior in Reactor Containments . . . . . . 87

A. Uncertainty in the Reactor Containment Geometry and Configurations . . . . . . . 97

B. Uncertainties in Accident Progression . . . . . . . . . . . . . . 102

1. Treatment of Accident Timing . . . . . . . . . . . . . 102

2. Uncertainty in Chemical Forms of Radionuclides Released to the Containment . . 103

3. Uncertainties in Nonradioactive Aerosol Masses Released to the Containment . . 104

4. Uncertainties in Pressure and Temperature . . . . . . . . . . . . . . 107

5. Steam Condensation Rates . . . . . . . . . . . . . . . . . 114

6. Uncertainty in the Zirconium Inventories . . . . . . . . . . . 116

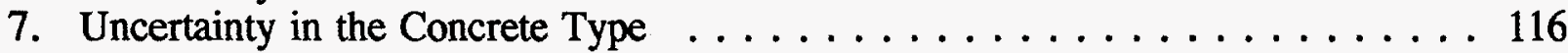

8. Uncertainty in Heat Losses to the Concrete . . . . . . . . . . . . . . . 116

9. Gas Generation During the Ex-Vessel Release Phase and the Late

In-Vessel Release Phase . . . . . . . . . . . . . . . . . . . . . . 118

10. Boiling Water Reactor Accident Sequences . . . . . . . . . . . . . . . 119

C. Phenomenological Uncertainties . . . . . . . . . . . . . . . . . . 122

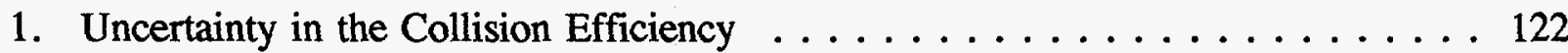

2. Sticking Coefficient ...................... 122

3. Uncertainty in the Turbulent Energy Dissipation Rate . . . . . . . . . . . 122

4. Uncertainty in the Aerosol Shape Factors . . . . . . . . . . . . . . 123

5. Uncertainty in Accommodation Coefficients . . . . . . . . . . . . . 124

6. Uncertainty in Particle Material Density . . . . . . . . . . . . . 126

7. Uncertainty in Aerosol Particle Thermal Conductivity . . . . . . . . . . . 127

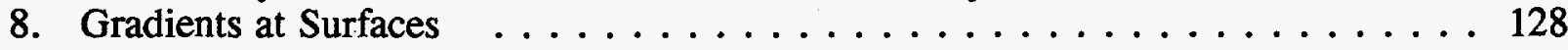

9. Summation of Deposition Mechanisms $\ldots \ldots \ldots \ldots \ldots \ldots \ldots \ldots \ldots$ 


\section{Table of Contents (concluded)}

IV. Correlations for Aerosol Behavior in Reactor Containments . . . . . . . . . . 133

V. Monte Carlo Uncertainty Analysis . . . . . . . . . . . . . . . . 144

A. Uncertainty Analyses for a Pressurized Water Reactor . . . . . . . . . . 145

B. Uncertainty Analyses for Radiological Design-Basis Accidents . . . . . . . . . 173

C. Uncertainty Analyses for Boiling Water Reactors $\ldots \ldots \ldots \ldots \ldots$

VI. Example Application of the Simplified Models of Decontamination by Natural

Aerosol Processes . . . . . . . . . . . . . . . . . . . . . . . 216

VII. Conclusions . . . . . . . . . . . . . . . . . . . . . . . . . 229

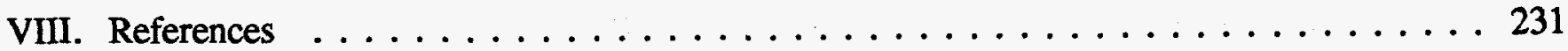




\section{List of Figures}

Figure

1 Effect of considering simultaneous gravitational and Brownian diffusion coagulation rather than simple summation of the respective kernels

2 Collision kernel for simultaneous Brownian and turbulent diffusion in comparison to the sum of independent kernels . . . . . . . . . . . . 17

3 Comparison of various summations of terms in the coagulation kernel . . . . . . . 19

4 Effect of surface curvature and salt dissolution on the equilibrium partial

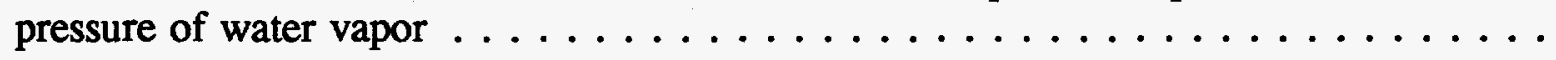

5 Comparison of the measured thermophoretic deposition of oil droplets to predictions obtained with the model developed by Talbot et al. . . . . . . . . . . . 35

6 Comparison of measured deposition data for $0.8 \mu \mathrm{m}$ iron particles to predictions obtained with the integration derived here $\ldots \ldots \ldots \ldots \ldots \ldots \ldots$

7 Comparison of predictions of particle deposition velocities $\ldots \ldots \ldots \ldots \ldots \ldots \ldots$

8 Sensitivity of predicted deposition velocities to the friction velocity $\ldots \ldots \ldots \ldots \ldots 45$

9 Photomicrographs of iron oxide particles formed (a) under dry conditions and (b) under humid conditions $\ldots \ldots \ldots \ldots \ldots \ldots \ldots \ldots \ldots \ldots \ldots \ldots$

10 Size-dependent aerosol shape factors for particles of various material densities $\ldots \ldots \ldots 50$

11 Comparison of the predicted slip correction factor from Phillips' model to values obtained in experiments and to the empirical correlation developed by Allen and Raabe .......................... 53

12 Temperature accommodation coefficients of various gases on glass as functions of temperature

13 Comparison of data for the diffusion coefficient of water vapor in air to a correlation

14 Predictions of the diffusion coefficient of steam in $\mathrm{H}_{2}, \mathrm{~N}_{2}$, and $\mathrm{CO}_{2} \ldots \ldots \ldots 6$

15 Distribution of electrostatic charges on particles of various sizes $\ldots \ldots \ldots \ldots \ldots$

16 Mean charge on aerosol particles when the background ion production rate is zero 


\section{List of Figures (continued)}

Figure

Page

17 Comparison of probability density functions used in this study $\ldots \ldots \ldots$. . . . . . . 88

18 Containment volumes of existing USA pressurized water reactors plotted against the nominal thermal power of the reactors . . . . . . . . . . . . . . . 98

19 Drywall volumes of existing USA boiling water reactors plotted against the nominal thermal power of the reactor

20 Comparison of aerosol mass predicted with the CONTAIN code and predicted with the correlation for a situation involving low levels of turbulence . . . . . . . . . 139

21 Comparison of aerosol mass predicted with the CONTAIN code and predicted with the correlation for a situation involving high levels of turbulence . . . . . . . . . 140

22 Comparison of the predictions of the CONTAIN code and the predictions of the modified correlation method for a situation involving two aerosol sources

23 Containment temperatures and pressures selected for the various phases of a particular accident at a $3000 \mathrm{MW}$ (th) pressurized water reactor

24 Steam condensation rates and the difference between the atmosphere temperature and structural surface temperatures in a particular accident at a $3000 \mathrm{MW}($ th) pressurized water reactor

25 Effective size of aerosol particles in the containment of a $3000 \mathrm{MW}$ (th) pressurized

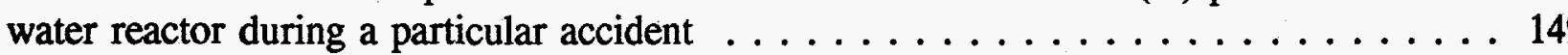

26 Concentrations of various classes of radioactive materials in the containment atmosphere as a function of time for a particular $3000 \mathrm{MW}(\mathrm{th})$ pressurized water reactor accident ............................ 150

27 Aerosol deposition velocities by various mechanisms during a particular accident at a $3000 \mathrm{MW}(\mathrm{th})$ pressurized water reactor

28 Uncertainty distribution for the decontamination factor for gap release in a $3000 \mathrm{MW}$ PWR at the end of in-vessel release $\ldots \ldots \ldots \ldots \ldots$

29 Uncertainty distribution for the decontamination factor for gap release in a $3000 \mathrm{MW}$ PWR at the end of ex-vessel release . . . . . . . . . . . . . . . . . . . 154

30 Uncertainty distribution for the decontamination factor for gap release in a $3000 \mathrm{MW}$ PWR at the end of late in-vessel release 


\section{List of Figures (continued)}

Figure

31 Uncertainty distribution for the decontamination factor for gap release in a $3000 \mathrm{MW}$ PWR at 80000 seconds . . . . . . . . . . . . . . . . . 156

32 Median values of the average effective decontamination coefficients for four classes of radioactive material released during accidents at a $3000 \mathrm{MW}$ (th) pressurized water reactor

33 Decontamination coefficients for gap releases from a $3000 \mathrm{MW}$ (th) PWR as

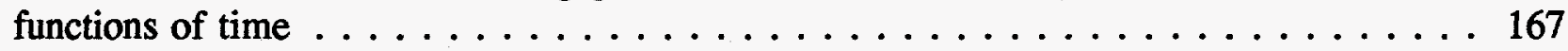

34 Time dependencies of median effective decontamination coefficients for gap release during accidents at pressurized water reactors of various powers

35 Dependencies of various effective decontamination coefficients for gap release on reactor power . . . . . . . . . . . . . . . . . . . . . . . . . . . 169

36 Dependencies of various effective decontamination coefficients on reactor power $\ldots \ldots 170$

37 Dependencies of various effective decontamination coefficients on reactor power $\ldots \ldots 171$

38 Uncertainty distributions for steam condensation rates at $1800 \mathrm{~s}$ and $80000 \mathrm{~s}$ during radiological design basis accidents at a $3000 \mathrm{MW}$ (th) reactor . . . . . . . . . 179

39 Median decontamination coefficients calculated for gap and in-vessel releases during radiological design basis accidents at a $3000 \mathrm{MW}($ th) reactor . . . . . . . . . . .

40 Median (50 percentile), upper bound (90 percentile), and lower bound (10 percentile) decontamination coefficients for gap releases during radiological design basis accidents at a $3000 \mathrm{MW}$ (th) reactor $\ldots \ldots \ldots \ldots \ldots \ldots \ldots \ldots$

41 Dependencies on reactor thermal power of median decontamination coefficients for gap releases during radiological design basis accidents

42 Average, effective decontamination coefficients for gap releases during radiological design basis accidents

43 Effective decontamination coefficients for gap releases and in-vessel releases during radiological design basis accidents at reactors of various thermal powers

44 Drywell atmosphere temperatures and pressures during a particular accident at a $2500 \mathrm{MW}$ (th) boiling water reactor 


\section{List of Figures (continued)}

Figure

Page

45 Temperature differences between the atmosphere and structural surfaces and between the atmosphere and the steam saturation temperature during a particular accident in a $2500 \mathrm{MW}$ (th) boiling water reactor

46 Drywell atmosphere composition during a particular accident at a $2500 \mathrm{MW}$ (th) boiling water reactor .

47 Molar rate of gas flow from the drywell to the suppression pool and the molar rate of steam condensation during a particular accident at a $2500 \mathrm{MW}$ (th)

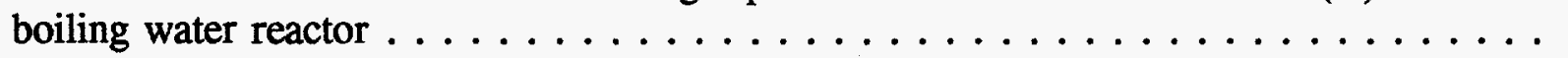

48 Effective size of aerosol particles in the drywell of a $2500 \mathrm{MW}$ (th) boiling water

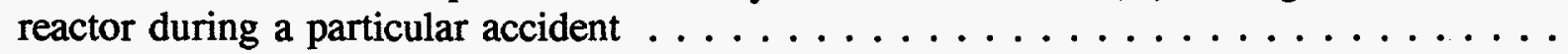

49 Concentrations of radioactive aerosols released to the drywell during various phases of a particular accident at a $2500 \mathrm{MW}$ (th) boiling water reactor

50 Aerosol deposition velocities by various mechanisms during a particular accident at $2500 \mathrm{MW}$ (th) boiling water reactor

51 Median values of the decontamination coefficients for the four classes of radioactive material released to the drywell during accidents at a $3500 \mathrm{MW}$ (th) boiling water reactor

52 Time dependence of the effective decontamination coefficient for gap release material in the drywell of a $3500 \mathrm{MW}$ (th) boiling water reactor

53 Dependence of gap release decontamination coefficients on boiling

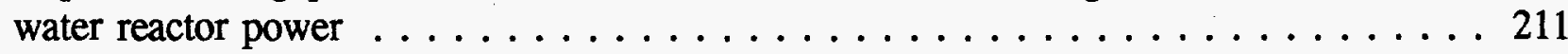

54 Dependence of gap release decontamination coefficients on boiling water reactor power

55 Dependence of gap release decontamination coefficients on boiling water reactor power

56 Dependence of the late in-vessel release decontamination coefficient

for the period from 19800 to $45000 \mathrm{~s}$ on boiling water reactor power . . . . . . . . 214

57 Percent of core inventory of iodine suspended in the containment of a $3000 \mathrm{MW}$ (th) pressurized water reactor as a function of time $\ldots \ldots \ldots \ldots \ldots \ldots \ldots \ldots \ldots \ldots$

58 Percent of core inventory of cesium suspended in the containment of a $3000 \mathrm{MW}$ (th) pressurized water reactor as a function of time 


\section{List of Figures (concluded)}

Figure

Page

59 Percent of core inventory of tellurium suspended in the containment of a $3000 \mathrm{MW}$ (th) pressurized water reactor as a function of time $\ldots \ldots \ldots \ldots \ldots \ldots$

60 Percent of core inventory of strontium suspended in the containment of a $3000 \mathrm{MW}(\mathrm{th})$ pressurized water reactor as a function of time . . . . . . . . . . . . . 224

61 Percent of core inventory of iodine suspended in the drywell of a $3000 \mathrm{MW}$ (th) boiling water reactor as a function of time

62 Percent of core inventory of cesium suspended in the drywell of a $3000 \mathrm{MW}$ (th) boiling water reactor as a function of time

63 Percent of core inventory of tellurium suspended in the drywell of a $3000 \mathrm{MW}(\mathrm{th})$ boiling water reactor as a function of time

64 Percent of core inventory of strontium suspended in the drywell of a $3000 \mathrm{MW}$ (th) boiling water reactor as a function of time 


\section{List of Tables}

Table

Page

1 Revised severe accident source terms for pressurized

water reactors (PWRs) and boiling water reactors (BWRs) $\ldots \ldots \ldots \ldots \ldots \ldots$

2 Radionuclide inventories in a particular pressurized water reactor (PWR) and a particular boiling water reactor (BWR) . . . . . . . . . . . 3

3 Determinations of the sticking coefficient of water cited by Pruppacher and Klett . . . . 21

4 Thermal conductivities of materials that might make up aerosol particles in

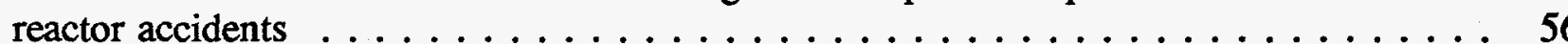

5 Parameter values for calculating binary diffusion coefficients of gases . . . . . . . 63

6 Parametric values for correlation of gas thermal conductivities . . . . . . . . . . . 67

7 Parameters for the calculation of gas viscosity $\ldots \ldots \ldots \ldots$. . . . . . . . . . 69

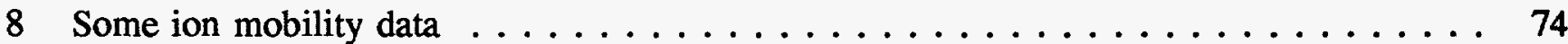

9 Radionuclide decay rates $\ldots \ldots \ldots \ldots \ldots \ldots \ldots \ldots$

10 Noble gas decay characteristics $\ldots \ldots \ldots \ldots \ldots \ldots \ldots \ldots \ldots$

11 Effects of parameter variations on the mean aerosol charge $\ldots \ldots \ldots$. . . . . . . 81

12 Uncertain quantities, range of values and subjective probability distributions . . . . . 89

13 Mass multipliers for radionuclides released to the containment . . . . . . . . . . . . 105

14 Pressure, temperatures, and steam condensation rates during the gap release phase of severe accidents .......................... 108

15 Pressure, temperatures, and steam condensation rates during the in-vessel release phase of severe accidents ... . . . . . . . . . . . . . . . . . . . . 110

16 Pressure, temperatures, and steam condensation rates during the ex-vessel and late in-vessel phases of severe accidents . . . . . . . . . . . . . . . . . . . . 112

17 Zirconium mass in core debris $\ldots \ldots \ldots \ldots \ldots \ldots \ldots \ldots \ldots \ldots \ldots$

18 Median (50 percentile) decontamination factors for pressurized water reactors . . . . . 157 


\section{List of Tables (continued)}

Table

Page

19 Reasonable upper bound (90 percentile) decontamination factors for pressurized water reactors

20 Reasonable lower bound (10 percentile) decontamination factors for pressurized water reactors

21 Mean decontamination factors for pressurized water reactors . . . . . . . . . . . . 160

22 Median (50 percentile) effective decontamination coefficients for pressurized water reactors . . . . . . . . . . . . . . . . . . . . . . . . 162

23 Reasonable upper bound ( 90 percentile) effective decontamination coefficients for pressurized water reactors

24 Reasonable lower bound (10 percentile) effective decontamination coefficients for pressurized water reactors

25 Mean effective decontamination coefficients for pressurized water reactors

26 Correlation of important PWR decontamination coefficients with reactor thermal power

27 Median (50 percentile) decontamination factors for radiological design basis accidents

28 Reasonable upper bound ( 90 percentile) decontamination factors for radiological design basis accidents

29 Reasonable lower bound (10 percentile) decontamination factors for radiological design basis accidents

30 Mean decontamination factors for radiological design basis accidents

31 Characteristic values of uncertainty distributions for steam condensation rates during radiological design basis accidents at a $3000 \mathrm{MW}$ (th) reactor

32 Median (50 percentile) decontamination coefficients for radiological design basis accidents

33 Reasonable upper bound (90 percentile) decontamination coefficients for radiological design basis accidents .

34 Reasonable lower bound (10 percentile) decontamination coefficients for radiological design basis accidents . 


\section{List of Tables (concluded)}

Table

Page

35 Mean decontamination coefficients for radiological design basis accidents . . . . . . . . 184

36 Correlation of effective decontamination coefficients for radiological design basis accidents with reactor thermal power . . . . . . . . . . . . . . . 191

37 Median decontamination factors for BWR drywells $\ldots \ldots \ldots \ldots \ldots \ldots \ldots$

3890 percentile decontamination factors for BWR drywells $\ldots \ldots \ldots \ldots \ldots \ldots \ldots 2$

3910 percentile decontamination factors for BWR drywells $\ldots \ldots \ldots \ldots \ldots \ldots$

40 Mean decontamination coefficients for BWR drywells . . . . . . . . . . . 204

4190 percentile decontamination coefficients for BWR drywells $\ldots \ldots \ldots \ldots \ldots \ldots$

4210 percentile decontamination coefficients for BWR drywells $\ldots \ldots \ldots \ldots \ldots$

43 Mean decontamination coefficients for BWR drywells . . . . . . . . . . . 207

44 Correlations of decontamination coefficients with boiling water reactor thermal power . . . . . . . . . . . . . . . . . . . 215 


\section{Introduction}

The U.S. Nuclear Regulatory Commission has proposed a revised severe accident source term for generic use in the regulation of nuclear reactors [1]*. This revised source term specifies the releases of radionuclides into the containment atmosphere during hypothetical, limiting, severe reactor accidents. The releases are specified as shown in Table 1 for four important periods in the course of a severe accident. These phases are the:

- Gap Release Phase,

- In-vessel Release Phase,

- Ex-vessel Release Phase, and

- Late In-vessel Release Phase.

Note that the Late In-vessel Release Phase begins at the same time as the Ex-vessel Release Phase, but lasts much longer. For a period of 2 or 3 hours radionuclides are released into the containment from two sources-the in-vessel source, which is largely a result of revaporization, and the ex-vessel source, which is predominantly the result of core debris interactions with concrete.

Source terms are somewhat different for pressurized water reactors (PWRs) than for boiling water reactors (BWRs). The radionuclide releases are specified as fractions of the initial core inventories of these radionuclides. Radionuclide inventories calculated to be present in the cores of a specific pressurized water reactor and a specific boiling water reactor after particular operating histories are shown in Table 2 [2]. Notice the release fractions specified in the proposed, revised source term have been interpreted here as referring to classes of radionuclides rather than to specific elements. Thus, the cesium release fraction is interpreted as specifying the releases of both cesium and rubidium and the lanthanum release fraction is interpreted as referring to the releases of yttrium and a number of trivalent, rare earth elements. Similar analog groupings of the many radioactive elements into eight classes have been made as indicated in Table 2. From these inventories and the release fraction specifications, it can be concluded that about $227 \mathrm{~kg}$ of radioactive elements in the case of a pressurized water reactor and $315 \mathrm{~kg}$ in the case of a boiling water reactor will be released to the containment atmosphere. With the exception of the noble gases and a small amount of the iodine, these materials will be released to the containment atmosphere as aerosol particles.

In addition to the radionuclide aerosols, the revised severe accident source term also recognizes that quite a lot of nonradioactive materials will be vaporized during the course of a severe reactor accident. These vaporized materials will also condense to form aerosols expelled into the containment atmosphere. The revised severe accident source term cites examples for the nonradioactive mass released during the in-vessel and ex-vessel release phases of accidents at pressurized water reactors and boiling water reactors:

* This work was based on a draft version of reference 1. After completion of the work, a final version of the reference was issued with somewhat modified releases for boiling water reactors. Releases for pressurized water reactors were the same in the draft and final versions. 


\begin{tabular}{cccccccccc}
\multicolumn{2}{c}{ Table 1. Revised severe accident source terms for pressurized water reactors (PWRs) and } \\
boiling \\
water reactors (BWRs) [1]
\end{tabular}


Table 2. Radionuclide inventories in a particular pressurized water reactor (PWR) and a particular boiling water reactor (BWR) [2]

\begin{tabular}{|c|c|c|c|c|}
\hline \multirow[b]{2}{*}{ Radionuclide } & \multicolumn{2}{|c|}{ PWR inventory* } & \multicolumn{2}{|c|}{ BWR inventory** } \\
\hline & moles & kg & moles & kg \\
\hline $\mathrm{I}(\mathrm{a})$ & 121 & 14.8 & 173 & 21.1 \\
\hline $\operatorname{Cs}(b)$ & 1510 & 191 & 2110 & 267 \\
\hline $\mathrm{Te}(\mathrm{c})$ & 278 & 33.7 & 396 & 47.9 \\
\hline $\mathrm{Sr}$ & 718 & 64.0 & 955 & 85.2 \\
\hline $\mathrm{Ba}$ & 630 & 86.8 & 884 & 122 \\
\hline $\operatorname{Ru}(d)$ & 4550 & 456 & 6470 & 650 \\
\hline $\mathrm{Ce}(\mathrm{e})$ & 6170 & 997 & 8950 & 1490 \\
\hline $\mathrm{La}(f)$ & 3310 & 456 & 4640 & 642 \\
\hline $\begin{array}{l}\text { *Power }=3412 \mathrm{MW}_{\text {th }} \\
\text { **Power }=3578 \mathrm{MW}_{\text {th }} \\
\text { (a) includes } \mathrm{Br} \text { and I } \\
\text { (b) includes } \mathrm{Rb} \text { and } \mathrm{Cs} \\
\text { (c) includes } \mathrm{Se}, \mathrm{Sn}, \mathrm{Sb}, \\
\text { (d) includes } \mathrm{Mo}, \mathrm{Tc}, \mathrm{Rh} \text {, } \\
\text { (e) includes } \mathrm{Zr} \text { (radioacti } \\
\text { (f) includes } \mathrm{Y}, \mathrm{Nb}, \mathrm{Pr}, \mathrm{N}\end{array}$ & $\begin{array}{l}\text { and } \mathrm{Te} \\
\mathrm{d} \text {, and } \mathrm{Ru} \\
\mathrm{Np}, \mathrm{Pu} \\
\mathrm{Pm}, \mathrm{Sm} \text {, }\end{array}$ & $\begin{array}{l}\text { tric tor } \\
\text { letric } t\end{array}$ & & \\
\hline
\end{tabular}


Introduction

Nonradioactive aerosol mass $(\mathrm{kg})$

released during the

$\begin{array}{ccc}\text { Reactor } & \underline{\text { In-vessel phase }} & \text { Ex-vessel phase } \\ \text { PWR } & 350 & 3800 \\ \text { BWR } & 780 & 5600\end{array}$

These nonradioactive materials will, of course, co-condense and co-agglomerate with radioactive materials so that distinct radioactive and nonradioactive aerosol particles will not be found in the containment atmosphere. As will be shown in the discussion below, the additional aerosol mass from nonradioactive sources can profoundly affect the behavior of radioactive aerosols in the reactor containment.

The consequences to the public of severe reactor accidents depend on how much of the radioactive material released to the containment during severe reactor accidents escapes the plant. There are a variety of natural and engineered processes that can trap aerosols injected into a reactor containment so that a large fraction of the radioactive aerosols cannot escape the plant. The U.S. Nuclear Regulatory Commission has sponsored the development of simplified, generic descriptions of these aerosol trapping processes. To date, work has concentrated on engineered systems. Simplified models have been developed to estimate source term reduction by water pools overlying reactor core debris interacting with concrete [3], containment sprays [4], and boiling water reactor steam suppression pools [5]. These simplified, generic models are not intended to replace detailed, mechanistic models for the analysis of specific accidents at specific nuclear reactors. Rather, the simplified models are intended to be readily accessible, readily used tools suitable for estimating source term attenuation when minimal amounts of information are available.

Source terms can be attenuated by natural aerosol processes as well as by engineered systems. The development of a simplified, generic model of source term attenuation by these natural aerosol processes is described in this document. Natural aerosol processes in reactor containments have been the subjects of intense research within the reactor safety community for many years. Analyses of severe accident source terms presented in the Reactor Safety Study [6] included a simplified description of source term attenuation by natural aerosol processes. It was quickly recognized that, because of the simplicity of this model, overly conservative estimates of the radionuclide releases from the plant might be predicted. Research of both analytic and experimental nature was undertaken to develop refined models of aerosol behavior in reactor containments. The imperative for the development of this technology was considerably stimulated by the unique safety requirements of fast breeder reactors [7]. Similar developments of the technology to predict aerosol behavior in reactor containments under accident conditions were undertaken in Germany [8], France, and the United Kingdom [9]. At the same time, interest in air pollution and environmental quality led to great improvements in the fundamental understanding of aerosol physics and development of improved mathematical techniques to calculate aerosol behavior [10].

Following the reactor accident at Three Mile Island, the U.S. Nuclear Regulatory Commission undertook an effort to reassess severe reactor accident source terms to take advantage of research results collected since publication of the Reactor Safety Study [6]. This effort included detailed attention to aerosol processes in both the reactor coolant system and in the reactor containment. The Source Term Code 
Package [11] developed to provide improved predictions of severe accident source terms employs the NAUA code [12] to describe the attenuation of severe accident source terms by natural aerosol processes in the reactor containments. In more recent years, the MELCOR code [13] has become a favored vehicle for the systems level analysis of severe reactor accidents. MELCOR uses a modified version of the MAEROS code [14] developed for the CONTAIN code [15] to predict natural aerosol processes. Several other mechanistic, very detailed models of natural aerosol processes in containments have been developed $[16,17]$.

Several large-scale experimental programs have been undertaken to validate predictions of the aerosol behavior models. Notable among these efforts are:

- the NSPP tests done at Oak Ridge National Laboratory $[18,19,20]$,

- the ABCOVE tests done at the Hanford Engineering and Development Laboratory $[21,22,23]$,

- the MARVIKEN tests done at Studsvik in Sweden [24],

- the DEMONA tests done at the Battelle Frankfurt Laboratory in Germany [25], and

- the LACE tests done at the Hanford Engineering and Development Laboratory [26].

A number of comparisons and sensitivity analyses of the various detailed mechanistic models of aerosol behavior codes have been reported [27-36]. Modern computer codes for predicting aerosol behavior in reactor containments are all rather similar in the attentions devoted to the agglomeration of aerosol particles. All of the codes use descriptions for the agglomeration of spherical particles. Corrections for the effects of non-sphericity of real aerosol particles are made with shape factors which are independent of size and, in general, are not known for aerosol particles produced in reactor accidents. The codes universally neglect electrostatic effects that might be of some importance for radioactive aerosol particles [37].

Most of the codes predict well the decline in suspended mass with time in tests with a single nonradioactive aerosol, in large volumes with simple gas flow patterns and no steam condensation at least for suspended mass concentrations of 10 to about $0.01 \mathrm{~g} / \mathrm{m}^{3}$. As suspended mass concentrations fall to lower values, the codes tend to overpredict the suspended mass concentration. More challenging simulations of reactor accidents such as those involving multicomponent aerosols and the condensation of steam are not easily predicted by the computer codes. It may be, however, that experimental difficulties and inaccuracies in the descriptions of the experiments are at least partly responsible for the discrepancies between predicted and observed suspended mass concentrations [38].

Examinations of code predictions in detail show that gravitational settling of aerosols is usually the dominant aerosol removal process. Indeed, for the types of tests done to date, involving relatively high initial aerosol concentrations, gravitational settling would be expected to be a dominant mechanism of aerosol removal. Other mechanisms, which may be significant in some accident situations, are responsible for aerosol deposition on surfaces other than floors. In general, available codes do consider aerosol deposition by thermophoresis and diffusiophoresis as well as some sort of diffusive deposition. Comparison of code predictions of deposition on vertical surfaces or ceilings to observations show, typically, that substantial discrepancies exist. The discrepancies have not attracted much attention 
because they amount to small percentages of the total aerosol mass in experiments. Whether deposition by these other processes will be small in all four stages of a severe reactor accident is, of course, not known.

There is a great deal of confidence within the technical community that aerosol behavior in reactor containments under accident conditions can be adequately predicted for the purposes of reactor safety assessments [39]. Some investigators note there is still room to further improve these models [40], and certainly the discussions below will include mention of remaining uncertainties. But, it is clear that there is now a substantial technical basis for the simplified generic model of aerosol behavior that is developed here.

The description of the development of a simplified model of source term attenuation in reactor containments by natural aerosol processes follows the same general pattern used to develop the other simplified models of source term attenuation $[3,4,5]$. In the next chapter, the physical and chemical phenomena expected to affect aerosol behavior in reactor containments are described. An emphasis is placed on the identification of uncertainties in these physical and chemical phenomena that will affect predictions of the radioactive mass suspended in a containment atmosphere. These phenomenological uncertainties are, however, not the only uncertainties that affect predictions of source term attenuation in reactor containments. The initial and boundary conditions affecting aerosol behavior in reactor containments during severe accidents are also uncertain and these uncertainties will also contribute to uncertainties in the predictions of source term attenuation. The uncertainties in initial and boundary conditions are discussed in Chapter III of this report. It is crucial that these many sources of uncertainty not be obscured in the development of a simplified model of natural aerosol deposition processes.

In the discussions of uncertainties of all types, credible ranges for parametric values that characterize these uncertainties are identified. Subjective probability distributions for values of the parameters within these ranges are defined. These uncertain parameters are sampled in a Monte Carlo uncertainty analysis of aerosol behavior in a reactor containment to obtain uncertainty distributions for the decontamination by natural aerosol removal processes during severe reactor accidents. Results of the Monte Carlo uncertainty analyses are presented in Chapter V.

The uncertainty distributions are used as the bases for the development of the simplified models of aerosol attenuation described here. Selected percentiles of the uncertainty distributions are correlated with the thermal power of the reactor, $\mathrm{P}$, and the four phases of the severe accident to develop a simplified model of decontamination:

$$
\frac{\mathrm{d} D F}{\mathrm{dt}}=\lambda_{\mathrm{e}}(\mathrm{P}, \mathrm{t}) \mathrm{DF}
$$

where:

$$
\begin{aligned}
D F= & \text { decontamination factor, } \\
\lambda_{\mathrm{e}}(\mathrm{P}, \mathrm{t})= & \begin{array}{l}
\text { effective decontamination coefficient derived from the correlation of results of the Monte } \\
\text { Carlo uncertainty analysis, and }
\end{array}
\end{aligned}
$$




$$
\mathrm{t}=\text { time. }
$$

Correlations are developed for medians (50 percentiles) of the uncertainty analyses. The medians are considered here to provide the best estimates of the actual decontamination that will occur. Reasonable upper bounds and reasonable lower bounds are found from similar correlations of the 90th and 10th percentiles of the aerosol decontamination distributions produced by the Monte Carlo uncertainty analyses. By using correlations for the best estimate values and for the upper and lower bound values, the uncertainty in predictions of containment decontamination by natural aerosol processes can be found.

Some examples of the use of the simplified model for estimating containment decontamination are presented in Chapter VI of this report. 
Physical

\section{Physical and Chemical Phenomena That Affect Aerosol Behavior in Reactor Containments}

\section{A. Aerosol Dynamic Equation}

As noted in the introduction to this report, the physical behavior of aerosols under reactor accident conditions has been the object of intense research. The nature of aerosols produced during reactor accidents and the behaviors of the aerosols in reactor containments are quite complex. As in any attempt to address complicated situations, there has been an effort to distill into models the essential, most important, elements of aerosol behavior. The models are augmented and refined until there is a satisfactory agreement between model predictions and the observations made in experiments. In the case of aerosol behavior, this iterative process of modeling and comparison to observations leading to refined modeling has progressed long enough that a fairly robust framework now exists for predicting aerosol behavior. This framework is often cast in terms of the aerosol dynamic equation. Perhaps the most careful presentation of the aerosol dynamic equation has been made by Williams and Loyalka [41]. In general, aerosols within reactor containments will be distributed in size. The size distributions and the concentrations of aerosol particles will, in general, depend on both time and location within the containment. It is usual, however, to assume that there are mechanisms that homogenize the aerosols at least within compartments of the containment if not throughout the entire containment. This assumption leads to the conclusion that the size distributions and concentrations of aerosols in the containment or compartment are functions of time but are not functions of location. Some details of the behavior of aerosol are lost especially near the points of aerosol input to the containment because of this assumption of homogeneity. It is assumed, without a great deal of justification, that the details omitted by the neglect of spatial variations in aerosol behavior do not significantly affect predictions of source term attenuation in the reactor containment.

When the homogeneous aerosol assumption has been made, the aerosol dynamic equation is:

$$
\begin{aligned}
\frac{\partial n(v, t)}{\partial t}= & \frac{1}{2} \int_{0}^{v} K[U, v-U] n(U, t) n(v-U, t) d U-n(v, t) \int_{0}^{\infty} K[U, v] n(U, t) d U \\
& +\frac{S(v, t)}{V}-\frac{R(v, t) n(v, t)}{V}-\frac{\partial I(v, t) n(v, t) / V}{\partial v}
\end{aligned}
$$

where:

$$
\begin{aligned}
n(v, t)= & \begin{array}{l}
\text { number concentration of particles having volumes of } v \text { to } \\
v+d v,
\end{array} \\
\int_{0}^{v} K[U, v-U] n(U, t) n(v-U, t) d U= & \begin{array}{l}
\text { the rate of formation of particles of volume } v \text { to } v+d v \\
\text { by coagulation of smaller particles, }
\end{array}
\end{aligned}
$$




$$
\begin{aligned}
& n(v, t) \int_{0}^{v} K[U, v] n(v, t) d U=\begin{array}{l}
\text { the rate of coagulation of particles of volume } v \text { to } v+d v \\
\text { to form larger particles, }
\end{array} \\
& \mathrm{K}[\mathrm{U}, \mathrm{v}]=\text { coagulation "kernel" for particles of volume } \mathrm{v} \text { with } \\
& \text { particles of volume } \mathrm{U} \text {, } \\
& S(v, t)=\text { rate at which particles of volume } v \text { to } v+d v \text { are supplied, } \\
& \mathrm{V}=\text { containment volume, } \\
& R(v, t) n(v, t)=\text { rate of removal of particles from the containment by any } \\
& \text { of a variety of mechanisms, } \\
& \frac{\partial I(v, t) n(v, t)}{\partial v}=\begin{array}{l}
\text { rate of growth by condensation of particles from the } \\
\text { volume interval of } v \text { to } v+d v \text {. }
\end{array}
\end{aligned}
$$

The removal term, $R(v, t) n(v, t)$, is, of course, of particular interest here. The source term, $S(v, t)$, is what is provided by the U.S. Nuclear Regulatory Commission's revised severe accident source terms [1]. The effects of these terms on the aerosol concentrations in the containment, and consequently, the radioactivity in the containment atmosphere available for release from the plant, cannot be understood without addressing the integral terms that describe aerosol coagulation. The condensation growth term is also of interest. The interest arises not from the condensation of vapors produced from the reactor core but from condensation of steam on aerosol particles in the reactor containment and the effects on particle agglomeraton and deposition. These various terms in the aerosol dynamic equation are discussed in the subsection below.

\section{B. Aerosol Growth by Coagulation}

Aerosol particles grow by coagulating with other aerosol particles or because steam condenses on them. As will be discussed further in Sections $C, D$, and $E$, the deposition of aerosols within reactor containments often depends on the size of the aerosol particles. Typically, it is found that larger particles are more rapidly removed from the containment atmosphere. Consequently, the growth of aerosol particles is central to the issue of containment decontamination during severe accidents. The growth of aerosol particles by coagulation is described in the aerosol dynamic equation by the coagulation kernel.

\section{The Coagulation Kernel}

Particles that come into contact can coagulate. ${ }^{*}$ Typically, four processes are considered that will bring aerosol particles into contact:

- because large particles settle faster than small particles, the large particles can sweep out small particles along their settling path,

\footnotetext{
*Trajectories of particles do not have to be such that actual physical contact is necessary. Surface forces that bind agglomerates can lead to coagulation for trajectories that imply sufficiently close "near misses."
} 
Physical

- Brownian motion can move particles across the streamlines of flow so that they intersect other particles,

- diffusion of particles by the turbulent motions of the gas phase, and

- particles, unable to respond to acceleration of the gas phase, cross streamlines of the flow and intersect other particles.

There is a fifth class of phenomena that can either lead to or prevent coagulation of particles. Aerosol particles can become electrostatically charged, especially if they are radioactive. Electrostatic forces between particles can either lead to coagulation or can retard coagulation by other processes. This fifth effect is controversial and it is not included in most existing models of aerosol behavior in reactor containments. Discussion of the fifth phenomenon is deferred to Section III-I, below. Here, only the first four, classic, mechanisms of aerosol coagulation are described. Usually these mechanisms are treated as being independent. They really are not [41]. The mechanisms are discussed here first as though they were independent. Then, the synergistic effects of the coagulation mechanisms are described.

\section{Gravitational Coagulation}

Gravitational coagulation is just the coagulation that can occur because large particles settle faster than small particles. For such a seemingly simple process, it has been the subject of substantial debate. The gravitational coagulation kernel for coagulation of particles of volume $v$ with particles of volume $U$ is usually taken to be [41]:

$$
\mathrm{K}_{\mathrm{G}}[\mathrm{U}, \mathrm{v}]=\frac{2 \pi}{9}\left(\frac{3}{4 \pi}\right)^{4 / 3} \cdot \frac{\gamma^{2} \mathrm{~g} \rho_{\mathrm{p}}}{\chi \mu_{\mathrm{g}}} \epsilon_{\mathrm{o}}\left(\frac{\mathrm{v}}{\mathrm{U}}\right)\left(\mathrm{v}^{1 / 3}+\mathrm{U}^{1 / 3}\right)^{2}\left|\mathrm{C}\left(\mathrm{v}^{1 / 3}\right) \mathrm{v}^{2 / 3}-\mathrm{C}\left(\mathrm{U}^{1 / 3}\right) \mathrm{U}^{2 / 3}\right|
$$

where:

$$
\begin{aligned}
\gamma & =\text { collision shape factor (see Section } \mathrm{G}-2, \text { below), } \\
\chi & =\text { dynamic shape factor (see Section } \mathrm{G}-2, \text { below), } \\
\mathrm{g} & =\text { gravitational acceleration, } \\
\rho_{\mathrm{p}} & =\begin{array}{l}
\text { material density of the aerosol particles that relates particle mass to particle volume } \\
\text { (see Section } \mathrm{G}-1, \text { below), }
\end{array} \\
\mu_{\mathrm{g}} & =\text { viscosity of the gas, } \\
\epsilon_{\mathrm{o}}(\mathrm{v} / \mathrm{U}) & =\text { uncertain factor to describe the efficiency of aerosol coagulation by gravitation, and } \\
\mathrm{C}\left(\mathrm{v}^{1 / 3}\right) & =\text { Cunningham slip correction factor for a particle of volume } \mathrm{v} \text { (see page 49). }
\end{aligned}
$$


The controversies over gravitational coagulation focus on the efficiency term, $\epsilon_{0}(v / U)$. The essential issue is that smaller particles in the settling path of a larger particle may not contact the larger particle because they can follow streamlines of the flow around the larger particle. Fuchs [42] derived an expression for the gravitational collision efficiency assuming that particles in the gas did not affect the gas flow around the larger particle:

$$
\epsilon_{\mathrm{o}}(\mathrm{v} / \mathrm{U})=1.5 \frac{\mathrm{v}^{2 / 3}}{\left[\mathrm{U}^{1 / 3}+\mathrm{v}^{1 / 3}\right]^{2}}
$$

Pruppacher and Klett [43] argued that particles in the gas would affect the streamlines significantly and suggested:

$$
\epsilon_{\mathrm{o}}(\mathrm{v} / \mathrm{U})=0.5 \frac{\mathrm{v}^{2 / 3}}{\left[\mathrm{U}^{1 / 3}+\mathrm{v}^{1 / 3}\right]^{2}}
$$

Both the expression derived by Fuchs and the expression derived by Pruppacher and Klett are based on the assumption $v^{1 / 3}<<U^{1 / 3}$. The expressions are, however, usually employed without regard to the relative sizes of the colliding particles. Williams and Loyalka [41] argue that the expression derived by Pruppacher and Klett is sufficiently accurate up to $\mathrm{v}^{1 / 3}=0.5 \mathrm{U}^{1 / 3}$. Some analysts [see, for example, Reference 44] truncate the Pruppacher-Klett expression based on evidence that collision efficiencies become invariant at about 0.05 for particles of comparable size [45]:

$$
\epsilon_{0}(v / U)= \begin{cases}1 / 2\left(\frac{v^{1 / 3}}{v^{1 / 3}+U^{1 / 3}}\right)^{2} & \text { for } 0 \leq v^{1 / 3} \leq 0.46 U^{1 / 3} \\ 0.05 & \text { for } 0.46 U^{1 / 3}<v^{1 / 3} \leq U^{1 / 3}\end{cases}
$$

Most of the debate on gravitational collision efficiency has focused on the factor of 3 difference between the Fuchs formula and the Pruppacher-Klett formula. Recent results of macroscopic simulant experiments seem to favor the Fuchs formula [46]. But, there are grounds for even greater uncertainty about the gravitational collision efficiency [47].

\section{Brownian Coagulation}

Coagulation among small particles is dominated by the Brownian diffusion process. The coagulation kernel is often taken to be: 
Physical

$$
\mathrm{K}_{\mathrm{B}}[\mathrm{v}, \mathrm{U}]=\frac{2 \mathrm{kT}}{3 \mu_{\mathrm{g}}}\left(\mathrm{v}^{1 / 3}+\mathrm{U}^{1 / 3}\right)\left[\frac{\mathrm{C}\left(\mathrm{v}^{1 / 3}\right)}{\mathrm{v}^{1 / 3}}+\frac{\mathrm{C}\left(\mathrm{U}^{1 / 3}\right)}{\mathrm{U}^{1 / 3}}\right]
$$

where $\mathrm{k}$ is the Boltzmann's constant.

This coagulation kernel is appropriate for particles larger than the mean free path of gas molecules in the atmosphere. Another expression for the Brownian coagulation kernel, developed by Fuchs, is [42]:

$$
K_{B}[v, U]=\frac{4 \pi(a+b)(Đ(a)+Đ(b))}{\left[\frac{a+b}{a+b+\delta(a b)}+\frac{4(Đ(a)+Đ(b))}{(a+b) \bar{v}(a b)}\right]}
$$

where:

$$
\begin{aligned}
a & =(3 v / 4 \pi)^{1 / 3} \\
b & =(3 U / 4 \pi)^{1 / 3} \\
Đ(a) & =C k T / 6 \pi \mu_{g} x^{a}, \\
\delta(a b) & =\left[\delta(a)^{2}+\delta(b)^{2}\right]^{1 / 2}, \\
\delta(a) & =\left(\frac{1}{6 a L(a)}\right)\left[(2 a+L(a))^{3}-\left(4 a^{2}+L(a)^{2}\right)^{3 / 2}\right]-2 a \\
L(a) & =8 \boxplus(a) / \pi \bar{v}(a), \\
\bar{v}(a b) & =\left[\bar{v}(a)^{2}+\bar{v}(b)^{2}\right]^{1 / 2}, \\
\bar{v}(a) & =\sqrt{8 k T / \pi \rho_{p} v}, \text { and } \\
v & =\text { particle volume. }
\end{aligned}
$$


This expression interpolates between the free molecular regime in which particles are smaller than the mean free path of gas molecules and the continuum regime in which particles are much larger than the mean free path of gas molecules.

These expressions for the Brownian coagulation have been developed based on the assumption that there is no potential field (either attractive or repulsive) between particles. Clearly, there will be, at a minimum, van der Waals forces between two particles that come near each other. There have been attempts to develop expressions that take these forces into account (see for examples Reference 48 and references therein) as well as viscous interactions [49]. The effects are strongest for particles of very small size. For the analysis of aerosol behavior in reactor containments, such small particles are not very important. Clearly, they could never account for much of the mass suspended in the reactor containment. Also, by the time aerosols reach the containment atmosphere they have aged sufficiently that the number concentration of very small aerosol particles is also small. On the other hand, as will be discussed further in Section I, larger particles are more likely to be electrostatically charged. Electrostatic fields can affect Brownian coagulation.

\section{Turbulent Diffusion Coagulation}

The coagulation kernel for turbulent diffusion is taken to be:

$$
K_{\mathrm{TD}}[v, U]=Z_{o} \frac{3}{4 \pi}\left(v^{1 / 3}+U^{1 / 3}\right)^{3}\left(\frac{\epsilon_{T} \rho_{g}}{\mu_{g}}\right)^{1 / 2}
$$

where $\epsilon_{T}$ is the turbulent energy dissipation rate and $Z_{0}$ is a parameter whose value is variously taken to be 1.29 [50] or 5.65 [41].

\section{Turbulent Inertial Coagulation}

Turbulent inertial impaction gives rise to a collision kernel of the form:

$$
\mathrm{K}_{\mathrm{TI}}[\mathrm{v}, \mathrm{U}]=0.188\left(\mathrm{v}^{1 / 3}+\mathrm{U}^{1 / 3}\right)^{2}\left(\mathrm{U}^{2 / 3}-\mathrm{v}^{2 / 3}\right) \frac{\rho_{\mathrm{p}}}{\mu_{\mathrm{g}}}\left(\frac{\epsilon_{\mathrm{T}}^{3} \rho_{\mathrm{g}}}{\mu_{\mathrm{g}}}\right)^{1 / 4}
$$

The leading coefficient may be 0.204 rather than 0.188 . Some analysts argue that this kernel should be multiplied by a "sticking coefficient" to indicate that not all particles coming into contact will remain in contact. Also, the kernel can be multiplied by the same collision efficiency term used for gravitational coagulation. Then, 
Physical

$$
\mathrm{K}_{\mathrm{TI}}[\mathrm{v}, \mathrm{U}]=0.188 \mathrm{~S} \epsilon_{\mathrm{o}}(\mathrm{v} / \mathrm{U})\left(\mathrm{v}^{1 / 3}+\mathrm{U}^{1 / 3}\right)\left(\mathrm{U}^{2 / 3}-\mathrm{v}^{2 / 3}\right) \frac{\rho_{\mathrm{p}}}{\mu_{\mathrm{g}}}\left[\frac{\epsilon_{\mathrm{T}}^{3} \rho_{\mathrm{g}}}{\mu_{\mathrm{g}}}\right]^{1 / 4}
$$

where $S$ is the sticking coefficient which could have values from 0 to 1 . It is, however, not obvious why the sticking coefficient should be less than 1 for the applications of interest here. Consequently, the sticking coefficient is neglected here and any effects of values of this coefficient different than one are assumed to be adequately reflected by the collision efficiency term, $\epsilon_{\mathrm{o}}(\mathrm{v} / \mathrm{U})$.

\section{Summation of Collision Kernels}

All four of the mechanisms discussed above will be operative within a reactor containment atmosphere to cause coagulation of aerosol particles. A not uncommon practice is to simply sum the collision kernels to obtain an overall collision kernel:

$$
\mathrm{K}[\mathrm{v}, \mathrm{U}]=\mathrm{K}_{\mathrm{G}}[\mathrm{v}, \mathrm{U}]+\mathrm{K}_{\mathrm{B}}[\mathrm{v}, \mathrm{U}]+\mathrm{K}_{\mathrm{TD}}[\mathrm{v}, \mathrm{U}]+\mathrm{K}_{\mathrm{TI}}[\mathrm{v}, \mathrm{U}]
$$

Williams and Loyalka [41] very much object to this practice. Simple summation of kernels might be defendable when only Brownian diffusion and gravitational coagulation are considered. Typically, only one of these processes will be dominant for particles of a particular size. Williams and Loyalka have quantitatively examined this argument. Let $\mathrm{K}_{\mathrm{s}}[\mathrm{v}, \mathrm{U}]$ be the coagulation kernel when both gravitational and Brownian diffusion processes are operative. Williams and Loyalka find for the ratio of the actual kernel to the simple sum of kernels for Brownian and gravitational collision:

$$
\frac{K_{s}[v, U]}{K_{G}[v, U]+K_{B}[v, U]}=\left(\frac{4 \pi}{4+\beta}\right) \frac{1}{\beta} \sum_{n=0}^{\infty}(-1)^{n} \frac{I_{n+1 / 2}(\beta / 2)(2 n+1)}{K_{n+1 / 2}(\beta / 2)}
$$

where

$$
\beta=\frac{4 \pi}{3 \mathrm{kT}} \rho_{\mathrm{p}} \mathrm{g} \mathrm{U}^{1 / 3} \mathrm{v}^{1 / 3}\left|\mathrm{U}^{2 / 3}-\mathrm{v}^{2 / 3}\right|\left(\frac{3}{4 \pi}\right)^{4 / 3}
$$

and the functions $I_{n+1 / 2}(x)$ and $K_{n+1 / 2}(x)$ are modified Bessel functions of half-integer order.

A plot of the ratio $\mathrm{K}_{\mathrm{s}}[\mathrm{v}, \mathrm{U}] /\left(\mathrm{K}_{\mathrm{G}}[\mathrm{v}, \mathrm{U}]+\mathrm{K}_{\mathrm{B}}[\mathrm{v}, \mathrm{U}]\right)$ against $\log _{10} \beta$ is shown in Figure 1. The combined effects of gravitational settling and Brownian diffusion enhance coagulation by less than 30 percent over the range of particle sizes of interest relative to what would be predicted by simply summing the kernels as though the two coagulation mechanisms were entirely independent. Williams and Loyalka [41] suggest: 
Physical
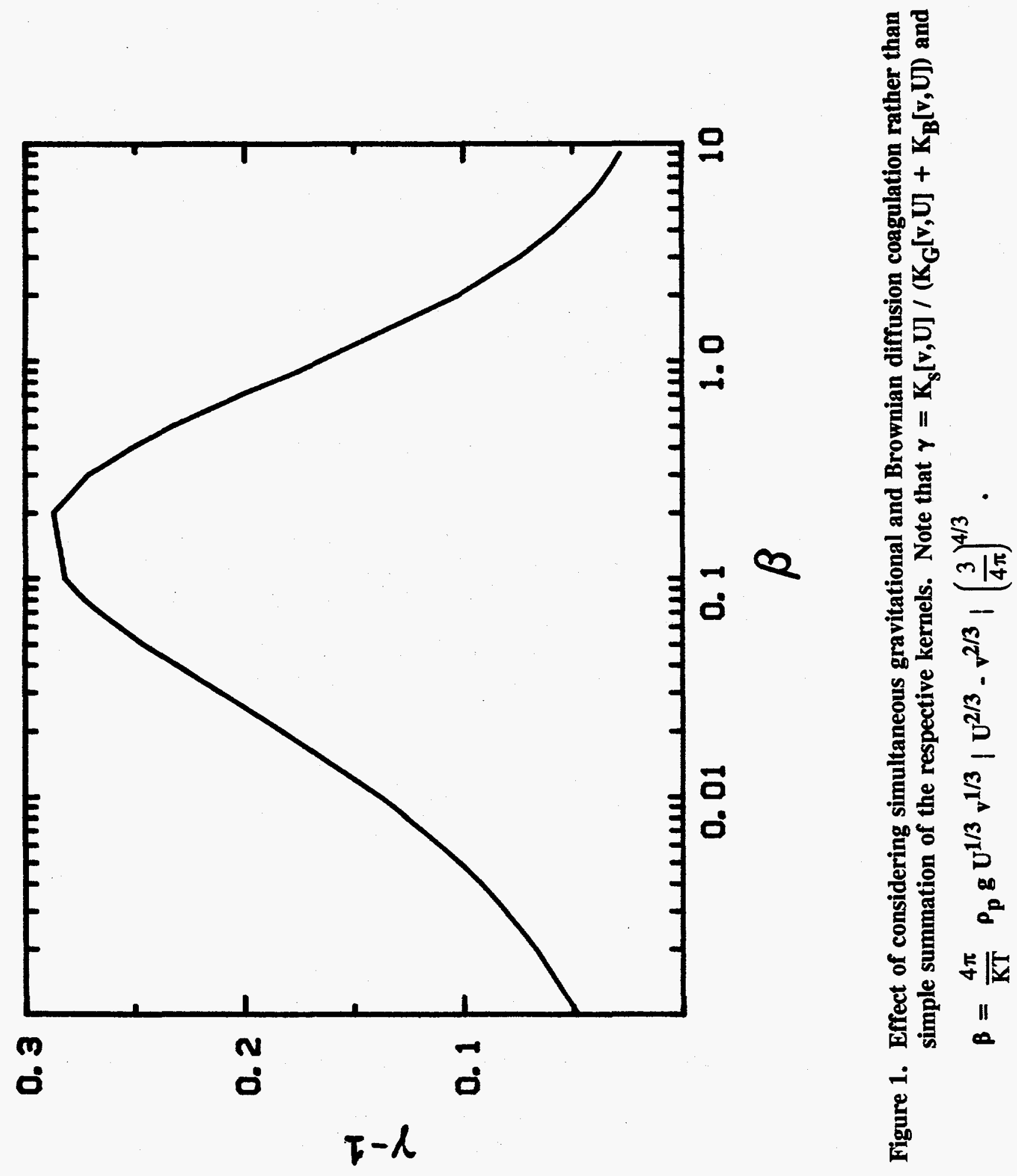
Physical

$$
K_{S}[v, U] \approx K_{G}[v, U]+\left(1+9 / 8 \beta^{2 / 3}\right) K_{B}[v, U]
$$

Simple summation is not obviously defensible for the combination of the Brownian diffusion and the turbulent diffusion mechanisms. Let $\mathrm{K}_{*}[\mathrm{v}, \mathrm{U}]$ be the coagulation kernel when both Brownian diffusion and turbulent diffusion are taking place. Williams and Loyalka [41] find:

$$
\frac{\mathrm{K}_{*}[\mathrm{v}, \mathrm{U}]}{\mathrm{K}_{\mathrm{B}}[\mathrm{v}, \mathrm{U}]+\mathrm{K}_{\mathrm{TD}}[\mathrm{v}, \mathrm{U}]}=\mathrm{g}(\mathrm{y}) /\left(1+3 \mathrm{y}^{2}\right)
$$

where

$$
\begin{aligned}
g(y) & =[1-\pi y / 2+y \operatorname{atn}(y)]^{-1}, \\
y & =\left(\frac{3}{4 \pi}\right)^{1 / 3}\left(U^{1 / 3}+v^{1 / 3}\right)\left[K_{e} /(\boxplus(a)+Đ(b))\right]^{1 / 2}, \text { and } \\
K_{e} & =0.15\left[\epsilon_{T} \rho_{g} / \mu_{g}\right]^{1 / 2}
\end{aligned}
$$

A plot of the ratio $K_{*}[v, U] /\left(K_{B}[v, U]+K_{T D}[v, U]\right)-1$ against $\log _{10} y^{2}$ is shown in Figure 2. Again, the kernel found by considering Brownian motion and turbulent diffusion simultaneously might be 30 percent larger than the kernel found by simply summing the two coagulation processes as though they were independent. This is not an overwhelming effect.

Other methods for summing the various mechanistic kernels to obtain an overall agglomeration kernel include [34]:

$$
\begin{aligned}
& \mathrm{K}[\mathrm{v}, \mathrm{U}]=\mathrm{K}_{\mathrm{B}}[\mathrm{v}, \mathrm{U}]+\left\{\mathrm{K}_{\mathrm{G}}[\mathrm{v}, \mathrm{U}]^{2}+\mathrm{K}_{\mathrm{TD}}[\mathrm{v}, \mathrm{U}]^{2}+\mathrm{K}_{\mathrm{TI}}[\mathrm{v}, \mathrm{U}]^{2}\right\}^{1 / 2} \\
& \mathrm{~K}[\mathrm{v}, \mathrm{U}]=\mathrm{K}_{\mathrm{B}}[\mathrm{v}, \mathrm{U}]+\mathrm{K}_{\mathrm{TD}}[\mathrm{v}, \mathrm{U}]+\left\{\mathrm{K}_{\mathrm{G}}[\mathrm{v}, \mathrm{U}]^{2}+\mathrm{K}_{\mathrm{TI}}[\mathrm{v}, \mathrm{U}]^{2}\right\}^{1 / 2}
\end{aligned}
$$


Physical

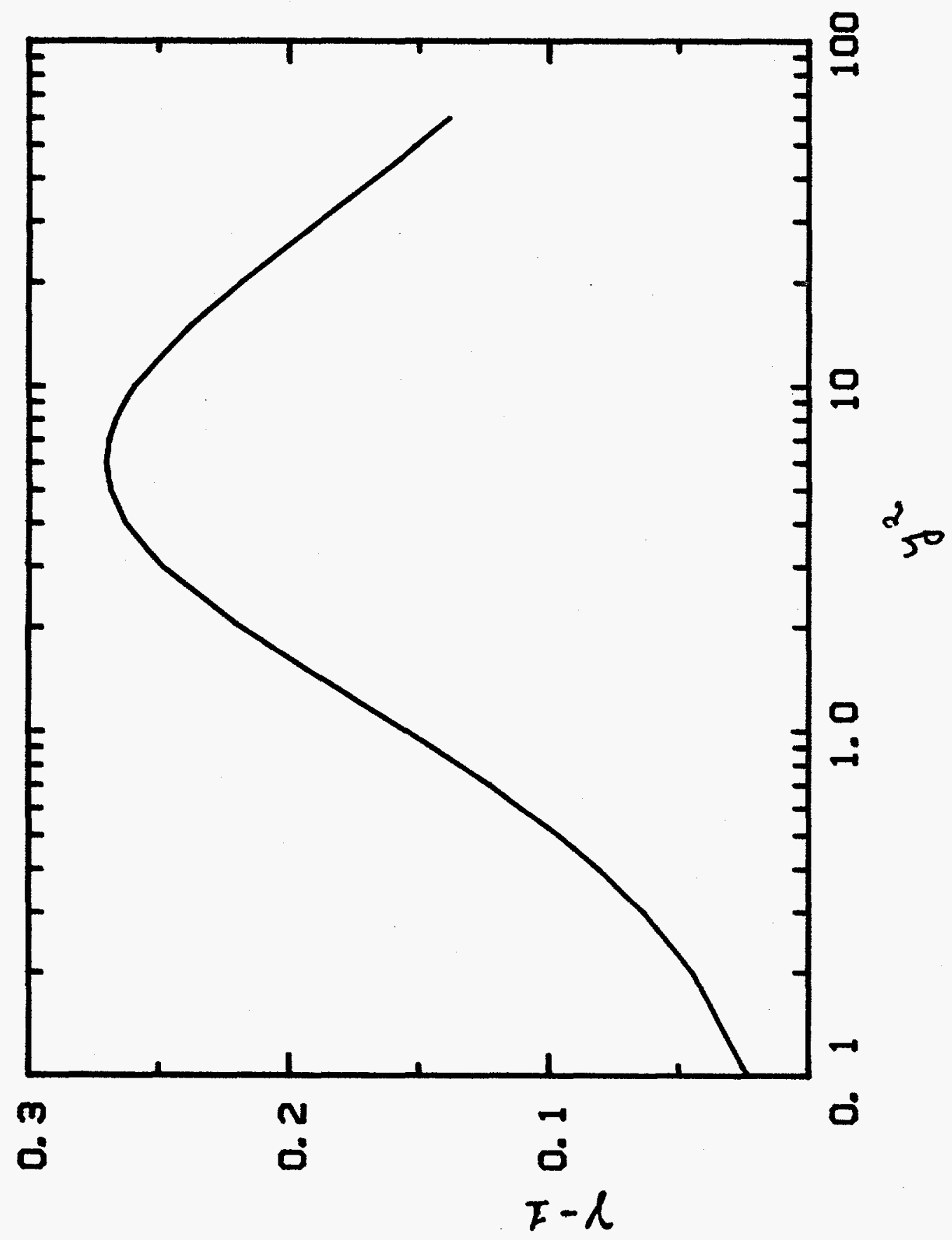

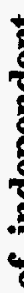

节

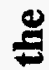

욯

ํㅡㄹ

․․․

용

표 뿡

뭉

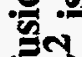

훙

ํํㄹ

를

站

$\exists+$

零

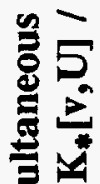

,

,

늘

$\overline{0}$

잉

z

昜昜

芫 
Physical

These various summation methods are compared in Figure 3.

\section{Aerosol Growth by Condensation}

Particles in the reactor containment can, in principle, grow by the condensation of water vapor on the particle surface. (Condensation of water within the porous structure of particle agglomerates is more likely to occur, but does not cause the particle size to increase. Internal condensation does affect aerosol particle behavior as discussed in Section G-2.) There are, however, physical phenomena that resist condensation of water vapor. Certainly, the convex surfaces of very small particles produce a Kelvin effect that increases the partial pressure of water in equilibrium with the surface. Perhaps, the most important effect that limits the condensation of water onto aerosol particles is the limited capacity of aerosol particle clouds to reject heat released when water condenses.

The kinetics of condensation of vapors on particles exhibit qualitative differences in the free-molecular regime where the mean free path of gases is large in comparison to the particle size and in the continuum regime where the mean free path is small in comparison to the particle size. Condensation kinetics in these two regimes and interpolation between these regimes are discussed in the subsections below.

\section{Condensation in the Free Molecular Regime}

In the free molecular regime, the mean free path of gas phase molecules is large in comparison to the size of aerosol particles. This is in contrast to the continuum regime in which the mean free path is small in comparison to the particle size. Only a very tiny amount of the aerosol mass injected into the reactor containment will be of such a small size that condensation kinetics will obey the free-molecular model described below. But, the free-molecular model is used to extrapolate the continuum regime kinetics into the slip regime where particle sizes and the mean free path of gas species are of similar sizes. Much of the aerosol in a containment during a severe accident will be in the slip regime.

It is assumed here that thermal gradients in the gas phase around a particle are negligibly small. The thermal accommodation coefficient for water molecules striking a water surface has been measured to be 0.96 [51]. This is sufficiently close to 1 that it appears permissible to assume water molecules will undergo diffuse reflection from particles onto which water is condensing. We can, then, take from Williams and Loyalka [41] the rate of water condensation onto a particle of diameter $d_{p}$ to be:

$$
\begin{aligned}
\frac{\mathrm{dN}\left(\mathrm{H}_{2} \mathrm{O}\right)}{\mathrm{dt}} & =\frac{\mathrm{S} \pi \mathrm{d}_{\mathrm{p}}^{2}}{4 \mathrm{R}}\left\{\frac{\mathrm{P}(\infty)}{\sqrt{\mathrm{T}(\infty)}}-\frac{\mathrm{P}(\mathrm{s})}{\sqrt{\mathrm{T}(\mathrm{s})}}\right\}\left[\frac{8 \mathrm{R}}{\pi \mathrm{MW}}\right]^{1 / 2} \\
& \simeq \mathrm{Sd}_{\mathrm{p}}^{2} 32.18\left\{\frac{\mathrm{P( \infty )}}{\sqrt{\mathrm{T}(\infty)}}-\frac{\mathrm{P}(\mathrm{s})}{\sqrt{\mathrm{T}(\mathrm{s})}}\right\} \text { moles/s }
\end{aligned}
$$




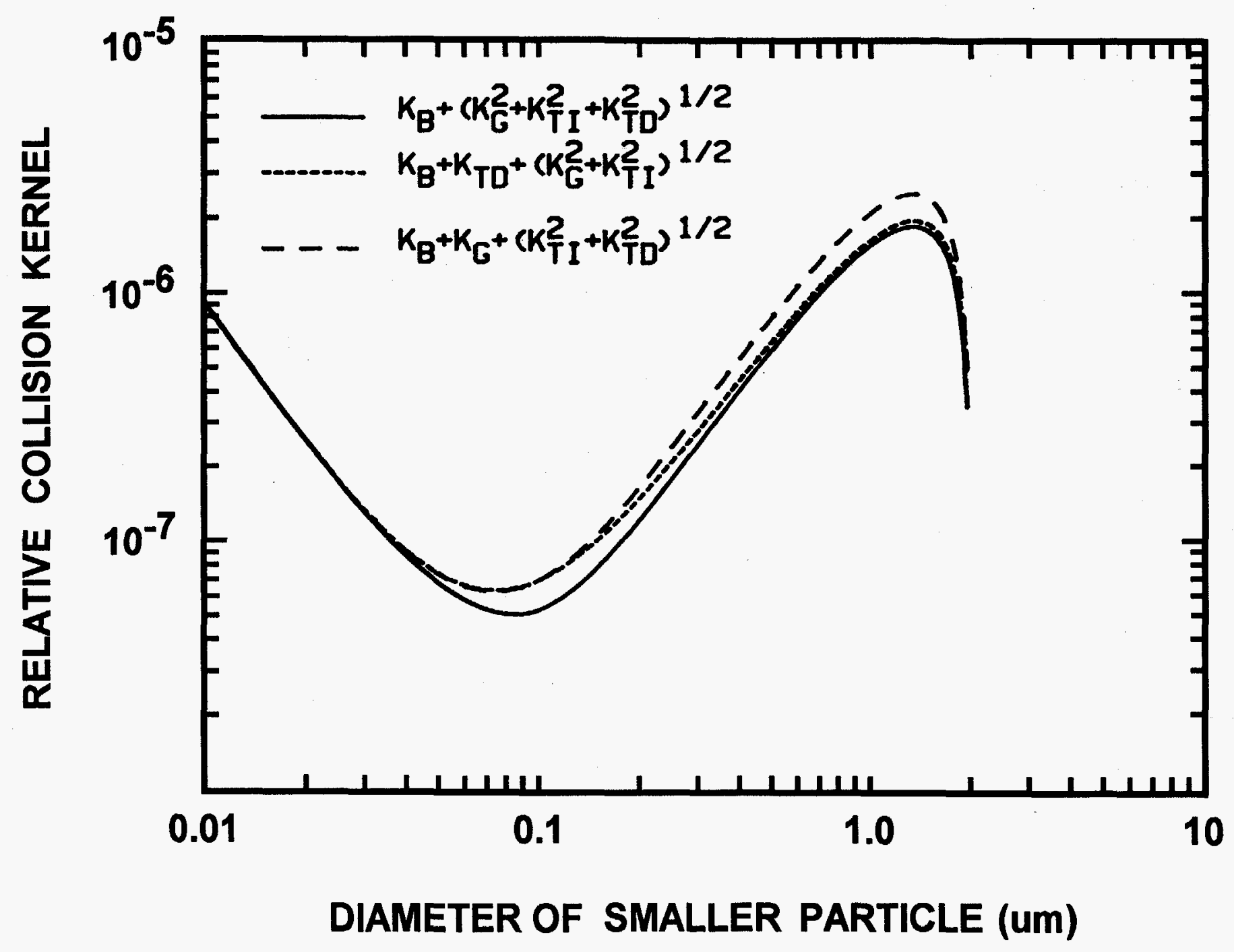

Figure 3. Comparison of various summations of terms in the coagulation kernel. Calculations were done for particles in air at one atmosphere and $373 \mathrm{~K}$. The diameter of the large particle was taken to be $2 \mu \mathrm{m}$. 
Physical

where

$$
\begin{aligned}
\mathbf{N}\left(\mathrm{H}_{2} \mathrm{O}\right) & =\text { moles of water condensed onto the particle, } \\
\mathbf{R} & =\text { gas constant, } \\
\mathbf{S} & =\text { the probability that a water molecule striking the surface will stick to that surface, } \\
\mathbf{M W} & =\text { molecular weight of water }=18.015 \text { grams/mole } \\
\mathbf{P}(\infty) & =\text { partial pressure (atm) of water vapor in the atmosphere, } \\
\mathrm{P}(\mathrm{s}) & =\text { equilibrium partial pressure of water vapor at the particle surface (atms), } \\
\mathrm{T}(\infty) & =\text { temperature of the containment atmosphere }(\mathrm{K}), \text { and } \\
\mathrm{T}(\mathrm{s}) & =\text { temperature of the particle surface }(\mathrm{K})
\end{aligned}
$$

The "sticking coefficient" of water molecules, S, is not well known. Prupacher and Klett cite several determinations [52]. Their citations are reproduced in Table 3. Low values listed in this table, S 0.03 , were determined by static methods. High values, $S \sim 1.0$, have been determined using methods that involve rapid renewal of the liquid surface. Hsu and Grapham [53] argue that because the water molecule has a large dipole moment, it should have a low sticking coefficient. Apparently, only vapor molecules in the proper orientation when they strike the surface will bind to the surface. Pruppacher and Klett recommended the use of low values of the sticking coefficient for water condensation on water droplets in clouds. Wagner, on the other hand, found large values of the sticking coefficient yielded better matches between theoretical predictions and observations of aerosol growth [54]. There were, however, a large number of assumptions and approximations in the theoretical model that could have affected the value of the sticking coefficient derived from aerosol growth data. Levine [55] used a Millikan oil drop apparatus to measure the sticking coefficient. He derived a mean value of 0.95 from 35 determinations. The variance in his measurements is, however, enormous. At this point, it seems prudent to concur with Barrett and Clement [56] that the issue of the sticking coefficient of water is unresolved.

Water condensation on the surface of an aerosol particle produces heat that must be removed by conduction into the atmosphere. Radiation heat removal from particle surfaces in the free molecular regime is very inefficient [57]. Also, convective motions of the gas do not provide a heat removal mechanism. In the development of the heat conduction model below, decay heating of the particle is neglected.

The rate of heat input to the aerosol particle is found by considering the rate of heat production and the rate of heat loss. In the free-molecular regime, the rate of heat production is:

$$
\left.\left[\mathrm{L}-\frac{\mathrm{RT}(\mathrm{s})}{2}\right] \frac{\mathrm{dN}\left(\mathrm{H}_{2} \mathrm{O}\right)}{\mathrm{dt}}\right|_{\mathrm{fm}}
$$


Table 3. Determinations of the sticking coefficient of water cited by Pruppacher and Klett [52]

\begin{tabular}{|c|c|c|c|}
\hline Author & Year & Temperature (K) & $\mathbf{S}$ \\
\hline Alty & 1931 & 291 to 333 & $0.006-0.016$ \\
\hline Alty and Nichole & 1931 & 291 to 333 & $0.01-0.02$ \\
\hline Alty & 1933 & 265 to 277 & 0.04 \\
\hline Alty and Mackay & 1935 & 288 & 0.036 \\
\hline Baramaer & 1939 & - & 0.033 \\
\hline Pruger & 1940 & 373 & 0.02 \\
\hline Yamamoto and Miura & 1949 & - & 0.023 \\
\hline Hammeke and Kappler & 1953 & 293 & 0.045 \\
\hline Delaney et al. & 1964 & 273 to 313 & 0.0415 \\
\hline Kiriukhin and Plaude & 1965 & 280 & 0.019 \\
\hline Chodes et al. & 1974 & 293 & 0.033 \\
\hline Rogers and Squires & 1974 & - & 0.065 \\
\hline $\begin{array}{l}\text { Narusawa and } \\
\text { Springer }\end{array}$ & 1975 & 291 to 300 & 0.038 \\
\hline Sinarwalla & 1975 & 295.6 to 298.8 & 0.026 \\
\hline Hickman & 1954 & 273 & 0.42 \\
\hline Berman & 1961 & - & 1.0 \\
\hline Nabavian and Bromley & 1963 & 283 to 323 & $0.35-1.0$ \\
\hline Jamieson & 1965 & 273 to 343 & 0.35 \\
\hline Mills and Seban & 1967 & 280 to 283 & $0.45-1.0$ \\
\hline Tamin and Hasson & 1974 & 323 & 0.2 \\
\hline $\begin{array}{l}\text { Narusawa and } \\
\text { Springer }\end{array}$ & 1975 & 291 to 300 & 0.18 \\
\hline
\end{tabular}


Physical

Then,

$$
\left.\frac{\mathrm{dQ}}{\mathrm{dt}}\right|_{\mathrm{fm}}=\left.\frac{-\mathrm{dq}}{\mathrm{dt}}\right|_{\mathrm{fm}}+\left.\left[\mathrm{L}-\frac{\mathrm{RT}(\mathrm{s})}{2}\right] \frac{\mathrm{dN}\left(\mathrm{H}_{2} \mathrm{O}\right)}{\mathrm{dt}}\right|_{\mathrm{fm}}
$$

where:

$$
\begin{aligned}
\left.\frac{\mathrm{dQ}}{\mathrm{dt}}\right|_{\mathrm{fm}} & =\text { net heat input to the aerosol particle in the free molecular regime, } \\
\left.\frac{\mathrm{dq}}{\mathrm{dt}}\right|_{\mathrm{fm}} & =\text { heat loss from the particle by conduction in the free molecular regime }= \\
& =553.5 \mathrm{~d}_{\mathrm{p}}{ }^{2}(\mathrm{~cm}) \mathrm{P}_{\mathrm{T}}(\mathrm{atm}) \frac{(\mathrm{T}(\mathrm{s})-\mathrm{T}(\infty))}{\sqrt{\mathrm{T}(\infty) \mathrm{MW}}} \mathrm{cal} / \mathrm{s} \\
\mathrm{L} & =\text { latent heat of water condensation and heat of solution of any soluble constituents of } \\
\mathrm{P}_{\mathrm{T}} & =\text { total pressure in the atmosphere, and } \\
\mathrm{MW} & =\text { average molecular weight of the atmospheric gases. }
\end{aligned}
$$

The closure of this set of equations is obtained from:

$$
Q=C_{p}(p) \frac{\pi}{6} d_{p}^{3} \rho_{p}[T(s)-T(\infty)]+C_{p}\left(H_{2} O\right) N\left(H_{2} O\right)[T(s)-T(\infty)]
$$

where

$$
\begin{aligned}
\mathrm{C}_{\mathrm{p}}(\mathrm{p})= & \begin{array}{l}
\text { heat capacity of the aerosol particle including any water condensed within particle } \\
\text { agglomerates, and }
\end{array} \\
\mathrm{C}_{\mathrm{p}}\left(\mathrm{H}_{2} \mathrm{O}\right)= & \text { heat capacity of liquid water condensed on the particle surface. }
\end{aligned}
$$

This closure equation amounts to an assumption that the thermal conductivity of the aerosol particle is infinitely large. This assumption leads to a lower bound on the surface temperature. An alternate closure expression would be to set the surface temperature to be the temperature that would make $P(s)=P(\infty)$ and, then, to account for finite rates of heat conduction into the aerosol particles. 
The estimation of $\mathrm{P}(\mathrm{s})$ must recognize the Kelvin effect that raises the equilibrium partial pressure of water. An estimate of $P(s)$ must also recognize that some small amounts of aerosol material will dissolve in water and that this dissolution will reduce the chemical activity of water and thus reduce $\mathrm{P}(\mathrm{s})$. Then,

$$
\ln \frac{\mathrm{P}(\mathrm{s})}{\mathrm{P}_{\mathrm{sat}}(\mathrm{T}(\mathrm{s}))}=\frac{4 \sigma_{1} \overline{\mathrm{v}}}{\mathrm{d}_{\mathrm{p}} \mathrm{RT}}-\frac{2 \mathrm{~m} \phi}{55.51}
$$

where:

$$
\begin{aligned}
\mathbf{P}(\mathrm{s}) & =\text { equilibrium partial pressure of water vapor at the particle surface, } \\
\mathbf{P}_{\mathrm{sat}}(\mathrm{T}(\mathrm{s})) & =\text { saturation partial pressure of water vapor at temperature } \mathrm{T}(\mathrm{s}), \\
\overline{\mathrm{v}} & =\text { molar volume of water, } \\
\mathrm{m} & =\text { molality of dissolved materials in water condensed on the particle surface, } \\
\phi & =\text { osmotic coefficient, and } \\
\sigma_{1} & =\text { surface tension of the liquid. }
\end{aligned}
$$

For slightly soluble inorganic materials, the osmotic coefficient is near 1. For more soluble materials, empirical data must be used to estimate this coefficient.

For very soluble materials such as $\mathrm{CsOH}$ and CsI, the osmotic coefficient can be estimated from [58]:

$$
\begin{aligned}
\phi & =1+\mathrm{f}^{\phi}+\mathrm{mB}^{\phi}+\mathrm{m}^{2} \mathrm{C}^{\phi} \\
\mathrm{f}^{\phi} & =-\mathrm{A}_{\phi}\left[\mathrm{m}^{1 / 2} / 1+1.2 \mathrm{~m}^{1 / 2}\right] \\
\mathrm{B}^{\phi} & =\boldsymbol{\beta}^{0}+\beta^{1} \exp \left(-2 \mathrm{~m}^{1 / 2}\right) \\
\mathrm{A}_{\boldsymbol{\phi}} & =4.48 \times 10^{-3}+1.223 \times 10^{-3} \mathrm{~T}(\mathrm{~K})
\end{aligned}
$$

and:

$$
\mathrm{CsOH} \quad \mathrm{CsI}
$$

$\begin{array}{llc}\boldsymbol{\beta}^{0} & 0.15 & 0.0244 \\ \boldsymbol{\beta}^{1} & 0.30 & 0.0262 \\ \boldsymbol{C}^{\boldsymbol{\phi}} & 0 & -0.00365\end{array}$

Plots of $\mathrm{P}(\mathrm{s}) / \mathrm{P}_{\text {sat }}(\mathrm{T}(\mathrm{s}))$ against aerosol particle size for $\mathrm{m}=0.1,1,5$, and $10 \mathrm{moles} / \mathrm{dm}^{3}$ are shown in Figure 4. Especially for larger particles where surface curvature (Kelvin effect) is unimportant, 


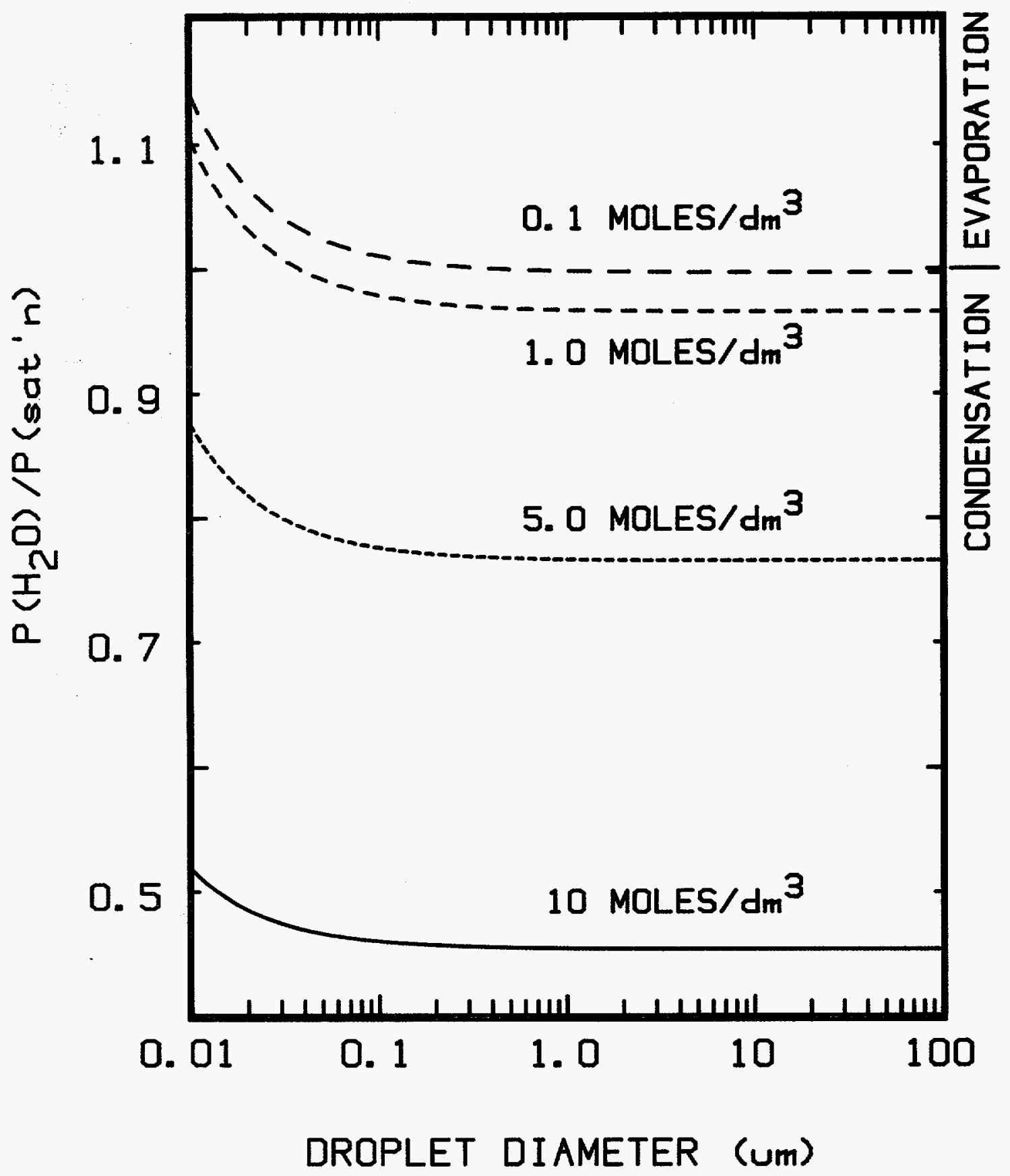

Figure 4. Effect of surface curvature and salt dissolution of the equilibrium partial pressure of water vapor. Curves are labelled according to the assumed solubility of aerosol material in water. 
dissolution of soluble components of the aerosol can dramatically decrease the chemical activity of water condensed on the particle surface and promote particle growth by water condensation. Surface curvature of smaller particles counters this reduction in the chemical activity of water. When condensation does occur, continuing condensation can reduce the molality of the water and an equilibrium particle size can be reached. The effects of water condensation on aerosol particle size will be discussed further below in connection with aerosol properties.

\section{Condensation in the Continuum Regime}

Kulmala and Vesla [59] have built upon earlier work by Barrett and Clement [56] to describe particle growth by water condensation in the continuum regime. Again, heat loss from particles is taken to be only by conduction. Decay heating of particles is neglected. The radial temperature profile around a particle is taken to be linear:

$$
T(r)=T(\infty)+[T(s)-T(\infty)] d_{p} / 2 r \quad r>d_{p} / 2
$$

where $\mathrm{r}$ is the radial distance from the particle. The diffusion coefficient for steam in the atmospheric gases is taken to have the functional form:

$$
Ð(T)=Đ(\infty)\left[\frac{T}{T(\infty)}\right]^{n}
$$

Thermophysical properties are discussed further below. Suffice it to say here that this is a satisfactory approximation in narrow temperature regimes. For steam in air at about $373 \mathrm{~K}(\mathrm{~T}(\infty))$ ), [60]:

$$
\begin{aligned}
\mathrm{D}(\infty) & =0.3716 \mathrm{~cm}^{2} / \mathrm{s} \\
\mathrm{n} & =1.82
\end{aligned}
$$

Then,

$$
\left.\frac{\mathrm{dN}\left(\mathrm{H}_{2} \mathrm{O}\right)}{\mathrm{dt}}\right|_{\text {cont }}=\frac{2 \pi \mathrm{d}_{\mathrm{p}} \mathrm{P}_{\mathrm{T}} \boxplus(\infty)}{\mathrm{RT}(\infty)}\left\{\mathrm{C}(1) \ln \left[\frac{\mathrm{P}_{\mathrm{T}}-\mathrm{P}(\mathrm{s})}{\mathrm{P}_{\mathrm{T}}-\mathrm{P}(\infty)}\right]+\frac{\mathrm{C}(2)}{4} \alpha[\mathrm{P}(\mathrm{s})-\mathrm{P}(\infty)]\right\}
$$

where:

$$
C(1)=\left[\frac{T(s)-T(\infty)}{T_{(\infty)}^{n-1}}\right]\left[\frac{2-n}{T_{(s)}^{2-n}-T_{(\infty)}^{2-n}}\right] \text {, }
$$


Physical

$$
\begin{aligned}
C(2) & =\left[\frac{T(s)-T(\infty)}{T_{(\infty)}^{n-1}}\right]\left[\frac{3-n}{T_{(s)}^{3-n}-T_{(\infty)}^{3-n}}\right], \text { and } \\
\alpha & =\text { thermal diffusion coefficient. }
\end{aligned}
$$

The heat imparted to the particle is:

$$
\left.\frac{\mathrm{dQ}}{\mathrm{dt}}\right|_{\text {cont }}=\left.\frac{-\mathrm{dq}}{\mathrm{dt}}\right|_{\text {cont }}+\left.\frac{\mathrm{LdN}\left(\mathrm{H}_{2} \mathrm{O}\right)}{\mathrm{dt}}\right|_{\text {cont }}
$$

where

$$
\begin{aligned}
\left.\frac{\mathrm{dq}}{\mathrm{dt}}\right|_{\text {cont }} & =2 \pi \mathrm{k}_{\mathrm{th}} \mathrm{d}_{\mathrm{p}}(\mathrm{T}(\mathrm{s})-\mathrm{T}(\infty)), \text { and } \\
\mathrm{k}_{\mathrm{th}} & =\text { thermal conductivity of the atmosphere. }
\end{aligned}
$$

The temperature at the particle surface is:

$$
T(s)=T(\infty)+\left.\frac{L}{2 \pi d_{p} k_{t h}} \frac{d N\left(H_{2} \mathrm{O}\right)}{d t}\right|_{\text {cont }}
$$

\section{Condensation in the Transition Regime}

Most aerosol particles in reactor containment atmospheres during severe accidents will be too large to be classified as being in the free-molecular regime. Many particles will still be too small to be classified as being in the continuum regime. There are no practically useful descriptions of the condensation process in the transition regime between the free-molecular and continuum limits. Williams and Loyalka [41] have proposed a scheme for interpolating from the limiting expressions into the transition regime:

$$
\left.\frac{\mathrm{dq}}{\mathrm{dt}}\right|_{\text {trans }}=\left.\frac{\mathrm{dq}}{\mathrm{dt}}\right|_{\text {cont }} \mathrm{H}[\mathrm{Kn}(\mathrm{h})]^{-1}
$$




$$
\left.\frac{\mathrm{dN}\left(\mathrm{H}_{2} \mathrm{O}\right)}{\mathrm{dt}}\right|_{\text {trans }}=\left.\frac{\mathrm{dN}\left(\mathrm{H}_{2} \mathrm{O}\right)}{\mathrm{dt}}\right|_{\text {cont }} \mathrm{F}[\mathrm{Kn}(\mathrm{c})]^{-1}
$$

where

$$
\begin{aligned}
& \mathrm{H}[\mathrm{Kn}(\mathrm{h})]=\quad 1+\frac{\mathrm{Kn}(\mathrm{H})(\Omega \mathrm{E}(\mathrm{h})+\mathrm{J}(\mathrm{h}))}{\mathrm{Kn}(\mathrm{h}) \mathrm{E}(\mathrm{h})+1} \\
& \mathrm{~F}[\mathrm{Kn}(\mathrm{c})]=\mathrm{G}(\mathrm{Kn}(\mathrm{c}))\left[1+\frac{(1-\mathrm{s})}{\mathrm{s}} / \mathrm{G}(\mathrm{Kn}(\mathrm{c}))\right] \\
& \mathrm{G}[\mathrm{Kn}(\mathrm{c})]=1+\frac{\mathrm{Kn}(\mathrm{c})(\theta \mathrm{E}(\mathrm{c})+\mathrm{J}(\mathrm{c}))}{\mathrm{Kn}(\mathrm{c}) \mathrm{E}(\mathrm{c})+1} \\
& \Omega=\left.\frac{\mathrm{dq}}{\mathrm{dt}}\right|_{\text {cont }} /\left.\frac{\mathrm{dq}}{\mathrm{dt}}\right|_{\mathrm{fm}} \\
& \theta=\left.\frac{\mathrm{dN}\left(\mathrm{H}_{2} \mathrm{O}\right)}{\mathrm{dt}}\right|_{\text {cont }} /\left.\frac{\mathrm{dN}\left(\mathrm{H}_{2} \mathrm{O}\right)}{\mathrm{dt}}\right|_{\mathrm{fm}} \\
& \mathrm{Kn}(\mathrm{h})=2 \lambda(\mathrm{h}) / \mathrm{d}_{\mathrm{p}} \\
& \mathrm{Kn}(\mathrm{c})=2 \lambda(\mathrm{c}) / \mathrm{d}_{\mathrm{p}} \\
& \lambda(\mathrm{h})=0.8 \mathrm{k}_{\mathrm{th}} \frac{\mathrm{T}(\infty)}{\mathrm{P}_{\mathrm{T}}}\left[\frac{\mathrm{MW}}{2 \mathrm{RT}(\infty)}\right]^{1 / 2} \\
& =\frac{2.562 \times 10^{-3} \mathrm{k}_{\mathrm{th}}(\mathrm{cal} / \mathrm{s}-\mathrm{cm}-\mathrm{K}) \mathrm{T}(\infty)^{1 / 2} \mathrm{MW}^{1 / 2}(\mathrm{~cm})}{\mathrm{P}_{\mathrm{T}}(\mathrm{atm})} \\
& \lambda(\mathrm{c})=2 \boxplus(\infty)\left[\frac{18.016}{\mathrm{RT}(\infty)}\right]^{1 / 2} \\
& =\frac{6.58 \times 10^{-4} Ð(\infty)}{T(\infty)^{1 / 2}}(\mathrm{~cm}) \\
& E(h)=1.9234 \\
& \mathrm{E}(\mathrm{c})=4 / 3 \\
& \mathrm{~J}(\mathrm{~h})=5 / 8 \sqrt{\pi} \xi
\end{aligned}
$$


Physical

$$
\begin{aligned}
J(c) & =0.9769-0.518 z+0.018 z^{2}+0.0196 z^{3} \\
z & =\log _{10}\left[\frac{\mathrm{MW}(\mathrm{nc})}{\mathrm{MW}\left(\mathrm{H}_{2} \mathrm{O}\right)}\right]
\end{aligned}
$$

where $M W(n c)$ is the molecular weight of the noncondensible gas.

Loyalka and Ferziger [61] suggest values of $\xi$ varying between 1.1136 and 1.1759 .

The effect of the interpolation between the continuum and the free-molecular limits is to reduce significantly the condensation flux of steam onto particles. The effect is most pronounced for submicron particles, but is still significant even for $1 \mu \mathrm{m}$ diameter particles.

\section{Sedimentation}

Sedimentation of aerosols under the influence of gravity is usually calculated assuming that the containment volume is well-mixed. The deposition velocity of aerosol particles is then:

$$
V_{D}=\rho_{p} d_{p}^{2} g C / 18 \mu_{g} \chi
$$

where $\mathrm{C}$ is the Cunningham slip correction factor and $\chi$ is the dynamic shape factor (see Section II-G). Dua et. al. [62] have validated this description of gravitational settling for particles of the size of interest here in a variety of permanent gas mixtures.

Especially in containments with highly compartmentalized geometries, there are situations in which the atmosphere can become stratified. Often, this stratification occurs because steam-rich gases flow into cool, closed-ended rooms. Condensation of the steam leaves the noncondensible gas in place and the atmosphere in the room is stratified. This is an area of active investigation within the reactor safety community because of its implications concerning hydrogen combustion. It is assumed here that stratification issues will be resolved such that atmosphere stratification will not be an important consideration for prediction of aerosol behavior in containment.

\section{E. Phoretic Phenomena}

Aerosol particles are small enough that they do respond to gradients in the atmospheric conditions. Two important processes of interest are thermophoresis and diffusiophoresis. Thermophoresis is the movement of particles down a temperature gradient. Thermophoresis can be a significant mechanism for aerosol trapping when cooled surfaces are present in the containment. Diffusiophoresis is an overall name for Stefan flow and diffusiophoretic force on particles in a non-equilibrium, multicomponent gas. The net flux of gas to a surface can drive particles into that surface. Diffusiophoretic deposition can be important when steam is being condensed from a containment atmosphere. Further descriptions of these phoretic phenomena are presented in the subsections below. 


\section{Diffusiophoresis}

A severe accident in a nuclear power plant will begin with the boiloff of coolant from the reactor coolant system. In most hypothesized accidents, steam produced by the boiloff will go into the containment. (Containment by-pass accidents are exceptions to this.) The containment will initially be cool on a relative basis, so the steam will condense.

Shortly after the boiloff of coolant has lowered the liquid level below the top of the reactor core, the release of radionuclides to the containment begins with the gap release. Aerosols generated by the gap release will enter the still steam-rich containment atmosphere. The condensing steam will provide an important mechanism to push these aerosol particles toward surfaces. Contact between the particle and a surface is usually assumed to result always in the trapping of a particle on the surface. Van der Waals forces, electrostatic forces and, in the case of wet surfaces, surface tension forces are believed to assure this high efficiency of particle trapping. This assumption is accepted here. That is, particles are assumed to never "bounce" off a surface they contact.

The deposition velocity for aerosol particles due to diffusiophoresis is given by [63]:

$$
\mathrm{V}_{\mathrm{D}}=-\left[1+\sigma_{12}\left(1-\mathrm{P}\left(\mathrm{H}_{2} \mathrm{O}\right) / \mathrm{P}_{\mathrm{T}}\right)\right] \frac{\mathrm{D}\left(\mathrm{H}_{2} \mathrm{O}\right)}{\mathrm{P}_{\mathrm{T}}-\mathrm{P}\left(\mathrm{H}_{2} \mathrm{O}\right)} \nabla \mathrm{P}\left(\mathrm{H}_{2} \mathrm{O}\right)
$$

where

$$
\begin{aligned}
\mathrm{P}\left(\mathrm{H}_{2} \mathrm{O}\right) & =\text { partial pressure of steam in the containment atmosphere } \\
\mathrm{P}_{\mathrm{T}} & =\text { total pressure in the containment atmosphere } \\
\mathrm{D}\left(\mathrm{H}_{2} \mathrm{O}\right) & =\text { diffusion coefficient of water vapor in the atmosphere } \\
\mathrm{\nabla}\left(\mathrm{H}_{2} \mathrm{O}\right) & =\text { gradient of steam partial pressure, and } \\
\sigma_{12} & =\text { scattering kernel }
\end{aligned}
$$

Waldmann and Schmitt [63] found $\sigma_{12}$ from theory to be:

$$
\sigma_{12}=\frac{m\left(\mathrm{H}_{2} \mathrm{O}\right)-\mathrm{m}(\mathrm{gas})}{\mathrm{m}+\left[\mathrm{m}\left(\mathrm{H}_{2} \mathrm{O}\right) \mathrm{m}(\mathrm{gas})\right]^{1 / 2}}
$$

This leads to the familiar expression: 
Physical

$$
V_{D}=\frac{-P_{T} \sqrt{m\left(H_{2} \mathrm{O}\right)}}{P\left(\mathrm{H}_{2} \mathrm{O}\right) \sqrt{m\left(\mathrm{H}_{2} \mathrm{O}\right)}+\mathrm{P}(\text { gas }) \sqrt{\mathrm{m}(\text { gas })}}\left(\frac{\oplus\left(\mathrm{H}_{2} \mathrm{O}\right)}{\mathrm{P}(\text { gas })}\right) \frac{\mathrm{dP}\left(\mathrm{H}_{2} \mathrm{O}\right)}{\mathrm{dx}}
$$

But, to match experimental results Waldmann and Schmitt had to use:

$$
\sigma_{12}=\frac{0.95\left[\mathrm{~m}\left(\mathrm{H}_{2} \mathrm{O}\right)-\mathrm{m}(\mathrm{gas})\right]}{\mathrm{m}\left(\mathrm{H}_{2} \mathrm{O}\right)+\mathrm{m}(\mathrm{gas})}-\frac{1.05\left[\sigma\left(\mathrm{H}_{2} \mathrm{O}\right)-\sigma(\text { gas })\right]}{\sigma\left(\mathrm{H}_{2} \mathrm{O}\right)+\sigma(\text { gas })}
$$

where:

$$
\begin{aligned}
\mathrm{m}\left(\mathrm{H}_{2} \mathrm{O}\right) & =\text { mass of an } \mathrm{H}_{2} \mathrm{O} \text { molecule } \\
\mathrm{m}(\mathrm{gas}) & =\text { average mass of a molecule of the non-condensible gas in the atmosphere } \\
\mathrm{m} & =\frac{\mathrm{P}(\mathrm{gas})}{\mathrm{P}_{\mathrm{T}}} \mathrm{m}(\mathrm{gas})+\frac{\mathrm{P}\left(\mathrm{H}_{2} \mathrm{O}\right)}{\mathrm{P}_{\mathrm{T}}} \mathrm{m}\left(\mathrm{H}_{2} \mathrm{O}\right) \\
\sigma\left(\mathrm{H}_{2} \mathrm{O}\right) & =\text { collision diameter of an } \mathrm{H}_{2} \mathrm{O} \text { molecule, and } \\
\sigma(\mathrm{gas}) & =\begin{array}{l}
\text { average collision diameter of the non-condensible gas molecules in the atmosphere } \\
\text { (see Section II-H). }
\end{array}
\end{aligned}
$$

Waldmann and Schmitt also describe another expression for $\sigma_{12}$ :

$$
\sigma_{12}=\left[1-\frac{\alpha_{m} \text { (gas) }}{\alpha_{m}\left(\mathrm{H}_{2} \mathrm{O}\right)}\right]+\frac{\alpha(\text { thermal) }}{5}
$$

where

$$
\begin{aligned}
\boldsymbol{\alpha}_{\mathrm{m}} \text { (gas) } & =\text { momentum accommodation coefficient of the gas, } \\
\boldsymbol{\alpha}_{\mathrm{m}}\left(\mathrm{H}_{2} \mathrm{O}\right) & =\text { momentum accommodation coefficient of the water vapor, and } \\
\alpha(\text { thermal }) & =\text { thermal diffusion factor for gas and water vapor. }
\end{aligned}
$$


Williams $[64,65]$ has formulated a very generalized expression for the scattering kernel. He considers there to be four types of gas molecule reflection from the surface of a particle:

- diffuse reflection in which the gas molecule is accommodated on the particle surface and is, then, emitted from the surface at an angle that is independent of the angle of incidence,

- specular reflection in which the angle of incidence equals the angle of reflection,

- backward reflection, and

- Lambert's Law reflection according to which the angle of reflection obeys a cosine distribution.

Distinctions in these types of reflections are quite important because of differences in gas molecules making up the containment atmosphere. The scattering kernel, $\sigma_{12}$, then is given by:

$$
\sigma_{12}=\alpha \sigma \text { (diffuse) }+\beta \sigma(\text { Lambert })+\gamma \sigma(\text { specular })+\delta \sigma \text { (backward) }
$$

where $\alpha, \beta, \gamma$, and $\delta$ are the fractions of the impacting molecules that undergo the various types of reflection. Note that $\alpha+\beta+\gamma+\delta=1$. For a binary mixture of noncondensible gas and steam:

$$
\begin{aligned}
& \sigma_{12}=\left\{m\left(\mathrm{H}_{2} \mathrm{O}\right)^{1 / 2}\left[1+\pi \alpha\left(\mathrm{H}_{2} \mathrm{O}\right) / 8+\delta\left(\mathrm{H}_{2} \mathrm{O}\right)+4 / 9 \beta\left(\mathrm{H}_{2} \mathrm{O}\right)\right]\right. \\
& \left.-\mathrm{m}(\text { gas })^{1 / 2}(1+\pi \alpha(\text { gas }) / 8+\delta(\text { gas })+4 / 9 \beta(\text { gas }))\right\} / \xi \\
& \xi=x\left(\mathrm{H}_{2} \mathrm{O}\right) \mathrm{m}\left(\mathrm{H}_{2} \mathrm{O}\right)^{1 / 2}\left[1+\frac{\pi}{8} \alpha\left(\mathrm{H}_{2} \mathrm{O}\right)+\delta\left(\mathrm{H}_{2} \mathrm{O}\right)+4 / 9 \beta\left(\mathrm{H}_{2} \mathrm{O}\right)\right]
\end{aligned}
$$

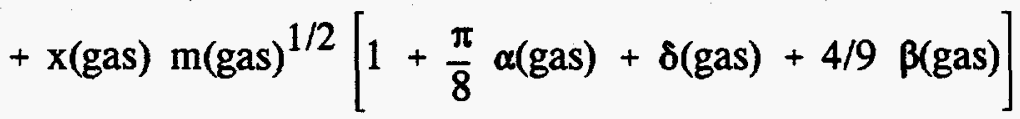

where $x\left(\mathrm{H}_{2} \mathrm{O}\right)$ and $x(\mathrm{gas})$ are the mole fractions of steam and noncondensible gas in the mixture, respectively.

Kuscer and Cercignani [66] consider both momentum and energy accommodation (see Section G-6) to derive:

$$
\sigma_{12}=\frac{\mathrm{m}\left(\mathrm{H}_{2} \mathrm{O}\right)^{1 / 2} \mathrm{Q}\left(\mathrm{H}_{2} \mathrm{O}\right)-\mathrm{m}(\text { gas })^{1 / 2} \mathrm{Q}(\mathrm{gas})}{\mathrm{x}\left(\mathrm{H}_{2} \mathrm{O}\right) \mathrm{m}\left(\mathrm{H}_{2} \mathrm{O}\right)^{1 / 2} \mathrm{Q}\left(\mathrm{H}_{2} \mathrm{O}\right)+\mathrm{x}(\text { gas }) \mathrm{m}(\text { gas })^{1 / 2} \mathrm{Q}(\mathrm{gas})}
$$

where

$$
\mathrm{Q}(\mathrm{i}) \quad=1+\pi / 8-0.5\left(1-\alpha_{\mathrm{m}}(\mathrm{i})\right)+\pi\left(1-\alpha_{\mathrm{t}}(\mathrm{i})\right) / 16
$$


Physical

Waldmann and Schmitt did their derivation for large, spherical particles. To approximately correct for nonsphericity of the particles and to extend the derivation into the small particle regime:

$$
\mathrm{V}_{\mathrm{D}}=-\frac{\mathrm{C}}{\chi}\left[\frac{\chi}{\mathrm{C}}+\sigma_{12}\left(1-\mathrm{P}\left(\mathrm{H}_{2} \mathrm{O}\right) / \mathrm{P}_{\mathrm{T}}\right)\right] \frac{\mathrm{D}\left(\mathrm{H}_{2} \mathrm{O}\right)}{\mathrm{P}_{\mathrm{T}}-\mathrm{P}\left(\mathrm{H}_{2} \mathrm{O}\right)} \nabla \mathrm{P}\left(\mathrm{H}_{2} \mathrm{O}\right)
$$

where

$$
\begin{aligned}
& \mathrm{C}=\text { Cunningham slip correction factor, and } \\
& \chi=\text { dynamic shape factor }
\end{aligned}
$$

Note that diffusiophoretic deposition of aerosol particles is independent of particle size except for the effect of the slip correction factor.

Finally, mention should be made of the empirical diffusiophoretic deposition velocity found by Goldsmith and May [67] for particles in air vapor mixtures (mole fraction air $=0.977$ ) at $298 \mathrm{~K}$ :

$$
V_{D}=-1.88 \times 10^{-7} \frac{\mathrm{dP}\left(\mathrm{H}_{2} \mathrm{O}\right)}{\mathrm{dx}}(\mathrm{cm} / \mathrm{s})
$$

Diffusiophoretic deposition is driven by the gradients in steam concentrations at surfaces in the containment. The steam partial pressure gradients adjacent to the containment surfaces can be found from correlations of steam mass transfer to the containment surfaces:

$$
\frac{\frac{1}{A} d N\left(H_{2} \mathrm{O}\right)}{d t}=\frac{k_{m}}{R T}\left[P\left(H_{2} \mathrm{O}\right)-P_{e q}\left(\mathrm{H}_{2} \mathrm{O}\right)\right]=\frac{Ð\left(\mathrm{H}_{2} \mathrm{O}\right)}{\left[1-\frac{\mathrm{P}_{2} \mathrm{O} \mathrm{H}_{2}}{\mathrm{P}_{\mathrm{T}}}\right]} \frac{\nabla P\left(\mathrm{H}_{2} \mathrm{O}\right)}{\mathrm{RT}}
$$

where

$$
\begin{aligned}
\mathrm{k}_{\mathrm{m}} & =\text { mass transfer coefficient, and } \\
\mathrm{A} & =\text { surface area. }
\end{aligned}
$$

Mass transport coefficients used here are derived from a model by Corradini [68] and are discussed below in connection with uncertainties in condensation rates. 


\section{Thermophoresis}

There will be a thermal gradient between surfaces and the bulk gas in reactor containments. This thermal gradient will impart a thermophoretic force on particles [41,69]. Talbot et al. [70] have derived a widely used expression for this force:

$$
F_{T}=\frac{\frac{-6 \pi \mu_{g}^{2} d_{p} C_{s}}{\rho_{g}}\left[\frac{k_{g}}{k_{p}}+C_{t} K n\right] \nabla \ln T}{\left(1+3 C_{m} K n\right)\left(1+\frac{2 k_{g}}{k_{p}}+2 C_{t} K n\right)}
$$

where

$$
\begin{aligned}
& F_{T}=\text { thermophoretic force, } \\
& C_{s}=1.128, \\
& k_{g}=\text { thermal conductivity of the gas, } \\
& k_{p}=\text { thermal conductivity of the aerosol particle, } \\
& C_{m}=\left(2-\alpha_{m}\right) / \alpha_{m} \\
& \alpha_{m}=\text { momentum accommodation coefficient, } \\
& C_{t}=\frac{15}{8} \frac{\left(1-\alpha_{t}\right)}{\alpha_{t}}, \text { and } \\
& \alpha_{t}=\text { thermal accommodation coefficient. }
\end{aligned}
$$

The Knudsen number, $\mathrm{Kn}$, is discussed in Section G.2.

Many investigators consider $C_{s}$ to be uncertain over an interval of about 0.75 to 2.0. The expression for the thermophoretic force has been derived for hard sphere gases. Loyalka [71] has suggested alternate values for the parameters in the expression for the thermophoretic force to account for the deviations from hard sphere behavior as gases approach a surface:

$$
\begin{aligned}
& \mathrm{C}_{\mathrm{s}}=0.75\left(1-\alpha_{\mathrm{m}}\right)+3 \alpha_{\mathrm{m}} \xi(\mathrm{s}) \\
& \mathrm{C}_{\mathrm{t}}=\frac{15}{8} \frac{\left(2-\alpha_{\mathrm{t}}\right)}{\alpha_{\mathrm{t}}}\left[\left(1-\alpha_{\mathrm{t}}\right) \frac{5}{8} \sqrt{\pi}+\alpha_{\mathrm{t}} \xi(\mathrm{t})\right]
\end{aligned}
$$


Physical

$$
\begin{aligned}
& C_{m}=\frac{\left(2-\alpha_{m}\right)}{\alpha_{m}}\left[\left(1-\alpha_{m}\right) \frac{\sqrt{\pi}}{2}+\alpha_{m} \xi(m)\right] \\
& \xi(s)=0.35 \text { to } 0.383 \\
& \xi(t)=1.263 \text { to } 1.296 \\
& \xi(m)=0.996 \text { to } 1.02
\end{aligned}
$$

Equating the thermophoretic force to the drag force yields the thermophoretic deposition velocity, $\mathrm{V}_{\mathrm{T}}$ :

$$
V_{T}=\frac{\frac{-2 \mu_{g} C_{s} C}{\rho_{g} \chi}\left[\frac{k_{g}}{k_{p}}+C_{t} K n\right] \nabla \ln T}{\left(1+3 C_{m} K n\right)\left(1+\frac{2 k_{g}}{k_{p}}+2 C_{t} K n\right)}
$$

A comparison of the predictions from this expression to experimental data is shown in Figure 5.

During steam condensation on surfaces, there are gradients in both the temperature distribution and the steam partial pressure near the surface. Diffusiophoretic and thermophoretic processes should, then, be simultaneously operative. Goldsmith and May [67] have shown that for conditions in which the bulk atmosphere is not saturated, the expressions discussed above for diffusiophoresis and thermophoresis can simply be added to obtain satisfactory predictions of particle deposition data. They found that when the bulk atmosphere was saturated, the deposition rates for particles were much greater than predicted by the simple sum of the thermophoretic deposition rate and the diffusiophoretic deposition rate. The reasons for the increase are not well established, but could have to do either with water condensation on aerosol particles or the effects of turbulence.

\section{F. Diffusive Deposition of Aerosols}

The containment atmosphere during a reactor accident is assumed to be well mixed. Though containments have large open regions in many cases, there are, in all reactor containments, substantial surface areas available for particle deposition. Aerosol-laden gases in turbulent flow will transport particles to these surfaces. Very small particles will deposit by Brownian diffusion. Larger particles will deposit as a result of impulses from velocity fluctuation in the turbulent gas.

In most aerosol models, the diffusive deposition of particles is formulated in terms of a simple diffusion problem: 


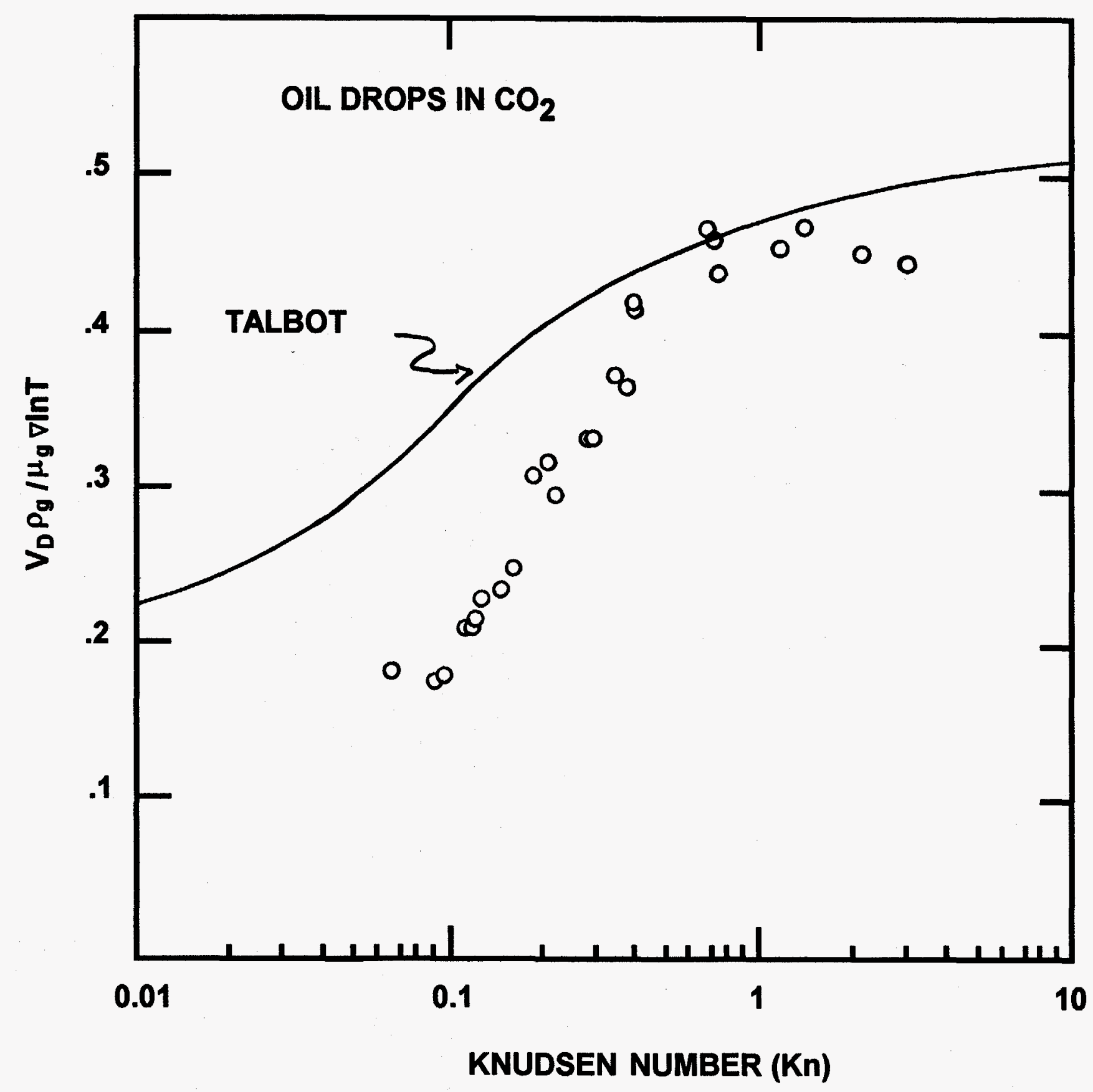

Figure 5. Comparison of the measured thermophoretic deposition of oil droplets to predictions obtained with the model developed by Talbot et al. 
Physical

$$
\frac{1}{A} \frac{d n\left(d_{p}\right)}{d t}=-\frac{Ð\left(d_{p}\right)}{V} \frac{\partial n\left(d_{p}\right)}{\partial y}=-\frac{Ð\left(d_{p}\right)}{\delta} \frac{n\left(d_{p}\right)}{V}
$$

where

$$
\begin{aligned}
\mathrm{n}\left(\mathrm{d}_{\mathrm{p}}\right) & =\text { number of aerosol particles of diameter } \mathrm{d}_{\mathrm{p}} \text { in the atmosphere } \\
\mathrm{A} & =\text { surface area available for deposition } \\
\mathrm{D}\left(\mathrm{d}_{\mathrm{p}}\right) & =\text { particle diffusion coefficient }=\mathrm{CkT} / 3 \mu_{\mathrm{g}} \pi \mathrm{d}_{\mathrm{p}} \chi \\
\mathrm{V} & =\text { containment volume, and } \\
\delta & =\text { boundary layer thickness. }
\end{aligned}
$$

In computer models such as MAEROS [14], the boundary layer thickness is taken to be constant, independent of flow conditions and aerosol particle size. Helton et al. [27-29] in their study of uncertainties in predictions of aerosol behavior obtained from the MAEROS code treated the boundary layer as uncertain over the range of 0.005 to $0.8 \mathrm{~cm}$. The basis for this range was not explained.

Fuchs [72] has argued that $\delta$ should be dependent on particle size. He contends that larger particles will be transported closer to the surfaces before diffusive motion can cause them to deposit. Fuchs estimated that $\delta$ should be proportional to $\boxplus^{1 / 4}$. Van de Vate has correlated experimental data to deduce [73]:

$$
\delta=4.6 \boxplus^{0.265} \mathrm{~cm}
$$

where $Đ$ is in units of $\mathrm{cm}^{2} / \mathrm{s}$. Then,

$$
\frac{1}{A} \frac{\mathrm{dn}\left(\mathrm{d}_{\mathrm{p}}\right)}{\mathrm{dt}}=-\frac{\mathrm{A} \oplus^{0.735} \mathrm{n}\left(\mathrm{d}_{\mathrm{p}}\right)}{4.6 \mathrm{~V}}
$$

and the particle-size dependence of the deposition flux of particles is reduced relative to that obtained when $\delta$ is treated as a constant.

This procedure seems to be best suited for the analysis of aerosol deposition from a relatively stagnant atmosphere. The atmosphere of a reactor containment during an accident would be expected to be vigorously stirred by natural convection. In an overall perspective, there is a hot source of decay and chemical energy low within the containment surrounded by heat sinks. For length scales, L, on the order of a few meters, Grashoff numbers, Gr, where 


$$
\mathrm{Gr}=\mathrm{g} \Delta \mathrm{T} \mathrm{L} \mathrm{L}^{3} \rho_{\mathrm{g}}^{2} / \mathrm{T} \mu_{\mathrm{g}}{ }^{2}
$$

are on the order of $6 \times 10^{10}$, which is well within the regime of turbulent flow.

Deposition of aerosol particles onto surfaces has been more thoroughly studied for turbulent, forced flows in pipes $[74,75,76]$ than for the deposition of particles from turbulent natural convection flows in large volumes. Under turbulent conditions, the diffusive flux of particles to surfaces is given by:

$$
\frac{1}{A} \frac{d N}{d t}=-\left.(\epsilon+Đ) \frac{d(N / V)}{d y}\right|_{y=0}
$$

where

$$
\begin{aligned}
& \mathbf{N}=\text { number of particles } \\
& \mathbf{A}=\text { surface area for deposition } \\
& \mathbf{D}=\text { particle diffusion coefficient } \\
& \boldsymbol{\epsilon}=\text { turbulent diffusion coefficient } \\
& \mathbf{V}=\text { volume, and } \\
& \mathbf{y}=\text { distance from the surface. }
\end{aligned}
$$

Solution of this equation revolves around the definition of the turbulent diffusion coefficient. An analogy between the turbulent diffusion coefficient and the eddy diffusivity is usually hypothesized to relate mass transfer to the momentum transfer of the flow. This has been criticized for aerosol particle transport [77]. Conventional correlations of the mass transport coefficient derived from the hypothesized analogy yield satisfactory results for Schmidt numbers, Sc, up to about 20 [78] where:

$$
\mathrm{Sc}=\mu_{\mathrm{g}} / \rho_{\mathrm{g}} \boxplus
$$

Schmidt numbers for mass transport of aerosol particles are on the order of $10^{6}$ to $10^{7}$. The conventional correlations, when applied to these high Schmidt number situations, yield particle deposition velocities that are too low by factors of 100 to 1000 for particles of the size $(>1 \mu \mathrm{m})$ of interest in reactor accident analyses. Mass transfer analogies to heat transfer may be adequate for treating deposition of very small particles $(<0.05 \mu \mathrm{m})$. A more detailed examination is required to predict turbulent deposition of large particles that are little affected by Brownian diffusion. 
The structure of turbulent flow near a surface is usually considered to consist of a laminar boundary layer adjacent to the surface and separated from the turbulent core by a buffer zone. Friedlander and Johnstone [74] argued that more extensive particle deposition could occur because particle momentum induced by turbulent velocity fluctuations could carry the particle deep into the buffer zone or even into the laminar layer. The diffusion distance to reach the surface would then be smaller than implicitly considered in the conventional correlations.

Following Sehmel [79], the formal solution of the differential equation for turbulent deposition on vertical walls is:

$$
-\int_{C_{b}}^{o} \frac{U^{*} d C}{\frac{1}{A} \frac{d N}{d t}}=-\int_{Y_{l}^{+}}^{Y_{u}^{+}} \frac{d Y^{+}}{\epsilon \rho g_{g} / \mu_{g}+Đ \rho_{g} / \mu_{g}}
$$

where

$$
\begin{aligned}
\mathrm{C} & =\text { particle concentration }(\mathrm{N} / \mathrm{V}) \\
\mathrm{C}_{\mathrm{b}} & =\text { particle concentration in the bulk gas } \\
\mathrm{U}^{*} & =\text { friction velocity } \\
\mathrm{Y}^{+} & =\mathrm{y} \mathrm{\textrm {U } ^ { * }} \rho_{\mathrm{g}} / \mu_{\mathrm{g}} \\
\mathrm{D} & =\mathrm{C} \mathrm{kT} / 3 \pi \mu_{\mathrm{g}} \chi \mathrm{d}_{\mathrm{p}} \\
\mathrm{Y}_{\mathrm{u}}^{+} & =\text {upper limit of the integration, and } \\
\mathrm{Y}_{\mathrm{I}}^{+} & =\text {lower limit of the integration. }
\end{aligned}
$$

The immediate difficulties in carrying the formal solution to a solution of practical value are definition of the limits of integration and the specification of $\epsilon$. Friedlander and Johnstone [74] argued that the lower limit is defined by the particle stopping distance. They assumed that a particle would have a velocity given by the root mean square of velocity fluctuations in the turbulent core. This hypothesis has been criticized [77,80,81]. It is usually justified as being the hypothesis that yields results comparable to experiments [81]. Sehmel [79] has, however, taken the lower limit of integration to be defined by the particle diameter:

$$
\mathrm{Y}_{1}^{+}=\mathrm{d}_{\mathrm{p}} \mathrm{U}^{*} \rho_{\mathrm{g}} / \mu_{\mathrm{g}}
$$


Willers [80] has argued that particles in the buffer zone will experience a frequency spectrum of velocity fluctuations. Depending on the size of the particle, there is a cutoff frequency of velocity fluctuations that is so large the particle is unable to respond. Based on this analysis and fitting to experimental data, he obtains for the lower limit of integration:

$$
Y_{1}^{+}=19.17 \exp \left(0.2 \rho_{p}\right)\left(d_{p} U^{*} \rho_{g} / \mu_{g}\right)^{2}
$$

where the particle material density, $\rho_{\mathrm{p}}$, is in $\mathrm{g} / \mathrm{cm}^{3}$.

Definition of $\epsilon$ across the hydrodynamic structure has been controversial [77]. Strictly interpreting the hypothesized hydrodynamic structure means that $\epsilon$ in the laminar boundary layer should be zero. But, in most attempts to model experiments involving turbulent particle deposition, it has been necessary to assume $\epsilon$ goes to zero at the surface and that it has non-zero values elsewhere in the boundary layer. This inconsistency is less troublesome if it is recognized that the laminar boundary layer is just a qualitative, approximate description of a zone in the flow.

Friedlander and Johnstone [74] took:

$$
\epsilon \rho_{\mathrm{g}} / \mu_{\mathrm{g}}= \begin{cases}\left(\mathrm{Y}^{+} / 14.5\right)^{3} & \text { for } 0<\mathrm{Y}^{+} \leq 5 \\ \mathrm{Y}^{+} / 5-0.959 & \text { for } 5<\mathrm{Y}^{+} \leq 30\end{cases}
$$

Sehmel [79] used data obtained in wind tunnel tests in some way to derive:

- for deposition on upward-facing surfaces:

$$
\epsilon \rho_{\mathrm{g}} / \mu_{\mathrm{g}}=0.531 \exp \left[-0.0330 \mathrm{U}^{*}(\mathrm{~cm} / \mathrm{s})\right]\left(\mathrm{Y}^{+}\right)^{2.6}\left(\tau^{+}\right)^{1.2}
$$

- for deposition on vertical walls:

$$
\epsilon \rho_{\mathrm{g}} / \mu_{\mathrm{g}}=0.011\left(\mathrm{Y}^{\dagger}\right)^{1.1}\left(\tau^{\dagger}\right)^{1.1}
$$

- for deposition on ceilings: 
Physical

$$
\epsilon \rho_{\mathrm{g}} / \mu_{\mathrm{g}}= \begin{cases}0.0041\left(\mathrm{Y}^{+}\right)^{1.3}\left(\tau^{+}\right)^{1.3} & \text { for } \mathrm{U}^{*}=34.1 \mathrm{~cm} / \mathrm{s} \\ 0.0087\left(\mathrm{Y}^{+}\right)^{2.6} \tau^{+} & \text {for } \mathrm{U}^{*}=72.6 \mathrm{~cm} / \mathrm{s}\end{cases}
$$

where $\tau^{+}=\rho_{\mathrm{g}} \rho_{\mathrm{p}} \mathrm{d}_{\mathrm{p}}^{2}\left(\mathrm{U}^{*}\right)^{2} / 18 \mu_{\mathrm{g}}^{2}$. The above relations are also bounded by:

$$
\begin{aligned}
& \epsilon \rho_{\mathrm{g}} / \mu_{\mathrm{g}}^{2}=1.1 \mathrm{Y}^{+} \\
& \epsilon \rho_{\mathrm{g}} / \mu_{\mathrm{g}}^{2}=0.002\left(\mathrm{Y}^{+} / 10\right)^{3} \\
& \epsilon \rho_{\mathrm{g}} / \mu_{\mathrm{g}}^{2}=140
\end{aligned}
$$

Sehmel used as the upper limit of integration:

$$
\mathrm{Y}_{\mathrm{u}}^{+}=\mathrm{U}^{*} \rho_{\mathrm{g}} / \mu_{\mathrm{g}}^{2}
$$

which corresponds to $y=1 \mathrm{~cm}$. This is typically well within the turbulent core which is usually taken to begin at $\mathrm{Y}^{+}=80$.

Selection of the upper limit of integration has an important effect on the predicted deposition velocities of very small particles $(<0.01 \mu \mathrm{m})$, since, for these small particles, the solution of the differential equation is:

$$
V_{d}=\frac{\oplus U^{*} \rho_{g}}{Y_{u}^{+} \mu_{g}}
$$

Deposition of such small particles is not an important issue for analysis of aerosol behavior in reactor containments.

Sauter and Bunz [82] applied Sehmel's formulation to the turbulent deposition of sodium aerosols under natural convection conditions in a large volume. They, like Sehmel, noted peculiarly large predictions of deposition on walls and proposed that deposition velocities predicted for vertical walls be reduced by a factor of 100 to 300 !

Wood [83] has developed a correlation of deposition velocities from data obtained in tests of forced flow through pipes: 


$$
\mathrm{V}_{\mathrm{d}} / \mathrm{U}^{*}= \begin{cases}0.019\left(\boxplus \rho_{\mathrm{g}} / \mu_{\mathrm{g}}\right)^{2 / 3}+1.75 \times 10^{-3}\left(\tau_{+}\right)^{2} & \text { for } \tau_{+} \leq 10 \\ 0.175 & \text { for } \tau_{+} \geq 10\end{cases}
$$

A third formulation of the turbulent deposition is offered here. The main features follow from the development of Friedlander and Johnstone. The turbulent diffusion coefficient is found from:

$$
\in \rho_{\mathrm{g}} / \mu_{\mathrm{g}}= \begin{cases}\left(\mathrm{Y}^{+} / 14.5\right)^{3} & \text { for } 0<\mathrm{Y}^{+} \leq 5 \\ \mathrm{Y}^{+} / 5-0.959 & \text { for } 5<\mathrm{Y}^{+} \leq 30 \\ \mathrm{Y}^{+} / 2.5-6.959 & \text { for } 30<\mathrm{Y}^{+} \leq 80\end{cases}
$$

The lower limit of integration is taken to be that derived by Willers [80]. The upper limit is taken to be $\mathrm{Y}^{+}=80$. With this upper limit, the model yields predictions for the deposition velocities of $10^{-3}$ to $0.1 \mu \mathrm{m}$ particles that are in very close agreement with predictions from Wood's empirical correlation.

Analytic integrals used in the evaluation of the model are:

$$
\begin{gathered}
\int_{Y_{1}^{+}}^{5} \frac{\mathrm{dy}^{+}}{\left(\frac{\mathrm{Y}^{+}}{14.5}\right)^{3}+\mathrm{D} / \nu}=(14.5)^{3} \int_{\mathrm{Y}_{1}^{+}}^{5} \frac{\mathrm{dy}^{+}}{\left(\mathrm{Y}^{+}\right)^{3}+(14.5)^{3} \mathrm{D} / \mathrm{v}} \\
\int \frac{\mathrm{dx}}{\mathrm{a}+\mathrm{x}^{3}}=\frac{1}{3 \mathrm{a}^{2 / 3}}\left[\left\{\frac{1}{2} \ln \left[\frac{\left(\mathrm{a}^{1 / 3}+\mathrm{x}\right)^{2}}{\left(\mathrm{a}^{2 / 3}-\mathrm{a}^{1 / 3} \mathrm{x}+\mathrm{x}^{2}\right)}\right]+\sqrt{3} \mathrm{atn}\left[\frac{2 \mathrm{x}-\mathrm{a}^{1 / 3}}{\mathrm{a}^{1 / 3} \sqrt{3}}\right]\right\}\right] \\
\int_{5}^{30} \frac{\mathrm{dy} \mathrm{Y}^{+} / 5-0.959+\mathrm{D} / \mathrm{v}}{\mathrm{Y}^{+}}=5 \ln \left\{\frac{(5.041+\mathrm{D} / \mathrm{v}}{(0.041+\mathrm{D} / \mathrm{v})}\right\}
\end{gathered}
$$

and 
Physical

$$
\int_{30}^{80} \frac{\mathrm{dy}^{+}}{\mathrm{Y}^{+} / 2.5-6.959+\boxplus / v}=2.5 \ln \left\{\frac{(25.041+Ð / v}{(5.041+Ð / v)}\right\}
$$

where $v=\mu_{\mathrm{g}} / \rho_{\mathrm{g}}$

This formulation somewhat underpredicts data obtained by Friedlander and Johnstone [74] as is shown in Figure 6. The underprediction is not as severe as the overprediction of these data by Friedlander and Johnstone's model. Underprediction is not altogether unexpected. As noted by Liu and Agrawal [75], there are many factors involved in deposition tests that are difficult to control and could provide additional mechanisms for particle deposition in the experiments.

Predictions of particle deposition velocities obtained from Wood's empirical correlation, Sehmel's formulation and from the integration done here are compared in Figure 7 for a friction velocity that Sauter and Bunz found to lead to peculiarly high deposition velocities in Sehmel's formulation. For particles of the size of interest in Sauter and Bunz's tests, the integration developed here yields results that are lower than predictions from Sehmel's formulation by about an order of magnitude. This is not as much as the factor of 100 to 300 Sauter and Bunz had to invoke to match experimental data. The integration developed here would predict such low deposition velocities if the lower limit of integration were adjusted. But, the predictions are also a strong function of the friction velocity as shown in Figure 8. Friction velocities for natural convection are not as easily estimated as they are for forced flow conditions. Sauter and Bunz considered the friction velocity to be 20 to 50 percent of the turbulent flow velocity whereas in forced flow conditions, friction velocity is 3 to 10 percent of the mean velocity. Sauter and Bunz's data could then be better matched by taking a different value for the friction velocity.

For the analysis of turbulent particle deposition in reactor containments done below using the integration described here, the friction velocity under turbulent, natural convection conditions is found from a model proposed by Corradini [68] to describe steam condensation rates in reactor containments. Corradini hypothesized a velocity distribution adjacent to a surface given by:

$$
v=\Gamma(y / \delta)^{1 / 7}(1-y / \delta)^{4}
$$

where

$\mathrm{v}=$ velocity parallel to the surface

$$
\Gamma=\frac{0.79 \mu_{\mathrm{g}} \mathrm{Gr}^{1 / 2}}{\rho_{\mathrm{g}} L\left(1+0.494 \operatorname{Pr}^{2 / 3}\right)^{1 / 2}}
$$




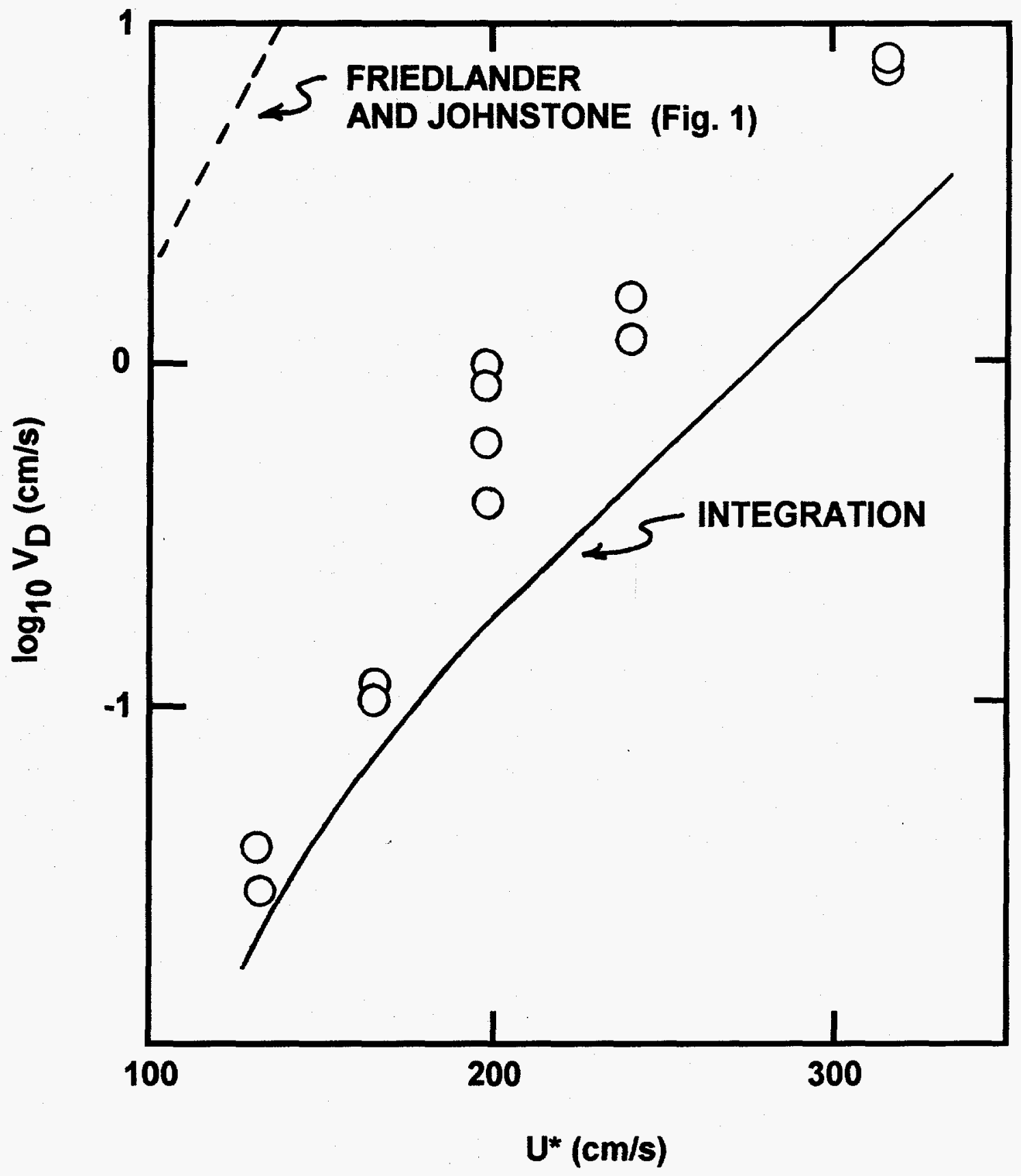

Figure 6. Comparison of measured deposition data for $0.8 \mu \mathrm{m}$ iron particles [74] to predictions obtained with the integration derived here 


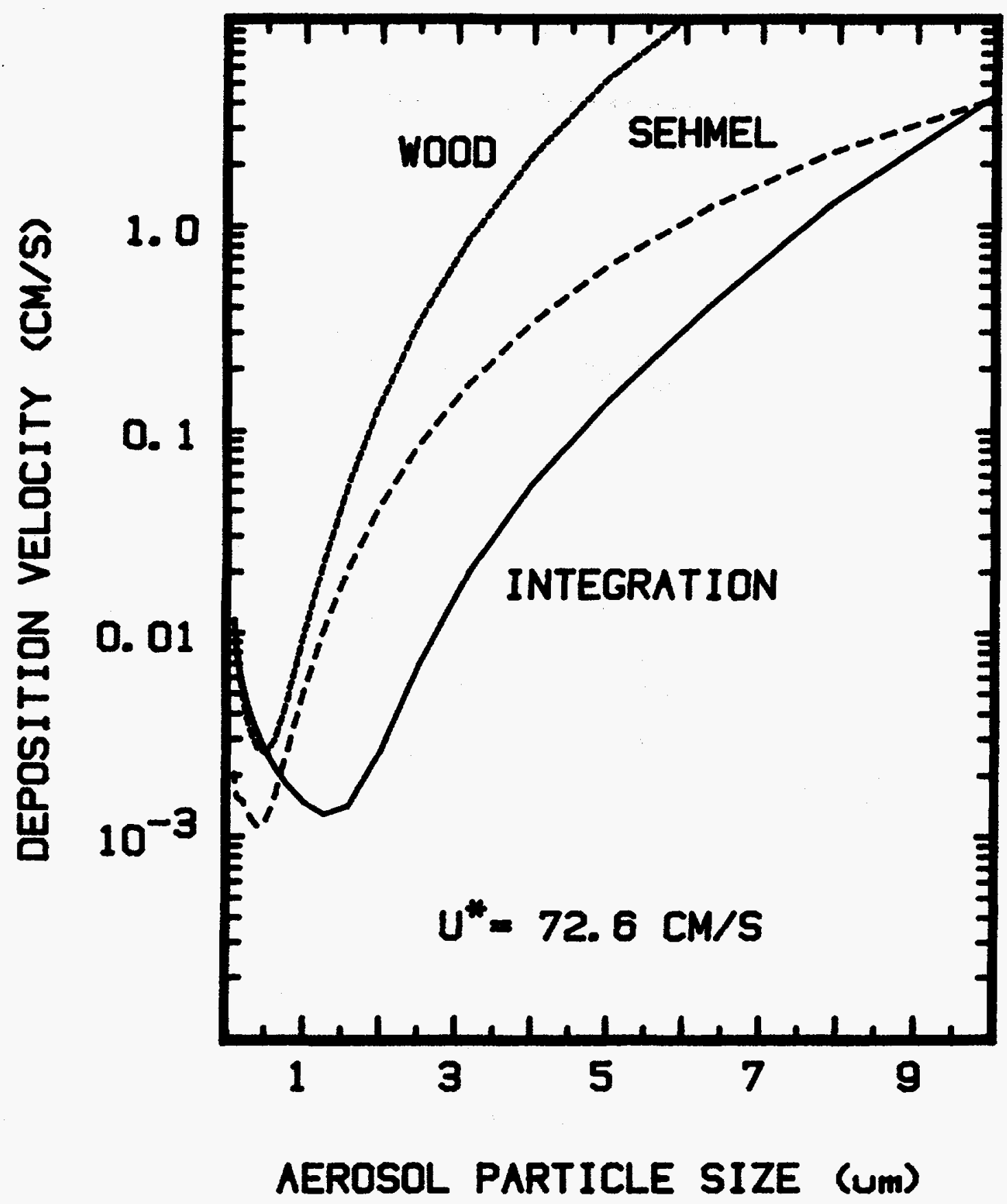

Figure 7. Comparison of predictions of particle deposition velocities 


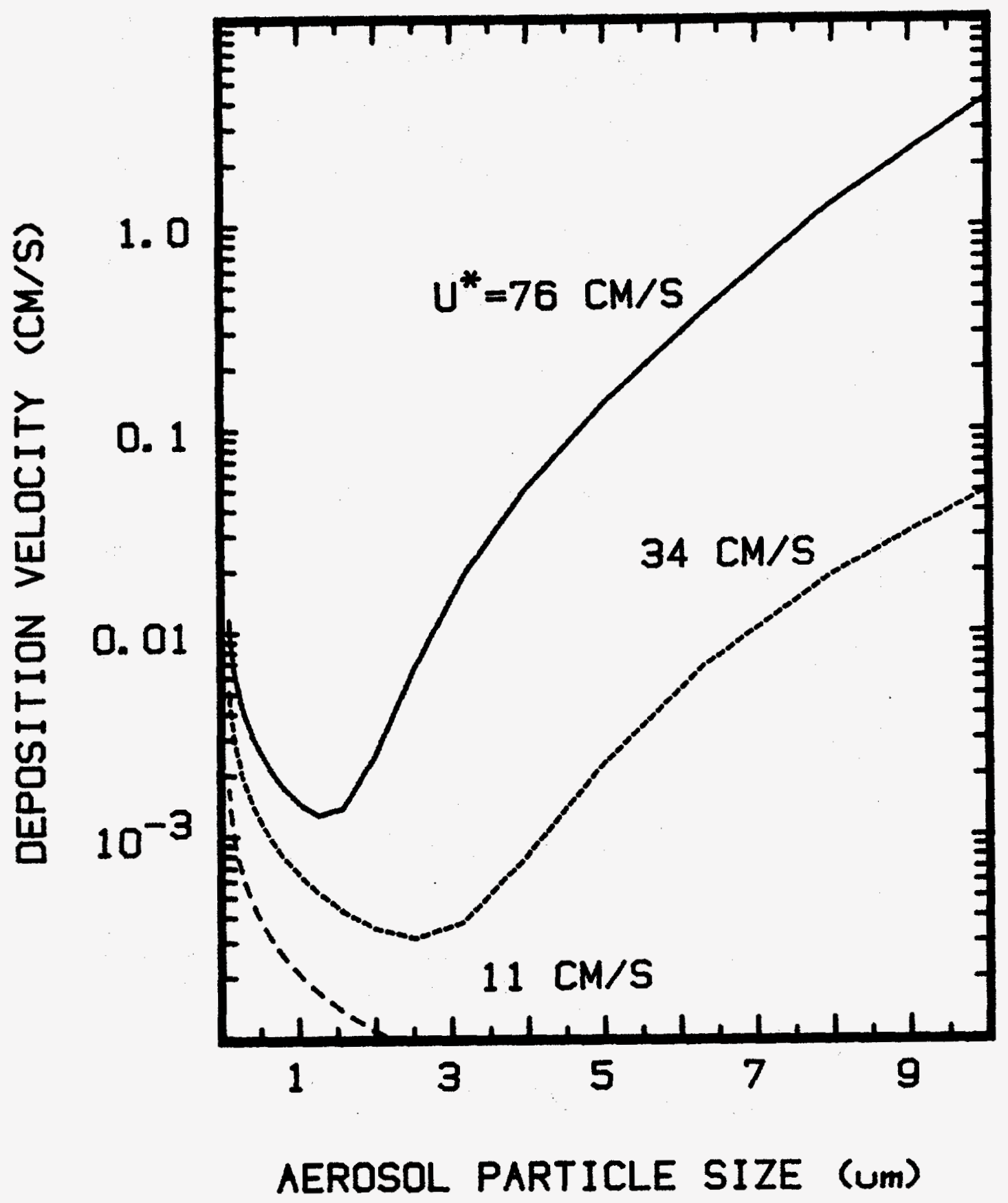

Figure 8. Sensitivity of predicted deposition velocities to the friction velocity 
Physical

$$
\begin{aligned}
\delta & =\frac{0.332 \mathrm{~L}\left(1+0.494 \mathrm{Pr}^{2 / 3}\right)^{0.1}}{\mathrm{Gr}^{0.1} \mathrm{Pr}^{8 / 15}} \\
\mathrm{Gr} & =(\mathrm{g} / \mathrm{T}) \Delta \mathrm{T} \mathrm{L}^{3} \rho_{\mathrm{g}}^{2} / \mu_{\mathrm{g}} \\
\mathrm{L} & =\text { characteristic length of the surface } \\
\Delta \mathrm{T} & =\text { temperature difference between the surface and the bulk gas } \\
\mathrm{T} & =\text { average of the surface temperature and the bulk gas temperature. }
\end{aligned}
$$

The friction factor is given by:

$$
\mathrm{f}=0.045\left(\mu_{\mathrm{g}} / \rho_{\mathrm{g}} \Gamma \delta\right)^{1 / 4}
$$

The velocity distribution hypothesized by Corradini has a maximum of $0.537 \Gamma$ at $y=\delta / 29$. The mean velocity over the interval from $\mathrm{y}=0$ to $\mathrm{y}=\delta$ is $0.1464 \Gamma$. The friction velocity, $\mathrm{U}^{*}$, can then be taken to be:

$$
\mathrm{U}^{*}=\sqrt{\frac{\mathrm{f}}{2}} \xi \mathrm{\Gamma}
$$

where $\xi$ is uncertain over the interval from 0.1464 to 0.537 . This uncertainty range is not greatly different than the uncertainty range Bunz and Sauter encountered in the estimation of friction velocity for their tests.

Definition of the characteristic length to be used in this expression for the friction velocity is also a source of uncertainty that is described further below in connection with the containment thermal hydraulics. 


\section{G. Aerosol Properties}

\section{Shape Factors}

The equations of aerosol physics are written for fully dense, spherical aerosol particles. Of course, real aerosol particles are never really spheres. ${ }^{*}$ In dry environments, fantastic distortions from spherical can develop as aerosols agglomerate to form chains such as those shown in Figure 9a. In the humid environment expected to exist in a reactor containment during a severe reactor accident, such great distortions of the particles are not expected. Typically, aerosol agglomerates formed in humid environments are porous and nearly spherical such as those shown in Figure $9 \mathrm{~b}$. Because the particles are not fully dense, some corrections to the aerosol equations need to be made. Typically, this is done by introducing so-called shape factors. The shape factors of greatest importance are the collision factor, $\gamma$, and the dynamic shape factor, $\chi$.

Brockmann [84] has argued that surface tension effects produced by water condensed in concave pores of particle agglomerates cause the particles to contract into the observed, porous, spherical configuration. He argues, further, that the collision and dynamic shape factors under these conditions are the same and that these shape factors depend only on the packing density of the aerosol material:

$$
x=\gamma=1 / \alpha^{1 / 3}
$$

where $\alpha$ is the effective density of the sphere divided by the density of the materials that makes up the aerosol. If, as is argued by Powers and Burson [5], the voids within an aerosol particle will fill with water, then

$$
\alpha=\left[\epsilon \rho_{\mathrm{p}}+(1-\epsilon) \rho_{\mathrm{w}}\right] / \rho_{\mathrm{p}}
$$

where $\epsilon$ is the packing fraction, $\rho_{p}$ is the density of the solid aerosol material, and $\rho_{w}$ is the density of water.

Random packing of particles to form agglomerates can produce $\epsilon=0.63$. Experimental studies reviewed by Brockmann [84] indicated $\epsilon=0.18$ to 0.5 though an exceptional case of $\epsilon=3 \times 10^{-4}$ was also cited. Powers and Burson [5] argued that the fractal nature of aerosol agglomerates produced by Brownian coagulation should make aerosol shape factors size dependent. They found:

$$
\epsilon=\min \left[1, \frac{\mathrm{d}(\mathrm{pr})^{1.214}}{\mathrm{~d}_{\mathrm{p}}^{1.214}}\right]
$$

\footnotetext{
*Even aerosol particles that are liquid are distorted by gravity and flow from perfectly spherical shapes.
} 
Physical
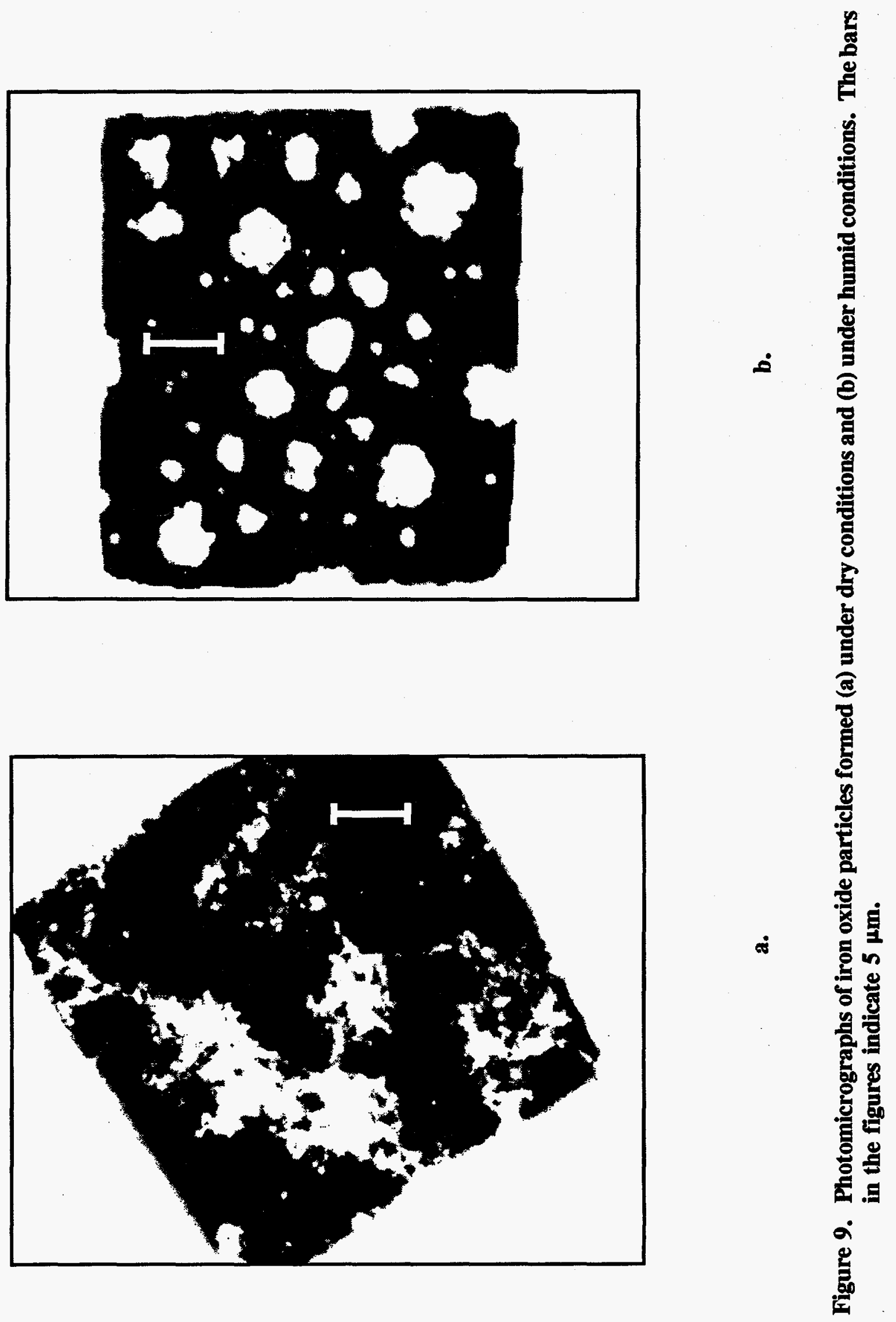
where $\mathrm{d}(\mathrm{pr})$ is the diameter of primary particles making up the agglomerates. The fractal dimension inherent in this model is 1.78 rather than 3 for nonporous spheres. Experimental studies of aerosols produced from titanium chloride in moist air show fractal dimensions that increase from about 1.5 to about 1.8 as the relative humidity increases from about 13 percent to about 87 percent [85]. Computational studies indicate fractal dimensions of 1.8 to 2.2 depending on the collision model [86]. Shape factors predicted with this model are shown in Figure 10 as functions of particle size for particles of various densities of materials.

\section{Slip Correction Factor}

Aerosol particles in reactor containments can be small enough that the motions of these particles cannot be deduced by treating the gas phase as a continuum. Some correction for non-continuum effects can be made by introducing a correction factor, $\mathrm{C}$, called the slip correction factor or the Cunningham slip correction factor. Several empirical correlations have been devised for this slip correction factor:

- $\quad$ Milliken [87]

$$
\mathrm{C}=1+\mathrm{Kn}[1.23+0.414 \exp (-0.876 / \mathrm{Kn})]
$$

- $\quad$ Allen and Raabe [88]

$$
\mathrm{C}=1+\mathrm{Kn}[1.142+0.588 \exp (-0.999 / \mathrm{Kn})]
$$

- Davies [89]

$$
\mathrm{C}=1+\mathrm{Kn}[1.257+0.400 \exp (-1.10 / \mathrm{Kn})]
$$

- $\quad$ Annis et al. [90]

$$
\mathrm{C}=1+\mathrm{Kn}[1.558+0.173 \exp (-0.769 / \mathrm{Kn})]
$$

- Jennings [91]

$$
\mathrm{C}=1+\mathrm{Kn}[1.255+0.399 \exp (-1.10 / \mathrm{Kn})]
$$

$\mathrm{Kn}$ in these expressions is the Knudsen number defined by:

$$
\mathrm{Kn}=\frac{2 \lambda}{\mathrm{d}_{\mathrm{p}}}
$$

where $\lambda$ is the mean free path of gas molecules. The usual definition of the mean free path is: 
Physical

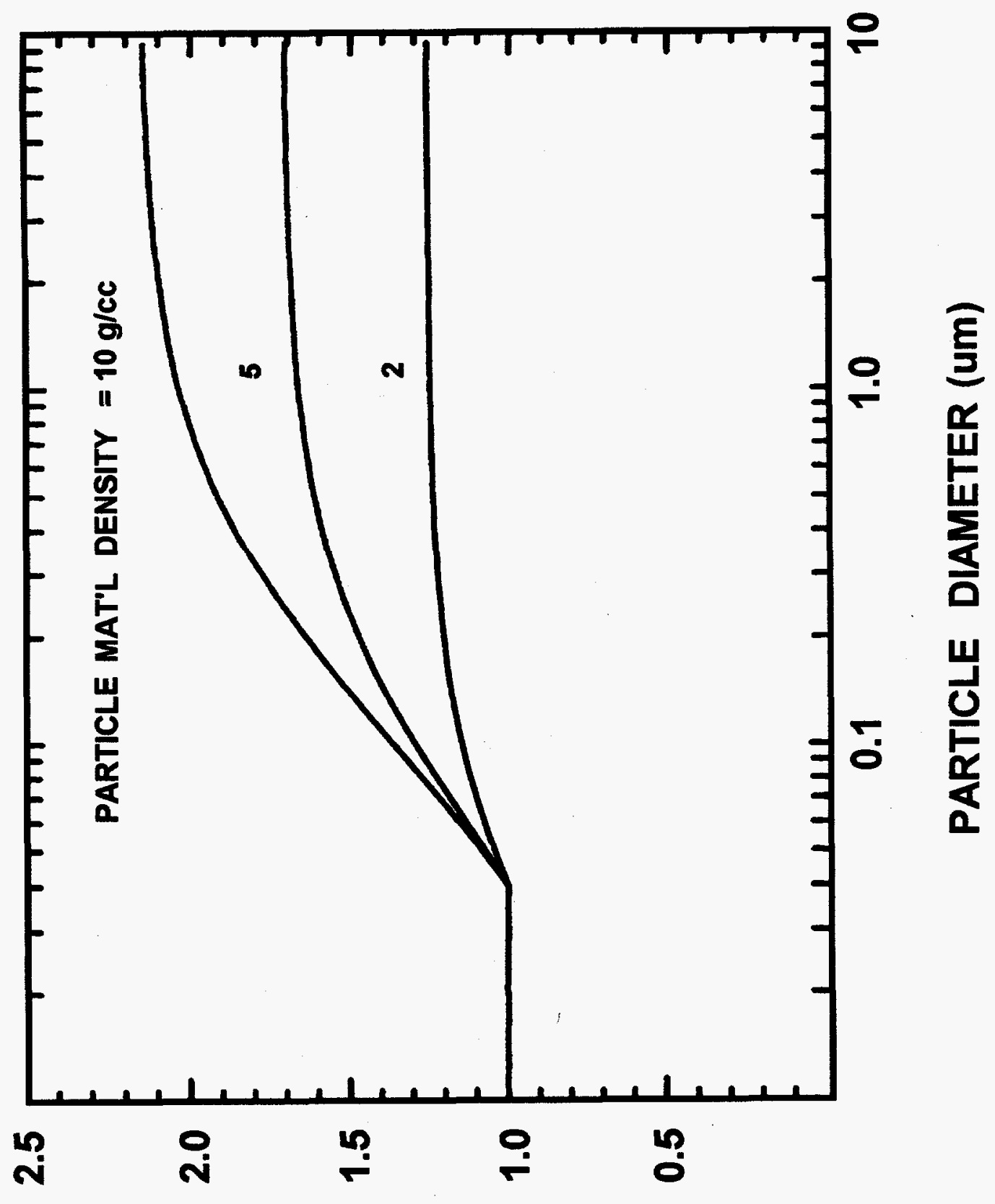

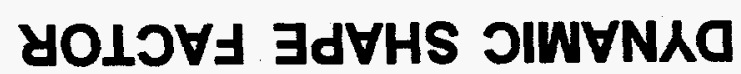

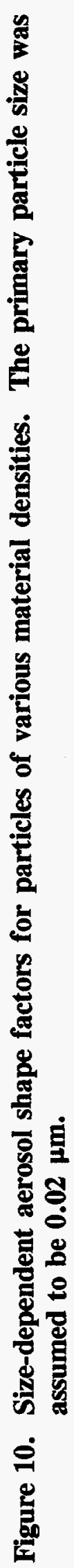




$$
\lambda=\mathrm{kT} / \sqrt{2} \mathrm{P}_{\mathrm{T}} \pi \sigma^{2}
$$

where

$$
\begin{aligned}
\mathbf{k} & =\text { Boltzmann's constant } \\
\mathrm{P}_{\mathbf{T}} & =\text { total pressure in rational units } \\
\mathbf{\sigma} & =\text { collision cross section of the gas molecules. }
\end{aligned}
$$

In conventional units this becomes:

$$
\lambda(\mathrm{cm})=3.065 \times 10^{-7} \mathrm{~T}(\mathrm{~K}) / \mathrm{P}(\mathrm{atms}) \sigma^{2}\left(\mathrm{~A}^{\circ}\right)
$$

For mixtures of gases, it is sometimes convenient to use:

$$
\lambda=\left[\frac{2 \mathrm{MW}}{\mathrm{RT}}\right]^{1 / 2} \mu_{\mathrm{g}} / \rho_{\mathrm{g}}
$$

where MW is the mean molecular weight of the gas and the gas constant, $R$, is in rational units.

Dua et al. [62] recommend for the calculation of mean free path in gas mixtures:

$$
\frac{1}{\lambda}=\frac{0.491 \rho_{\mathrm{g}}}{\mu_{\mathrm{g}}}\left(\frac{8 \mathrm{RT}}{\pi}\right)^{1 / 2} \sum_{\text {all gases }} \mathrm{x}(\mathrm{i}) / \sqrt{\mathrm{MW}(\mathrm{i})}
$$

where

$$
\begin{aligned}
\mathrm{R} & =\text { gas constant }=8.31448 \times 10^{7} \mathrm{~g}-\mathrm{cm}^{2}-\mathrm{s}^{-2}-\mathrm{K}^{-1}-\mathrm{mole}^{-1} \\
\mathrm{x}(\mathrm{i}) & =\text { mole fraction of the } \mathrm{i}^{\text {th }} \text { gas in the mixture, and } \\
\mathrm{MW}(\mathrm{i}) & =\text { molecular weight of the } \mathrm{i}^{\text {th }} \text { gas in the mixture. }
\end{aligned}
$$

All of the empirical expressions treat the slip correction factor strictly as a function of geometry. Though the empirical descriptions of the slip correction satisfactorily fit available data, the data base is not large. It certainly does not include either the types of particles or the types of gases encountered in reactor accidents. Temperatures as high as those expected in reactor accidents have not been used in experimental studies of the slip correction factor. A superior theoretical basis for the slip correction 
Physical

must be used to account for such factors. A theoretical study of the issue of slip correction factors by Philips [92] yielded a different expression and non-geometric dependencies:

$$
\mathrm{C}=\frac{15+12 \mathrm{C}_{1} \mathrm{Kn}+9\left(\mathrm{C}_{1}^{2}+1\right) \mathrm{Kn}^{2}+18 \mathrm{C}_{2}\left(\mathrm{C}_{1}^{2}+2\right) \mathrm{Kn}^{3}}{15-3 \mathrm{C}_{1} \mathrm{Kn}+\mathrm{C}_{2}\left(8+\pi \alpha_{t}\right)\left(\mathrm{C}_{1}^{2}+2\right) \mathrm{Kn}^{2}}
$$

where

$$
\begin{aligned}
& \alpha_{\mathrm{t}}=\text { thermal accommodation coefficient, } \\
& \mathrm{C}_{1}=\left(2-\alpha_{\mathrm{m}}\right) / \alpha_{\mathrm{m}}, \\
& \mathrm{C}_{2}=1 /\left(2-\alpha_{\mathrm{m}}\right), \text { and } \\
& \alpha_{\mathrm{m}}=\text { momentum accommodation coefficient. }
\end{aligned}
$$

A comparison of Phillips' theoretical expression to data for oil droplets [87] and to predictions obtained from the empirical expression for solid particles found by Allen and Raabe [88] is shown in Figure 11. The agreement is quite good. Phillips' expression is more attractive than the empirical correlations since it reflects dependencies that may be significant in reactor accidents but dependencies not explored in experiments to date that have been used to develop the empirical correlations. Phillips' theoretical model is used in the aerosol behavior analyses described in Sections IV and V.

The slip correction factors defined above are for spherical particles. Again, the aerosol particles to be expected in reactor containments will not be perfect spheres. For small distortions from spherical, the volume equivalent particle size can be used to obtain the slip correction factors. Dahneke $[93,94,95]$ has proposed a more accurate procedure called the Adjusted Sphere Approximation. This more elaborate procedure does not produce dramatically different results for small distortions from spherical [3].

\section{Hygroscopicity}

Aerosol materials that are hygroscopic will be strongly affected by the steam-rich atmosphere expected to exist in the containment throughout an accident. Hygroscopic materials are sufficiently soluble in water that they substantially reduce the chemical activity of water so that liquid water condenses from an atmosphere that is otherwise superheated. Particles of hygroscopic materials suspended in the containment atmosphere will, then, grow. Particle growth substantially accelerates deposition of particles by sedimentation. (Particle growth, on the other hand, reduces deposition by diffusion.)

All materials are soluble, to some extent, in water. Dissolution of most of the inorganic materials of interest in reactor accidents reduces the chemical activity of water. Only very highly water soluble, materials reduce the chemical activity of water in saturated solutions enough to have a significant effect on aerosol behavior. Among the materials so soluble in water that hygroscopicity affects their behavior are species such as $\mathrm{CsOH}$ and CsI. These compounds are frequently mentioned as possible chemical forms of fission product cesium and iodine that will be suspended in the containment atmosphere during an accident. Several papers have been published describing the expected effects of hygroscopicity on 
Physical

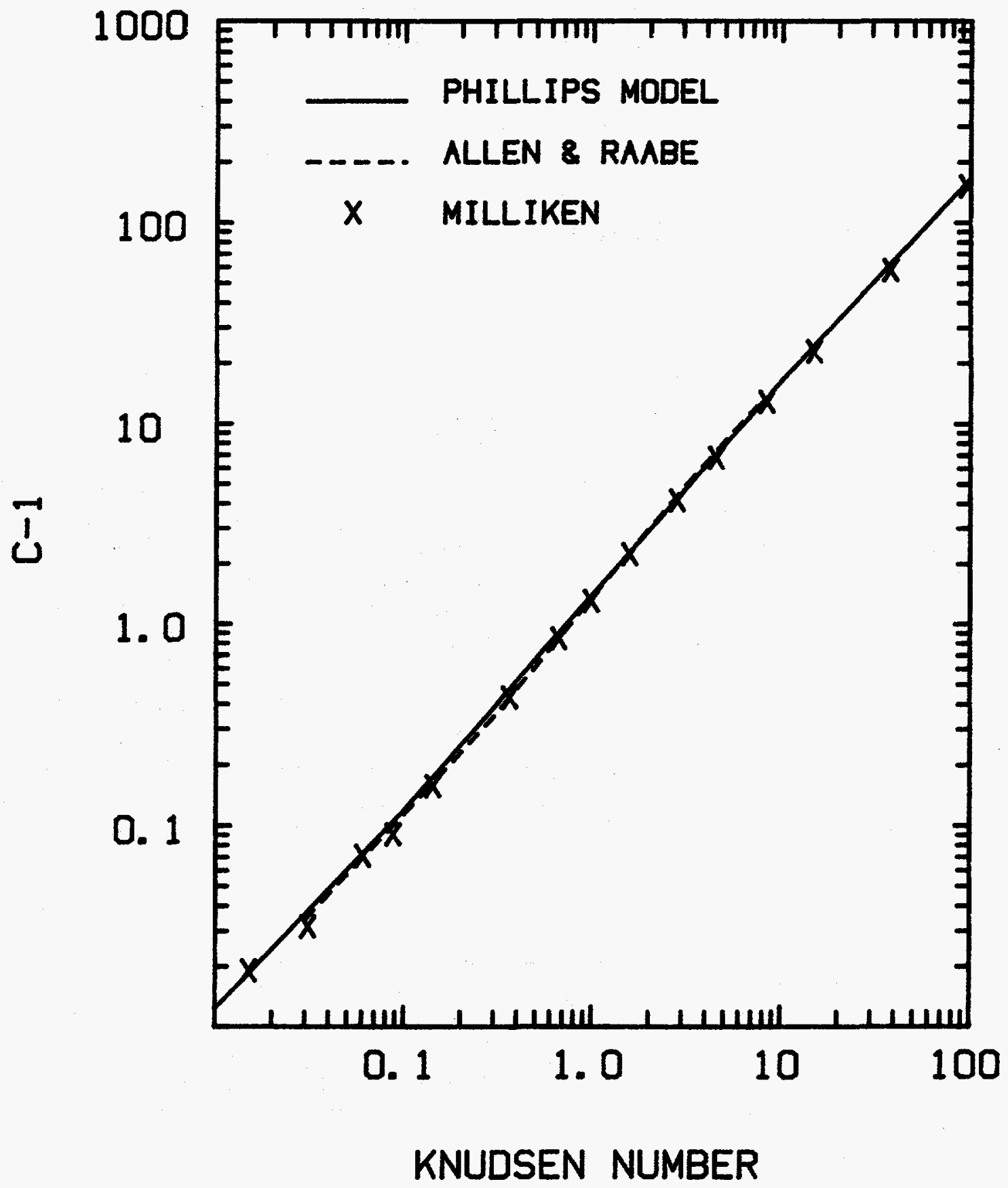

Figure 11. Comparison of the predicted slip correction factor from Phillips' model [92] to values obtained in experiments [87] and to the empirical correlation developed by Allen and Raabe [88] 
aerosols of $\mathrm{CsOH}$ and CsI under accident conditions [96-99]. The LACE experiments demonstrated that hygroscopicity of $\mathrm{CsOH}$ affected its aerosol behavior [26].

The expected effects of hygroscopicity on aerosols of $\mathrm{CsOH}$ and $\mathrm{CsI}$ are not in question. There are, however, two issues that must be confronted before the analytic and experimental results on very hygroscopic aerosol particles can be applied to the analysis of reactor accidents. The first issue is whether very highly water soluble forms of the fission products will actually be present in the containment atmosphere. $\mathrm{CsOH}$ at elevated temperatures is quite a chemically reactive species. There will be abundant opportunities for aerosols of $\mathrm{CsOH}$ to react with other oxides to form less soluble species such as cesium stannate, cesium zirconate, cesium molybdate, cesium uranate, cesium borate, and the like. In the reactor containment, carbon dioxide will almost assuredly convert any $\mathrm{CsOH}$ to cesium carbonate or cesium bicarbonate. Though CsI is often considered the likely chemical form of aerosolized iodine in the reactor containment, another possible chemical form of iodine is AgI which is not at all hygroscopic. There is no way, now, to assure that very hygroscopic species will be present in the aerosol.

The second issue that must be confronted, physical configuration of an aerosol particle, may even be more significant than the chemical speciation issue. In general, there will be no isolated aerosol particles composed of pure $\mathrm{CsOH}$ or CsI (or any other particular species) in a reactor containment atmosphere. Aerosol particles in the containment will be physical agglomerates of a variety of species. Cesium and iodine make up only a small part of the aerosol in the reactor containment-especially after the ex-vessel release. If $\mathrm{CsOH}$ or CsI is a chemical species making up aerosol material in the containment, it will be embedded in a matrix of other, typically nonradioactive, materials that, in general, will not be especially hygroscopic.

As discussed above in connection with shape factors, aerosol particles are visualized here as being porous spheres. Only if by chance the hygroscopic constituents of the aerosol agglomerate are on the surface will the adsorption of water from the atmosphere result in an increase in the physical dimension of the particle. Hygroscopic materials within the agglomerate may adsorb water, but the water will only fill voids in the agglomerate. As discussed above in connection with the discussion of shape factors, this internal condensation of water will affect the density of the particle, but not necessarily its physical dimension.

The effects of condensation and hygroscopicity on aerosol behavior are quite complicated. It is not simply a matter of considering particle growth by adsorption of water. Experimental evidence on the effects of water on materials other than $\mathrm{CsOH}$ and $\mathrm{CsI}$ is decidedly mixed. Adams [20] has shown that a condensing steam atmosphere accelerates the deposition of $\mathrm{U}_{3} \mathrm{O}_{8}$ and $\mathrm{Fe}_{2} \mathrm{O}_{3}$ aerosols. Since neither of these materials is especially hygroscopic, the observation has been rationalized in terms of the effects water has on the dynamic shape factor, $\chi$, of the aerosol. On the other hand, in similar experiments with aerosols formed by passing powdered concrete through a plasma torch, no effect of the condensing steam atmosphere on particle sedimentation was observed. Clearly, a far more detailed understanding of the chemical and physical form of the actual aerosols produced in reactor accidents would be needed to make detailed predictions of the effects of water and hygroscopicity on aerosol behavior.

Here, more general assumptions are made. It is assumed that for at least a transient period of time, water condenses in the concave interstices of aerosol agglomerates. Surface tension of this condensed water is sufficient a force to draw particle agglomerates into the porous spheres discussed above in connection with particle shape factors. 


\section{Thermal Conductivity}

Thermal conductivity of the aerosol particles enters into the expression for the thermophoretic deposition of particles. Aerosol particle thermal conductivity under reactor accident conditions must be one of the most uncertain quantities imaginable. A general particle is considered here to be a porous agglomerate of very small primary particles. The interstices of the agglomerate may contain water. The compositions of the primary particles are not known and may vary from one primary particle to the next. The primary particles need not be single phase materials. They may consist of multiple phases arrayed in layered or random structures. The primary particles are thought here to be so small $(0.02$ to $0.1 \mu \mathrm{m})$ that phonon scattering at the surfaces causes the thermal conductivity of the particles to differ from thermal conductivities of macroscopic samples. Finally, contact resistances between particles may also depress the thermal conductivity.

Thermal conductivities of some materials that might make up the aerosol in a reactor accident are listed in Table 4.

\section{Density of Aerosol Material}

Chemical species that will make up aerosols produced during a reactor accident are not known. Consequently, it is difficult to predict the density of the aerosol material. Aerosols produced during the gap release phase and the in-vessel release phase are assumed in the Source Term Code Package [11] to have a material density of $3.0 \mathrm{~g} / \mathrm{cm}^{3}$. Room temperature densities for some chemical species that could make up the aerosol produced during these stages of a severe accident are:

\begin{tabular}{|c|c|}
\hline Material & Density $\left(\mathrm{g} / \mathrm{cm}^{3}\right)$ \\
\hline CsI & 4.51 \\
\hline AgI & $5.68-6.10$ \\
\hline $\mathrm{CsOH}$ & 3.675 \\
\hline $\mathrm{Cs}_{2} \mathrm{CO}_{3}$ & 3.5 \\
\hline $\mathrm{B}_{2} \mathrm{O}_{3}$ & 2.46 \\
\hline$\stackrel{2}{\mathrm{~T}} \mathrm{e}^{\mathrm{J}}$ & 6.25 \\
\hline $\mathrm{TeO}$ & 5.682 \\
\hline $\mathrm{TeO}_{3}$ & $5.075-6.1$ \\
\hline $\mathrm{UO}_{2}^{\mathrm{J}}$ & 10.96 \\
\hline $\mathrm{U}_{3} \mathrm{O}_{8}$ & 8.30 \\
\hline $\mathrm{UO}_{3}{ }^{\circ}$ & 7.29 \\
\hline $\mathrm{ZrO}_{2}^{3}$ & $5.6-5.89$ \\
\hline $\mathrm{Cd}^{2}$ & 8.64 \\
\hline $\mathrm{CdI}_{2}$ & 5.67 \\
\hline $\mathrm{CdO}$ & $8.15-6.95$ \\
\hline $\mathrm{CdMoO}_{4}$ & 5.35 \\
\hline $\mathrm{CdTe}^{+}$ & 6.20 \\
\hline $\mathrm{CdCO}_{3}$ & 4.258 \\
\hline $\mathrm{Cd}\left(\mathrm{BO}_{3}\right)_{2} \cdot \mathrm{H}_{2} \mathrm{O}$ & 3.76 \\
\hline $\mathrm{Sn}$ & 7.28 to 5.75 \\
\hline $\mathrm{SnO}$ & 6.446 \\
\hline $\mathrm{SnO}_{2}$ & 6.95 \\
\hline SnTé & 6.48 \\
\hline $\mathrm{Fe}_{3} \mathrm{O}_{4}$ & 5.18 \\
\hline
\end{tabular}


Physical

Table 4. Thermal conductivities of materials that might make up aerosol particles in reactor accidents [100]

\begin{tabular}{|c|c|c|}
\hline Material & $\begin{array}{c}\text { Temperature range } \\
\text { of the data } \\
(\mathbf{K})\end{array}$ & $\begin{array}{c}\text { Thermal conductivity } \\
(\mathrm{cal} / \mathrm{cm}-\mathrm{s}-\mathrm{K})\end{array}$ \\
\hline CsI & $316-361$ & 0.023 \\
\hline $\mathrm{NaOH}$ & 592 & 0.0022 \\
\hline $\mathrm{AgSbTe}_{2}$ & 300 & 0.0026 \\
\hline $\mathrm{Ag}_{2} \mathrm{Se}$ & $\begin{array}{l}303-328 \\
532-546\end{array}$ & $\begin{array}{l}0.0040-0.0063 \\
0.0057-0.0069\end{array}$ \\
\hline InAs & $300-500$ & $0.063-0.030$ \\
\hline $\mathrm{In}_{2} \mathrm{Se}_{3}$ & 270 & 0.0025 \\
\hline $\mathrm{In}_{2} \mathrm{Te}_{3}$ & $313-385$ & $0.0028-0.0034$ \\
\hline $\mathrm{NiSb}$ & $298-466$ & $0.173-0.162$ \\
\hline SnTe & $306-440$ & $0.0148-0.0152$ \\
\hline $\mathrm{Cd}$ & $300-500$ & $0.231-0.220$ \\
\hline In & $300-429$ & $0.195-0.174$ \\
\hline $\mathrm{Ag}$ & $300-400$ & $1.02-1.00$ \\
\hline $\mathrm{Te}$ & $\begin{array}{l}300 \\
500\end{array}$ & $\begin{array}{l}0.0095-0.0050 \\
0.0060-0.0036\end{array}$ \\
\hline $\mathrm{Ag}(64 w / 0)+C d$ & $\begin{array}{l}395 \\
483\end{array}$ & $\begin{array}{l}0.294 \\
0.321\end{array}$ \\
\hline $\operatorname{Ag}(95 w / 0)+I n$ & 298 & 0.552 \\
\hline InO & 1200 & 0.0135 \\
\hline $\mathrm{SnO}_{2}$ & $300-400$ & 0.053 to 0.076 \\
\hline $\mathrm{B}_{2} \mathrm{O}_{3}(1)$ & 769 & 0.0026 \\
\hline $\mathrm{UO}_{2}$ & $300-500$ & $3.1 \times 10^{-4}$ to 0.048 \\
\hline $\mathrm{U}_{3} \mathrm{O}_{8}$ & $300-500$ & 0.0013 to $6.7 \times 10^{-4}$ \\
\hline $\mathrm{UO}_{2}+\mathrm{Zr}$ (a) & 498 & 0.029 \\
\hline $\mathrm{UO}_{2}+\mathrm{Zr}(\mathrm{b})$ & 343 & 0.026 \\
\hline $\mathrm{ZrO}_{2}+\mathrm{Zr}(\mathrm{c})$ & 298 & $6.2 \times 10^{-4}$ \\
\hline $\mathrm{ZrO}_{2}+\mathrm{Zr}(\mathrm{d})$ & 298 & $4.7 \times 10^{-4}$ \\
\hline $\mathrm{CeO}_{2}+\mathrm{UO}_{2}$ & $300-500$ & 0.0031 to 0.0091 \\
\hline $\mathrm{UO}_{2}+\mathrm{ZrO}_{2}$ & $300-500$ & 0.00547 \\
\hline
\end{tabular}


Table 4. Thermal conductivities of materials that might make up aerosol particles in reactor accidents (concluded)

\begin{tabular}{|c|c|c|}
\hline Material & $\begin{array}{c}\text { Temperature range } \\
\text { of the data } \\
(\mathrm{K})\end{array}$ & $\begin{array}{c}\text { Thermal conductivity } \\
\text { (cal/cm-s-K) }\end{array}$ \\
\hline $\mathrm{CeO}_{2}$ & 400 & 0.023 to 0.015 \\
\hline $\mathrm{ZrO}_{2}$ & $300-400$ & 0.0024 to 0.0043 \\
\hline $\mathrm{ZrO}_{2}+\mathrm{Y}_{2} \mathrm{O}_{3}$ & 550 & 0.0036 to 0.0029 \\
\hline $\mathrm{BaO}$ & $490-508$ & 0.131 to 0.160 \\
\hline SrO & 493 & 0.12 \\
\hline $\mathrm{SnZrO}_{3}$ & 298 & 0.0054 \\
\hline $\mathrm{CaO}$ & $300-500$ & 0.023 to 0.029 \\
\hline $\mathrm{CaCO}_{3}$ & $300-400$ & 0.005 to 0.010 \\
\hline $\mathrm{CaSnO}_{3}$ & $300-400$ & 0.0069 to 0.0079 \\
\hline $\mathrm{UO}_{2}+$ stainless steel & $395-500$ & 0.016 to 0.022 \\
\hline $\mathrm{Fe}_{3} \mathrm{O}_{4}$ & 300 & 0.0106 to 0.017 \\
\hline fused $\mathrm{SiO}_{2}$ & $300-400$ & 0.0033 to 0.0036 \\
\hline $\mathrm{SiO}_{2}+\mathrm{B}_{2} \mathrm{O}_{3}$ & $300-400$ & 0.0031 to 0.0036 \\
\hline $\mathrm{BaO}+\mathrm{SiO}_{2}$ & $300-400$ & 0.002 \\
\hline $\mathrm{Mg}_{2} \mathrm{SiO}_{4}$ & $300-400$ & 0.0005 to 0.018 \\
\hline $\mathrm{Al}_{2} \mathrm{O}_{3}+\mathrm{SiO}_{2}$ & $300-400$ & 0.0022 to 0.038 \\
\hline $\mathrm{ZrSiO}_{4}$ & $300-400$ & 0.0067 to 0.018 \\
\hline \multicolumn{3}{|c|}{$\begin{array}{l}\text { (a) } 43 \mathrm{w} / 0 \mathrm{UO}_{2}+57 \mathrm{w} / \mathrm{o} \mathrm{Zr} \\
\text { (b) } 80 \mathrm{w} / 0 \mathrm{UO}_{2}+20 \mathrm{w} / \mathrm{o} \mathrm{Zr} \\
\text { (c) } 54.5 \mathrm{w} / \mathrm{o} \mathrm{ZrO}_{2}+45.5 \mathrm{w} / \mathrm{or} \\
\text { (d) } 90 \mathrm{w} / 0 \mathrm{ZrO}_{2}+10 \mathrm{w} / \mathrm{o} \mathrm{Zr}\end{array}$} \\
\hline
\end{tabular}


Physical

There is, obviously, a substantial opportunity for the aerosols produced during the gap release phase and the in-vessel release phase of an accident to have material densities substantially different than $3.0 \mathrm{~g} / \mathrm{cm}^{3}$.

Much more attention has been paid to the densities of materials aerosolized during the ex-vessel phase of an accident. The aerosols are typically [101-107] predicted to have densities of about $4.5 \mathrm{~g} / \mathrm{cm}^{3}$ with a range of 6.15 to $3.5 \mathrm{~g} / \mathrm{cm}^{3}$ during the first 2 hours of vigorous interaction between core debris and concrete. After this intense interaction period, the material density of aerosols produced during the longterm interaction of core debris with concrete is calculated to vary between about 3.9 and $2.1 \mathrm{~g} / \mathrm{cm}^{3}$ [101-107].

\section{Accommodation Coefficients}

Accommodation coefficients arise frequently in the discussion of gas interactions with aerosol particles. There are four so-called Knudsen accommodation coefficients:

- accommodation of normal momentum

- accommodation of tangential momentum

- accommodation of energy, and

- the radiometric accommodation coefficient.

Here, interests are confined to the accommodation of normal momentum and the accommodation of energy. Because the energy of an ideal monatomic gas is a function of temperature and because the concept of accommodation arose in the study of heat transfer at low pressures, the energy accommodation coefficient is often called the temperature accommodation coefficient or the thermal accommodation coefficient. Accommodation is most intuitively defined in terms of temperature. Consider a gas of temperature $\mathrm{T}(\mathrm{g})$ and a surface of temperature $\mathrm{T}(\mathrm{s})$. Gas species that collide with the surface reflect back into the gas phase with properties indicative of a temperature $T(r)$. Then, the temperature accommodation coefficient, $\alpha_{t}$, is defined by:

$$
\alpha_{t}=\lim _{T(g) \rightarrow T(s)} \frac{T(r)-T(g)}{T(s)-T(g)}
$$

The definition is more rigorously correct and more readily applied to polyatomic gas species if energy rather than temperature is used in the equation. Similar definitions can be constructed for the other accommodation coefficients. From these definitions, it appears that accommodation coefficients can assume values between 0 and 1 . Closer examination of the gas-solid interaction process shows the conceivable range for the accommodation coefficients is not so narrowly restricted. But, in reality, measurements of these coefficients are nearly always in this range.

Measurements of accommodation coefficients for aerosol particles of interest here are, of course, nonexistent. Momentum accommodation coefficients have been derived from the data used to define slip 
correction factors. Rader [108] seems to consider the momentum accommodation coefficient to be just a function of the gas composition and provides:

$\begin{array}{cc}\text { Gas } & \underset{\alpha}{m}- \\ \text { air } & 0.8972 \\ \mathrm{Ar} & 0.8891 \\ \mathrm{He} & 0.8694 \\ \mathrm{H}_{2} & 0.9251 \\ \mathrm{CH}_{4} & 0.9195 \\ \mathrm{C}_{2} \mathrm{H}_{6} & 0.8784 \\ \mathrm{~N}_{2} \mathrm{O} & 0.8972 \\ \mathrm{CO}_{2} & 0.8968\end{array}$

There are few surface materials for which the momentum accommodation has been measured. Nearly all the data examined by Rader were for oil droplets. Indeed, the only systematics in the results he cites is a rough correlation of momentum accommodation with the molecular weight of the gas and the solubility of the gas in oil. One would also expect that surface roughness on a molecular level would lead to higher accommodation coefficients. Such roughness would seem to make it more likely that a colliding gas species would be trapped or adsorbed on the surface at least temporarily and there would be an opportunity for the gas species to equilibrate with the surface. Oil droplets, of course, do not have rough surfaces so data to confirm this suspicion about accommodation are not available.

Data available for review by Rader were obtained at temperatures not too different than room temperature. If the view that transient adsorption of gases on surfaces leads to high values of the momentum accommodation coefficient is true, then, the momentum accommodation coefficient should be somewhat temperature-dependent. As temperature increases, the mean speed of molecules striking a surface increases. A larger fraction of the molecules will have collisions that are too energetic to lead to adsorption so the accommodation coefficient should decrease.

A great deal more is known about the temperature accommodation coefficient. Saxena and Joshi [109] have reviewed the available data. Data on the temperature accommodation coefficient of various gases on glass are shown in Figure 12. The most noticeable feature of these data is that temperature accommodation coefficients are typically smaller than the momentum accommodation coefficients discussed above. The temperature accommodation coefficients do decrease with temperature at least for surfaces that are somewhat inert chemically. Temperature accommodation coefficients decrease with the molecular weight of the gas. One would expect, then, that the accommodation coefficient of water vapor would fall between that of nitrogen and hydrogen.

There have been several theoretical studies of the temperature accommodation coefficient $[110,111,112]$. An often-cited, simple expression for the temperature accommodation coefficient is:

$$
\alpha_{t}=2 \eta /(1+\eta)^{2}
$$

where $\eta$ is the ratio of the molecular weights of the gas and the surface material. As noted by Goodman and Wachman [112], neither this simple formula nor other simple formulae yield general agreement with 
TEMPERATURE ACCOMMODATION COEFFICIENT

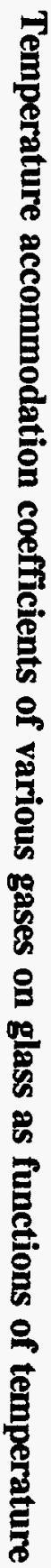

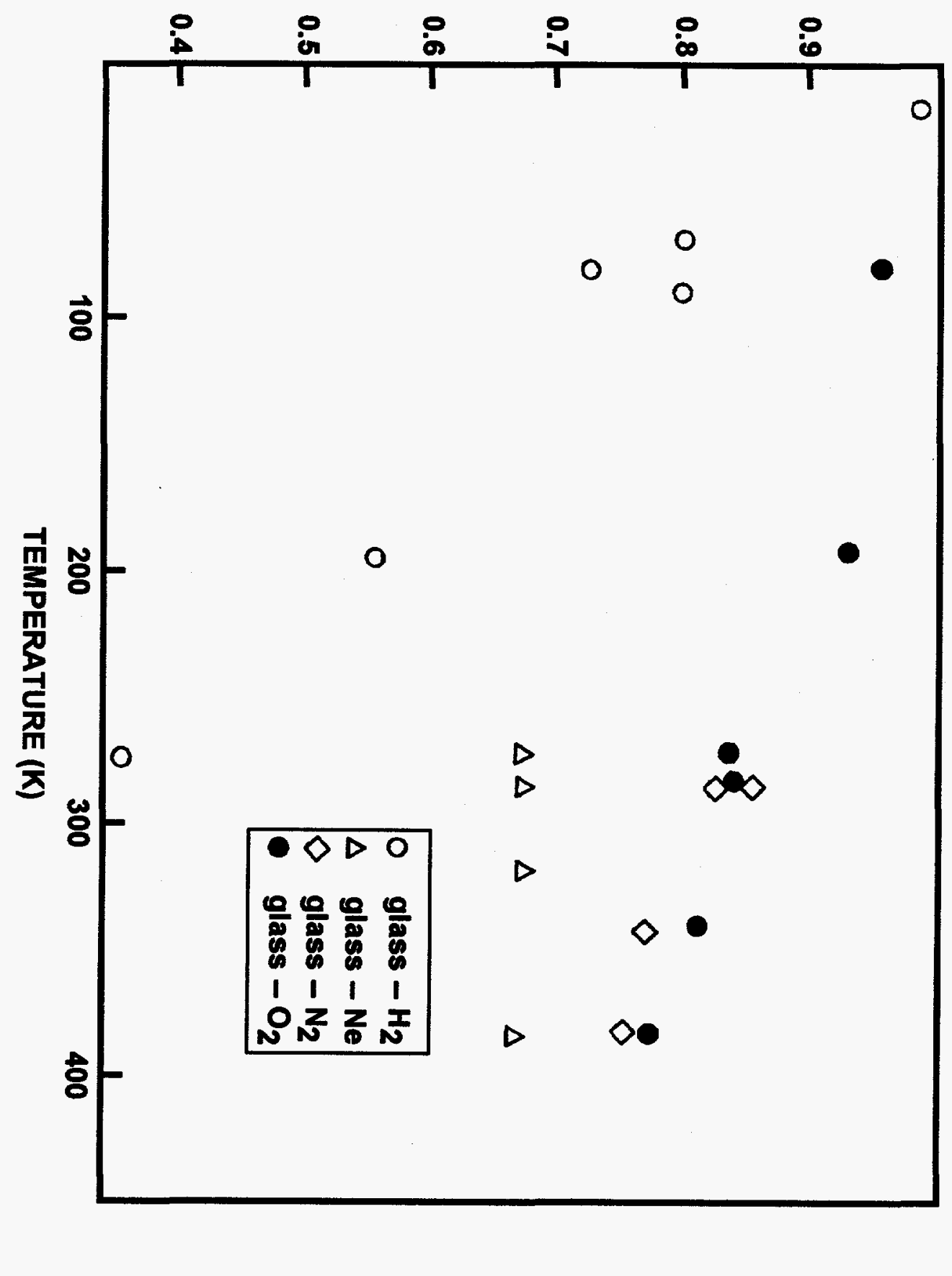


available data. More complicated theoretical expressions for the temperature accommodation coefficient require information on the surface properties and the surface-gas interaction that are unlikely to ever be available for aerosols produced during severe reactor accidents. It would seem, then, necessary to consider temperature accommodation coefficients to be uncertain. Furthermore, it seems necessary to consider in reactor accident analyses accommodation coefficients that are less than one.

\section{H. Thermophysical Properties of the Gas Phase}

The containment atmosphere is treated here as an ideal gaseous mixture. Some properties of the gas phase needed in the various calculations are described below.

\section{The Diffusion Coefficient of Steam}

The diffusion coefficient of water vapor in air has been measured many times. Some of the results of these measurements [60] are shown in Figure 13. The data can be correlated by $D(T)=$ $0.3106(\mathrm{~T} / 373)^{1.82} \mathrm{~cm}^{2} / \mathrm{s}$. Diffusion coefficients of water vapor in more complex gas mixtures that can arise during reactor accidents have to be estimated.

Water molecules are quite polar. Consequently, it is not likely that the diffusion coefficient of steam in a containment atmosphere will be accurately predicted by theoretical models based on the assumption that gas-phase species are hard spheres. Indeed, Reid et al. [113] have judged the predictive capabilities of such models to be erratic. They recommend more empirical expressions for the prediction of binary gaseous diffusion coefficients such as the model developed by Fuller et al. [114,115]:

$$
\mathrm{D}_{\mathrm{AB}}=\frac{0.00143 \mathrm{~T}^{1.75}}{\mathrm{P}_{\mathrm{T}} \mathrm{M}_{\mathrm{AB}}^{1 / 2}\left[\mathrm{~V}_{\mathrm{D}}(\mathrm{A})^{1 / 3}+\mathrm{V}_{\mathrm{D}}(\mathrm{B})^{1 / 3}\right]^{2}}
$$

where

$$
\mathrm{M}_{\mathrm{AB}}=2 /\left[\frac{1}{\mathrm{M}(\mathrm{A})}+\frac{1}{\mathrm{M}(\mathrm{B})}\right]
$$

$M(A), M(B)=$ molecular weights of gaseous species $A$ and $B$, and

$V_{D}(A), V_{D}(B)=$ diffusion volumes of gaseous species $A$ and $B$ (see Table 5).

Other studies [116] have recommended the Wilke-Lee model [117]:

$$
\bigoplus_{\mathrm{AB}}=\frac{0.001\left[3.03-\left(0.98 / \mathrm{M}_{\mathrm{AB}}^{1 / 2}\right)\right] \mathrm{T}^{3 / 2}}{\mathrm{P} \mathrm{M}_{\mathrm{AB}}^{1 / 2} \sigma_{\mathrm{AB}}^{2} \Omega}
$$


Physical

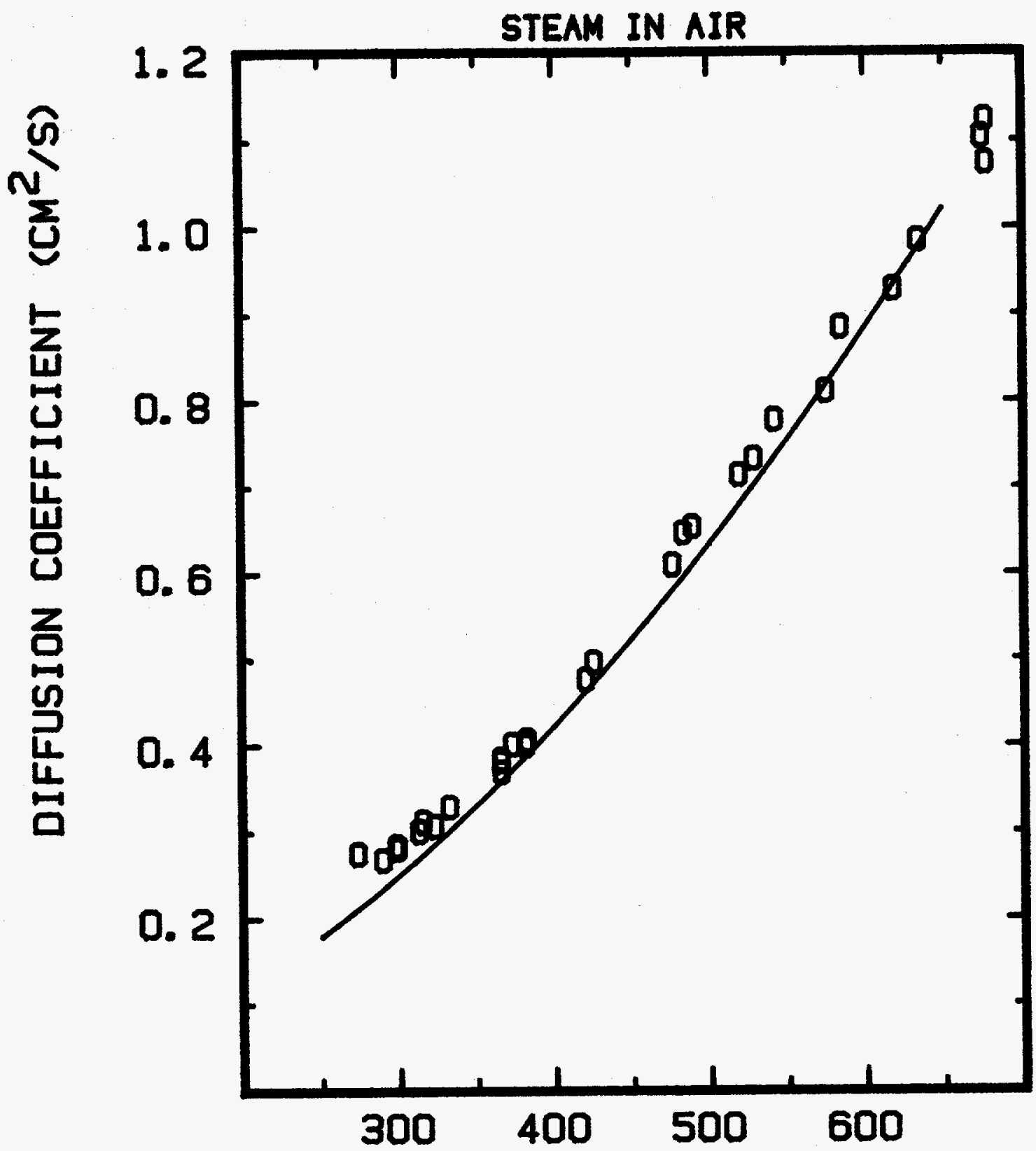

TEMPERATURE (K)

Figure 13. Comparison of data for the diffusion coefficient of water vapor in air to a correlation [60] 
Table 5. Parameter values for calculating binary diffusion coefficients of gases

\begin{tabular}{|c|c|c|c|c|c|}
\hline $\begin{array}{c}\text { Gas } \\
\text { species }\end{array}$ & $\begin{array}{c}\text { MW(i) } \\
\text { (g/mole) }\end{array}$ & $\begin{array}{c}\mathbf{V}_{\mathbf{p}^{(\mathbf{i})}} \\
\left(\mathrm{cm}^{3} / \text { mole }\right)\end{array}$ & $\begin{array}{l}\sigma(\mathbf{i}) \\
\left(\mathbf{A}^{\circ}\right) \\
\end{array}$ & $\begin{array}{c}\mathbf{\epsilon}(\mathbf{i}) / \mathbf{k} \\
(\mathbf{K})\end{array}$ & $\underset{\left(\mathrm{cm}^{3} / \mathrm{mole}\right)}{\mathbf{V}_{\mathbf{f}}}$ \\
\hline $\mathbf{H}_{2}$ & 2.01594 & 6.12 & 2.827 & 59.7 & 28.5 \\
\hline $\mathrm{H}_{2} \mathrm{O}$ & 18.01534 & 13.1 & 2.641 & 809.1 & 18.7 \\
\hline $\mathbf{N}_{2}$ & 28.0134 & 18.5 & 3.798 & 71.4 & 34.7 \\
\hline $\mathrm{O}_{2}$ & 31.9988 & 16.3 & 3.467 & 106.7 & 27.9 \\
\hline $\mathrm{CO}$ & 28.01050 & 18.0 & 3.690 & 91.7 & \\
\hline $\mathrm{CO}_{2}$ & 44.0099 & 26.9 & 3.941 & 195.2 & 37.3 \\
\hline
\end{tabular}

where

$$
\sigma_{\mathrm{AB}}=[\sigma(\mathrm{A})+\sigma(\mathrm{B})] / 2,
$$

$\sigma(\mathrm{A}), \sigma(\mathrm{B})=$ collision cross sections for gaseous species A and B (see Table 5),

$$
\begin{aligned}
\mathbf{Q} & =\frac{\mathrm{A}}{\left(\mathrm{T}^{*}\right)^{\mathrm{B}}}+\frac{\mathrm{C}}{\exp \left(\mathrm{DT}^{*}\right)}+\frac{\mathrm{E}}{\exp \left(\mathrm{FT}^{*}\right)}+\frac{\mathrm{G}}{\exp \left(\mathrm{HT}^{*}\right)}, \\
\mathrm{A} & =1.06036, \\
\mathrm{~B} & =0.15610, \\
\mathrm{C} & =0.193, \\
\mathrm{D} & =0.47635, \\
\mathrm{E} & =1.03587, \\
\mathrm{~F} & =1.52996, \\
\mathrm{G} & =1.76474, \\
\mathrm{H} & =3.89411, \\
\mathrm{~T}^{*} & =\mathrm{kT} / \epsilon_{\mathrm{AB}}, \\
\epsilon_{\mathrm{AB}} / \mathrm{k} & =\left[\epsilon(\mathrm{A}) \epsilon(\mathrm{B}) / \mathrm{k}^{2}\right]^{1 / 2}, \text { and } \\
\epsilon(\mathrm{A}), \epsilon(\mathrm{B}) & =\text { energy parameters for gaseous species } \mathrm{A} \text { and } \mathrm{B} .
\end{aligned}
$$


Physical

Predictions of the diffusion coefficients of steam in $\mathrm{H}_{2}, \mathrm{~N}_{2}$, and $\mathrm{CO}_{2}$ are shown in Figure 14. Data [60] for the $\mathrm{H}_{2} / \mathrm{H}_{2} \mathrm{O}$ system are shown in this figure. The correlations from Fuller et al. [114] and Wilke-Lee [117] bracket these data.

The pseudo-binary diffusion coefficient of water vapor in gaseous mixtures is calculated from binary diffusion coefficients using:

$$
\frac{1-\frac{P\left(\mathrm{H}_{2} \mathrm{O}\right)}{\mathrm{P}_{T}}}{Ð(\operatorname{mix})}=\sum_{\mathrm{i} \neq \mathrm{H}_{2} \mathrm{O}}^{n} \frac{P(\mathrm{i}) / \mathrm{P}_{T}}{\mathrm{D}\left(\mathrm{i}, \mathrm{H}_{2} \mathrm{O}\right)}
$$

where

$$
\begin{aligned}
Ð(\text { mix }) & =\text { pseudo-binary diffusion coefficient of steam in a gaseous mixture, } \\
\mathbf{P}\left(\mathrm{H}_{2} \mathrm{O}\right) & =\text { partial pressure of water vapor, } \\
\mathbf{P}_{\mathrm{T}} & =\text { total pressure, } \\
\mathbf{P}(\mathbf{i}) & =\text { partial pressure of the } \mathrm{i} \frac{\text { th }}{\text { constituent of the gas mixture, and }} \\
Ð\left(\mathrm{i}, \mathrm{H}_{2} \mathrm{O}\right) & =\text { binary diffusion coefficient of water vapor with the } \mathrm{ith} \text { constituent of the gas. }
\end{aligned}
$$

\section{Thermal Conductivity}

The thermal conductivity of gaseous mixtures in the containment atmosphere can be estimated from the thermal conductivities of constituents of the mixture using a formula recommended by Mason and Saxena [118]:

$$
k_{t h}(\operatorname{mix})=\sum_{i=1}^{n}\left\{k_{t h}(i) /\left[1+\sum_{j \neq i}^{n} \phi(i, j) x(i) x(j)\right]\right\}
$$

where

$$
\begin{aligned}
\mathrm{k}_{\mathrm{th}}(\mathrm{mix}) & =\text { thermal conductivity of the mixture, } \\
\mathrm{k}_{\mathrm{th}}(\mathrm{i}) & =\text { thermal conductivity of the pure } \mathrm{i} \text { th } \text { constituent of the mixture, }
\end{aligned}
$$




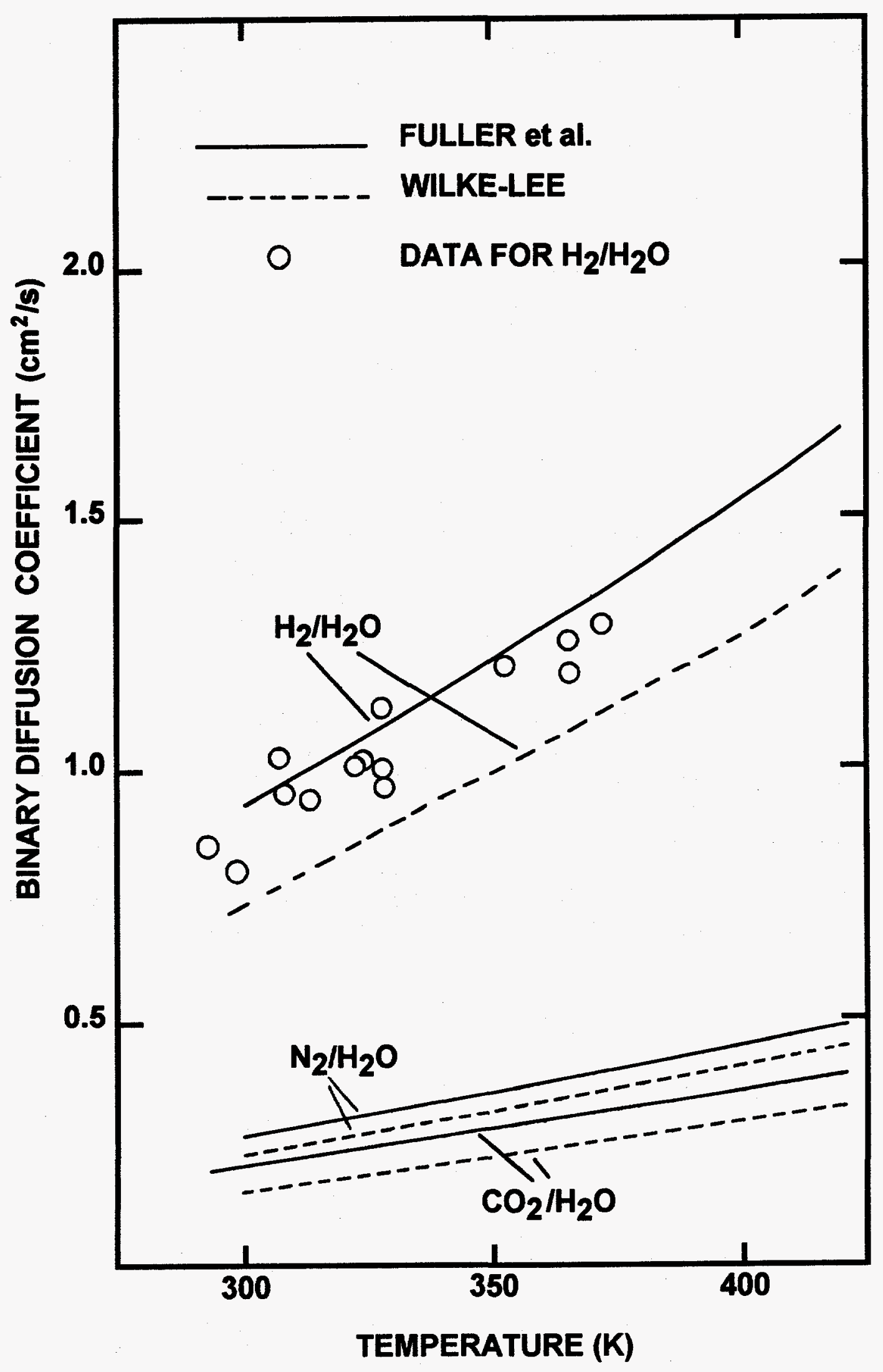

Physical 
Physical

$$
\begin{aligned}
n & =\text { number of mixture constituents, and } \\
\phi(i, j) & =\frac{\frac{C}{2 \sqrt{2}}\left\{1+\left(\frac{k_{t h}(i) M W(i)}{k_{t h}(j) M W(j)}\right)^{1 / 2}\right\}^{2}}{\left(1+\frac{M W(i)}{M W(j)}\right)^{1 / 2}}
\end{aligned}
$$

Mason and Saxena [118] recommend that $C=1.065$. Tondon and Saxena recommend that $\mathbf{C}=0.85$ for mixtures of polar and nonpolar gases such as steam in air.

The thermal conductivities of the constituents of the gas are calculated from [5]:

$$
\lambda(i)=\frac{10^{-5}}{4.184}\left[L_{0}+L_{1} T+L_{2} T^{2} / 1000+L_{3} T^{3} / 10^{6}\right] \frac{c a l}{c m-s-K}
$$

where $L_{i}$ for $i=0$ to 3 are parameters peculiar to each gas and are listed in Table 6 .

\section{Viscosity of the Gas}

Viscosities of gaseous mixtures in the containment atmosphere can be calculated from the HerringZipperer formula [119]:

$$
\mu_{g}(\operatorname{mix})=\frac{\sum_{i=1}^{n} \mu_{g}(i) x(i) M W(i)^{1 / 2}}{\sum_{i=1}^{n} x(i) M W(i)^{1 / 2}}
$$

where

$$
\begin{aligned}
\mu_{g}(\operatorname{mix}) & =\text { viscosity of the mixture, } \\
\mu_{\mathrm{g}}(\mathrm{i}) & =\text { viscosity of the pure } \mathrm{i} \frac{\text { th }}{\mathrm{n}} \text { constituent of the mixture, } \\
\mathbf{n} & =\text { number of constituents in the mixture } \\
\mathbf{x}(\mathrm{i}) & =\text { mole fraction of the } \mathrm{i} \frac{\text { th }}{\text { constituent, and }} \\
\mathbf{M W}(\mathrm{i}) & =\text { molecular weight of the } \mathrm{i} \text { th } \text { constituent. }
\end{aligned}
$$


Table 6. Parametric values for correlation of gas thermal conductivities

\begin{tabular}{llccc}
\hline Gas & $\mathbf{L}_{0}$ & $10^{3} \mathbf{L}_{1}$ & $10^{6} \mathbf{L}_{2}$ & $10^{9} \mathbf{L}_{3}$ \\
\hline $\mathrm{H}_{2}$ & 0.0187 & 588.6 & -226.342 & \\
$\mathrm{~N}_{2}$ & 2.78051 & 78.9354 & -12.2826 & 1.53154 \\
$\mathrm{O}_{2}$ & 0.162631 & 93.8793 & -18.7651 & 2.74256 \\
$\mathrm{CO}$ & 1.60784 & 80.4387 & -12.2788 & 1.43727 \\
$\mathrm{CO}_{2}$ & -11.0318 & 97.4037 & -17.2777 & 1.77997 \\
\hline
\end{tabular}

The viscosity of pure steam is calculated from [120]:

$$
\mu_{\mathrm{g}}\left(\mathrm{H}_{2} \mathrm{O}\right)=\frac{0.55 \times 10^{-4} \sqrt{\mathrm{T}^{*}}(\mathrm{~g} / \mathrm{cm}-\mathrm{s})}{1+\frac{0.978197}{\mathrm{~T}^{*}}+\frac{0.579829}{\mathrm{~T}^{* 2}}-\frac{0.202354}{\mathrm{~T}^{* 3}}}
$$

where $\mathrm{T}^{*}=\mathrm{T}(\mathrm{K}) / 647.27$.

The viscosities of $\mathrm{N}_{2}, \mathrm{CO}, \mathrm{CO}_{2}$ and $\mathrm{O}_{2}$ are calculated from [156]:

$$
\mu_{g}(i)=\frac{5}{16}\left[\frac{M W(i) R T}{\pi}\right]^{1 / 2} \frac{f(\eta)}{N_{A} \sigma_{(i)}^{2} \Omega(2,2)}
$$

where

$$
\begin{aligned}
\text { MW(i) } & =\text { molecular weight of the gas } \mathrm{i} \text { where } \mathrm{i}=\mathrm{N}_{2}, \mathrm{CO}, \mathrm{CO}_{2} \text { or } \mathrm{O}_{2} \\
\mathrm{R} & =\text { gas constant }=8.31451 \times 10^{7} \mathrm{erg} / \mathrm{mole}-\mathrm{K} \\
\mathrm{N}_{\mathrm{A}} & =\text { Avogadro's number }=6.0221367 \times 10^{23} \\
\sigma(\mathrm{i}) & =\text { collision cross section, } \\
\mathrm{f}(\eta) & =1+\frac{3}{196}\left(8 \mathrm{E}^{*}-7\right)^{2}
\end{aligned}
$$


Physical

$$
\begin{aligned}
\mathrm{E}^{*} & =1+0.25 \mathrm{~T}^{*} \mathrm{~d} \ln \Omega(2,2) / \mathrm{dT}^{*}, \text { and } \\
\Omega(2,2) & =\text { collision integral. }
\end{aligned}
$$

The collision integral is calculated from:

$$
\begin{aligned}
& \Omega(2,2)=\exp \left[0.46641-0.56991 \mathrm{z}+0.19591 \mathrm{z}^{2}-0.03879 \mathrm{z}^{3}+0.00259 \mathrm{z}^{4}\right] \text { for } 1 \leq \mathrm{T}^{*} \leq 10 \\
& \Omega(2,2)=\left(\rho^{*}\right)^{2} \alpha^{2}\left[1.04+\mathrm{a}_{1} / \mathrm{z}+\mathrm{a}_{2} / \mathrm{z}^{2}+\mathrm{a}_{3} / \mathrm{z}^{3}+\mathrm{a}_{4} / \mathrm{z}^{4}\right] \quad \text { for } \mathrm{T}^{*} \geq 10
\end{aligned}
$$

where

$$
\begin{aligned}
\mathrm{z} & =\ln \mathrm{T}^{*} \\
\mathrm{~T}^{*} & =\mathrm{kT} / \epsilon(\mathrm{i}) \\
\mathrm{k} & =\text { Boltzmann's constant }=1.380658 \times 10^{-16} \mathrm{ergs} / \mathrm{K} \\
\epsilon(\mathrm{i}) & =\text { energy scaling parameter, } \\
\alpha & =\ln \left(\mathrm{V}_{\mathrm{o}}^{*}\right)-\ln \left(\mathrm{T}^{*}\right) \\
\alpha_{10} & =\ln \left(\mathrm{V}_{\mathrm{o}}^{*} / 10\right) \\
\mathrm{V}_{\mathrm{o}}^{*} & =\mathrm{V}_{\mathrm{o}} / \epsilon(\mathrm{i}) \\
\mathrm{a}_{1} & =0, \\
\mathrm{a}_{2} & =-33.0383+\left(\alpha_{10} \rho^{*}\right)^{-2}\left[20.0862+72.1059 / \alpha_{10}+\left(8.27648 / \alpha_{10}\right)^{2}\right] \\
\mathrm{a}_{3} & =101.571-\left(\alpha_{10} \rho^{*}\right)^{-2}\left[56.4472+286.393 / \alpha_{10}+\left(17.7610 / \alpha_{10}\right)^{2}\right] \\
\mathrm{a}_{4} & =-87.7036+\left(\alpha_{10} \rho^{*}\right)^{-2}\left[46.3130+277.146 / \alpha_{10}+\left(19.0573 / \alpha_{10}\right)^{2}\right], \text { and } \\
\rho^{*} & =\rho / \sigma(\mathrm{i})
\end{aligned}
$$

The various parametric quantities needed for these calculations are listed in Table 7.

The viscosity of hydrogen is calculated from [5]:

$$
\mu_{\mathrm{g}}\left(\mathrm{H}_{2}\right)=10^{-6}\left\{20.9161+248.797 \xi-83.6226 \xi^{2}+19.551 \xi^{3}\right\}(\mathrm{g} / \mathrm{cm}-\mathrm{s})
$$

where $\xi=\mathrm{T}(\mathrm{K}) / 1000$. 
Table 7. Parameters for the calculation of gas viscosity

\begin{tabular}{lcccc}
\hline & \multicolumn{5}{c}{ Value for } \\
\cline { 2 - 5 } Parameter & $\mathrm{N}_{2}$ & $\mathrm{O}_{2}$ & $\mathrm{CO}$ & $\mathrm{CO}_{2}$ \\
\hline $\begin{array}{l}\mathrm{MW}(\mathrm{i}) \\
(\mathrm{g} / \mathrm{mole})\end{array}$ & 28.0135 & 31.9988 & 28.010 & 44.010 \\
$\begin{array}{l}\sigma(\mathrm{i}) \\
(\mathrm{cm})\end{array}$ & $3.652 \times 10^{-8}$ & $3.407 \times 10^{-8}$ & $3.652 \times 10^{-8}$ & $3.769 \times 10^{-8}$ \\
$\in(\mathrm{i}) / \mathrm{k}$ & 98.4 & 121.1 & & \\
$(\mathrm{~K})$ & & & 98.4 & 245.3 \\
$\rho^{*}$ & 0.1080 & 0.0745 & 0.1080 & 0.0720 \\
$\mathrm{~V}_{\mathrm{o}}^{*}$ & 53080 & $1.322 \times 10^{6}$ & 53080 & $2.800 \times 10^{6}$ \\
$\mathrm{C}_{6}{ }^{*}$ & 2.18 & 2.27 & 2.63 & 1.86 \\
\hline
\end{tabular}

\section{Effects of Radioactivity on Aerosol Behavior}

Tests of aerosol behavior in reactor containments under accident conditions such as the LACE, MARVIKEN, DEMONA, and ABCOVE tests have used nonradioactive particles. Intense radiation fields have not been present during these tests. Similarly, models of aerosol behavior in reactor containments have not considered any phenomenon unique to radioactive particles or phenomena that could arise because of the intense radiation fields that would be expected in a reactor containment under accident conditions.

There are, however, phenomena that arise in radioactive environments that might affect aerosol behavior. Perhaps, the phenomenon most likely to affect aerosol behavior is the electrostatic charging of aerosol particles. Electrostatic charges on aerosol particles could affect both the agglomeration and the deposition of particles. Terms to account for these effects have not been incorporated into reactor accident models. In the subsections below, analyses are presented to determine if radioactive particles will be charged and what effect charging might have on aerosol behavior.

\section{Charging of Radioactive Aerosol Particles}

Decay of radionuclides in an aerosol particle can leave the aerosol particle with a residual charge. Certainly, beta decay would be expected to leave an aerosol particle with a positive residual charge of one elementary charge $(+1$ e) if the beta particle escapes the aerosol particle. Secondary electrons produced as the beta particle passes through aerosol material might lead to a somewhat higher, positive, residual charge. Clement and Harrison [121] conclude that charging of aerosol particles by beta decay is satisfactorily described by assuming that each decay event produces a residual charge of $+1 \mathrm{e}$. Experimental studies by Ivanov et al. [122] suggest beta decay yields a residual charge on aerosol particles of +1 to $2 \mathrm{e}$. 
Physical

Decay events that produce gamma particles do not typically produce significant charging of aerosol particles. The penetrating power of gamma rays is so great that aerosol charging is not significant. Typical estimates of the residual charge produced by gamma decay are less than 1/40 e.

Emission of an alpha particle might be expected to leave a residual charge of $-2 \mathrm{e}$. But, secondary (or delta) electrons produced as an alpha particle travels through the aerosol material will usually more than compensate for the charge left by alpha decay. Emets et al. [123] suggest that the residual charge on an aerosol particle left by an alpha decay event can be eight to as many as 40 elementary charges.

Radioactive decay will also produce ion pairs in the atmosphere. Ionization of air typically requires an energy of about $35 \pm 1 \mathrm{eV}$ (Note: $1 \mathrm{eV}=1.6022 \times 10^{-12}$ ergs). Bricard and Pradel [124] suggest that an alpha particle produced by radioactive decay can generate $2 \times 10^{5}$ ion pairs in air. Beta and gamma disintegrations will yield about $2 \times 10^{4}$ ion pairs.

The dynamic situation created by radioactive decay, then, involves charge formation on the aerosol particles and ionization of the atmosphere. The flux of ions toward the charged particle will tend to neutralize residual charges on the particles. Ion recombination in the atmosphere will attenuate this flux.

The dynamic equations for charging of aerosol particles are easily formulated for aerosol particles of a single particle size, $d_{p}$, and for decay processes that yield a single, positive elementary charge on the particle $[121,123,125]$. Let $n(t)$ and $n(-)$ designate the number concentrations of positive and negative ions in the atmosphere, respectively. Let $\mathrm{N}(\mathrm{k})$ designate the number concentration of aerosol particles having a charge of $\mathrm{k}$ elementary charge units (ke). Then, following developments by Clement and Harrison [121]:

$$
\begin{aligned}
& \frac{\mathrm{dN}(\mathrm{k})}{\mathrm{dt}}=\boldsymbol{\beta}^{+}(\mathrm{k}-1) \mathrm{n}(+) \mathrm{N}(\mathrm{k}-1)+\boldsymbol{\beta}^{-}(\mathrm{k}+1) \mathrm{n}(-) \mathrm{N}(\mathrm{k}+1) \\
& +v N(k-1)-\left(\beta^{+}(k) n(+)+\beta^{-}(k) n(-)+v\right) N(k) \\
& \frac{\mathrm{dn}(+)}{\mathrm{dt}}=-\mathrm{n}(+) \sum_{\mathrm{k}=-\infty}^{+\infty} \beta^{+}(\mathrm{k}) \mathrm{N}(\mathrm{k})+\mathrm{q}+\mathrm{ZvI}-\alpha \mathrm{n}(+) \mathrm{n}(-) \\
& \frac{\mathrm{dn}(-)}{\mathrm{dt}}=-n(-) \sum_{k=-\infty}^{+\infty} \beta^{-}(\mathrm{k}) \mathrm{N}(\mathrm{k})+\mathrm{q}+\mathrm{Zv}(\mathrm{I}+1)-\alpha n(+) n(-)
\end{aligned}
$$


where

$$
\begin{aligned}
\boldsymbol{\beta}^{+}(\mathbf{k}) & =\text { positive ion-particle attachment coefficient for a particle with charge ke, } \\
\boldsymbol{\beta}^{-}(\mathbf{k}) & =\text { negative ion-particle attachment coefficient for a particle with charge ke, } \\
\mathbf{Z} & =\text { number density of aerosol particles }=\sum_{-\infty}^{+\infty} \mathrm{N}(\mathbf{k}) \\
\mathbf{v} & =\text { disintegration events per particle per unit time, } \\
\mathbf{I} & =\text { atmospheric ion pairs formed by each disintegration event in a particle, } \\
\boldsymbol{\alpha} & =\text { ion-ion recombination rate coefficient, and } \\
\mathbf{q} & =\text { ion pair formation rate as a result of radioactive decay not involving aerosol particles. }
\end{aligned}
$$

Note that recombination of ions on structural surfaces has been neglected here in the belief that such processes do not greatly affect charge dynamics in the bulk atmosphere.

This set of differential equations conserves charge since:

$$
\begin{aligned}
& \frac{\mathrm{d}}{\mathrm{dt}} \sum_{\mathrm{k}=-\infty}^{+\infty} \mathrm{kN}(\mathrm{k})=\sum \mathrm{k} \frac{\mathrm{dN}(\mathrm{k})}{\mathrm{dt}}=\sum_{\mathrm{k}=-\infty}^{+\infty} \mathrm{k} \boldsymbol{\beta}^{+}(\mathrm{k}-1) \mathrm{n}(+) \mathrm{N}(\mathrm{k}-1) \\
& -\sum_{k=-\infty}^{+\infty} k \beta^{+}(k) n(+) N(k)+\sum_{k=-\infty}^{+\infty} k \beta^{-}(k+1) n(-) N(k+1) \\
& -\sum_{k=-\infty}^{+\infty} k \beta^{-}(k) N(k)+v\left\{\sum_{k=-\infty}^{+\infty} k N(k-1)-\sum_{k=-\infty}^{+\infty} k N(k)\right\} \\
& =\sum_{k=-\infty}^{+\infty} \beta^{+}(k) n(+) N(k)-\sum_{k=-\infty}^{+\infty} \beta^{-}(k) N(k)+v Z
\end{aligned}
$$

and

$$
\frac{d}{d t}\left(\sum_{k=-\infty}^{+\infty} k N(k)+n(+)-n(-)\right)=0
$$

At steady state, the time derivatives disappear. The charge distribution equations can be solved by noting that the transfer of charge from particles of charge ke to particles of charge $(k+1) e$ must equal the transfer of charge in the reverse direction. Then, 
Physical

$$
\frac{N(k+1)}{N(k)}=\frac{\beta^{+}(k) n(+)+v}{\beta^{-}(k+1) n(-)}
$$

Hoppel and Frick [126] have provided a detailed review of the ion-particle attachment coefficients over the entire range of aerosol particle sizes. Here, attachment coefficients appropriate for the continuum situation are used [121]:

$$
\begin{gathered}
\beta^{+}(k)=\frac{k e \mu(+)}{\exp (2 \lambda k)-1} \quad \text { for } k \neq 0 \\
\beta^{-}(k)=\frac{k e \mu(-)}{1-\exp (-2 \lambda k)} \quad \text { for } k \neq 0 \\
\beta^{+}(0)=2 \pi d_{p} D(+) \\
\beta^{-}(0)=2 \pi d_{p} D(-)
\end{gathered}
$$

where

$$
\begin{aligned}
\mathrm{e} & =4.803 \times 10^{-10} \text { statcoulombs, } \\
\lambda & =\mathrm{e}^{2} / \mathrm{d}_{\mathrm{p}} \mathrm{kT}, \\
\mathrm{k} & =1.38 \times 10^{-16} \mathrm{ergs} / \mathrm{K}, \\
\mu(+) & =\text { electrical mobility of positive ions, } \\
\mu(-) & =\text { electrical mobility of negative ions, } \\
\mathrm{D}(+) & =\text { diffusion coefficient of positive ions, and } \\
\mathrm{D}(-) & =\text { diffusion coefficient of negative ions. }
\end{aligned}
$$


For weak fields, the electrical mobility of an ion is related to its diffusion coefficient by:

$$
\mu( \pm)=e \mathrm{D}( \pm) / \mathrm{kT}
$$

Note, electrical mobilities are often quoted in units of $\mathrm{cm}^{2} / \mathrm{V}$-s. To convert to statvolts, $\mu( \pm)=$ $\mathrm{eD}( \pm) / 299.79 \mathrm{kT}$.

Experimental data on the mobilities and diffusion coefficients of ions in gas mixtures are available $[127,128]$. Some representative data are shown in Table 8. Primary ionization processes for oxygen and water vapor are [129]:

$\frac{\text { Primary ion }}{\mathrm{H}_{2} \mathrm{O}^{+}}$
$\mathrm{OH}^{+}$
$\mathrm{H}^{+}$
$\mathrm{H}_{2}^{+}$
$\mathrm{O}_{2}^{+}$
$\mathrm{O}^{+}$

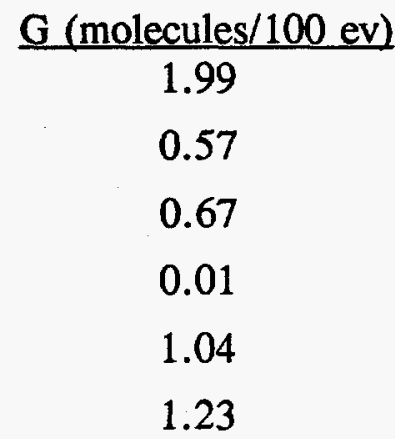

Clement and Harrison [121] make the point that the negative ions in normal air are more mobile than the positive ions. This may not always be the case. Negative ions, because of the additional electron in their molecular orbitals with no compensating positive charge in the nucleus, have larger collision cross-sections, typically, than the corresponding neutral species. Electron-electron repulsion expands the spatial extent of high electron density. The opposite is true for positive ions which typically have smaller collision cross-sections and consequently higher diffusion coefficients. Thus, for ions that differ only in the sign of the charge on them, the positive ion would be expected to have a higher mobility and a larger diffusion coefficient. This is certainly demonstrated by the data for $\mathrm{O}_{2}^{-}$and $\mathrm{O}_{2}^{+}$shown in Table 8.

Wiedensohler and Fissan [130] argue that the apparent higher mobility of negative ions is caused by the presence of free electrons. They have done experiments in very pure gases such as Ar. The expected ions would be $\mathrm{Ar}^{+}$and $\mathrm{Ar}^{-}$. Still they observe a propensity for aerosol particles to be preferentially charged negatively which is indicative of higher mobility of negative ions. They argue that this higher mobility of negative ions is only apparent. It appears negative ions seem more mobil only because there is some small concentration of free electrons that bombard aerosol particles. Because of the very high mobility of the free electrons, this small concentration of free electrons makes the average mobility of negative species large. Their arguments neglect, however, the polarizing capacity of high charge density positive ions and the possibility of forming low mobility positive ion-neutral associated species. Consequently, it is not obvious that free electrons must be invoked to explain the experimental observations.

The ions present in a containment atmosphere will be more varied than by just differences in the sign of their charges. Quite complicated species can form. Because of their high charge density and often 
Physical

Table 8. Some ion mobility data $[127,128]$

\begin{tabular}{|c|c|c|c|}
\hline Ion & Gas & $\left(\mathrm{cm}^{2 / \text { volt-s })}\right.$ & $\begin{array}{c}\mathrm{D} \\
\left(\mathrm{cm}^{2} / \mathrm{s}\right)\end{array}$ \\
\hline $\mathrm{CO}_{2}^{+}$ & $\mathrm{Ne}$ & 6.94 & 0.178 \\
\hline $\mathrm{CO}_{2}^{+}$ & $\mathbf{N}_{2}$ & 2.18 & 0.056 \\
\hline $\mathrm{Cs}^{+}$ & $\mathrm{H}_{2}$ & 12.9 & 0.332 \\
\hline $\mathrm{Cs}^{+}$ & $\mathrm{Ne}$ & 6.0 & 0.154 \\
\hline $\mathrm{Cs}^{+}$ & $\mathrm{Ar}$ & 2.11 & 0.054 \\
\hline $\mathrm{Cs}^{+}$ & $\mathrm{Kr}$ & 1.30 & 0.033 \\
\hline $\mathrm{Cs}^{+}$ & $\mathrm{Xe}$ & 0.89 & 0.023 \\
\hline $\mathrm{Cs}^{+}$ & $\mathrm{O}_{2}$ & 2.27 & 0.058 \\
\hline $\mathrm{Cs}^{+}$ & $\mathrm{CO}_{2}$ & 1.13 & 0.029 \\
\hline $\mathrm{HO}^{-}$ & $\mathrm{He}$ & 24.5 & 0.630 \\
\hline $\mathrm{H}_{3} \mathrm{O}^{+}$ & $\mathrm{He}$ & 21.5 & 0.55 \\
\hline $\mathrm{H}_{3} \mathrm{O}^{+}$ & $\mathrm{N}_{2}$ & 2.76 & 0.071 \\
\hline $\mathrm{H}_{3} \mathrm{O}^{+} \bullet \mathrm{H}_{2} \mathrm{O}^{+}$ & $\mathrm{He}$ & 17.3 & 0.44 \\
\hline $\mathrm{H}_{3} \mathrm{O}^{+} \bullet \mathrm{H}_{2} \mathrm{O}^{+}$ & $\mathrm{N}_{2}$ & 2.28 & 0.059 \\
\hline $\mathrm{H}_{3} \mathrm{O}^{+} \cdot 2 \mathrm{H}_{2} \mathrm{O}^{+}$ & $\mathrm{He}$ & 13.8 & 0.35 \\
\hline $\mathrm{H}_{3} \mathrm{O}^{+} \cdot 2 \mathrm{H}_{2} \mathrm{O}^{+}$ & $\mathbf{N}_{2}$ & 2.13 & 0.054 \\
\hline $\mathbf{I}^{-}$ & $\mathrm{He}$ & 16.3 & 0.42 \\
\hline $\mathbf{I}^{-}$ & $\mathrm{Ar}$ & 2.27 & 0.058 \\
\hline $\mathbf{N}^{+}$ & $\mathrm{He}$ & 19.9 & 0.511 \\
\hline $\mathrm{N}^{+}$ & $\mathrm{N}_{2}$ & -- & 0.080 \\
\hline $\mathrm{N}_{2}^{+}$ & $\mathrm{He}$ & 20.8 & 0.534 \\
\hline $\mathrm{N}_{2}^{+}$ & $\mathrm{N}_{2}$ & -- & 0.057 \\
\hline $\mathrm{O}^{-}$ & $\mathrm{O}_{2}$ & -- & 0.073 \\
\hline $\mathrm{O}_{2}^{-}$ & $\mathrm{O}_{2}$ & -- & 0.049 \\
\hline $\mathrm{O}_{2}^{+}$ & $\mathrm{O}_{2}$ & -- & 0.069 \\
\hline
\end{tabular}


because of a molecular orbital only partially occupied, positive ions have a tendency to associate with neutral species. A reaction important to the comparison of the mobilities of $\mathrm{O}_{2}^{-}$and $\mathrm{O}_{2}{ }^{+}$in oxygen is:

$$
\mathrm{O}_{2}+\mathrm{O}_{2}^{+} \rightarrow \mathrm{O}_{4}^{+}
$$

Formation of $\mathrm{O}_{4}{ }^{+}$by this ion-neutral association will substantially reduce the apparent mobility of $\mathrm{O}_{2}{ }^{+}$ because of both the larger mass and the larger collision cross-section of $\mathrm{O}_{4}{ }^{+}$. Since a corresponding association of $\mathrm{O}_{2}{ }^{-}$to form $\mathrm{O}_{4}{ }^{-}$is less likely, positive ions in oxygen can have lower apparent mobilities than negative ions.

In the steam-rich environment of a reactor containment atmosphere under accident conditions, a particularly important ion-neutral association reaction is the ion-dipole reaction with water vapor. This leads to large, charged, polymeric ions such as:

$$
\begin{aligned}
& \mathrm{H}_{3} \mathrm{O}^{+}+\mathrm{H}_{2} \mathrm{O} \rightarrow \mathrm{H}_{5} \mathrm{O}_{2}^{+} \\
& \mathrm{H}_{5} \mathrm{O}^{+}+\mathrm{H}_{2} \mathrm{O} \rightarrow \mathrm{H}_{7} \mathrm{O}_{3}^{+} \\
& \text {etc. } \\
& \mathrm{OH}^{-}+\mathrm{H}_{2} \mathrm{O} \rightarrow \mathrm{H}_{3} \mathrm{O}_{2}^{-} \\
& \mathrm{H}_{3} \mathrm{O}_{2}^{-}+\mathrm{H}_{2} \mathrm{O} \rightarrow \mathrm{H}_{5} \mathrm{O}_{3}^{-} \\
& \text {etc. }
\end{aligned}
$$

Over the last 30 years a large body of data on these ion hydrates has been assembled [131]. Hydrates involving up to eight water molecules are known. Hydration increases both the mass and the collision cross-sections of ions. It causes a decrease in the mobilities and diffusion coefficients of ionic species.

Collision of ionic species with neutral species allows more stable species to form by charge migration. For example, reactions expected to occur in a containment atmosphere might include

$$
\begin{gathered}
\mathrm{H}_{3} \mathrm{O}^{+}+\mathrm{CsI} \rightarrow \mathrm{Cs}^{+}+\mathrm{HI}+\mathrm{H}_{2} \mathrm{O} \\
\mathrm{I}+\mathrm{OH}^{-} \rightarrow \mathrm{OH}+\mathrm{I}^{-}
\end{gathered}
$$

Charge transfer to more massive species does, of course, reduce the apparent mobility of ions. 
Physical

Hoppel and Frick [126] also reviewed the theory of ion recombination coefficients. Theoretical predictions of the ion recombination coefficient, $\alpha$, fall in the range of about $1.0 \times 10^{-6} \mathrm{~cm}^{3} / \mathrm{s}$ to $2.4 \mathrm{x}$ $10^{-6} \mathrm{~cm}^{3} / \mathrm{s}$. Armstrong [129] cites experimental values of the recombination coefficient for some specific reactions:

$$
\begin{array}{ll}
\mathrm{H}_{3} \mathrm{O} \cdot \mathrm{nH}_{2} \mathrm{O}^{+}+\mathrm{e}^{-} & \alpha=4.0 \pm 1.0 \times 10^{-6} \mathrm{~cm}^{3} / \mathrm{s} \\
\mathrm{CO}_{2} \cdot \mathrm{nCO}_{2}^{+}+\mathrm{e}^{-} & \alpha=4.0 \times 10^{-6} \\
\mathrm{O}_{4}^{+}+\mathrm{O}_{2}^{-} & \alpha=0.2 \times 10^{-6}
\end{array}
$$

Three-body collisions leading to ion recombination may also be important in reactor containments when pressures are high [129]. Above about 5 atmospheres, the ion recombination coefficient is expected to vary with the sum of the mobilities of the positive and negative ions involved in the neutralization reaction. These mobilities vary inversely with pressure. Consequently, $\alpha$ is observed to pass through a maximum with increasing pressure.

There has not been an attempt to characterize the ion chemistry of reactor containment atmospheres under accident conditions. There may be sufficient data available on ionic species to predict the nature of ions in reactor containments. Such an effort is outside the scope of this work. It is assumed here that ion mobilities can be substantially less than those listed in Table 8 because of hydration. It is also assumed that the relative mobility of positive ions may be greater than or less than the mobility of negative ions.

With so little data on the ionization of the containment atmosphere under accident conditions, it would take a great deal more analysis than can be afforded for this work to develop realistic descriptions of the ionic mobilities that affect aerosol charging. Consequently, here, attempts are made only to illustrate the nature and trends of ionization and particle charging processes.

For illustrative purposes, typical ranges of the particle decay rate, $v$, and the ion production rate, $q$, are needed. Decay rates $(\mathrm{Bq} / \mathrm{mole})$ for various classes of radionuclides are shown in Table 9. Based on these data, the decay rates for $1 \mu \mathrm{m}$ aerosol particles could vary from 2000 to 5 decay events per second. The assumption made here is that decay rates and consequently residual charge generation rates vary with particle volume. Williams and Loyalka [41] have discussed other assumptions.

Ionization of the atmosphere will occur from radioactive decay of radionuclides other than those in aerosol particles. Of particular interest is the ionization caused by decay of noble gases uniformly distributed within the containment atmosphere. The decay characteristics of some noble gas isotopes are listed in Table 10. Of particular interest are isotopes that beta decay. From information in the table, it appears that disintegration rates will amount to about $2 \times 10^{8}$ events $/ \mathrm{cm}^{3}-\mathrm{s}$. The disintegration events can produce between 4000 and 20000 ion pairs each. Thus, q should be in the range of 0.8 to $4.0 \times 10^{12}$ ion pairs $/ \mathrm{cm}^{3}$-s. 
Table 9. Radionuclide decay rates

\begin{tabular}{ccc}
\hline \multirow{2}{*}{$\begin{array}{c}\text { Radionuclide } \\
\text { class }\end{array}$} & \multicolumn{1}{c}{$\mathbf{B q} / \mathbf{m o l e}$} \\
\cline { 2 - 3 } at $2 \mathrm{hr}$ & \multicolumn{1}{c}{ at $10 \mathrm{hr}$} \\
\hline $\mathrm{I}$ & $1.3 \times 10^{17}$ & $0.82 \times 10^{17}$ \\
$\mathrm{Te}$ & $0.016 \times 10^{17}$ & $0.0044 \times 10^{17}$ \\
$\mathrm{Sr}$ & $0.25 \times 10^{17}$ & $0.16 \times 10^{17}$ \\
$\mathrm{Ba}$ & $0.11 \times 10^{17}$ & $0.064 \times 10^{17}$ \\
$\mathrm{Ru}$ & $0.10 \times 10^{17}$ & $0.067 \times 10^{17}$ \\
$\mathrm{La}$ & $0.04 \times 10^{17}$ & $0.036 \times 10^{17}$ \\
$\mathrm{Ce}$ & $0.10 \times 10^{17}$ & $0.071 \times 10^{17}$ \\
\hline
\end{tabular}

Charge distributions calculated for aerosol particles 0.2 to $5.0 \mu \mathrm{m}$ in diameter are shown in Figure 15 . For calculation of these distributions, parametric quantities that affect charging were set to:

$$
\begin{aligned}
\mathrm{D}(+) & =0.05 \mathrm{~cm}^{2} / \mathrm{s} \\
\mathrm{D}(-) & =0.08 \mathrm{~cm}^{2} / \mathrm{s} \\
\alpha & =2 \times 10^{-6} \mathrm{~cm}^{3} / \mathrm{s} \\
\mathrm{Q} & =2 \times 10^{12} \text { ion pairs } / \mathrm{cm}^{3}-\mathrm{s} \\
v & =300 \text { disintegrations } / \text { particle-s for } 1 \mu \mathrm{m} \text { particles. }
\end{aligned}
$$

The aerosol was assumed to be present at a mass concentration of $1 \times 10^{-7} \mathrm{~g} / \mathrm{cm}^{3}$. The effective density of the particle materials was taken to be $3 \mathrm{~g} / \mathrm{cm}^{3}$.

The mean charge on the aerosol particles is predicted to become more negative with increasing particle size:

\section{Particle size $(\mu \mathrm{m})$}

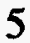

2

1

0.2
Mean charge

$-12.04$

$-9.61$

$-5.16$

$-1.06$ 
Table 10. Noble gas decay characteristics

\begin{tabular}{|c|c|c|c|c|c|}
\hline \multirow[b]{2}{*}{ Isotope } & \multirow[b]{2}{*}{ Half-life } & \multicolumn{2}{|c|}{ Inventory $(\mathbf{B q})$ at } & \multirow{2}{*}{$\begin{array}{l}\text { Decay } \\
\text { mode }\end{array}$} & \multirow{2}{*}{$\begin{array}{c}E \\
\text { (Mev) }\end{array}$} \\
\hline & & $2 \mathrm{hr}$ & $24 \mathrm{hr}$ & & \\
\hline $\mathrm{Kr}^{83 \mathrm{~m}}$ & $1.86 \mathrm{hr}$ & $5.1 \times 10^{17}$ & $0.022 \times 10^{17}$ & $\gamma$ & \\
\hline $\mathrm{Kr}^{85}$ & $10.4 \mathrm{yr}$ & $0.25 \times 10^{17}$ & $0.25 \times 10^{17}$ & $\beta$ & 0.67 \\
\hline $\mathrm{Kr}^{85 \mathrm{~m}}$ & $4.4 \mathrm{hr}$ & $10.0 \times 10^{17}$ & $0.28 \times 10^{17}$ & $\gamma, \beta$ & $0.88(22 \%)$ \\
\hline $\mathrm{Kr}^{87}$ & $78 \mathrm{~min}$ & $12.4 \times 10^{17}$ & -- & $\beta$ & 3.8 \\
\hline $\mathrm{Kr}^{88}$ & $2.8 \mathrm{hr}$ & $22.4 \times 10^{17}$ & $0.075 \times 10^{17}$ & $\beta$ & $\begin{array}{l}2.7(20 \%) \\
0.52(68 \%)\end{array}$ \\
\hline$X e^{131 m}$ & & $0.20 \times 10^{17}$ & $0.2 \times 10^{17}$ & $\gamma$ & 0.164 \\
\hline $\mathrm{Xe}^{133}$ & $5.27 \mathrm{~d}$ & $66.6 \times 10^{17}$ & $65.4 \times 10^{17}$ & $\beta$ & 0.35 \\
\hline$X e^{133 m}$ & $2.3 \mathrm{~d}$ & $2.1 \times 10^{17}$ & $1.92 \times 10^{17}$ & $\gamma$ & 0.233 \\
\hline$X e^{135}$ & $9.13 \mathrm{hr}$ & $15.7 \times 10^{17}$ & $15.7 \times 10^{17}$ & $\beta$ & $0.91(97 \%)$ \\
\hline$X e^{135 m}$ & & $7.9 \times 10^{17}$ & $0.78 \times 10^{17}$ & $\gamma$ & \\
\hline $\mathrm{Xe}^{138}$ & $17 \mathrm{~min}$ & $0.17 \times 10^{17}$ & -- & $\beta$ & 2.4 \\
\hline
\end{tabular}

The distribution of charges on the particles becomes of increasing breadth with increasing particle size. None of the distributions mimics well the classic Boltzmann charge distribution. The breadths of the distributions make it apparent that it may not be entirely useful to think in terms of a single average charge on particles. Even where the mean charge is quite negative, a significant fraction of the aerosol mass has positive charges.

The background ion production by the decay of noble gases in the atmosphere has a significant effect on these calculated charge distributions. Without this ion production, the mean charge varies in a complicated way with particle size as shown in Figure 16 . The mean charge actually becomes positive for the larger particles.

This sensitivity to the background ion production rate has several implications. Certainly, it shows that the ionization of the atmosphere will greatly affect the charging of the particles. Consequently, it would be expected that the charge distribution on particles is affected by the particle activity and the ionization produced by the decay of radionuclides in particles. The charge distribution also ought to be affected by the ion recombination rate. Another implication is, of course, that it will be difficult to conduct prototypic experiments to validate these analyses since both radioactive particles and intense radiation fields are important aspects of the problem.

Some of the sensitivities of the charging of aerosol particles are illustrated by results of calculations for $2 \mu \mathrm{m}$ particles shown in Table 11. Of particular note is that the mean charge on the particles is very 


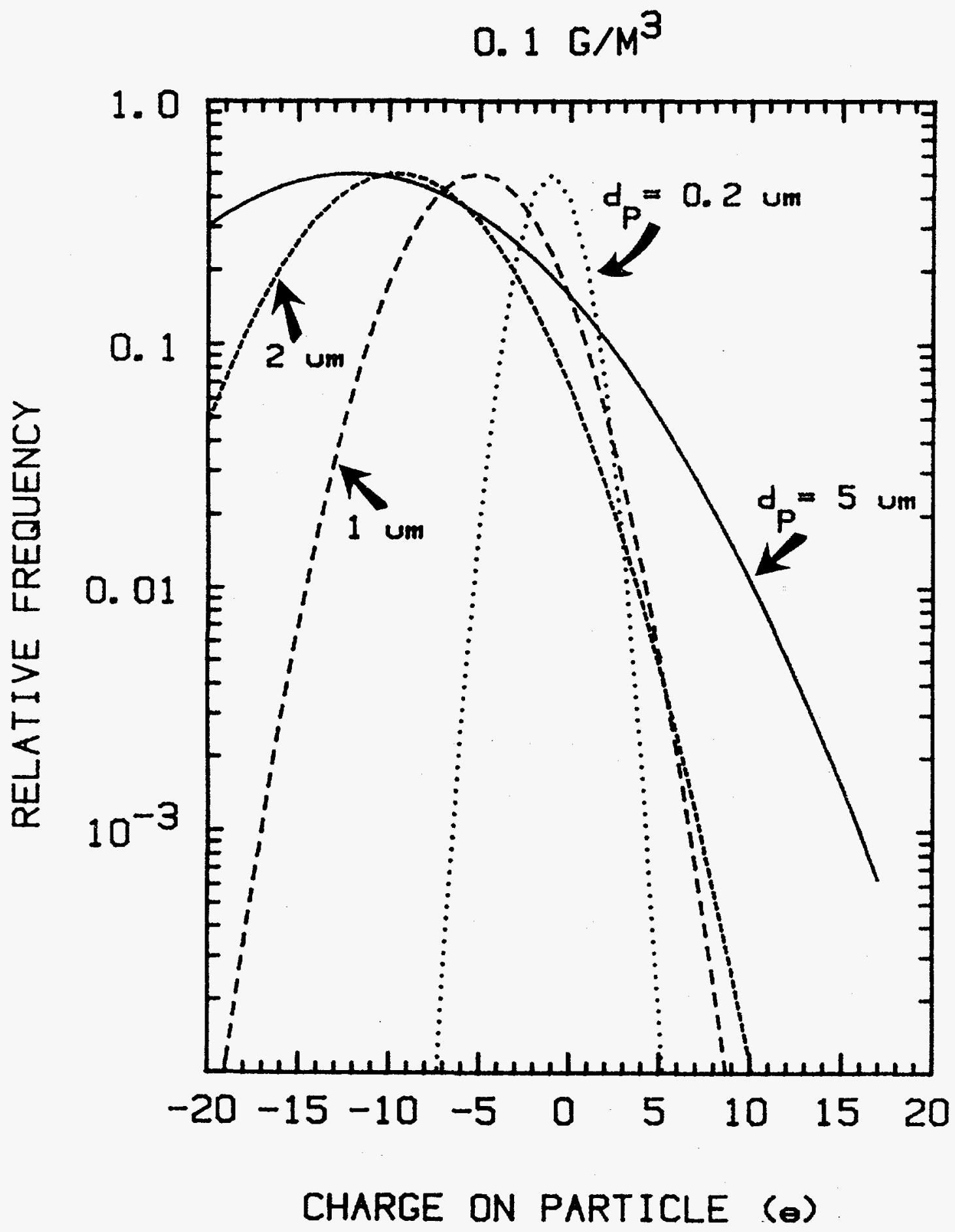

Figure 15. Distribution of electrostatic charges on particles of various sizes 
Physical

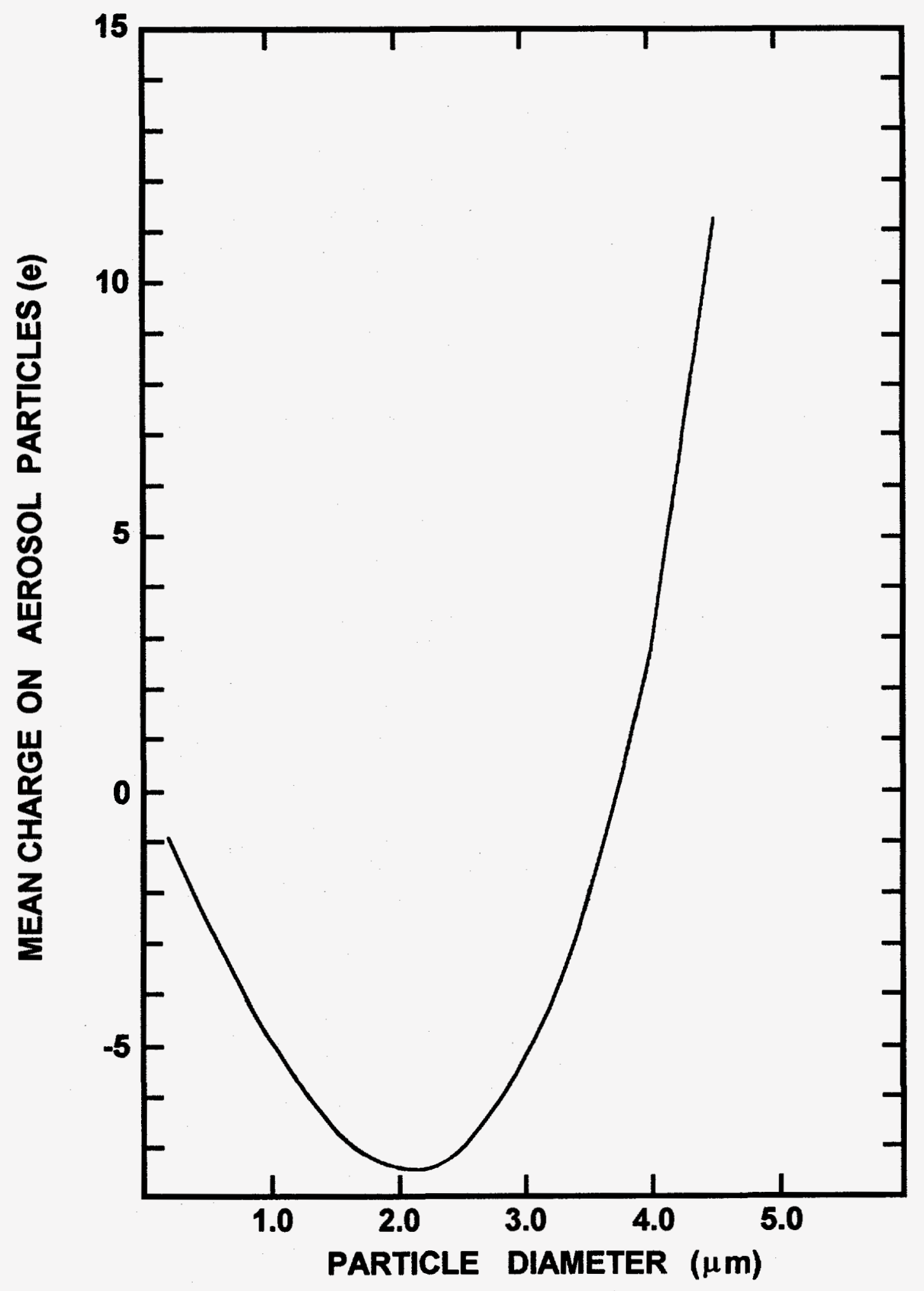

Figure 16. Mean charge on aerosol particles when the background ion production rate is zero 
Table 11. Effects of parameter variations on the mean aerosol charge ${ }^{*}$

\begin{tabular}{|c|c|c|c|c|c|c|}
\hline $\begin{array}{c}D(-) \\
\left(\mathrm{cm}^{2} / \mathrm{s}\right)\end{array}$ & $\begin{array}{c}\mathrm{D}(+) \\
\left(\mathrm{cm}^{2} / \mathrm{s}\right)\end{array}$ & $\mathbf{D}(+) / \mathbf{D}(-)$ & $\begin{array}{c}\alpha \\
\left(\mathrm{cm}^{3} / \mathrm{s}\right)\end{array}$ & $\begin{array}{c}Q \\
\text { (ion pairs } \\
\mathrm{cm}^{3} / \mathbf{s} \text { ) }\end{array}$ & $\begin{array}{c}v \\
\left(\frac{\mathrm{Bq}}{\text { particle }}\right)\end{array}$ & $\begin{array}{l}\text { Mean charge } \\
\left(4.803 \times 10^{-10}\right. \\
\text { statcoulombs) }\end{array}$ \\
\hline 0.0800 & 0.0500 & 0.625 & $2 \times 10^{-6}$ & $1 \times 10^{12}$ & 2400 & -9.61 \\
\hline 0.0684 & 0.0616 & 0.900 & $2 \times 10^{-6}$ & $1 \times 10^{12}$ & 2400 & -1.46 \\
\hline 0.065 & 0.065 & 1.000 & $2 \times 10^{-6}$ & $1 \times 10^{12}$ & 2400 & +0.88 \\
\hline 0.0616 & 0.0684 & 1.110 & $2 \times 10^{-6}$ & $1 \times 10^{12}$ & 2400 & +3.21 \\
\hline 0.0500 & 0.0800 & 1.600 & $2 \times 10^{-6}$ & $1 \times 10^{12}$ & 2400 & +10.5 \\
\hline 0.0800 & 0.0500 & 0.625 & $1 \times 10^{-6}$ & $1 \times 10^{12}$ & 2400 & -9.88 \\
\hline 0.0800 & 0.0500 & 0.625 & $0.2 \times 10^{-6}$ & $1 \times 10^{12}$ & 2400 & -10.2 \\
\hline 0.0800 & 0.0500 & 0.625 & $5.0 \times 10^{-6}$ & $1 \times 10^{12}$ & 2400 & -9.1 \\
\hline 0.0800 & 0.0500 & 0.625 & $2 \times 10^{-6}$ & $1 \times 10^{10}$ & 2400 & -7.58 \\
\hline 0.0800 & 0.0500 & 0.625 & $2 \times 10^{-6}$ & $1 \times 10^{11}$ & 2400 & -8.36 \\
\hline 0.0800 & 0.0500 & 0.625 & $2 \times 10^{-6}$ & $2 \times 10^{12}$ & 2400 & -9.86 \\
\hline 0.0800 & 0.0500 & 0.625 & $2 \times 10^{-6}$ & $1 \times 10^{12}$ & 40 & -10.5 \\
\hline 0.0800 & 0.0500 & 0.625 & $2 \times 10^{-6}$ & $1 \times 10^{12}$ & 10,000 & -5.56 \\
\hline
\end{tabular}

*Aerosol particles are $2 \times 10^{-4} \mathrm{~cm}$ in diameter, have an effective density of $3 \mathrm{~g} / \mathrm{cm}^{3}$ and are present at a mass concentration of $10^{-7} \mathrm{~g} / \mathrm{cm}^{3}$. 
sensitive to the relative diffusion coefficients of positive and negative ions. As noted above, it is difficult to predict the ion mobilities under accident conditions. The preponderance of conventional arguments is that the negative ions are more mobile than are the positive ions. As these mobilities become more nearly equal, the charge distribution on the $2 \mu \mathrm{m}$ particles is shifted toward more positive values.

Results presented in Table 11 contrast with results obtained by Clement and Harrison [121], who do not consider the background ion production caused by the decay of the noble gases. In particular, it is found here that even quite small particles $\left(d_{p}=0.2 \mu \mathrm{m}\right)$ will be charged. The magnitude of the charge on particles is much less sensitive to the aerosol concentration. If, as Clement and Harrison contend and as is found in experiments in atmospheres that are not rich in water vapor, positive ions are less mobile than negative ions, there is a strong tendency for there to be a net negative charge on the aerosol particles of all sizes.

The conclusion to be drawn from these analyses is that radioactive particles can, indeed, be charged under severe accident conditions. Larger particles are more highly charged than smaller particles. The exact magnitude of the charge on particles will be sensitive to both the intensity of the radiation field and the physical chemistry of containment atmosphere ions. The breadth of the charge distribution on particles of given size can be large so that even when the mean charge is quite negative, a substantial fraction of the particles could still be positively charged.

\section{Effects of Charging on Aerosol Coagulation}

Dunbar [37] as well as Williams and Loyalka [41] have discussed formulation of the aerosol dynamic equation to account for the Coulombic effects of aerosol charging on particle agglomeration. Accounting for these effects involves major changes to the aerosol dynamic equation. Distributions of both particle size and particle charge must be considered. To the authors' knowledge, such reformulations have not been applied to the analysis of reactor accidents. Certainly, the effort needed to make the modifications to the aerosol dynamic equation and apply it would go well beyond the bounds of the work described here. Nevertheless, the issue of aerosol charging looks to be a significant uncertainty that needs to be examined for the purposes of this work.

Williams and Loyalka have suggested a simplified treatment of the effects of electrostatic charge on the Brownian coagulation kernel-in the aerosol dynamic equation [41]. They suggest that the repulsive effect of like charges can be considered to reduce the coagulation kernel by an amount

$$
\frac{\lambda}{\exp (\lambda)-1}
$$

where $\lambda=Q^{2} / d^{2} \mathrm{kT}$ and $\mathrm{Q}$ is the charge on each particle. The reduction in the coagulation kernel for singly charged $2 \mu \mathrm{m}$ particles is by a factor of 0.989 . For $2 \mu \mathrm{m}$ particles with five elementary charges, the coagulation kernel is reduced to 0.746 of the value for uncharged particles.

Similarly, the coagulation kernel for particles having charges of different sign is enhanced by the factor: 


\section{$\frac{\lambda}{1-\exp (-\lambda)}$}

Without doing the detailed calculations, it appears that the Coulombic effects may not greatly affect the macroscopic coagulation of aerosol particles. Because relatively broad charge distributions are predicted, the enhancement of coagulation between particles with charges of different sign should, at least partially, compensate for the inhibition of coagulation of particles with charges of the same sign.

\section{Effect of Charging on Aerosol Particle Deposition}

An effect of charging is to inhibit the agglomeration of aerosol particles and thus enhance the lifetimes of small particles. This should reduce particle deposition by sedimentation, but enhance the opportunities for particle deposition by diffusive mechanisms. There is, however, also an electrostatic effect on particle deposition behavior.

At macroscopic length scales (scales larger than the Debye length), the bulk atmosphere of the reactor containment will be electrically neutral. There is, then, no electrical field gradient that can produce a net drift of aerosol particles. If positive and negative ions in the containment atmosphere do not have the same diffusion coefficients, there can be electrical field gradients near surfaces. These gradients can enhance the deposition of aerosol particles. To estimate the magnitude of this additional deposition mechanism, a development that parallels that used by Kolomeitsev et al. for charged particle deposition in pipes is adopted [132].

Because of the high turbulence, the containment atmosphere is taken to be electrically neutral up to a boundary layer of thickness $\delta$ near surfaces. This boundary layer is identified here as the laminar sublayer of the turbulent structure described above in connection with turbulent particle deposition. The layer thickness is, then, given by:

$$
5=\mathrm{y}^{+}=\delta \mathrm{U}^{*} \rho_{\mathrm{g}} / \mu_{\mathrm{g}}
$$

where $U^{*}$ is the friction velocity of the turbulent flow over the surface.

Surfaces are considered here to be electrically insulating. In the cases of metal surfaces, it is assumed that an oxide corrosion layer is present and that charge recombination takes place on this layer at a rate that is much faster than the rate of charge tunneling through the layer.

Gaseous ions diffuse across the laminar boundary layer and recombine on the surface. Here, recombination on the surface is taken to be very much faster than gas phase recombination. The surface is taken to lie in the $y-z$ Cartesian plane at $x=0$. The time rates of change of ion concentrations in the boundary layer are taken to be: 
Physical

$$
\begin{aligned}
& \frac{\partial n(+)}{\partial t}=q+\nabla D(+) \nabla n(+) \\
& \frac{\partial n(-)}{\partial t}=q+\nabla D(-) \nabla n(-)
\end{aligned}
$$

where:

$$
\begin{aligned}
\mathrm{q} & =\text { ion pair production rate per unit volume, } \\
\mathrm{D}(+) & =\text { diffusion coefficient of positive ions, and } \\
\mathrm{D}(-) & =\text { diffusion coefficient of negative ions. }
\end{aligned}
$$

Note that it has been assumed that the Brownian diffusive flux of ions is very much greater than the drift flux due to the electrical field.

At steady state,

$$
\begin{aligned}
& \mathrm{D}(+) \nabla \mathrm{n}(+)=-\mathrm{qx}+\mathrm{C}(+) \\
& \mathrm{D}(-) \nabla \mathrm{n}(-)=-\mathrm{qx}+\mathrm{C}(-)
\end{aligned}
$$

where $\mathrm{C}(+)$ and $\mathrm{C}(-)$ are constants of integration. Since the concentration gradient at the edge of the boundary layer $(x=\delta)$ is to be zero, $C(+)=C(-)=q \delta$ and

$$
D(+) n(+)=-q x^{2} / 2+q \delta x+\Lambda
$$

where $\Lambda$ is a constant of integration.

The surface ion concentrations are also taken to be time invariant so

$$
\begin{aligned}
& \frac{\partial \mathrm{n}_{\mathrm{s}}(+)}{\partial \mathrm{t}}=\alpha_{\mathrm{s}} \mathrm{n}(+) \mathrm{n}(-)-\mathrm{D}(+) \nabla \mathrm{n}(+)=0 \\
& \frac{\partial \mathrm{n}_{\mathrm{s}}(-)}{\mathrm{dt}}=\alpha_{\mathrm{s}} \mathrm{n}(+) \mathrm{n}(-)-\mathrm{D}(-) \nabla \mathrm{n}(-)=0
\end{aligned}
$$

where $\alpha_{s}$ is the surface recombination rate coefficient. Then, 


$$
\begin{aligned}
\alpha_{\mathrm{s}} \mathrm{n}(+) \mathrm{n}(-) & =\alpha_{\mathrm{s}} \Lambda^{2} / \mathrm{D}(+) \mathrm{D}(-)=\mathrm{q} \delta \\
& \text { or } \\
\Lambda & =[\mathrm{qD}(+) \mathrm{D}(-) \delta / \alpha]^{1 / 2}
\end{aligned}
$$

The electrical field is found from Poisson's equation:

$$
E(x)-E(r e f)=4 \pi e \int_{0}^{x} n(+)-n(-) d x
$$

$\mathrm{E}(\mathrm{ref})$ is an arbitrary reference potential. The reference potential is selected here so that the potential at the edge of the boundary layer $\mathrm{E}(\mathrm{x}=\boldsymbol{\delta})$ is zero. Then,

$$
E(x)=4 \pi e\left[\frac{1}{D(+)}-\frac{1}{D(-)}\right]\left\{\frac{-q}{6}(x-\delta)^{3}+(x-\delta)\left(\Lambda+\frac{q \delta^{2}}{2}\right)\right\}
$$

Clearly, there is an electric field gradient whenever $D(+) \neq D(-)$. Charged aerosol particles in this electrical field will be drawn toward or repelled from the surface. The particle deposition is given by:

$$
\frac{1}{\mathrm{~A}} \frac{\mathrm{dN}(\mathrm{k})}{\mathrm{dt}}=\frac{-4 \pi \mathrm{D}\left(\mathrm{d}_{\mathrm{p}}\right) \mathrm{ke}^{2} \Lambda}{\mathrm{kT} \mathrm{V}}\left(\frac{1}{\mathrm{D}(+)}-\frac{1}{\mathrm{D}(-)}\right) \mathrm{N}(\mathrm{k})
$$

For situations in which $D(-)>D(+)$, negatively charged particles are repelled from the surface and positively charged particles are drawn to the surface. Of course, if $D(+)>D(-)$, then negatively charged particles are drawn to the surface. Typical deposition velocities for $2 \mu \mathrm{m}$ particles carrying one and five electrical charges are \pm 0.04 and $\pm 0.2 \mathrm{~cm} / \mathrm{s}$, respectively, where the sign depends on the sign of the charge on the particles. These deposition (or repulsion) velocities are significant, but not necessarily overwhelming. They are larger than typical diffusiophoretic or thermophoretic deposition velocities.

\section{Neglect of Charging Effects}

Charging of aerosols as a result of radioactive decay of aerosol materials and especially because of the radiation field produced by the decay of radioactive noble gases can affect both the coagulation and the deposition of aerosols in containments or drywells. The effects of charging have not been included in models of aerosol behavior used for reactor accident analyses. The effects of charging can be either to 
inhibit or to accentuate coagulation and deposition of aerosols. Establishing with any confidence the relative magnitudes of the effects of aerosol charging is beyond the scope of the work undertaken here. Though aerosol charging effects clearly represent sources of uncertainty in the prediction of decontamination by natural aerosol processes, these uncertainties are neglected here. The authors believe that there is a high likelihood that neglecting electrostatic charge effects on aerosol behavior leads to conservative results with respect to the mass of aerosol suspended in containments or drywells. That is, were these electrostatic effects taken into account, there would be more rapid deposition of aerosol particles. The accelerated deposition would come as a result of accentuated coagulation of particles and despite electrostatic repulsion from surfaces.

The preponderance of thought is that there will be some disparity between the mobilities of positive and negative ions in containment or drywell atmospheres under accident conditions. It is difficult to imagine how there could not be some differences in the relative mobilities of oppositely charged ions. There is some empirical evidence that negative ions will be more mobile. When the mobilities of positive and negative ions are different, the aerosol particles become charged. There will be a steady-state charge distribution for the particles. But, no individual particle will have any particular charge for long. As the charge on a particle fluctuates, there will be times when its overall charge is opposite that of adjacent particles or surfaces. During these brief periods of time, there will be strong attractive forces that enhance particle coagulation or deposition. But, both coagulation and deposition are irreversible processes. This contrast with the reversible processes that occur when adjacent particles or particles and surfaces have charges of the same sign and are subject to repulsive forces. Because the fluctuations brought on by the ion bombardment of aerosol particles lead to irreversible growth or deposition, it would appear that charging of aerosol will enhance decontamination.

Charging of aerosol particles obviously deserves further attention. The conditions that are expected to affect particle charging during reactor accidents are well outside conventional experience and available data. Key issues in the further examination of charging effects under such extreme conditions are definitions of ion mobilities and ion concentrations in steam-rich, high-temperature and high-pressure atmospheres. 


\section{Uncertainties in the Prediction of Aerosol Behavior in Reactor Containments}

The simplified model that is discussed in Chapter IV takes into account uncertainties in the prediction of aerosol behavior in reactor containments during accidents. Uncertainty distributions of predictions of aerosol behavior are calculated in Chapter $V$ by Monte-Carlo sampling of the uncertain quantities expected to affect predictions of aerosol behavior. These uncertain quantities are discussed in this chapter. The discussions focus on the identification of uncertain quantities and plausible ranges of values for these quantities. Subjective probability distributions for values within these ranges are selected according to the following set of rules:

1. Quantities calculated from correlations of data are taken to have uncertainties distributed about the correlation prediction according to a Student's $t$ distribution.

2. An uncertain quantity whose meaningful range of plausible values spans less than an order of magnitude is assigned a uniform uncertainty distribution.

3. An uncertain quantity whose meaningful range of plausible values spans more than an order of magnitude is assigned a log-uniform uncertainty distribution.

4. Where the data base or the knowledge base indicates greater certitude about a quantity, values of this quantity are assigned a lognormal distribution.

Probability density functions for these uncertainty distributions are compared in Figure 17. Note that the log normal and the Student's $t$ distributions are continuous distributions. Limits on the plausible ranges of values for quantities having these uncertainty distributions are taken to correspond to the first and 99 th percentiles of the cumulative distributions.

All four of these distributions used for the uncertainty analyses are high-entropy distributions. The advantages of using high-entropy distributions have been discussed elsewhere [5]. High-entropy distributions are selected here for uncertain quantities because the authors find no bases for more constrained distributions. When such bases were identified in an area of uncertainty, parameters were redefined so high-entropy distributions were appropriate for the parameters. Some effort has been expended to identify the sets of uncertain parameters so that there is no obvious correlation of the respective parameter values in most cases. Detection of correlation among parameters is, often, a subjective matter and the authors cannot attest that all readers will agree that the uncertain parameters chosen here are not correlated.

The parameters discussed here are quantities that reflect uncertainty in various aspects of the prediction of aerosol behavior. The discussions of these uncertainties and the associated parameters in the subsections below are organized in terms of (a) uncertainty in the geometry and configuration of nuclear reactor containments, (b) uncertainty in the progression of reactor accidents, and (c) uncertainty in the physical and chemical phenomena that affect aerosol behavior in reactor containments. The various uncertain quantities, together with their plausible ranges and uncertainty distributions identified in the discussions, are summarized in Table 12. 


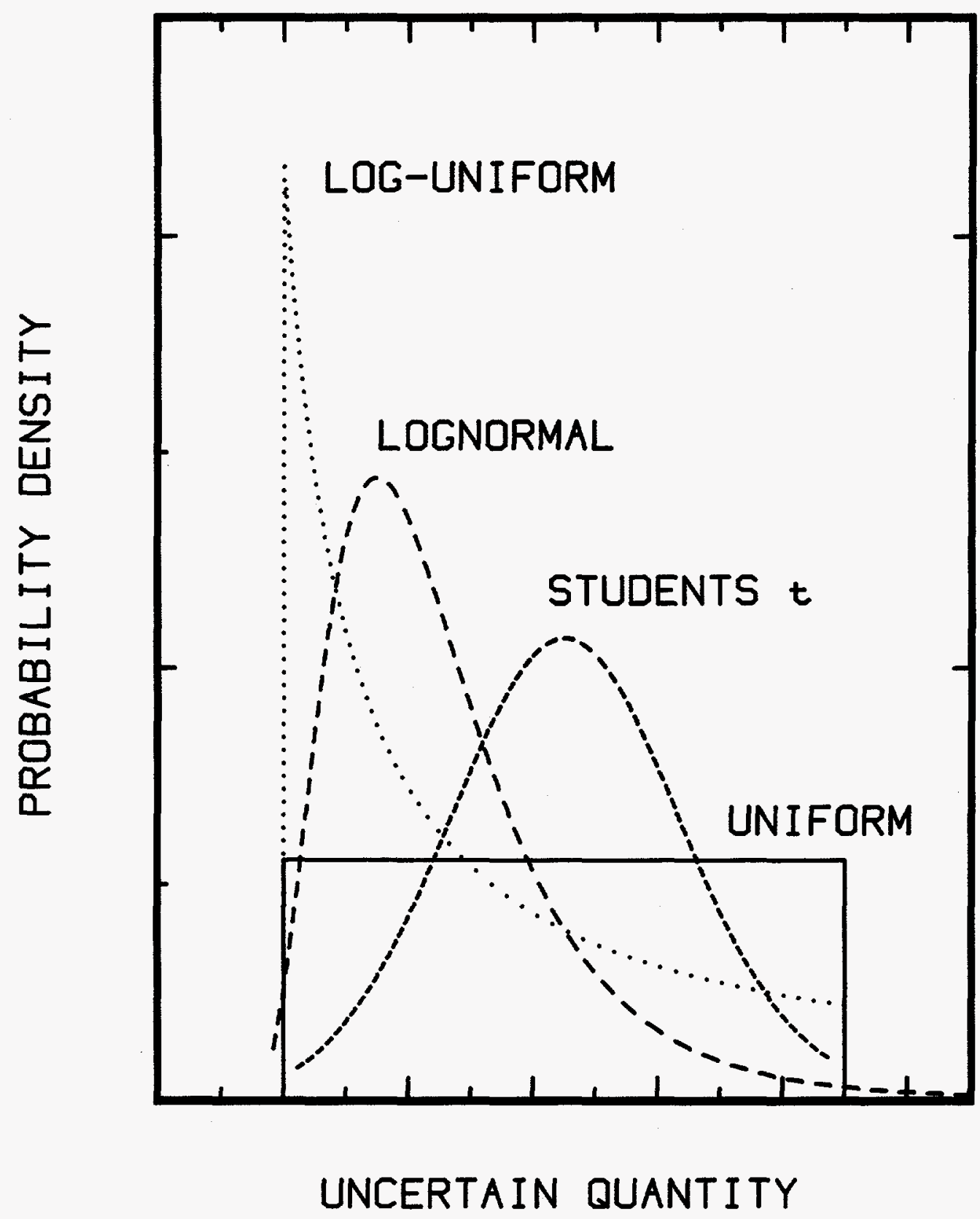

Figure 17. Comparison of probability density functions used in this study 
Table 12. Uncertain quantities, range of values and subjective probability distributions

\begin{tabular}{|c|c|c|c|}
\hline Quantity & Plausible range of values & \multicolumn{2}{|c|}{ Probability density function } \\
\hline \multicolumn{4}{|l|}{$\begin{array}{l}\Delta \mathrm{V} \text { uncertainty in the correlation of } \\
\text { volume with reactor power }\left(\mathrm{m}^{3}\right)\end{array}$} \\
\hline \multirow[t]{2}{*}{ - PWR containments } & continuous distribution (see text) & $\begin{array}{l}\text { Student's } t \text { distribution } \\
40 \text { degrees of freedom }\end{array}$ & \\
\hline & & se: $\left[\frac{1}{42}+\frac{(P-2750)^{2}}{2.58 \times 10^{7}}\right]^{1 / 2}$ & 35000 \\
\hline \multirow[t]{2}{*}{ - BWR drywells } & continuous distribution (see text) & $\begin{array}{l}\text { Student's } t \text { distribution } \\
40 \text { degrees of freedom }\end{array}$ & \\
\hline & & se: $\left[\frac{1}{26}+\frac{(P-2739)^{2}}{1.14 \times 10^{7}}\right]^{1 / 2}$ & 40000 \\
\hline$\Delta\left(\mathrm{A}_{\mathrm{F}}\right)$ uncertainty in floor area & \pm 0.25 & uniform & \\
\hline $\begin{array}{l}\epsilon(A) \text { multiplier to account for internal } \\
\text { vertical surfaces }\end{array}$ & 0.2 to 2.0 & log-uniform & \\
\hline \multicolumn{4}{|l|}{$\frac{A_{E}}{V} \begin{array}{l}\text { envelope surface area-to-volume } \\
\text { ratio }\end{array}$} \\
\hline - PWR $\left(m^{-1}\right)$ & 0.128 to 0.173 & uniform & \\
\hline - BWR $\left(\mathrm{m}^{-1}\right)$ & \pm 0.0225 & uniform & \\
\hline
\end{tabular}


Table 12. Uncertain quantities, range of values and subjective probability distributions (continued)

\begin{tabular}{ccc}
\hline Quantity & Plausible range of values & Probability density function \\
\hline
\end{tabular}

Reduction factor for surface areas at the start of ex-vessel release

- floor

- vertical surfaces

$\Delta \mathrm{t}(\mathrm{s})=\mathrm{t}_{\mathrm{o}}-1980$

$t_{0}=$ time after scram when gap release starts

Mass multipliers for

$$
\begin{aligned}
& 1.0 \text { to } 1.38 \\
& 1.05 \text { to } 1.22 \\
& 1.0 \text { to } 1.25 \\
& 1.18 \text { to } 1.67 \\
& 1.11 \text { to } 1.43 \\
& 1.0 \text { to } 1.47 \\
& 1.17 \text { to } 1.22 \\
& 1.11 \text { to } 1.17 \\
& 0.01 \text { to } 1.0
\end{aligned}
$$

0.5 to 2.0 uniform

uniform and $100 \%$ correlated with factor for floors

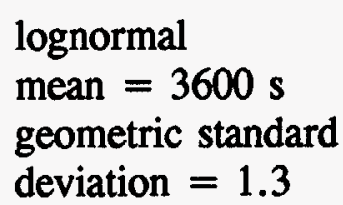

uniform

uniform

uniform

uniform

uniform

uniform

uniform

uniform

log-uniform

uniform

$\epsilon(\mathrm{m}$, in-vessel) uncertainty in the nonradioactive aerosol mass released to containment during the in-vessel release phase 
Table 12. Uncertain quantities, range of values and subjective probability distributions (continued)

\begin{tabular}{|c|c|c|}
\hline Quantity & Plausible range of values & Probability density function \\
\hline $\begin{array}{l}\epsilon(m, x) \text { uncertainty in the nonradioactive } \\
\text { aerosol mass released during the ex-vessel } \\
\text { release phase }\end{array}$ & 0.1 to 1.2 & log-uniform \\
\hline $\begin{array}{l}\dot{\mathrm{m}} \text { (late) }(\mathrm{g} / \mathrm{s}) \text { release rates of } \\
\text { nonradioactive mass during the late } \\
\text { in-vessel release phase }\end{array}$ & 0.1 to 10 & log-uniform \\
\hline $\begin{array}{l}\stackrel{\circ}{\mathrm{m}} \text { (very late) (g/s) release rates of } \\
\text { nonradioactive mass after completion of } \\
\text { the late in-vessel release phase }\end{array}$ & $10^{-4}$ to 1.0 & log-uniform \\
\hline $\begin{array}{l}\mathrm{P}(\mathrm{gap})(\mathrm{atm}) \text { atmospheric pressure during } \\
\text { the gap release phase }\end{array}$ & 1.16 to 2.79 & uniform \\
\hline \multicolumn{3}{|l|}{$\begin{array}{l}\mathrm{P}(\mathrm{in} \text {-vessel) (atm) atmospheric pressure } \\
\text { during the in-vessel release phase }\end{array}$} \\
\hline - for PWRs & 1.12 to 3.92 & uniform \\
\hline - for BWRs & 1.16 to 5.52 & uniform \\
\hline $\begin{array}{l}\Delta \mathrm{T}_{\mathrm{I}}(\mathrm{s})(\mathrm{K}) \text { superheating of the } \\
\text { containment atmosphere during the } \\
\text { in-vessel release phase }\end{array}$ & 1 to 16 & uniform \\
\hline $\begin{array}{l}\mathrm{P}(\mathrm{ex}-\mathrm{vessel})(\mathrm{atm}) \text { pressure in the } \\
\text { containment atmosphere during the } \\
\text { ex-vessel release phase }\end{array}$ & $\mathrm{P}$ (in-vessel) to $\mathrm{P}($ fail) & uniform \\
\hline $\mathbf{P}(\mathrm{fail})(\mathrm{atm})$ containment failure pressure & 8 to 11 & uniform \\
\hline
\end{tabular}


Table 12. Uncertain quantities, range of values and subjective probability distributions (continued)

\begin{tabular}{l} 
Quantity \\
\hline$\Delta \mathrm{T}_{\mathbf{X}}(\mathrm{s})(\mathrm{K})$ atmosphere superheating \\
during the ex-vessel release phase \\
- for PWRs \\
- for BWRs \\
$\mathrm{P(late)} \mathrm{(atms)} \mathrm{pressure} \mathrm{in} \mathrm{the} \mathrm{containme}$ \\
during the late in-vessel release \\
$\Delta \mathrm{T}_{\mathrm{L}}$ (s) (K) atmosphere superheating \\
during the late in-vessel release phase \\
- for PWRs \\
- for BWRs
\end{tabular}

$\Delta \mathbf{P}$ (atms) pressure increase due to the sudden release of steam at the end of the in-vessel release phase

$\Delta \mathrm{Zr}(\mathrm{kg})$ uncertainty in the initial zirconium inventory:

- for PWRs

- for BWRs
Plausible range of values

Probability density function

$\begin{array}{cc}1 \text { to } 21 & \text { uniform } \\ 0 \text { to } 850-T \text { (sat) } & \text { uniform } \\ P(\text { ex-vessel) to } P \text { (fail) } & \text { uniform }\end{array}$

$\Delta \mathrm{T}_{\mathbf{X}}(\mathrm{s})$ to $550-\mathrm{T}$ (sat) uniform

$\Delta \mathrm{T}_{\mathrm{x}}(\mathrm{s})$ to $850-\mathrm{T}$ (sat) uniform

0 to 2

uniform

$6.719 \mathrm{P}(\mathrm{Mw}) \pm 1500 \quad$ uniform

$19.93 \mathrm{P}(\mathrm{Mw}) \pm 3500 \quad$ uniform 
Table 12. Uncertain quantities, range of values and subjective probability distributions (continued)

\begin{tabular}{|c|c|c|}
\hline Quantity & Plausible range of values & Probability density function \\
\hline \multicolumn{3}{|c|}{$\begin{array}{l}\mathrm{Zr}(\mathrm{x})(\mathrm{kg}) \text { : percent of the initial } \\
\text { zirconium metal present at the start of the } \\
\text { ex-vessel release phase: }\end{array}$} \\
\hline - for PWRs & 0 to 60 & uniform \\
\hline - for BWRs & 50 to 80 & uniform \\
\hline \multicolumn{3}{|c|}{$\begin{array}{l}\Delta H(x) \text { : percent of heat generated in core } \\
\text { debris transferred to the concrete during } \\
\text { the ex-vessel release phase: }\end{array}$} \\
\hline - for siliceous concrete & 15 to 30 & uniform \\
\hline - for calcareous concrete & 5 to 20 & uniform \\
\hline \multicolumn{3}{|c|}{$\begin{array}{l}\Delta H(1): \text { percent of heat generated in the } \\
\text { core debris transferred to the concrete } \\
\text { during the late in-vessel release: }\end{array}$} \\
\hline - for siliceous concrete & 35 to 50 & uniform \\
\hline - for calcareous concrete & 25 to 35 & uniform \\
\hline Wt. $\% \mathrm{H}_{2} \mathrm{O}$ in concrete & 5 to 8 & uniform \\
\hline \multicolumn{3}{|l|}{ Wt. $\% \mathrm{CO}_{2}$ in concrete: } \\
\hline - siliceous concrete & 1 to 2 & uniform \\
\hline - calcareous concrete & 13 to 36 & uniform \\
\hline
\end{tabular}




\begin{tabular}{cccc}
\hline Quantity & Plausible range of values & Probability density function \\
\hline$\xi(Q)=$ equilibrium constant for $\mathrm{H}_{2} / \mathrm{H}_{2} \mathrm{O}$ & 1 to 10 & log-uniform
\end{tabular}
ratio

quench temperature $(\mathrm{K})$

percent of heat to concrete surfaces

concrete heat of ablation $(\mathrm{cal} / \mathrm{g})$ :

- siliceous concrete

- calcareous concrete

$\rho$ (gap) $\left(\mathrm{g} / \mathrm{cm}^{3}\right)$ aerosol material density during the gap release phase

$\rho$ (in-vessel) $\left(\mathrm{g} / \mathrm{cm}^{3}\right)$ aerosol material

density during the in-vessel release phase

$\rho$ (ex-vessel) $\mathrm{g} / \mathrm{cm}^{3}$ ) aerosol material density during the ex-vessel release phase

$\rho$ (late in-vessel) $\mathrm{g} / \mathrm{cm}^{3}$ ) aerosol material density during the late in-vessel release phase

$\epsilon(k)$ contact thermal resistence factor

$\epsilon(c)$ coefficient in the collision efficiency expression

$\mathrm{d}(\mathrm{pr})(\boldsymbol{\mu} \mathrm{m})$ diameter of primary particles

A coefficient in the expression for the momentum accommodation coefficient

$\begin{array}{cc}1000 \text { to } 1300 & \text { uniform } \\ 0 \text { to } 20 & \text { uniform }\end{array}$

353 to 523

uniform

535 to 730

uniform

2.8 to 4.5

uniform

3.25 to 10.96

log-uniform

2.9 to 5.65

uniform

2.65 to 3.15

uniform

$10^{-3}$ to 0.5

log-uniform

0.1 to 1.0

$\log$-uniform

0.02 to 0.2

log-uniform

0 to 0.6

uniform 
Table 12. Uncertain quantities, range of values and subjective probability distributions (continued)

\begin{tabular}{|c|c|c|}
\hline Quantity & Plausible range of values & Probability density function \\
\hline $\begin{array}{l}\mathrm{A}^{\prime} \text { coefficient in the expression for the } \\
\text { temperature accommodation coefficient }\end{array}$ & 0 to 0.6 & uniform \\
\hline $\begin{array}{l}\epsilon(t)\left(\mathrm{cm}^{2} / \mathrm{s}^{3}\right) \text { coefficient in the expression } \\
\text { for the turbulent energy dissipation rate }\end{array}$ & 2 to 20 & log-uniform \\
\hline $\begin{array}{l}\mathrm{k}_{\mathrm{p}} \text { (gap) (cal/cm-s-k) thermal conductivity } \\
\text { of aerosol material during gap release } \\
\text { phase }\end{array}$ & 0.023 to 0.0022 & log-uniform \\
\hline $\begin{array}{l}\mathrm{k}_{\mathrm{p}}(\mathrm{in} \text {-vessel) (cal/cm-s-k) thermal } \\
\text { conductivity of aerosol material during the } \\
\text { in-vessel release phase }\end{array}$ & 0.1 to $3 \times 10^{-4}$ & log-uniform \\
\hline $\begin{array}{l}k_{p}(e x-v e s s e l)(\mathrm{cal} / \mathrm{cm}-\mathrm{s}-\mathrm{k}) \text { thermal } \\
\text { conductivity of aerosol material during the } \\
\text { ex-vessel release phase and the late in- } \\
\text { vessel release phase }\end{array}$ & 0.02 to $5 \times 10^{-4}$ & log-uniform \\
\hline $\begin{array}{l}\epsilon(\mathrm{Nu}) \text { uncertain coefficient in the } \\
\text { correlation for the heat transfer coefficient }\end{array}$ & 0.0148 to 0.059 & uniform \\
\hline $\begin{array}{l}\epsilon(\mathrm{Sh}) \text { uncertain coefficient in the } \\
\text { correlation for the mass transfer } \\
\text { coefficient }\end{array}$ & 0.0094 to 0.0376 & uniform \\
\hline $\begin{array}{l}\epsilon(L) \text { uncertain parameter in the definition } \\
\text { of the length scale for natural convection } \\
\text { heat and mass transfer }\end{array}$ & 0.1 to 1.0 & log-uniform \\
\hline $\begin{array}{l}\delta_{\Sigma} \text { coefficient to select the model for the } \\
\text { summation of deposition mechanism }\end{array}$ & 0 to 1 & uniform \\
\hline
\end{tabular}


$\xi(s)$ term to account for the gas/surface potential in the $\mathrm{C}_{\mathrm{s}}$ parameter for thermophoretic deposition

uniform

$\xi(t)$ term to account for the gas/surface potential in the $C_{t}$ parameter for thermophoretic deposition

uniform

$\xi(m)$ term to account for the gas/surface potential in the $C_{m}$ parameter for thermophoretic deposition

0.996 to 1.02

uniform

$\delta(\mathrm{k})$ parameter for selection of the diffusiophoretic scattering kernel
0 to 1
uniform

$\xi\left(U^{*}\right)$ parameter in the definition of the friction velocity 


\section{A. Uncertainty in the Reactor Containment Geometry and Configurations}

Aerosol behavior in a containment depends on the geometry of the containment. The critical features of a containment are:

- volume, $\mathrm{V}$

- floor surface area, $A_{F}$

- downward facing surface area, $A_{D}$, and

- the vertical surface area, $A_{v}$.

The containments of primary interest here are the actual containment buildings for pressurized water reactors and the primary containments, or drywells, of boiling water reactors. These are sufficiently different types of volumes that distinct models are developed for pressurized water reactor containments and for boiling water reactor drywells. Secondary containments for boiling water reactors are sufficiently similar to pressurized water reactor containments that it was felt a distinct model for these secondary containments is not needed.

The variability of reactor containment designs within the two broad categories is indeed well known. The detailed geometry information needed for the analysis of aerosol behavior within these containments is difficult to obtain and would probably reflect greater precision than is possible with simplified models. As a result, the geometric and configuration features of containments are treated in terms of correlations with respect to reactor power.

Volumes of existing pressurized water reactor containments are plotted in Figure 18 against the thermal power of the reactors $[133,134]$. The correlation line in this figure is given by:

$$
V\left(m^{3}\right)=16700( \pm 5500)+16.16( \pm 1.94) P\left(M_{\text {th }}\right)
$$

where

$$
\begin{aligned}
\mathrm{V}\left(\mathrm{m}^{3}\right) & =\text { containment free volume, and } \\
\mathbf{P}\left(\mathrm{MW}_{\mathrm{th}}\right) & =\text { nominal thermal power of the reactor. }
\end{aligned}
$$

Dashed lines shown in the figure nearly bound volumes of existing reactors. Uncertainties in the predictions of containment volume obtained from this correlation in terms of reactor power have a Student's $t$ distribution with $\mathbf{4 0}$ degrees of freedom and a standard error given by: 


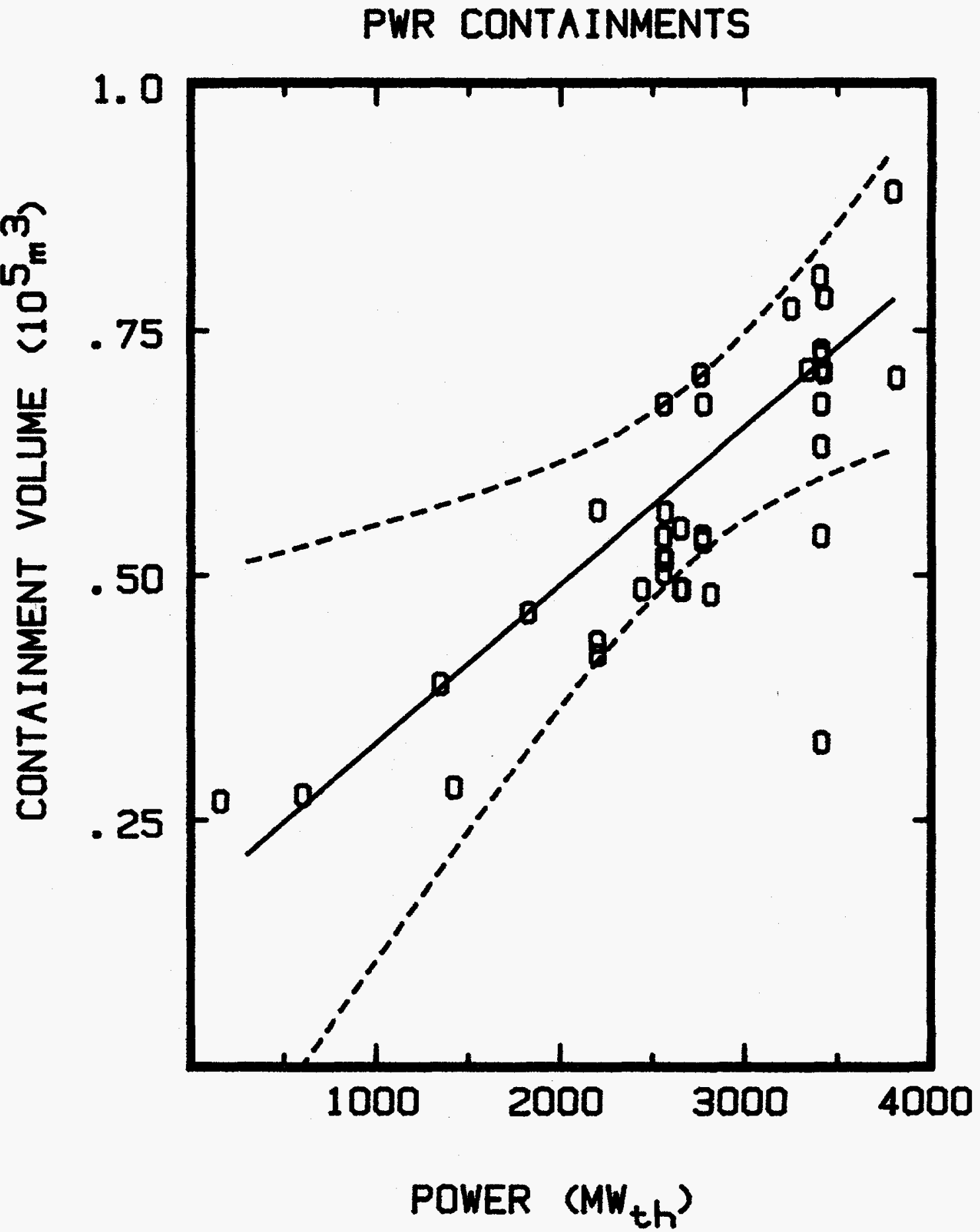

Figure 18. Containment volumes of existing USA pressurized water reactors plotted against the nominal thermal power of the reactors. The solid line is the linear correlation of volume with thermal power. The 90 percent confidence interval is demarked by dashed lines. 


$$
\mathrm{se}=35000\left[\frac{1}{42}+\frac{(\mathrm{P}(\mathrm{MW})-2750)^{2}}{2.58 \times 10^{7}}\right]^{1 / 2}
$$

where $P(M W)$ is the selected reactor thermal power in megaWatts.

Data for the largest and smallest containments shown in the figure are:

\begin{tabular}{cccc}
$\begin{array}{c}\text { Volume } \\
\left(\mathrm{m}^{3}\right)\end{array}$ & $\begin{array}{c}\text { Floor area } \\
\left(\mathrm{m}^{2}\right)\end{array}$ & $\begin{array}{c}\text { Effective } \\
\text { fall height } \\
(\mathrm{m})\end{array}$ & $\begin{array}{c}\frac{\text { Surface }}{\text { volume }} \\
\left(\mathrm{m}^{-1}\right)\end{array}$ \\
\cline { 2 - 3 } & 1330 & 77 & 0.128 \\
$2.02 \times 10^{5}$ & 804 & 35 & 0.173
\end{tabular}

The "effective fall height" listed above is simply the volume divided by the floor area. It is a parameter that enters into the correlation model of aerosol behavior described in Chapter IV. The surface-tovolume ratio listed above is the internal surface of the containment envelope divided by the containment volume. These limiting values were used to obtain the expressions for other geometrical features of pressurized water reactor containments shown below:

1. The upward facing floor area is taken to be:

$$
A_{F}\left(m^{2}\right)=419+0.417 V\left(m^{3}\right)^{2 / 3} \pm 25 \text { percent }
$$

2. The downward facing surface area, $A_{D}$, is taken to be equal to $A_{F}$,

3. The envelope surface area-to-volume ratio $\left(\mathrm{A}_{\mathrm{E}} / \mathrm{V}\right)$ is taken to be uniformly distributed over the interval of 0.128 to 0.173 .

4. The vertical surface area, $A_{V}$, found from the envelope surface area, $A_{E}$ :

$$
\left(A_{E}-2 A_{F}\right)(1+\epsilon(A))=A_{v}
$$

The parameter $\epsilon(\mathrm{A})$ is introduced to account for the surface areas of structures within the reactor containment. The parameter is taken here to be uncertain and to be log-uniformly distributed over the interval of 0.2 to 2 .

Volumes of the drywells in existing USA boiling water reactors are plotted in Figure 19 against the nominal thermal power of the reactors [133,134]. The correlation line in this figure is given by:

$$
\mathrm{V}\left(\mathrm{m}^{3}\right)=1440( \pm 910)+1.42( \pm 0.32) \mathrm{P}\left(\mathrm{MW}_{\mathrm{th}}\right)
$$




\section{BWR DRYWELLS}

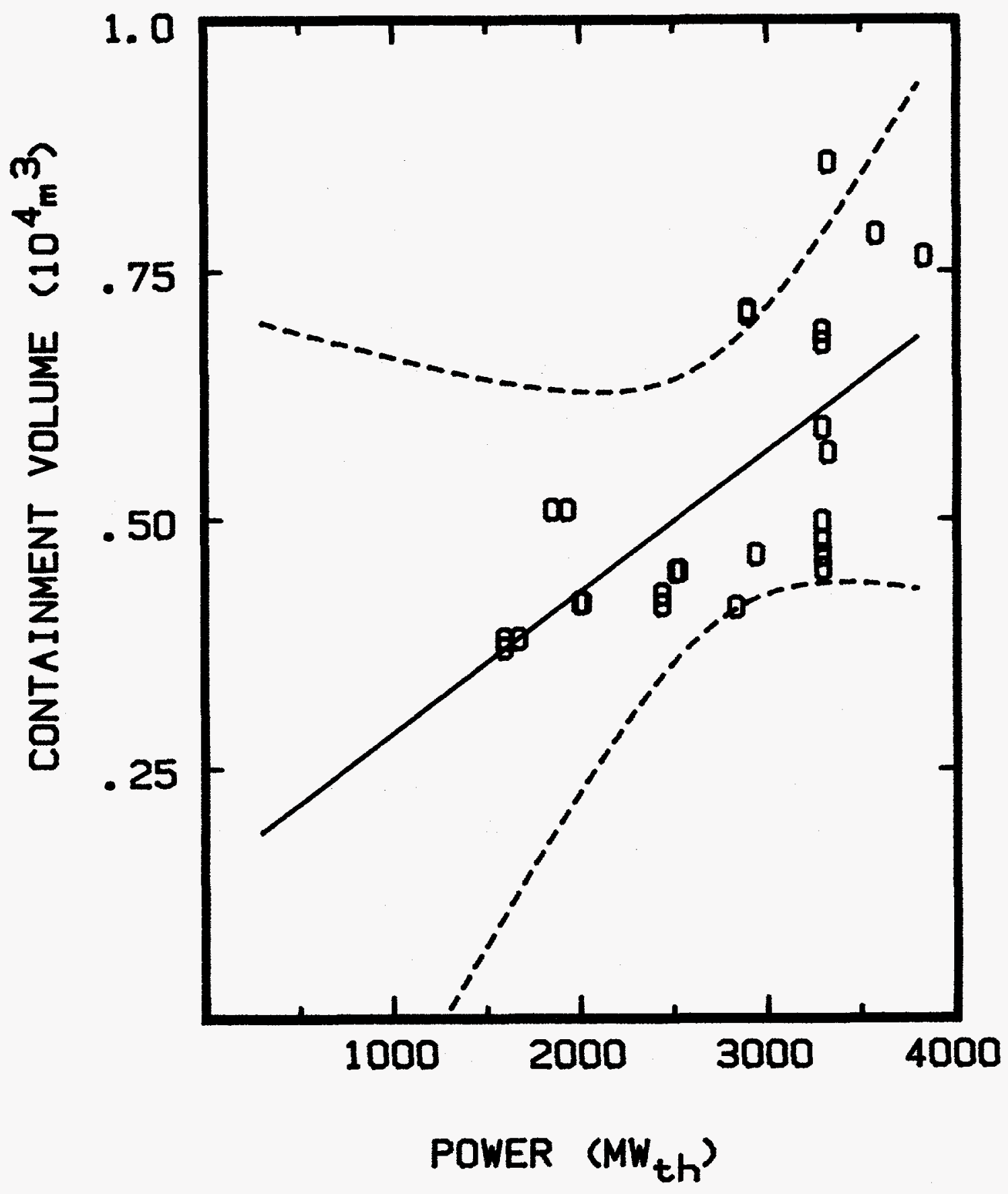

Figure 19. Drywell volumes of existing USA boiling water reactors plotted against the nominal thermal power of the reactor. The solid line is the linear correlation of volume with thermal power. The 90 percent confidence limits are demarked by dashed lines. 
Uncertainties in predictions obtained from this correlation have a Student's t distribution with 24 degrees of freedom and a standard error given by:

$$
\text { se }=40000\left[\frac{1}{26}+\frac{\left(\mathrm{P}\left(\mathrm{MW}_{\mathrm{th}}\right)-2739\right)^{2}}{1.14 \times 10^{7}}\right]^{1 / 2}
$$

Some data for drywells of three types of boiling water reactors are listed below:

\begin{tabular}{|c|c|c|c|c|}
\hline Type & $\begin{array}{c}\text { Volume } \\
\left(\mathrm{m}^{3}\right) \\
\end{array}$ & $\begin{array}{l}\text { Floor Area } \\
\left(\mathrm{m}^{2}\right) \\
\end{array}$ & $\begin{array}{c}\text { Effective } \\
\text { Fall Height } \\
\text { (m) }\end{array}$ & $\begin{array}{l}\text { Surface } \\
\text { Volume } \\
\left(\mathrm{m}^{-1}\right) \\
\end{array}$ \\
\hline $\begin{array}{l}\text { Peach Bottom } \\
\text { (Mark I BWR) }\end{array}$ & $4.5 \times 10^{3}$ & 152 & 30 & 0.36 \\
\hline $\begin{array}{l}\text { LaSalle } \\
\text { (Mark II BWR) }\end{array}$ & $6.5 \times 10^{3}$ & 499 & 13 & 0.31 \\
\hline $\begin{array}{l}\text { Grand Gulf } \\
\text { (Mark III BWR) }\end{array}$ & $7.65 \times 10^{3}$ & 371 & 21 & 0.28 \\
\hline
\end{tabular}

From these data, correlations for other geometrical features of drywells were derived in manners similar to those used to develop correlations for features of pressurized water reactor containments:

$$
\begin{gathered}
A_{F}\left(m^{2}\right)=-415+2.25 V\left(m^{3}\right)^{2 / 3} \pm 25 \text { percent } \\
A_{D}=A_{F} \\
\frac{A_{E}}{V}=0.469-2.43 \times 10^{-5} V\left(m^{3}\right) \pm 0.0225 \\
A_{v}=\left(A_{E}-2 A_{F}\right)(1+\epsilon(A))
\end{gathered}
$$

As an accident progresses from the in-vessel release phase to the ex-vessel release phase, the reactor coolant system is penetrated by core debris. This rupture of the reactor coolant system at the start of the ex-vessel interaction opens additional volume. The NUREG-1465 source term specifies, however, that revaporization which gives rise to the late in-vessel release also starts at this time. There must, then, be a flow from the reactor coolant system into the greater containment volume that will prevent 
aerosols in the containment from mixing into this increment in volume. At the conclusion of the invessel release, mixing into this reactor coolant system might be possible, but this possibility is neglected in the calculations described in Chapter V.

Surface areas available for particle deposition, heat transfer and steam condensation change over the course of a severe reactor accident. The most profound change occurs when core debris is expelled from the reactor vessel and can interact with concrete. The surface area covered by this expelled core debris will no longer act as a heat sink. It will instead be a heat source. It is unlikely that water will condense on this surface. Furthermore, gases produced by decomposition of concrete below the core debris will sparge through the core debris and impede, if not completely prevent, aerosol deposition on the core debris.

Radiant and convective heat transfer from the core debris will raise the temperatures of surrounding surfaces perhaps to melting. Certainly, many of these adjacent surfaces will become hot enough that they too will not act as important sites of steam condensation or aerosol deposition.

To account for the changes in surface areas available for heat transfer, condensation and particle deposition, the surface areas are changed at the start of the ex-vessel release phase of an accident. The floor area is reduced by a factor uniformly distributed over the range 0 to 50 percent. The vertical surface area is reduced by a factor uniformly distributed over the range of 0 to 30 percent. The reduction factors for the floor and vertical surfaces are completely correlated. That is, when a 90th percentile value of the reduction factor for floor area is selected, a 90 th percentile value for the vertical surface reduction factor is also selected. When these changes in the surface are made, the effective height of the containment or drywell is not changed.

\section{B. Uncertainties in Accident Progression}

In the subsections below, uncertainties in the progression of a severe reactor accident that are expected to have major effects on the predicted behavior of aerosols in containment are described.

\section{Treatment of Accident Timing}

The four phases of a severe accident defined in the revised severe accident source term are treated as though they were not uncertain. This was done simply to make the simplified models easier to use in conjunction with the revised source term [1]. In fact, the simplified model developed in Chapter VI is a convenient tool for exploring the effects of differences in the timing of various phases of reactor accidents.

The time after scram when radionuclide release begins was considered to be uncertain. This time for the start of release to the containment affects the amount of decay heat that must be dissipated when aerosols are present in the containment atmosphere. This, in turn, affects some of the deposition mechanisms-notably deposition by thermophoresis and by diffusiophoresis. 
Decay heat rates are calculated from:

$$
\frac{P(t)}{P\left(M W_{t h}\right)}= \begin{cases}0.130\left(t_{o}+t\right)^{-0.283} & \text { for } 150<t+t_{o} \leq 4 \times 10^{6} \\ 0.266\left(t_{o}+t\right)^{-0.335} & \text { for } 4 \times 10^{6}<t+t_{o} \leq 2 \times 10^{8}\end{cases}
$$

where

$$
\begin{aligned}
P(t) & =\text { decay power }(M W) \text { at } t+t_{0} \\
P\left(M W_{t h}\right) & =\text { nominal operating thermal power of the reactor }(M W), \\
t_{0} & =\text { time (s) after shutdown when gap release begins, and } \\
t & =\text { time (s) from the start of gap release. }
\end{aligned}
$$

The time after reactor scram at which gap release begins, $t_{0}$, is uncertain. Inspection of a variety of severe reactor accident analyses [101-107] shows that $t_{o}$ can be as short as 1980 seconds. For some station blackout accidents where battery power is available, $\mathrm{t}_{\mathrm{o}}$ may be as long as about 8 hours = 28,800 seconds. There is, however, a substantial and increasing probability that power will be recovered in long duration station blackout accidents. Further, very short intervals between reactor shutdown and the start of gap release are characteristic of accidents involving large breaks in the reactor coolant system which have low probabilities. Consequently, $t_{0}$ is assumed to be given by

$$
t_{o}=1980+\Delta t
$$

where $\Delta t$ is an uncertain parameter having a lognormal uncertainty distribution with a mean of 3600 seconds and a geometric standard deviation of 1.3. Note in the discussions of results in subsequent chapters, time is referenced to the start of gap release. That is, reactor scram is taken to occur at $-t_{0}$.

\section{Uncertainty in Chemical Forms of Radionuclides Released to the Containment}

Release fractions listed in Table 1 are considered to be known exactly. This was done to facilitate use of the simplified aerosol behavior model with the proposed revision to the severe accident source term [1]. Radionuclide inventories for pressurized water reactors and boiling water reactors are taken to be strictly proportional to the nominal thermal power of the reactor. Inventories listed in Table 2 are multiplied by $\mathrm{P}\left(\mathrm{MW}_{\mathrm{th}}\right) / 3412$ for pressurized water reactors and by $\mathrm{P}\left(\mathrm{MW}_{\mathrm{th}}\right) / 3578$ for boiling water reactors.

Radionuclide inventories are listed in Table 2 in elemental form. Most of the radionuclides released into the containment will not be in elemental form. As discussed at several junctures above in Chapter II, there is a great deal of uncertainty about the exact chemical forms radionuclides will assume. Chemical form needs to be known at least in a broad sense because the aerosol equations described in Chapter II deal with mass (or volume). Chemical forms that radionuclides might adopt in the containment are quite varied. Cesium, for instance, is often thought to be present in the containment as cesium 
hydroxide, $\mathrm{CsOH}$. But, $\mathrm{CsOH}$ is quite a reactive material. Before it even reaches the containment, any cesium hydroxide is quite likely to react to form such species as $\mathrm{Cs}_{2} \mathrm{MoO}_{4}, \mathrm{Cs}_{2} \mathrm{UO}_{4}, \mathrm{CsBO}_{2}$ etc. If $\mathrm{CsOH}$ does reach the containment atmosphere, it is very likely to react with $\mathrm{CO}_{2}$ in the atmosphere to form $\mathrm{Cs}_{2} \mathrm{CO}_{3}$ (or, equivalently, $\mathrm{Cs}\left(\mathrm{CO}_{3}\right)_{1 / 2}$ ) or $\mathrm{CsHCO}_{3}$.

For the proper accounting of the mass of radionuclides released to the containment atmosphere, it is only necessary to consider reactions that amount to reactions with gases such as:

$$
\begin{gathered}
\mathrm{Cs}+\mathrm{H}_{2} \mathrm{O} \rightarrow \mathrm{CsOH}+1 / 2 \mathrm{H}_{2} \\
\mathrm{Cs}+1 / 2 \mathrm{H}_{2} \mathrm{O} \rightarrow \mathrm{CsO}_{0.5}+1 / 2 \mathrm{H}_{2} \\
2 \mathrm{Cs}+\mathrm{H}_{2} \mathrm{O}+\mathrm{CO}_{2} \rightarrow \mathrm{Cs}_{2} \mathrm{CO}_{3}+\mathrm{H}_{2}
\end{gathered}
$$

If species are expected to form intermetallic compounds, such as $\mathrm{SnTe}$, or compound oxides, such as $\mathrm{CsBO}_{2}$, the metallic portion of the compound is accounted for in the nonradioactive aerosol mass released to the containment. (This nonradioactive aerosol mass is discussed further in the subsection immediately below). Thus, for mass-accounting purposes, tellurium in the containment as tin telluride (SnTe) would be considered to have been released to the containment as Te and its mass would be the elemental mass. On the other hand, tellurium released to the containment as $\mathrm{TeO}_{2}$ would have to be treated as having a mass 1.25 times the elemental mass. Similarly, iodine released to the containment as CsI, AgI or $\mathrm{CdI}_{2}$ would have a mass equal to its elemental mass. But, iodine released to the containment as $\mathrm{CsIO}_{3}$ would be considered present as $\mathrm{IO}_{3}^{-}$and the mass would be 1.38 times the elemental mass.

To account for the uncertain chemical form of radionuclides, some possible limiting chemical forms were hypothesized. Mass multipliers for these possible limiting forms were calculated. Results are shown in Table 13. The actual mass multipliers for each class of radionuclide are assumed to be uniformly distributed over the range indicated in the table.

\section{Uncertainties in Nonradioactive Aerosol Masses Released to the Containment}

Helton et al. [27-29] have conducted detailed, quantitative sensitivity analyses of the predictions made by the MAEROS model of aerosol behavior in the reactor containment. These investigators considered the effects of a second aerosol being injected into an atmosphere burdened with a pre-existing aerosol. The analyses were done using a Latin Hypercube random sampling of uncertain parameters. Results were analyzed using regression analyses to determine the relative importance of the various uncertainties. These analyses did not consider the effects of water condensation and diffusiophoresis, but did consider many of the other phenomenological uncertainties described above in Chapter II.

Helton et al. distinguished between the factors that most affected the airborne concentrations of the pre-existing aerosol and factors that affected the airborne concentration of the second aerosol. They found that the relative importance of quantities considered in their calculations varied over the period of aerosol deposition. Initially, the airborne concentration of the pre-existing aerosol depended most on: 
Table 13. Mass multipliers for radionuclides released to the containment

\begin{tabular}{ccc}
\hline Radionuclide & $\begin{array}{c}\text { Possible chemical } \\
\text { forms }\end{array}$ & $\begin{array}{c}\text { Range of } \\
\text { mass multipliers }\end{array}$ \\
\hline $\mathrm{I}$ & $\mathrm{I}^{-}\left(\right.$as $\mathrm{CsI}$ or $\left.\mathrm{CdI}_{2}\right) ; \mathrm{IO}_{3}^{-}$ & 1.0 to 1.38 \\
$\mathrm{Cs}$ & $\mathrm{CsO}_{0.5} ; \mathrm{Cs}\left(\mathrm{CO}_{3}\right)_{0.5}$ & 1.05 to 1.22 \\
$\mathrm{Te}$ & $\mathrm{Te} ; \mathrm{TeO}_{2}$ & 1.0 to 1.25 \\
$\mathrm{Sr}$ & $\mathrm{SrO} ; \mathrm{SrCO}_{3}$ & 1.18 to 1.67 \\
$\mathrm{Ba}$ & $\mathrm{BaO} ; \mathrm{BaCO}_{3}$ & 1.11 to 1.43 \\
$\mathrm{Ru}$ & $\mathrm{Ru} ; \mathrm{RuO}_{3}$ & 1.0 to 1.47 \\
$\mathrm{Ce}$ & $\mathrm{CeO}$ & $1.5 ; \mathrm{CeO}_{2}$ \\
$\mathrm{La}$ & $\mathrm{LaO} ; \mathrm{LaO}_{1.5}$ & 1.11 to 1.22 \\
\hline
\end{tabular}

- the collision shape factor of the aerosol, and

- the mass rate at which the second aerosol was injected into the containment atmosphere.

As the suspended mass of the pre-existing aerosol was depleted, its initial concentration became of much less importance. The rate and duration of injection of the second aerosol were found to be important, as were factors that affected aerosol coagulation such as aerosol density, turbulent energy dissipation rates, and the collision shape factor of the aerosol particle.

The airborne concentration of the second aerosol depended most, of course, on the rate and duration of injection into the containment atmosphere. It also depended on the turbulent energy dissipation rate and both the collision and dynamic shape factors.

Results obtained by Helton et al. draw attention to the nonradioactive aerosol masses hypothesized to accompany radionuclide releases during the in-vessel and ex-vessel stages of the reactor accident. From the results obtained by Helton et al., it is evident that these nonradioactive aerosol masses will have important effects on both pre-existing radioactive aerosols suspended in the containment atmosphere and the airborne concentrations of the radioactive aerosols they accompany into the containment atmosphere.

Though the nonradioactive masses are described in the proposed revision to the severe accident source term, they are presented more as examples than prescriptions [1]. Since past studies show these nonradioactive materials to be of substantial importance to predictions of aerosol behavior, they are treated here as uncertainties. They are considered uncertain because of uncertainties in the models used to predict nonradioactive aerosol production that are the bases of the proposed revision to the severe accident source term. For instance, the data base for the models of nonradioactive material release 
during the gap release and in-vessel release phases of an accident is not as extensive as the data bases for releases of the volatile radionuclides $[135,136]$. It is, then, not certain that there should be no nonradioactive mass accompanying the gap release of radionuclides as is indicated in the revised severe accident source term. The model of aerosol generation during the ex-vessel release phase predicts that the generation of nonradioactive aerosol depends rather strongly on the type of concrete and the amount of zirconium metal in the core debris [137]. The magnitude of nonradioactive aerosol mass generation may vary substantially from the magnitude cited as an example in NUREG-1465.

To account for the uncertainties in the production of nonradioactive aerosol mass, the following steps were taken:

\section{a. Nonradioactive Aerosol Mass During Gap Release, $\epsilon(m$, gap)}

Nonradioactive aerosols in the form of cadmium from control rods or boron oxide vaporized from surfaces in the reactor coolant system may accompany radioactive aerosol produced during the gap release phase of an accident. This mass of nonradioactive material was taken to be uncertain over the range of 0.01 to 1.0 times the mass of radioactive material released during the gap release phase of an accident. Values of this multiplicative factor were taken to be distributed log-uniformly within this range.

\section{b. Nonradioactive Aerosol Mass During the In-Vessel Release Phase, $\epsilon(\mathrm{m}$, in-vessel)}

The nonradioactive mass described in Reference 1 for the in-vessel phase of an accident was taken to be uncertain by a factor of 2 . That is, the actual nonradioactive aerosol mass could be between 0.5 and 2.0 times that indicated in Reference 1. Values within this range were taken to be uniformly distributed.

\section{c. Nonradioactive Aerosol Mass During the Ex-Vessel Release Phase, $\epsilon(\mathrm{m}, \mathbf{x})$}

Nonradioactive aerosol masses during the ex-vessel release phase of an accident are expected to be large. Releases cited in Reference 1 are very nearly upper bounds on predictions for reactor accidents reported in References 101-107. The uncertainty range defined to account for differences in concrete type, zirconium metal content of the core debris, as well as uncertainties concerning the aerosol production processes is defined here to be 0.1 to 1.2 times the nonradioactive aerosol mass defined in Reference 1 . Values were taken to be log-uniformly distributed over this range.

\section{d. Nonradioactive Aerosol Mass During the Late In-vessel Release Phase, $\stackrel{\circ}{\text { (late) }}$}

No nonradioactive mass is indicated in the revised severe accident source term to accompany radioactive aerosol releases to the containment during the late in-vessel release phase [1]. But, surely there will be some. Again, cadmium, indium, and boric acid at the least will be released by revaporization from the reactor coolant system. A more important source of nonradioactive materials during the late in-vessel release phase will be the continued interaction of core debris with concrete. Experiments [138] and analyses [101-107] show that aerosols continue to be produced by such interactions even after the core debris has begun to solidify. Of course, it is possible that by the late stage of an accident, water has covered the core debris interacting with concrete, and that this water scrubs aerosols from gases produced by interactions with concrete. Consequently, an uncertainty range of 0.1 to $10 \mathrm{~g} / \mathrm{s}$ is defined 
for the rate of nonradioactive aerosols generation during the late in-vessel phase of an accident. Values within this range are taken to be log-uniformly distributed.

\section{e. Nonradioactive Aerosol Mass Very Late in a Reactor Accident-1, $\mathbf{m}$ (very late)}

At the conclusion of the late in-vessel release phase, no more radioactive aerosol is released to the reactor containment. There can still, however, be production of nonradioactive aerosol. Again, the interactions of core debris with concrete even if the core debris is solidified is the cause of this long-term release of nonradioactive aerosols. To account for this possibility, a nonradioactive aerosol source term is defined here for the indeterminant stage of the accident after completion of the late in-vessel release phase. The magnitude of aerosol generation is taken to be log-uniformly distributed over the range from $10^{-4}$ to $1.0 \mathrm{~g} / \mathrm{s}$. The value is, however, correlated with the value of nonradioactive aerosol mass production during the late in-vessel phase of the accident. The correlation is taken to be that aerosol generation rates during the very late phase of an accident are less than or equal to the rates of nonradioactive aerosol generation during the late in-vessel release phase.

\section{Uncertainties in Pressure and Temperature}

The simplified models developed here may be used to estimate aerosol behavior in:

- the containment buildings of large dry containment and subatmospheric containment pressurized water reactors,

- drywells of boiling water reactors,

- secondary containments of boiling water reactors, and

- upper and lower volumes of ice condenser containment buildings.

Each specific accident sequence produces different conditions of pressure and temperature in these various volumes. Examples of the pressure and temperature conditions are shown for a variety of accident sequences in tables below (Tables 14, 15 and 16). These results have been obtained from calculations done with the Source Term Code Package [11] and used in the analyses done for NUREG-1150. Undoubtedly, other accident analysis models would produce somewhat different results for specific accidents. It is, however, not likely that results obtained with other codes would be outside the ranges of pressure and temperature shown in the tables*

Note that brief temperature and pressure excursions caused by hydrogen combustion events and rupture of pressurized reactor vessels have been neglected in assembling the tables. Note also that the accidents listed in the tables do not represent a complete cross-section of possible severe accidents. The analyses that have been documented to date are, undoubtedly, biased toward accidents that make the biggest contributions to risk.

\footnotetext{
*The authors wish to acknowledge the excellent documentation of accident analyses by the authors of References 101 to 107 and to thank them, especially, for inclusion of well defined tabular results.
} 
Table 14. Pressure, temperatures, and steam condensation rates during the gap release phase of severe accidents

\begin{tabular}{|c|c|c|c|c|c|}
\hline $\begin{array}{l}\text { Reactor } \\
\text { (Ref.) }\end{array}$ & $\begin{array}{c}\text { Volume } \\
\text { type }\end{array}$ & Accident & $\begin{array}{c}\text { Pressure range } \\
\text { (atm) }\end{array}$ & $\begin{array}{c}\text { Temperature range } \\
(\mathbf{K})\end{array}$ & $\begin{array}{c}\text { Steam condensation } \\
(\mathrm{g} / \mathrm{s})\end{array}$ \\
\hline Surry (101) & $\begin{array}{l}\text { Subatmospheric } \\
\text { containment }\end{array}$ & TMLB'- $\epsilon$ & $1.96-1.75$ & $377-371$ & $18901-7522$ \\
\hline (101) & & $S_{2} D-\epsilon$ & $1.32-0.92$ & $357-325$ & $6227-0$ \\
\hline (101) & & $S_{2-\gamma}$ & $1.32-0.92$ & $357-326$ & $6235-0$ \\
\hline (101) & & AB- $\epsilon$ & $2.73-2.42$ & $392-386$ & $29344-13597$ \\
\hline (102) & & $S_{3} B$ & $1.34-1.52$ & $358-368$ & $10306-14694$ \\
\hline Zion (103) & $\begin{array}{l}\text { Large, dry } \\
\text { containment }\end{array}$ & $\mathrm{S}_{2} \mathrm{D} \mathrm{Cr}$ & $1.51-1.44$ & $352-349$ & $3367-1808$ \\
\hline (103) & & $\mathrm{S}_{2} \mathrm{DCFI}$ & $2.21-2.46$ & $377-383$ & $8043-5720$ \\
\hline (103) & & TMLU & $1.28-1.12$ & $338-324$ & $0-227$ \\
\hline (104) & & TMLB' & $2.79-2.74$ & 388 & $13953-8066$ \\
\hline (104) & & $S_{2} D$ & 1.41 & $349-345$ & $2898-885$ \\
\hline Sequoyah (102) & $\begin{array}{l}\text { Ice condenser } \\
\text { lower compartment }\end{array}$ & $\mathbf{S}_{3} B$ & 1.45 & $385-389$ & $3420-1324$ \\
\hline$(102)$ & & $\mathbf{S}_{\mathbf{3}} \mathrm{HF}$ & 1.16 & $331-334$ & $257-60$ \\
\hline (105) & & TMLB' $-\gamma$ & 1.52 & $385-382$ & $6485-4431$ \\
\hline (105) & & TML- $\gamma$ & $1.32-1.17$ & $369-341$ & $4101-0$ \\
\hline
\end{tabular}


Table 14. Pressure, temperatures, and steam condensation rates during the gap release phase of severe accidents (concluded)

\begin{tabular}{|c|c|c|c|c|c|}
\hline $\begin{array}{l}\text { Reactor } \\
\text { (Ref.) }\end{array}$ & $\begin{array}{l}\text { Volume } \\
\text { type }\end{array}$ & Accident & $\begin{array}{c}\text { Pressure range } \\
\text { (atm) }\end{array}$ & $\begin{array}{c}\text { Temperature range } \\
(\mathbf{K})\end{array}$ & $\begin{array}{c}\text { Steam condensation } \\
(\mathrm{g} / \mathrm{s})\end{array}$ \\
\hline Sequoyah (102) & $\begin{array}{c}\text { Ice condenser } \\
\text { upper compartment }\end{array}$ & $\mathrm{S}_{3} \mathrm{~B}$ & 1.45 & 313 & $0-7.6$ \\
\hline (102) & & $\mathrm{S}_{3} \mathrm{HF}$ & 1.16 & 313 & 0 \\
\hline (105) & & TMLB' $-\gamma$ & 1.52 & $323-317$ & 0 \\
\hline (105) & & TML- $\gamma$ & $1.32-1.17$ & 312 & 15 \\
\hline $\begin{array}{l}\text { Peach Bottom } \\
\text { (102) }\end{array}$ & Mark I Drywell & TBUX & 1.16 & 311 & $15-38$ \\
\hline (106) & & $\mathrm{TC} 2$ & 2.06 & $346-343$ & $5387-1400$ \\
\hline (106) & & TB1 & $1.69-1.86$ & $329-338$ & $514-416$ \\
\hline (106) & & TB2 & $1.66-1.81$ & $325-334$ & 291 \\
\hline Grand Gulf (107) & Mark III Drywell & TB1 & $1.97-2.06$ & $338-337$ & $0-348$ \\
\hline (107) & & TBS/TBR & $1.18-1.28$ & 340 & 295 \\
\hline
\end{tabular}


Table 15. Pressure, temperatures, and steam condensation rates during the in-vessel release phase of severe accidents

\begin{tabular}{lc}
\hline $\begin{array}{l}\text { Reactor } \\
\text { (Ref.) }\end{array}$ & \multicolumn{1}{c}{$\begin{array}{c}\text { Volume } \\
\text { type }\end{array}$} \\
\hline Surry (101) & $\begin{array}{c}\text { Subatmospheric } \\
\text { containment }\end{array}$ \\
$(101)$ & \\
$(101)$ & \\
$(101)$ & \\
$(107)$ & \\
Zion (103) & \\
$(103)$ & Large, dry \\
$(103)$ & containment \\
$(104)$ & \\
$(104)$ &
\end{tabular}

Sequoyah (102) Ice condenser low compartment

$\mathrm{S}_{3} \mathrm{HF}$

TMLB' $-\gamma$
TML- $\gamma$
TML- $\delta$

$S_{2} D-\epsilon$
$S_{2} D-\gamma$
$A B-\epsilon$
$S_{3} B$

$\mathrm{S}_{2} \mathrm{D} \mathrm{Cr}$

$S_{2} D$ CFI
TMLU
TMLB'
$S_{2} D$

$$
\mathrm{S}_{3} \mathrm{~B}
$$

1.56

$$
\begin{gathered}
1.16-1.36 \\
1.46 \\
1.16-1.39 \\
1.32-1.18
\end{gathered}
$$

Temperature range Steam condensation $(\mathrm{g} / \mathrm{s})$

$5176-10427$

$365-396$

$328-335$
$328-358$
$394-369$
$368-373$

$346-362$

$362-394$

$324-374$

$383-403$

$342-356$

$389-427$

$334-382$

$382-387$

$335-368$

$369-341$

$$
\begin{gathered}
204-2686 \\
182-1362 \\
0-13567 \\
14694-5925
\end{gathered}
$$

$734-17426$

2436 - 2966

$0-6159$

8066 - 5433

$696-2315$

0 - 1324

$60-0$

4131 - 0

0 - 2520

4101 - 0 
Table 15. Pressure, temperatures, and steam condensation rates during the in-vessel phase of severe accidents (concluded)

\begin{tabular}{|c|c|c|c|c|c|}
\hline $\begin{array}{l}\text { Reactor } \\
\text { (Ref.) }\end{array}$ & $\begin{array}{c}\text { Volume } \\
\text { type }\end{array}$ & Accident & $\begin{array}{c}\text { Pressure range } \\
\text { (atm) }\end{array}$ & $\begin{array}{c}\text { Temperature range } \\
(\mathbf{K})\end{array}$ & $\begin{array}{c}\text { Steam condensation } \\
(\mathrm{g} / \mathrm{s})\end{array}$ \\
\hline Sequoyah (102) & $\begin{array}{l}\text { Ice condenser } \\
\text { upper compartment }\end{array}$ & $S_{3} B$ & 1.56 & $314-319$ & $0-7$ \\
\hline (102) & & $\mathrm{S}_{3} \mathrm{HF}$ & $1.16-1.36$ & $314-316$ & 0 \\
\hline (105) & & TMLB' $-\gamma$ & 1.46 & $323-317$ & 0 \\
\hline (105) & & TML- $\gamma$ & $1.16-1.39$ & 312 & 0 \\
\hline (105) & & TML- $\delta$ & $1.32-1.18$ & 312 & 15 \\
\hline $\begin{array}{l}\text { Peach Bottom } \\
\text { (102) }\end{array}$ & $\begin{array}{l}\text { Mark I BWR } \\
\text { Drywell }\end{array}$ & TBUX & $1.16-2.65$ & $312-327$ & $0-204$ \\
\hline (106) & & TC2 & $2.05-5.52$ & $343-370$ & $4646-0$ \\
\hline (106) & & TC3 & $2.05-5.22$ & $343-373$ & $4640-0$ \\
\hline (106) & & TB1 & $1.86-3.52$ & $341-364$ & $325-1867$ \\
\hline (106) & & TB2 & $1.66-3.51$ & $334-363$ & $98-257$ \\
\hline Grand Gulf (107) & Mark III Drywell & TB1 & $2.06-3.25$ & $337-407$ & $1120-0$ \\
\hline (107) & & TBS/TBR & $1.28-1.88$ & 340 & $182-7460$ \\
\hline
\end{tabular}


Table 16. Pressure, temperatures, and steam condensation rates during the ex-vessel and late in-vessel phases of severe accidents

\begin{tabular}{|c|c|c|c|c|c|}
\hline $\begin{array}{l}\text { Reactor } \\
\text { (Ref.) }\end{array}$ & $\begin{array}{l}\text { Volume } \\
\text { type }\end{array}$ & Accident & $\begin{array}{c}\text { Pressure range } \\
\text { (atm) }\end{array}$ & $\begin{array}{c}\text { Temperature range } \\
(\mathrm{K})\end{array}$ & $\begin{array}{c}\text { Steam condensation } \\
(\mathbf{g} / \mathbf{s})\end{array}$ \\
\hline Surry (101) & $\begin{array}{l}\text { Subatmospheric } \\
\text { containment }\end{array}$ & TMLB- $\epsilon$ & $3.13-3.65$ & 396 & $4941-0$ \\
\hline$(101)$ & & $S_{2} D-\epsilon$ & 0.93 & $334-328$ & $0-91$ \\
\hline$(101)$ & & $\mathrm{AB}-\epsilon$ & $2.31-3.12$ & $369-388$ & 0 \\
\hline Zion (103) & $\begin{array}{l}\text { Large, dry } \\
\text { containment }\end{array}$ & $\mathrm{S}_{2} \mathrm{D} C F 2$ & $3.27-10.1$ & $394-445$ & $26839-2618$ \\
\hline (104) & & TMLB' & $6.47-7.76$ & $426-456$ & 0 \\
\hline (104) & & $\mathrm{S}_{2} \mathrm{D}$ & $1.53-1.73$ & $340-356$ & 325 \\
\hline $\begin{array}{l}\text { Peach Bottom } \\
(102)\end{array}$ & $\begin{array}{l}\text { Mark I BWR } \\
\text { drywell }\end{array}$ & TBUX & $5.71-11.8$ & $427-850$ & 0 \\
\hline$(106)$ & & TC3 & 1.71 & 384 & 832 \\
\hline$(106)$ & & TB1 & $8.11-9.03$ & $437-531$ & 0 \\
\hline Grand Gulf (107) & Mark III BWR & TB1 & $3.40-4.83$ & $413-432$ & $39067-0$ \\
\hline (107) & & TB2 & $4.42-4.83$ & $415-417$ & $53996-0$ \\
\hline
\end{tabular}


For the purpose of uncertainty analyses, containment temperatures and pressures during the four release phases of a severe reactor accident are taken to have distinct, constant values. These constant values were taken to be uncertain as described below.

\section{a. Gap Release Phase}

The atmospheric pressure in both pressurized water reactor containments and boiling water reactor drywells during the gap release phase is uniformly distributed over the range of 1.16 to $2.79 \mathrm{~atm}$. The atmosphere pressurized water reactor containments is taken to be composed of air and steam. The temperature is chosen such that the atmosphere is saturated in steam. The atmospheres of the boiling water reactor drywells are assumed to be 100 percent steam at the start of the gap release phase of the accident.

\section{b. In-Vessel Release Phase}

The atmospheric pressure is uniformly distributed over the range of 1.12 to $3.92 \mathrm{~atm}$ in the case of pressurized water reactor containments. In the case of boiling water reactor drywells, the pressure range is 1.16 to 5.52 atmospheres. It might be presumed that there should be some correlation between the atmosphere pressure during the in-vessel release phase and the pressure during the gap release phase. Accident analyses show (see Table 15), however, that this correlation is not strong, if it exists at all. Here, it is assumed that there is no correlation.

The atmosphere is considered to consist of steam, air, and hydrogen produced by metal/water reactions during core degradation. The atmosphere temperature is taken to be superheated by 1 to $16 \mathrm{~K}$.

\section{c. Ex-Vessel Release Phase}

Many of the available accident analyses, especially for boiling water reactors and for ice condenser containment pressurized water reactors, involve containment failure prior to, or at the start of the ex-vessel phase of an accident. There is, then, less information to guide definition of the atmosphere pressure and temperature during the later stages of a reactor accident for cases in which the containment (or drywell) has not failed. The pressure range selected here has a lower bound equal to the pressure during the in-vessel phase of the accident and the containment failure pressure which is taken to be uniformly distributed over the range from 8 to 11 atmospheres.

The atmosphere in the ex-vessel phase of an accident can become a complicated mixture of air, steam, and the other products of concrete decomposition, $\mathrm{CO}$ and $\mathrm{CO}_{2}$, as well as hydrogen. The contributions of these gases to the atmosphere are discussed in the next subsection.

The atmosphere temperature during the ex-vessel phase of an accident in a pressurized water reactor containment is taken such that the atmosphere is superheated between 1 and 21 degrees with respect to the steam concentration.

Atmospheric temperatures in the drywells of boiling water reactors can become quite high during the ex-vessel phase of a reactor accident. The temperature range is selected here to vary from the steam saturation temperature to $850 \mathrm{~K}$ (see Table 16). 


\section{d. Late In-Vessel Release Phase}

The pressure in the containment is taken to be uniformly distributed over the range defined by the pressure during the ex-vessel release phase and the containment failure pressure. Temperatures in the atmosphere are uncertain over the range of the temperature during the ex-vessel release phase and $550 \mathrm{~K}$ in the case of pressurized water reactors. The upper bound on the temperature range for the atmosphere of boiling water reactor drywells is $850 \mathrm{~K}$.

\section{Steam Condensation Rates}

Also shown in Tables 14 to 16 are rates of steam condensation on surfaces within the containment. Accident analyses typically show that steam condensation rates are quite variable over each of the four phases of severe reactor accidents. Here, constant, steady state rates are defined for each of the four phases of an accident.

Diffusiophoretic and thermophoretic deposition of aerosols play important roles in the natural aerosol removal from containment atmospheres. As discussed in Chapter $\mathrm{V}$, diffusiophoresis is very important in the gap release and in-vessel release phases of an accident. Thermophoresis can become quite important late in a reactor accident when the atmosphere of the containment becomes quite hot.

The analyses of pressurized water reactor accidents done here are based on the assumption of steady-state conditions during each phase of an accident so that pressure and temperature are constant. Pressures and temperatures do change from one accident phase to the next, but they are treated as being constant during a particular accident phase. This means that heat generated by radioactive decay and chemical reaction must be dissipated from the containment atmosphere by condensation and convective heat transfer. The containment atmospheres are assumed to be opaque so radiation heat transfer is not explicitly considered. Then,

$$
\mathrm{Q}(\text { decay })+\mathrm{Q}(\text { chem })-\mathrm{Q}(\text { conc })=\mathrm{A}_{\mathrm{T}} \mathrm{h}\left(\mathrm{T}_{\mathrm{a}}-\mathrm{T}_{\mathrm{s}}\right)+\frac{2 \Delta \mathrm{H}_{\mathrm{fg}} \mathrm{A}_{\mathrm{T}} \mathrm{k}_{\mathrm{m}} \Delta \mathrm{P}\left(\mathrm{H}_{2} \mathrm{O}\right)}{\mathrm{R}\left(\mathrm{T}_{\mathrm{a}}+\mathrm{T}_{\mathrm{S}}\right)}
$$

where:

$$
\begin{aligned}
\mathrm{Q}(\text { decay }) & =\text { heat production by radioactive decay including the decay of noble gases } \\
\mathrm{Q}(\text { chem }) & =\text { heat production by chemical reactions } \\
\mathrm{Q}(\text { conc }) & =\text { heat loss to the concrete } \\
\mathrm{A}_{\mathrm{T}} & =\text { total area available for heat transfer and steam condensation } \\
\mathrm{h} & =\text { heat transfer coefficient } \\
\mathrm{T}_{\mathrm{a}} & =\text { bulk atmosphere temperature } \\
\mathrm{T}_{\mathrm{S}} & =\text { surface temperature }
\end{aligned}
$$




$$
\begin{aligned}
\Delta \mathrm{H}_{\mathrm{fg}} & =\text { latent heat of steam condensation } \\
\mathbf{R} & =\text { gas constant } \\
\mathrm{k}_{\mathrm{m}} & =\text { mass transfer coefficient for steam } \\
\Delta \mathrm{P}\left(\mathrm{H}_{2} \mathrm{O}\right) & =\mathrm{P}_{\mathrm{a}}\left(\mathrm{H}_{2} \mathrm{O}\right)-\mathrm{P}_{\mathrm{s}}\left(\mathrm{H}_{2} \mathrm{O}\right) \\
\mathrm{P}_{\mathrm{a}}\left(\mathrm{H}_{2} \mathrm{O}\right) & =\text { partial pressure of steam in the atmosphere } \\
\mathrm{P}_{\mathrm{s}}\left(\mathrm{H}_{2} \mathrm{O}\right) & =\text { saturation partial pressure of steam at the surface temperature } \\
& \approx \text { exp }\left[13.3349-4976.65 / \mathrm{T}_{\mathrm{s}}(\mathrm{K})\right](\mathrm{atm})
\end{aligned}
$$

Note that the heat consumed by raising the temperature of core materials has been neglected in this model as have several other small terms. The surfaces available for heat transfer and steam condensation are assumed to be at a single temperature, which is found by iterative solution of the equation. This surface temperature is some sort of a weighted average that does not include very hot surfaces described in Section II-A produced when core debris is expelled from the reactor coolant system.

Heat transfer and mass transfer to surfaces are assumed to by driven by natural convection. Corradini's model of natural convection heat transfer discussed in Chapter II (Section E) is used to estimate heat and mass transfer coefficients. The length scale in this model is taken to be an uncertain variable loguniformly distributed over the range from $0.1 \mathrm{H}$ to $\mathrm{H}$ where $\mathrm{H}$ is the effective height of the containment.

Decay heat production is calculated using the model described in Section III-B.1. Chemical heat production is assumed to be due exclusively to steam reactions with Zircaloy cladding of reactor fuel. This chemical heat production occurs only during the in-vessel and ex-vessel phases of an accident. Heat losses to the concrete are considered in the ex-vessel, late in-vessel and post-release phases of an accident as described in Section III-B.8, below.

This simplified model of heat and mass transfer within a containment does not account for transient events such as hydrogen combustion events or the sudden steam production that would be expected when core debris collapses into the lower plenum of the reactor vessel or when a pressurized reactor vessel ruptures. Hydrogen combustion events can raise the containment atmosphere temperature significantly, but for only a short time. Such transient heating ought not significantly affect the long-term, natural deposition of aerosols. Hydrogen combustion events might cause some resuspension of aerosols deposited on surfaces in the containment [139]. Such resuspension processes have not received much attention and no attempt is made here to model them. The effects of sudden steam generation associated with core debris quenching and vessel rupture are approximately treated by neglecting heat accumulation in the reactor coolant system.

Heat transfer and mass transfer within the drywells of boiling water reactors are modeled in a similar way except there is an additional term needed to describe flow of gas from the drywell to the steam suppression pool. This additional term is discussed in Section III-B.10. 
Uncertainties

\section{Uncertainty in the Zirconium Inventories}

The initial zirconium inventory of the reactor is taken to be linearly proportional to the reactor power. The correlations were obtained from data in Table 17 and are:

- for pressurized water reactors:

$$
\mathrm{Zr} \text { mass }(\mathrm{kg})=6.719\left(\mathrm{~kg} / \mathrm{MW}_{\mathrm{th}}\right) \mathrm{P}\left(\mathrm{MW}_{\mathrm{th}}\right) \pm 1500
$$

- for boiling water reactors:

$$
\mathrm{Zr} \operatorname{mass}(\mathrm{kg})=19.83\left(\mathrm{~kg} / \mathrm{MW}_{\mathrm{th}}\right) \mathrm{P}\left(\mathrm{MW}_{\mathrm{th}}\right) \pm 3500
$$

The amount of zirconium in core debris at the start of the ex-vessel release phase of the accident depends on the nature of the accident. Results of several accident analyses are shown in Table 17. From these results, it is concluded here that between 0 and 60 percent of the initial inventory of zirconium metal may still be metallic at the start of the ex-vessel release phase of an accident in a pressurized water reactor. Between 50 and 80 percent of the initial zirconium inventory of a boiling water reactor will still be metallic at the start of the ex-vessel release phase. Oxidation of zirconium within the reactor coolant system is assumed to proceed at a constant rate over the duration of the in-vessel phase of the accident. This oxidation within the reactor coolant system is taken to be responsible for the hydrogen source to the containment according to the reaction:

$$
\mathrm{Zr}+2 \mathrm{H}_{2} \mathrm{O} \rightarrow \mathrm{ZrO}_{2}+2 \mathrm{H}_{2}
$$

\section{Uncertainty in the Concrete Type}

Concretes used for the construction of nuclear power plants can usually be categorized as being either calcareous or siliceous (The magnetite concrete in the Susquehanna plants is unusual). Calcareous concretes have limestone $\left(\mathrm{CaCO}_{3}\right)$ or dolomite $\left(\mathrm{MgCa}\left(\mathrm{CO}_{3}\right)_{2}\right)$ aggregate. Siliceous concretes typically have oolite, granite, granodirite or other $\mathrm{SiO}_{2}$-rich rock as aggregate. The aggregate greatly affects the nature of core debris behavior in the ex-vessel release phase. Unfortunately, there is not a good data base to decide the types of concrete in reactors. Geographic evidence suggests that reactors in the Northeast of the USA will have siliceous aggregate concretes whereas those in the Midwest and the Southeast will have calcareous aggregates. This suggests that the probability of calcareous aggregates is about 0.6. Siliceous aggregates are, however, being specified for advanced reactors [140].

In light of the great uncertainty about aggregates in concretes used for reactors, the probability of having calcareous aggregate is taken to be 0.5 .

\section{Uncertainty in Heat Losses to the Concrete}

Ex-vessel core debris interactions have at least one virtue. The interactions are endothermic and consume a portion of the heat generated by radioactive decay and by chemical reactions. The heat is consumed in the decomposition and melting of concrete and, therefore is not discharged to the containment. Experimental studies [141] and analyses [142] of core debris/concrete interactions show that the fraction of heat generated in core debris that is imparted to the concrete depends on the depth 
Table 17. Zirconium mass in core debris [101-107]

\begin{tabular}{|c|c|c|c|}
\hline $\begin{array}{l}\text { Reactor } \\
\text { (power) }\end{array}$ & Accident & $\begin{array}{c}\text { Initial } \mathbf{Z r} \\
\text { mass } \\
(\mathbf{k g}) \\
\end{array}$ & $\begin{array}{l}\text { Percent } \mathrm{Zr} \text { metal } \\
\text { at the start of the } \\
\text { ex-vessel release phase }\end{array}$ \\
\hline $\begin{array}{c}\text { Sequoyah } \\
\text { (3423) }\end{array}$ & $\begin{array}{c}S_{3} B \\
S_{3} H F \\
S_{2} H F \\
T_{M L B^{\prime}}\end{array}$ & 23000 & $\begin{array}{l}24 \\
26 \\
34 \\
51\end{array}$ \\
\hline $\begin{array}{l}\text { Surry } \\
(2441)\end{array}$ & $\begin{array}{c}S_{3} b \\
\text { AB- } 8 \\
\text { TMLB-8 } \\
S_{2} D-\epsilon \\
S_{2} D-\gamma \\
\text { V } \\
\text { AG }\end{array}$ & 16400 & $\begin{array}{l}46 \\
61 \\
41 \\
39 \\
11 \\
60 \\
28\end{array}$ \\
\hline $\begin{array}{l}\text { Zion } \\
(3250)\end{array}$ & $\begin{array}{c}S_{2} D \\
S_{2} D C F 1 \\
S_{2} D C F 2 \\
S_{2} D C r \\
\text { TMLB } \\
\text { TMLU }\end{array}$ & 20200 & $\begin{array}{c}22 \\
17 \\
52 \\
52 \\
38 \\
0\end{array}$ \\
\hline $\begin{array}{c}\text { Limerick } \\
\text { (3293) }\end{array}$ & $\begin{array}{c}\text { TC3 } \\
\text { TC4 } \\
\text { TPE } \\
\text { TQUV }\end{array}$ & 63400 & $\begin{array}{l}66 \\
71 \\
69 \\
77\end{array}$ \\
\hline $\begin{array}{l}\text { Peach Bottom } \\
\text { (3293) }\end{array}$ & $\begin{array}{c}\text { TC1 } \\
\text { TC2/3 } \\
\text { TBUX } \\
\text { TB1/TB2 }\end{array}$ & 65300 & $\begin{array}{l}81 \\
55 \\
75 \\
80\end{array}$ \\
\hline $\begin{array}{l}\text { Grand Gulf } \\
\text { (3833) }\end{array}$ & $\begin{array}{c}\text { TC } \\
\text { TB } \\
\text { TBS/TBR }\end{array}$ & 79000 & $\begin{array}{l}76 \\
73 \\
69\end{array}$ \\
\hline
\end{tabular}


of the core debris, the rate of gas generation, and the type of concrete. Here, it is assumed that during the ex-vessel release phase, 5 to 20 percent of the heat is imparted to concrete made with calcareous aggregate, whereas 15 to 30 percent is imparted to concrete made with a siliceous aggregate. The differences are the result of higher rates of gas generation and higher decomposition and melting temperatures when calcareous concretes are used.

Of the thermal energy produced by long-term steady-state core debris/concrete interactions during the late in-vessel release phase, 25 to 35 percent of heat generated in core debris is transferred to calcareous concrete and 35 to 50 percent is transferred to siliceous concretes. The higher fractions of heat transfer to the concrete late in an accident occurs because gas generation rates are lower, the surface area of concrete exposed to core debris is larger, and the effectiveness of radiation heat transfer from the top of the core debris is reduced by smaller view factors and lower surface temperatures.

Values within the ranges assigned above are assumed to be uniformly distributed.

\section{Gas Generation During the Ex-Vessel Release Phase and the Late In-Vessel Release Phase}

Core debris interactions with concrete during the ex-vessel release phase and the late in-vessel release phase will produce gases that will alter the composition of the containment or drywell atmosphere. The gases produced by core debris/concrete interactions depend on the composition of the concrete. Calcareous concrete, of course, contains carbon dioxide in the form of carbonate $\left(\mathrm{CaCO}_{3}, \mathrm{MgCa}\left(\mathrm{CO}_{3}\right)_{2}\right.$ etc.) as well as water in the form of water molecules and hydroxide ions $\left(\mathrm{Ca}(\mathrm{OH})_{2} \mathrm{etc}\right.$. $)$.

Typical calcareous concretes contain 13 to 36 weight percent carbon dioxide. The water content of concretes depends on the relative humidity and temperature of the service environment. Concretes typically have 5 to 8 weight percent water of which 2 to 3 percent is in the form of hydroxide ions that unite to produce water vapor at temperatures in the vicinity of $670 \mathrm{~K}$. The rest of the water is vaporized at temperatures from about 323 to $423 \mathrm{~K}$.

Siliceous concretes contain about the same amounts of water as do calcareous concretes, but only 1 to 2 weight percent carbon dioxide. Most of this carbon dioxide comes from reaction of atmospheric gases with calcium hydroxide in the cementitious phases during placement and curing of concrete:

$$
\mathrm{Ca}(\mathrm{OH})_{2}+\mathrm{CO}_{2} \rightarrow \mathrm{CaCO}_{3}+\mathrm{H}_{2} \mathrm{O}
$$

Carbon dioxide and water vapor that evolve from concrete during the ex-vessel and late in-vessel phase of the accident can react with the core debris to form carbon monoxide and hydrogen. The reaction is sensibly complete during the ex-vessel phase of the accident when a strong reducing agent ( $\mathrm{Zr}$ metal) is present in the core debris. Once the reducing agent has been consumed, reactions of carbon dioxide and water proceed to only a limited extent. Typically, during the late in-vessel phase of the accident, the ratio of hydrogen to steam

$$
\xi(\mathrm{g})=\mathrm{P}\left(\mathrm{H}_{2}\right) / \mathrm{P}\left(\mathrm{H}_{2} \mathrm{O}\right)
$$

is uncertain and here is taken to be log-uniformly distributed over the range of 1 to 10 . 
Hot gases that emerge from the core debris continue to react. An important reaction is the shift reaction:

$$
\begin{aligned}
\mathrm{CO}_{2} & +\mathrm{H}_{2}-\mathrm{CO}+\mathrm{H}_{2} \mathrm{O} \\
-\Delta \mathrm{G} / \mathrm{RT} & =\ln \left[\frac{\mathrm{P}(\mathrm{CO}) \mathrm{P}\left(\mathrm{H}_{2} \mathrm{O}\right)}{\mathrm{P}\left(\mathrm{CO}_{2}\right) \mathrm{P}\left(\mathrm{H}_{2}\right)}\right]
\end{aligned}
$$

where $\Delta G$ is the standard state change in the Gibbs free energy and $R$ is the gas constant $(1.987 \mathrm{cal} / \mathrm{mole}-\mathrm{K})$. The equilibrium involving these four gases will be maintained as the gases cool until the kinetics of gas phase reactions slow. The temperature at which this happens, the so-called "quench" temperature, is typically found to be 1000 to $1300 \mathrm{~K}$ [2].

A complication arises in the analyses of containments with concrete surfaces exposed to radiant energy transfer from the core debris. Carbon dioxide and water vapor can evolve from these concrete surfaces, but these gases will not react with the core debris.

For the analyses done below, the composition of the containment atmosphere is adjusted in the ex-vessel and late in-vessel phases of the accident by:

- assuming a quasi-steady state attack of core debris on concrete so the gas production is proportional to the energy imparted to the concrete, and

- 0 to 20 percent of the decay energy is imparted to concrete that is not in contact with core debris.

Enthalpies of concrete ablation are taken to be [142]:

- siliceous concrete

$$
\Delta \mathrm{H}=353 \text { to } 523 \mathrm{cal} / \mathrm{g}
$$

- calcareous concrete

$$
\Delta \mathrm{H}=535 \text { to } 730 \mathrm{cal} / \mathrm{g}
$$

Gases produced by the attack on concrete during the ex-vessel phase of the accident are assumed to be completely reduced to hydrogen and carbon monoxide. Gases produced by attack on concrete during the late in-vessel phase of the accident are taken to have hydrogen-to-steam partial pressure ratios given by $\xi(\mathrm{g})$ defined above and carbon dioxide-to-carbon monoxide partial pressure ratios given by the shift reaction equilibrium at the uncertain quench temperature.

\section{Boiling Water Reactor Accident Sequences}

Severe reactor accidents hypothesized to occur in boiling water reactors may be grouped broadly into three categories according to the nature of radionuclide discharge from the reactor coolant system: 
- Bypass accident sequences in which radionuclides are released from the reactor coolant system directly to some volume outside the reactor containment.

- Transient event sequences in which radioactive aerosols produced during the gap release and in-vessel release phases of an accident are discharged from the reactor coolant system to the steam suppression pool. Radionuclides released during the ex-vessel release phase and the late in-vessel release phase of the accident pass into the drywell and may, eventually, reach the steam suppression pool.

- Loss-of-coolant accident sequences in which radionuclide releases during all phases of an accident pass into the drywell and may go from there to the steam suppression pool.

Bypass accident sequences are outside the scope of interest here.

Aerosols discharged from the reactor coolant system directly to the steam suppression pool will be extensively scrubbed from the carrier gas by the pool. Aerosol removal by steam suppression pools is discussed extensively elsewhere [5]. Only a small fraction of aerosols generated during the gap release phase and in-vessel release phase of a transient accident sequence will pass through the steam suppression pool and accumulate in the wetwell vapor space. There will be natural processes that remove aerosols from the wetwell vapor space. All of the mechanisms of aerosol removal discussed in Chapter II (gravitational settling, diffusiophoresis, thermophoresis and turbulent diffusion) will be operative. In addition, it is likely that water droplets and water aerosols will be present in the wetwell atmosphere. Water droplets and water aerosols will be produced by entrainment in the gas flowing to the pool [143] and by the rupture of gas bubbles at the pool surface [144]. Water droplets will, of course, sweep out aerosols as they fall. Water aerosols will coagglomerate with radioactive aerosol particles and enhance the rate of aerosol deposition by gravitational settling. These natural processes will further attenuate the already small amounts of radioactivity suspended in the wetwell vapor space.

The incremental aerosol removal by natural processes in the wetwell vapor space is not analyzed quantitatively here. Instead, attentions are concentrated on natural aerosol removal processes in the drywells of boiling water reactors. Analyses are done for loss-of-coolant accident sequences in which aerosols produced during all phases of an accident are released into the drywell. It will be apparent from the discussion of results in Chapter $\mathrm{V}$ that aerosols produced during the gap release phase and the in-vessel release phase of an accident little perturb the behavior of the more massive amounts of aerosol produced during the ex-vessel release phase and late in-vessel release phase of an accident. Consequently, results obtained for the aerosols produced during these later stages of loss-of-coolant accident sequences are, at least approximately, applicable to aerosols released into the drywell during transient event accident sequences.

Physical phenomena responsible for removing aerosols from the drywell atmosphere include gravitational settlings, turbulent diffusion and phoretic processes discussed in connection with the containments of pressurized water reactors. There is, however, another aerosol removal process that has to be considered for the drywells of boiling water reactors. Aerosol-laden gases can flow from the drywell into the steam suppression pool. This flow, $f$, gives rise to an effective decontamination coefficient, $\lambda$ (flow), given by: 


$$
\lambda(\text { flow })=\frac{\mathrm{f} \mathrm{RT}}{\mathrm{PV}}
$$

where:

$$
\begin{aligned}
& \mathbf{f}=\text { flow to the suppression pool, (moles/s) } \\
& \mathbf{R}=\text { gas constant } \\
& \mathrm{P}=\text { drywell pressure } \\
& \mathrm{T}=\text { drywell atmospheric temperature } \\
& \mathrm{V}=\text { drywell volume. }
\end{aligned}
$$

To estimate this flow, quasi-steady state conditions are assumed to prevail during each phase of an accident just as in the analyses of pressurized water reactors. Then,

$$
\mathrm{Q}(\text { decay })+\mathrm{Q}(\text { chem })-\mathrm{Q}(\text { conc })=\mathrm{x}\left(\mathrm{H}_{2} \mathrm{O}\right) \mathrm{f} \Delta \mathrm{H}_{\mathrm{fg}}+\Delta \mathrm{H}_{\mathrm{v}} \mathrm{Q}(\text { cond })+\mathrm{h} \Delta_{\mathrm{T}}\left(\mathrm{T}_{\mathrm{a}}-\mathrm{T}_{\mathrm{S}}\right)
$$

where:

$$
\begin{aligned}
& x\left(\mathrm{H}_{2} \mathrm{O}\right)=\text { mole fraction of steam in the drywell atmosphere } \\
& \mathrm{Q}(\text { cond })=\frac{2 \mathrm{k}_{\mathrm{M}} \mathrm{A}_{\mathrm{T}}\left(\mathrm{P}\left(\mathrm{H}_{2} \mathrm{O}\right)-\mathrm{P}_{\mathrm{S}}\left(\mathrm{H}_{2} \mathrm{O}\right)\right)}{\mathrm{R}\left(\mathrm{T}_{\mathrm{a}}+\mathrm{T}_{\mathrm{S}}\right)}
\end{aligned}
$$

and other symbols have been defined in Section III-B.5.

Also,

$$
\mathrm{f}=\mathrm{S}(\mathrm{NC})+\mathrm{S}\left(\mathrm{H}_{2} \mathrm{O}\right)-\mathrm{Q}(\text { cond })
$$

where

$\mathrm{S}(\mathrm{NC})=$ source rates of non-condensible gases $\left(\mathrm{H}_{2}, \mathrm{CO}\right.$, and $\left.\mathrm{CO}_{2}\right)$ to the drywell atmosphere, and

$\mathrm{S}\left(\mathrm{H}_{2} \mathrm{O}\right)=$ source rates of steam to the drywell atmosphere.

It is assumed that flows to the suppression pool do not perturb the natural convection heat and mass transfer to surfaces in the drywell. The equations above and the equations for the heat and mass transfer coefficients are solved iteratively to determine $f$ and $T_{s}$.

The surface temperature is taken to be applicable to all surfaces in the drywell where steam condensation and heat transfer from the atmosphere to the surfaces take place. The surface temperature is some sort of a weighted average of the drywell surface temperatures that would actually exist in a reactor accident. This average does not, however, include very hot surfaces produced when core debris is expelled from 
Uncertainties

the reactor coolant system into the drywell. As discussed in Section II-A such very hot surfaces are unlikely to be places where steam will condense or aerosols will deposit.

\section{Phenomenological Uncertainties}

In the subsections below, phenomenological uncertainties in aerosol physics that may affect the agglomeration and deposition of particles are discussed. Parameters indicative of the uncertainties are defined, ranges of plausible values of these parameters are identified, and probability density functions are assigned to the parameters. These discussions are summarized in Table 12.

\section{Uncertainty in the Collision Efficiency}

The collision efficiency is defined as:

$$
\epsilon_{\mathrm{o}}(U / v)=\frac{3}{2} \epsilon(c) \frac{v^{2 / 3}}{\left(v^{1 / 3}+U^{1 / 3}\right)^{2}}
$$

where $\epsilon(c)$ is uncertain. The range of values defined by the Fuchs formulation [42] and the PruppacherKlett formulation [43], $1 / 3 \leq \epsilon$ (c) $\leq 1$, does not seem to completely span the range of uncertainty for $\epsilon(c)$. Here, the values of $\epsilon(c)$ are taken to be distributed log-uniformly over the range of 0.1 to 1.0 . The lower bound on the range accommodates arguments on the large-size cut-off discussed above (see Section II-B.2). The upper bound on the range might not accommodate all arguments concerning the collision behavior of larger particles [46]. But, the range should be large enough to reflect the considerable uncertainty about collision efficiency for the particles of the size of most interest here.

\section{Sticking Coefficient}

The "sticking" coefficient of particles is taken here to be certain and equal to 1 . The authors find no basis for thinking that particles, once in contact, will not remain in contact. There do not appear to be situations of interest here in which collision velocities of particles will be so high that rebound will overcome the Van der Waals forces between particles. If, in fact, there is a layer of liquid water on the surfaces of aerosol particles, then, surface tension forces will also act to maintain particle-particle contact. Even particles that are electrostatically charged with charges of the same sign will experience attractive forces when in close proximity because of image forces [145]. The only readily imaginable physical process that could reverse particle-particle contact is particle recoil during a radioactive decay event. It is not obvious, however, that this deagglomeration mechanism is important nor is it obvious how the effects of such a mechanism could be incorporated in models in terms of a sticking factor different than one.

\section{Uncertainty in the Turbulent Energy Dissipation Rate}

Williams [146] has formulated a simplified description of the natural convection in containment to relate the turbulent energy dissipation rate to other physical parameters in the system. He obtains: 


$$
\epsilon=0.5 \mathrm{~g} \frac{\mathrm{h}}{\rho_{\mathrm{g}} \mathrm{C}_{\mathrm{p}} \text { (gas) }} \frac{\Delta \mathrm{T}}{\mathrm{T}} \frac{\Delta_{\mathrm{v}} \mathrm{H}}{\mathrm{V}}
$$

where

$\mathrm{h}=$ heat transfer coefficient to the walls, and

$\Delta T=$ temperature difference between the bulk atmosphere and the vertical walls.

Williams' analyses with the CONTAIN code showed turbulent energy dissipation rates could vary from 60 to $170 \mathrm{~cm}^{2} / \mathrm{s}^{3}$. This analysis neglected turbulence induced by the condensation of steam. The QUEST study used a range for the turbulent energy dissipation rate of $10^{-3}$ to $1000 \mathrm{~cm}^{2} / \mathrm{s}^{3}$ [35]. Helton et al. [27] in their analysis of the sensitivity of calculations done with the MAEROS code took the uncertainty range for the turbulent energy dissipation rate to be 10 to $300 \mathrm{~cm}^{2} / \mathrm{s}^{3}$. The turbulent energy should be proportional in some sense to the reactor power and geometry. Here the turbulent energy dissipation rate is taken to be:

$$
\epsilon=\epsilon(t) \frac{A_{v}\left(m^{2}\right) H(m)}{V\left(m^{3}\right)} \quad \mathrm{cm}^{2} / s^{3}
$$

where $\epsilon(t)$ is an uncertain parameter log-uniformly distributed over the range of 2 to $20 \mathrm{~cm}^{2} / \mathrm{s}^{3}$. This reproduces (to one significant digit) the range found by Williams for the turbulent energy dissipation rate in the Surry containment during a station blackout accident. The range does not, of course, account for very high rates of turbulent energy dissipation that might accompany transient events such as hydrogen combustion events or the rupture of a pressurized reactor vessel. These very intense events last for too short a period to drastically affect the long-term behavior of aerosols.

\section{Uncertainty in the Aerosol Shape Factors}

Aerosol particles are assumed here to be porous agglomerates. Concave interstices of these agglomerates are assumed to be filled with condensed water, and surface tension forces of this water are assumed to have drawn the particles into spherical shapes. Then, the dynamic and the collision shape factors are equal and depend on the effective density:

$$
\chi=\gamma=1 / \alpha^{1 / 3}
$$

The values of the shape factor are determined by the packing efficiency of the primary particles and the material densities of these primary particles:

$$
\alpha=\left\{\epsilon(p) \rho_{p}+[1-\epsilon(p)] \rho_{w}\right\} / \rho_{p}
$$


where

$$
\begin{aligned}
& \epsilon(p)=\text { packing efficiency of the primary particles } \\
& \rho_{p}=\text { material density of the primary particles, and } \\
& \rho_{w}=\text { density of water }
\end{aligned}
$$

If atmosphere temperatures are so high that water even in concave interstices evaporates from the agglomerates, then $\alpha=\epsilon(p)$. The primary particles are taken to be fully dense spheres. Electron micrographs of aerosol particles obtained in a variety of reactor safety experiments seem to support this assumption. The random packing of equal sized spheres would yield a maximum packing efficiency of about 0.63. Brockmann [84] cites examples of far less efficient packing. Values of 0.18 to 0.5 are commonly encountered. Here, packing efficiency is taken from results of numerical studies of fractal growth of agglomerates by Brownian motion [46]. The effective size of an agglomerate was found to vary as:

$$
\mathrm{d}_{\mathrm{p}} / 2=\mathrm{kn}^{0.56}
$$

where $\mathbf{k}$ is a constant and $\mathrm{n}$ is the number of primary particles in the agglomerate. Then,

$$
\epsilon(p)=\left(\frac{d(p r)}{d_{p}}\right)^{1.214}
$$

where

$$
\begin{aligned}
\mathrm{d}(\mathrm{pr}) & =\text { diameter of the primary particles, and } \\
d_{p} & =\text { diameter of the particle in question. }
\end{aligned}
$$

Primary particle sizes are very uncertain. Here the primary particle size is taken to be log-uniformly distributed over the range from $0.02 \mu \mathrm{m}$ to $0.2 \mu \mathrm{m}$. For a water-filled agglomerate of $1 \mu \mathrm{m}$ spherical equivalent diameter and composed of primary particles having a material density of $3 \mathrm{~g} / \mathrm{cm}^{3}$, shape factors then vary over the range of 1.33 to 1.43 . These values are consistent with values obtained by back-calculation of aerosol settling rates observed in tests with moist atmospheres [84].

\section{Uncertainty in Accommodation Coefficients}

Two accommodation coefficients are of interest here-the momentum accommodation coefficient and the temperature accommodation coefficient. The available data base on the momentum accommodation coefficient is very limited. Reported values are for a narrow range of materials-typically oil droplets. Reported values of the momentum accommodation coefficient vary from 0.74 to 1.00 , but most values are around 0.9. Intuition suggests that the momentum accommodation coefficient ought to decrease with temperature, but the available data base is concentrated at room temperature. Here, the momentum accommodation coefficient is taken to be given by: 


$$
\alpha_{m}=1.0-A \exp (-300 / T)
$$

where $\mathrm{A}$ is taken to be uniformly distributed over the range of 0 to 0.6 .

What data are available suggest that the temperature accommodation coefficient is no greater than the momentum accommodation coefficient. Theoretical analyses also suggest that the temperature accommodation coefficient increases with the molecular weight of the gas. Consequently, the temperature accommodation coefficient is taken here to be given by:

$$
\alpha_{t}=\frac{4(M W / 44)}{(1+M W / 44)^{2}} \alpha_{m}\left\{1-A^{\prime} \exp (-300 / T)\right\}
$$

where

$$
\begin{aligned}
\mathrm{MW} & =\text { average molecular weight of the gas, and } \\
\mathbf{A}^{\prime} & =\text { uncertain quantity uniformly distributed over the range of } 0 \text { to } 0.6 .
\end{aligned}
$$

Thermal and momentum accommodation coefficients arise most directly in the calculation of particle deposition by thermophoresis and by diffusiophoresis. In the expression for the thermophoretic deposition velocity derived by Talbot et al. (see Section II-E.2), there are three parameters dependent on the accommodation coefficients. These parameters are usually defined in terms of the hard sphere gas approximation which is usually an adequate description of gas-solid interactions when the gas is monatomic and inert. For analyses of aerosol behavior in containment, it is useful to recognize that there will be interaction potentials between the gases and the atoms making up surfaces of aerosol particles. A Lennard-Jones potential, while not a perfect model of this potential, is certainly more realistic than a hard sphere approximation. The precise nature of the Lennard-Jones potential is not known. But, suitable ranges for such potentials have been considered by Loyalka [71]. Then, the parameters in the thermophoretic deposition velocity are:

$$
\begin{gathered}
\mathrm{C}_{\mathrm{s}}=0.75\left(1-\alpha_{\mathrm{m}}\right)+3 \alpha_{\mathrm{m}} \xi(\mathrm{s}) \\
\mathrm{C}_{\mathrm{t}}=\frac{15}{8} \frac{\left(2-\alpha_{\mathrm{t}}\right)}{\alpha_{\mathrm{t}}}\left[\left(1-\alpha_{\mathrm{t}}\right) \frac{5}{8} \sqrt{\pi}+\alpha_{\mathrm{t}} \xi(\mathrm{t})\right] \\
\mathrm{C}_{\mathrm{m}}=\frac{\left(2-\alpha_{\mathrm{m}}\right)}{\alpha_{\mathrm{m}}}\left[\left(1-\alpha_{\mathrm{m}}\right) \frac{\sqrt{\pi}}{2}+\alpha_{\mathrm{m}} \xi(\mathrm{m})\right]
\end{gathered}
$$


where $\xi(\mathrm{s})$ is uniformly distributed over the range from 0.35 to $0.383, \xi(\mathrm{t})$ is uniformly distributed over the range from 1.263 to 1.296 , and $\xi(\mathrm{m})$ is uniformly distributed over the range from 0.996 to 1.02 as discussed above (see Section II.E.2).

A substantially less sophisticated approach is taken toward handling the uncertain scattering kernel in the description of deposition by diffusiophoresis (see Section II-E.1). The kernel is selected to be that given by theory [63] or the empirical kernel, depending on the value of the parameter $\delta(\mathrm{k})$ which is taken to be uniformly distributed over the interval from 0 to 1 :

$$
\sigma_{12}= \begin{cases}\frac{\mathrm{m}\left(\mathrm{H}_{2} \mathrm{O}\right)-\mathrm{m}(\mathrm{gas})}{\mathrm{m}+\left[\mathrm{m}\left(\mathrm{H}_{2} \mathrm{O}\right) \mathrm{m}(\mathrm{gas})\right]^{1 / 2}} & \text { for } 0 \leq \delta(\mathrm{k})<0.5 \\ \frac{0.95\left[\mathrm{~m}\left(\mathrm{H}_{2} \mathrm{O}\right)-\mathrm{m}(\mathrm{gas})\right]}{\mathrm{m}\left(\mathrm{H}_{2} \mathrm{O}\right)+\mathrm{m}(\mathrm{gas})}-\frac{1.05\left[\sigma\left(\mathrm{H}_{2} \mathrm{O}\right)-\sigma(\mathrm{gas})\right]}{\sigma\left(\mathrm{H}_{2} \mathrm{O}\right)+\sigma(\mathrm{gas})} & \text { for } 0.5 \leq \delta(\mathrm{k})<1.0\end{cases}
$$

\section{Uncertainty in Particle Material Density}

The aerosol particle material density is assumed to vary over the course of a reactor accident. Therefore, distinct uncertainty ranges are defined for each of the release phases.

The gap release consists of just cesium and iodine (noble gases are not of interest here) and, perhaps, some nonradioactive materials. The chemical forms of cesium and iodine are often taken to be $\mathrm{CsOH}$ and CsI, which have room temperature densities of 3.675 and $4.51 \mathrm{~g} / \mathrm{cm}^{3}$, respectively. Though the speciation of radionuclides is often quite uncertain, it is certainly plausible that $\mathrm{CsOH}$ and CsI would be important species during the gap release phase when little else is vaporizing. Released CsOH could react with boric acid in pressurized water reactors to form $\mathrm{CsBO}_{2}$ which has a density of about $3.4 \mathrm{~g} / \mathrm{cm}^{3}$. In the containment atmosphere, the cesium hydroxide could react to form $\mathrm{Cs}_{2} \mathrm{CO}_{3}$ with a density of $3.5 \mathrm{~g} / \mathrm{cm}^{3}$. The cesium salts are hygroscopic and deliquescent so they might actually be present as saturated solutions with densities of 2.8 to $3.2 \mathrm{~g} / \mathrm{cm}^{3}$. Therefore, the material density during the gap release is taken to be uniformly distributed over the range of 2.8 to $4.51 \mathrm{~g} / \mathrm{cm}^{3}$.

Aerosol produced during the in-vessel phase of an accident is expected to be dominated by the nonradioactive materials such as $\mathrm{Cd}, \mathrm{CdO}, \mathrm{Ag}, \mathrm{UO}_{2}, \mathrm{U}_{3} \mathrm{O}_{8}, \mathrm{Fe}_{3} \mathrm{O}_{4}$ etc. Based on the discussion above (see Section II-G.5), the density of aerosol material is taken to be distributed over the range 3.25 to $10.96 \mathrm{~g} / \mathrm{cm}^{3}$. This range is so large and probabilities of high densities decrease sufficiently that the distribution is taken to be log-uniform.

Aerosol produced during the ex-vessel release phase are dominated by nonradioactive species vaporized during core debris/concrete interactions. Material densities calculated [101-107] during accident analyses for this phase of an accident vary from 2.9 to $5.65 \mathrm{~g} / \mathrm{cm}^{3}$. The distribution of values within this range is taken to be uniform. 
Aerosols produced by core debris/concrete interactions are also expected to dominate during the late invessel release phase. Material densities calculated for accident analyses [101-107] vary from 3.15 to $2.65 \mathrm{~g} / \mathrm{cm}^{3}$. The distribution of values within this narrow range is taken to be uniform.

\section{Uncertainty in Aerosol Particle Thermal Conductivity}

The thermal conductivity of aerosol particles presents a challenge. The thermal conductivities have not been measured. Thermal conductivities of constituents of the aerosol are not directly applicable since particles are porous and may contain water. Also, dimensions of primary particles are so small that there can be substantial phonon scattering from surfaces which will reduce thermal conductivities below values found for bulk materials. The issue of particle thermal conductivity is of some importance since very highly conductive particles are less susceptible to thermophoretic deposition than particles of low thermal conductivity.

To account for the complications of particle thermal conductivity, a simple multiphase model is used here. Particles are assumed to be agglomerates of primary particles with contact resistances to heat transfer among them. The porous regions of the particle are taken to be filled with water at low temperatures and gas at elevated temperatures. Then, the effective thermal conductivity is taken to be

$$
\mathrm{k}(\mathrm{eff})=\frac{\epsilon}{\frac{\delta}{2 \mathrm{k}_{3} \mathrm{~d}(\mathrm{pr})}+\frac{1}{\mathrm{k}_{\mathrm{p}}}}+\mathrm{k}_{\mathrm{f}}(1-\epsilon)
$$

where

$$
\begin{aligned}
\epsilon & =\text { packing efficiency }=\epsilon(\mathrm{p}) \\
\mathrm{d}(\mathrm{pr}) & =\text { diameter of the primary particles } \\
\mathrm{k}_{\mathrm{p}} & =\text { thermal conductivity of the aerosol material } \\
\mathrm{k}_{3} & =\epsilon(\mathrm{k}) \mathrm{k}_{\mathrm{p}}=\text { contact zone thermal conductivity } \\
\delta & =0.1 \mathrm{~d}(\mathrm{pr}) \\
\mathrm{k}_{\mathrm{f}} & =\text { thermal conductivity of fluid (gas or water) in the porous portion of an agglomerate. }
\end{aligned}
$$

The parameter $\epsilon(\mathrm{k})$ is taken to be uncertain and is log-uniformly distributed over the range of $10^{-3}$ to 0.5 .

The aerosol material thermal conductivities are assumed to depend on the phase of the accident. Ranges for the thermal conductivities are defined here based on data in Table 4. During the gap release, the range for the thermal conductivity of the aerosol material is taken to be defined by values for CsI $(0.023 \mathrm{cal} / \mathrm{cm}-\mathrm{s}-\mathrm{K})$ and $\mathrm{NaOH}$ (as a simulant for $\mathrm{CsOH})(0.0022 \mathrm{cal} / \mathrm{cm}-\mathrm{s}-\mathrm{K})$. Values are taken to be log-uniformly distributed in this range. 


\section{Uncertainties}

During the in-vessel phase of the accident, aerosol materials can be metallic ( $\mathrm{Ag}, \mathrm{Cd}, \mathrm{In}, \mathrm{Te}$, etc.) or oxidic $\left(\mathrm{UO}_{2}, \mathrm{U}_{3} \mathrm{O}_{8}, \mathrm{Fe}_{2} \mathrm{O}_{3}\right.$ etc.). The range of thermal conductivities is then taken to be 0.1 to $3 \times 10^{-4} \mathrm{cal} / \mathrm{cm}-\mathrm{s}-\mathrm{K}$.

Aerosols in the ex-vessel phase and the late in-vessel phase of the accident will be more oxidic. The thermal conductivity range is taken to be 0.02 to $5 \times 10^{-4} \mathrm{cal} / \mathrm{cm}-\mathrm{s}-\mathrm{K}$ which is a range defined by measurements for $\mathrm{Fe}_{3} \mathrm{O}_{4}$ and $\mathrm{Mg}_{2} \mathrm{SiO}_{4}$.

\section{Gradients at Surfaces}

The heat balance in the containment is defined by:

$$
\mathrm{Q}(\text { decay })+\mathrm{Q}(\text { chem })=\mathrm{Q}(\text { concrete })+\Delta \mathrm{H}_{\mathrm{fg}} \dot{\mathrm{m}}\left(\mathrm{H}_{2} \mathrm{O}\right)+\mathrm{Q} \text { (convective) }
$$

where

$$
\begin{aligned}
\mathrm{Q}(\text { decay }) & =\text { decay heat generation } \\
\mathrm{Q}(\text { chem }) & =\text { heat production by chemical reaction } \\
\mathrm{Q}(\text { concrete }) & =\text { heat transferred to the concrete } \\
\Delta \mathrm{H}_{\mathrm{fg}} & =\text { latent heat of vaporization of water } \\
\dot{\mathrm{m}}\left(\mathrm{H}_{2} \mathrm{O}\right) & =\text { water condensation rate, and } \\
\mathrm{Q}(\text { convective }) & =\text { convective heat transfer rate. }
\end{aligned}
$$

This water condensation rate is given by:

$$
\dot{\mathrm{m}}=\frac{\Delta \mathrm{k}_{\mathrm{m}}}{\mathrm{RT}}\left[\mathrm{P}_{\mathrm{b}}\left(\mathrm{H}_{2} \mathrm{O}\right)-\mathrm{P}_{\mathrm{sat}}\left(\mathrm{T}_{\mathrm{w}}\right)\right]=\left.\frac{-\mathrm{Ð}\left(\mathrm{H}_{2} \mathrm{O}\right)}{\left(1-\mathrm{P}_{\mathrm{b}}\left(\mathrm{H}_{2} \mathrm{O}\right) / \mathrm{P}_{\mathrm{T}}\right) \mathrm{RT}} \frac{\partial \mathrm{P}\left(\mathrm{H}_{2} \mathrm{O}\right)}{\partial \mathrm{y}}\right|_{\mathrm{y}=0}
$$

where

$$
\begin{aligned}
A & =\text { surface area } \\
k_{m} & =\text { mass transport coefficient } \\
R & =\text { gas constant } \\
T & =\left(T_{b}+T_{w}\right) / 2 \\
T_{b} & =\text { bulk atmosphere temperature }
\end{aligned}
$$




$$
\begin{aligned}
T_{w} & =\text { wall temperature } \\
P_{b}\left(H_{2} \mathrm{O}\right) & =\text { partial pressure of water vapor in the gas phase, } \\
\mathbf{P}_{\text {sat }}\left(\mathrm{T}_{w}\right) & =\text { saturation partial pressure of water at the wall temperature } \\
\mathbf{P}_{T} & =\text { total pressure in the atmosphere } \\
\bigoplus_{(}\left(\mathrm{H}_{2} \mathrm{O}\right) & =\text { diffusion coefficient of water vapor in the atmosphere at temperature } T \\
\left.\frac{\partial \mathrm{P}\left(\mathrm{H}_{2} \mathrm{O}\right)}{\partial y}\right|_{\mathrm{y}=0} & =\text { water vapor partial pressure gradient at the surface }
\end{aligned}
$$

The convective heat transfer is given by

$$
Q(\text { convective })=A h\left(T_{b}-T_{w}\right)=\left.A k_{t h}^{(\text {gas })} \frac{\partial T}{\partial y}\right|_{y=0}
$$

where

$$
\mathrm{h}=\text { heat transfer coefficient }
$$

$$
\left.\frac{\partial T}{\partial y}\right|_{y}=0=\text { thermal gradient at the surface }
$$

Heat and mass transport coefficients can be calculated from natural convection correlations. Corradini [68] suggests:

$$
\frac{\mathrm{hL}}{\mathrm{k}_{\mathrm{th}} \text { (gas) }}=\epsilon(\mathrm{Nu}) \mathrm{Gr}^{0.4} \mathrm{Pr}^{7 / 15} /\left(1+0.494 \mathrm{Pr}^{2 / 3}\right)^{0.4}
$$

where

$L=$ length of the surface

$$
\begin{aligned}
& \mathrm{Gr}=\frac{\mathrm{g}\left(\mathrm{T}_{\mathrm{b}}-\mathrm{T}_{\mathrm{w}}\right) \mathrm{L}^{3} \rho_{\mathrm{g}}^{2}}{\mathrm{~T} \mu_{\mathrm{g}}^{2}} \\
& \operatorname{Pr}=\mathrm{C}_{\mathrm{p}} \text { (gas) } \mu_{\mathrm{g}} / \mathrm{k}_{\mathrm{th}} \text { (gas) }
\end{aligned}
$$


and $\epsilon(\mathrm{Nu})$ is an uncertain parameter uniformly distributed over the range 0.0148 to 0.059 . This correlation has a stronger dependence on the Grashoff number, $\mathrm{Gr}$, than that used in the CONTAIN code $[14]^{*}$ :

$$
\frac{\mathrm{hL}}{\mathrm{k}_{\mathrm{th}}(\mathrm{gas})}=0.13(\mathrm{GrPr})^{0.33}
$$

As noted by Corridini [68], it does seem, however, to be in good accord with data on the Grashoff number dependence.

By analogy (Reynolds) to heat transfer, Corradini derives:

$$
\mathrm{k}_{\mathrm{m}} / \Gamma=\epsilon(\mathrm{Sh}) / \mathrm{Re}^{1 / 4} \mathrm{Sc}^{2 / 3}
$$

where

$$
\begin{aligned}
\mathrm{Sc} & =\mu_{\mathrm{g}} / \rho_{\mathrm{g}} \boxplus\left(\mathrm{H}_{2} \mathrm{O}\right) \\
\operatorname{Re} & =\rho_{\mathrm{g}} \Gamma \delta / \mu_{\mathrm{g}} \\
\Gamma & =1.185\left(\mu_{\mathrm{g}} / \rho_{\mathrm{g}} \mathrm{L}\right) \mathrm{Gr}^{1 / 4} /\left(1+0.434 \mathrm{Pr}^{2 / 3}\right)^{1 / 2} \\
\delta & =0.565 \mathrm{~L} \mathrm{Gr}^{-0.1} / \mathrm{Pr}^{8 / 15}\left(1+0.494 \mathrm{Pr}^{2 / 3}\right)^{0.1}
\end{aligned}
$$

and $\epsilon(\mathrm{Sh})$ is an uncertain parameter uniformly distributed over the range 0.0094 to 0.0376 . Note that the upper bound on this range corresponds to forced convection. Also note, that though the mass transfer correlation was derived by analogy to the heat transfer correlation, the uncertain parameters in the two correlations are considered independent.

Simultaneous solution of the above equations provides the temperature gradient and the pressure gradient needed to calculate particle deposition by thermophoresis and diffusiophoresis, respectively. To use Corradini's correlations, it is necessary to know the characteristic dimensions of the surface, $L$. This characteristic dimension need not be the overall geometric dimension if discontinuities in surfaces disrupt the natural convection flow pattern. Such discontinuities are common on surfaces in reactor containments, so here

$$
L= \begin{cases}\epsilon(L) H & \text { for vertical surfaces } \\ \epsilon(L)\left(A_{F} / \pi\right)^{1 / 2} & \text { for horizontal surfaces }\end{cases}
$$

\footnotetext{
*Note typographical error in the reference.
} 
where $\epsilon(\mathrm{L})$ is an uncertain parameter taken to have values log-uniformly distributed between 0.1 and 1.0.

Deposition by diffusion is calculated using the integration described in Section II-F. The friction velocity needed for this calculation is taken to be:

$$
U^{*}=\xi\left(u^{*}\right) \Gamma \sqrt{\frac{f}{2}}
$$

where

$$
f=0.045\left[\mu_{\mathrm{g}} / \rho_{\mathrm{g}} \delta \Gamma\right]^{1 / 4}
$$

and $\xi\left(\mathrm{u}^{*}\right)$ is an uncertain parameter uniformly distributed over the range of 0.1464 to 0.537 . This range corresponds to using the mean or the peak gas velocity parallel to the surface in the definition of the friction velocity.

\section{Summation of Deposition Mechanisms}

Thermophoretic, diffusiophoretic and turbulent deposition processes can be simultaneously operative on all surfaces. They may be augmented, opposed or unaffected by gravitational deposition depending on whether the surface is facing upward, downward or is vertical. But, the various deposition processes cannot result in deposition of a particle more than once. The issue of adding together mechanisms then arises. Very complicated analyses are needed, in general, to solve this issue. Experimental data cited above show that deposition velocities for diffusiophoresis and for thermophoresis can simply be added. It is, however, not clear that this is the case for gravitational sedimentation and turbulent deposition.

It has not been possible to conduct the very detailed analyses that would be needed to resolve this summation issue in general. To capture the sense of uncertainty about this summation issue, the particle deposition velocities are calculated as follows:

- At upward-facing surfaces:

$$
\mathrm{V}_{\mathrm{D}}=\mathrm{V}(\mathrm{grav})+\mathrm{V}(\text { other })
$$

- At downward-facing surfaces:

$$
\mathrm{V}_{\mathrm{D}}=\max [0, \mathrm{~V} \text { (other) }-\mathrm{V}(\text { grav })]
$$

- At vertical surfaces:

$$
\mathrm{V}_{\mathrm{D}}=\mathrm{V}(\text { other })
$$


Uncertainties

where

$$
\begin{aligned}
V_{D} & =\text { overall deposition velocity } \\
V(\text { other }) & = \begin{cases}V(\text { thermo })+V(\text { diff })+V(\text { turb }) & \text { for } 0 \leq \delta \Sigma<1 / 3 \\
\left.\left\{[V(\text { thermo })+V(\text { diff })]^{2}+V(\text { turb })^{2}\right]\right\}^{1 / 2} & \text { for } 1 / 3 \leq \delta_{\Sigma}<2 / 3 \\
\text { max }[V(\text { thermo })+V(\text { diff }), V(t u r b)] & \text { for } 2 / 3 \leq \delta_{\Sigma}<1\end{cases} \\
V(\text { thermo }) & =\text { deposition velocity due to thermophoresis } \\
V(\text { diff }) & =\text { deposition velocity due to diffusiophoresis } \\
V(\text { turb }) & =\text { deposition velocity due to turbulent convection }
\end{aligned}
$$

and $\delta_{\Sigma}$ is an uncertain parameter uniformly distributed over the interval from 0 to 1 . 


\section{Correlations for Aerosol Behavior in Reactor Containments}

Accident analysis computer codes such as the Source Term Code Package [11], NAUAHYGROS [148] and MELCOR [13] solve the aerosol dynamic equation to describe the behavior of aerosols in the reactor containment. The sectional method of solution originally developed by Gelbard and Seinfeld [10] has become, by far, the most popular method to solve the aerosol dynamic equation. This method involves the discretization of the aerosol size distribution into size classes (bins) and solution of the dynamic equation for representative particles in each size class. The computationally slow step in the calculations is the evaluation of the collision kernels. The selection of the sectional method for solution of the aerosol dynamic equation was made because the size distributions of aerosols in the containment during a reactor accident can be complicated. The most usual source of complexity arises when fresh aerosol having small particle sizes is injected into a containment atmosphere already laden with an aerosol that had aged so that the particles were relatively large. When this happens, the aerosol size distribution in the containment becomes bimodal. This creates computational challenges for many popular methods of solving the aerosol dynamic equation such as the moments methods [41]. This problem of a fresh aerosol mixing with aged aerosol is also a challenge to simplified modeling of natural aerosol processes. The sectional method can treat this complex size distribution problem. The choices of the aerosol size sections and some problems with numerical diffusion are issues thought to affect the accuracy of predictions obtained with the sectional method.

Complexities in the size distributions of aerosol particles create complexities in the deposition of these particles since so many of the aerosol processes depend so strongly on aerosol particle size. Complex particle size distributions do not, however, last for long times. Coagulation and deposition quickly convert polydisperse, multimodal distributions into single mode distributions. Indeed, analytic and numerical studies have shown that aerosol size distributions can, after some period of coagulation, exhibit a "self-preserving" character. That is, the size distribution reached after some period of time becomes independent of the initial size distribution [149-156]. The time required to achieve the particular size distribution depends on the particle concentration. The more concentrated the aerosol is initially, the more rapidly its self-preserving size distribution is reached. The rapid evolution of aerosol particle size distributions from initially complicated forms to a consistent form make simplification of aerosol models feasible.

Epstein and coworkers [157-158] used this observation of self-preserving aerosol size distributions to argue that simple correlations could be used to predict the behavior of aerosol in a reactor containment to satisfactory levels of accuracy. Epstein and coworkers considered gravitational coagulation and coagulation by Brownian diffusion to construct a simple correlation with parametric values found by fits to data or to calculated results obtained by solving the detailed aerosol dynamic equations with the CONTAIN code [147]. Subsequently, Otter and Vaughn $[159,160]$ have corrected and refined the correlations developed by Epstein et al. They also considered coagulation by gravitational settling and Brownian diffusion. They ignored the effects of turbulence and electrostatic effects.

The QUEST study [35] showed that turbulence of sufficient magnitude had a considerable effect on the rate of aerosol coagulation. Indeed, uncertainty studies by Helton et al. [55-59] have shown that the turbulent energy dissipation rate is an important parameter in the prediction of aerosol behavior. Most large-scale tests of aerosol behavior in the reactor containment have not attempted to simulate well the turbulence to be expected in the containment during a reactor accident. Turbulence could well be of even greater importance in future generations of nuclear power plants employing passively cooled containments. It would seem, then, to be appropriate to include this effect. 


\section{Correlations}

The development of the correlations by Otter and Vaughn [159] begins with the definition of dimensionless groups:

- dimensionless aerosol concentration:

$$
M=\frac{\gamma K_{o} H C(p)}{\chi \rho_{p} B}\left[\frac{\gamma \epsilon_{o} g \rho_{p}}{\mu_{g} K_{o}}\right]^{1.25}
$$

where

$$
\mathrm{B}=\frac{2}{9}\left(\frac{3}{4 \pi}\right)^{2 / 3} \mathrm{~g} \rho_{\mathrm{p}} / \chi \mu_{\mathrm{g}}
$$

- dimensionless aerosol source rate:

$$
\dot{M}=\left(\frac{\gamma \epsilon_{o} g \rho_{p}}{\mu_{g} K_{o}}\right)^{7 / 4} \frac{\gamma K_{o} H^{2}}{\chi \rho_{p} B^{2}} \dot{s}
$$

- dimensionless decontamination coefficient:

$$
\Lambda=\left(\frac{\gamma \epsilon_{\mathrm{o}} \mathrm{g} \rho_{\mathrm{p}}}{\mu_{\mathrm{g}} \mathrm{K}_{\mathrm{o}}}\right)^{1 / 2}\left(\frac{\mathrm{H}}{\mathrm{B}}\right) \lambda
$$

- dimensionless time:

$$
\tau=\left(\frac{\mu_{\mathrm{g}} \mathrm{K}_{\mathrm{o}}}{\gamma \epsilon_{\mathrm{o}} \mathrm{g} \rho}\right)^{1 / 2}\left(\frac{\mathrm{B}}{\mathrm{H}}\right) \mathrm{t}
$$

where $\mathrm{H}$ is the "effective" height of the containment defined as the containment volume divided by the horizontal surface area available to receive sedimenting aerosol particles, and $\epsilon_{0}$ is an uncertain parameter indicative of the uncertainty in the efficiency of gravitational coagulation (see Section III C-1). Otter and Vaughn restrict the value of $\epsilon_{0}$ to be either 1 (Fuchs model) or 1/3 (Pruppacher-Klett model). Here $\epsilon_{\mathrm{o}}$ is taken to be uniformly distributed over the interval 0.1 to 1 (see Section III C-1).

When turbulent diffusion is neglected as a mechanism for coagulation of aerosols, the quantity $\mathrm{K}_{\mathrm{o}}$ is:

$$
\mathrm{K}_{\mathrm{o}}=4 \mathrm{kT} / 3 \mu_{\mathrm{g}}
$$


The dimensional description of the evolution of mass in the containment is taken to be given by the differential equation:

$$
\frac{\mathrm{dm}}{\mathrm{dt}}=-\lambda \mathrm{m}+\dot{\mathbf{s}}
$$

The non-dimensional form of the equation is:

$$
\frac{d M}{d \tau}=-\Lambda M+\dot{M}
$$

Correlations are introduced by developing expressions for $\boldsymbol{\Lambda}$ in terms of $\mathbf{M}$. Two correlations were found to be necessary. Under steady-state conditions such that aerosol losses from the containment atmosphere are exactly matched by aerosol inputs to the containment atmosphere:

$$
\Lambda=0.226 \mathrm{M}^{0.282}\left[1+1.89 \mathrm{M}^{0.8}\right]^{0.695}
$$

When there are no sources of aerosol input to the containment atmosphere:

$$
\Lambda=0.528 \mathrm{M}^{0.235}\left[1+0.473 \mathrm{M}^{0.754}\right]^{0.786}
$$

These correlations are what give the method its name. To apply the method for the purposes of interest here, the correlations must be augmented some. The correlation methods have been derived for aerosol particles that have grown sufficiently to reach a self-preserving size distribution. Some time is required for this amount of growth. The dimensionless time required is [161]:

$$
\phi=10.5 \mathrm{M}^{-0.33}\left[1+0.623 \mathrm{M}^{0.66}\right]^{-0.82}
$$

where

$$
\begin{aligned}
& \phi=\left[\frac{\alpha g \rho_{\mathrm{p}} \mathrm{K}_{\mathrm{o}}}{\chi^{2} \gamma \mu_{\mathrm{g}} \mathrm{H}^{2}}\right]^{1 / 2} \mathrm{t} \\
& \mathrm{M}=\left[\frac{\gamma^{9} \mathrm{~g} \mathrm{H}{ }^{4}}{\alpha^{3} \mathrm{~K}_{\mathrm{o}} \mu_{\mathrm{g}} \rho_{\mathrm{p}}^{3}}\right]^{1 / 4} \mathrm{~m}(\mathrm{t})
\end{aligned}
$$




\section{Correlations}

An evaluation of the age of particles in the containment must be made to see if the self-preserving size distribution assumed in the correlational models has been reached. To do this, particles being added to the containment are assumed to enter at zero age. Particles that deposit from the containment volume are assumed to have the mean age, $\tau$. The time variation of $\tau$ is given by:

$$
\frac{d m(t) \tau}{d t}=m(t)-\lambda \tau m(t)+0 * \dot{s}
$$

Then,

$$
m(t) \frac{d \tau}{d t}+\tau \frac{d m(t)}{d t}=m(t)(1-\lambda \tau)
$$

or,

$$
m(t) \frac{d \tau}{d t}+\tau[-\lambda m(t)+\dot{s}]=m(t)(1-\lambda \tau)
$$

so,

$$
\frac{\mathrm{d} \tau}{\mathrm{dt}}=1-\frac{\dot{\mathrm{s}} \tau}{\mathrm{m}(\mathrm{t})}
$$

When no source of aerosol to the volume exists, the particle age increases directly with time as would be expected. Deposition of aerosol particles, of course, does not affect the age of particles that remain suspended in the atmosphere. If a constant source of aerosol particles exists and the deposition coefficient, $\lambda$, is constant, $m(t)=(\dot{s} / 2) \exp (-\lambda t)$, and

$$
\frac{d \tau}{d t}=1-\frac{\lambda \tau}{1-\exp (-\lambda t)}
$$

The aging rate of the aerosol suspended in the volume is independent of the magnitude of the source. For $\lambda \tau<<1$,

$$
\frac{\mathrm{d} \tau}{\mathrm{dt}}=1-\frac{\tau}{\mathrm{t}}
$$

That is, early in time the aging rate is independent of both the source and the deposition. The differential equation is easily solved in terms of the variables $z=t \tau$ and $t$ to yield:

$$
\mathrm{t} \tau=\mathfrak{t}^{2} / 2 \text { and } \frac{\mathrm{d} \tau}{\mathrm{dt}}=1 / 2
$$


That is, when a source is operative, the aerosol suspended in an atmosphere ages at half the rate of increase of time. Numerical tests with the differential equation for aerosol aging show that $d \tau / d t$ remains in the range of 0.2 to 0.5 until the aerosol concentration reaches about 90 percent of its steady state value.

Until aerosols have aged sufficiently to have a self-preserving size distribution, gravitational sedimentation will progress at a rate less than predicted by the correlations. It is assumed here that

$$
\Lambda(\tau)=[1-\exp (-\delta / \phi)] \Lambda \text { (steady) }
$$

where:

$\Lambda(\tau)=$ dimensionless deposition velocity for aerosol particles of age $\tau$,

$\Lambda$ (steady) $=$ dimensionless gravitational deposition velocity for aerosol particles derived from the correlation, and

$$
\delta=\left[\frac{\alpha g \rho_{p}}{\chi^{2} \gamma \mu_{g} H^{2}}\right]^{1 / 2} t
$$

To account for the effects of turbulent diffusion, the value of $\mathrm{K}_{\mathrm{o}}$ is here redefined to be $\mathrm{K}_{\mathrm{o}}{ }^{\prime}$ :

$$
\mathrm{K}_{\mathrm{o}}{ }^{\prime}=\frac{4 \mathrm{kT}}{3 \mu_{\mathrm{g}}}\left[1+\frac{3 \mathrm{Z}_{\mathrm{o}}}{4 \pi}\left(\frac{\epsilon_{\mathrm{T}} \rho_{\mathrm{g}}}{\mu_{\mathrm{g}}}\right)^{1 / 2}\left(\frac{3 \mu_{\mathrm{g}}}{4 \mathrm{kT}}\right)^{1 / 4} \frac{1}{\mathrm{~K}_{\mathrm{Go}}^{3 / 4}}\right]
$$

where

$$
\mathrm{K}_{\mathrm{Go}}=\frac{2 \pi}{9}\left(\frac{3}{4 \pi}\right)^{4 / 3} \frac{\gamma^{2} \epsilon_{\mathrm{o}} \mathrm{g} \rho_{\mathrm{p}}}{\chi \mu_{\mathrm{g}}}
$$

When turbulence in the atmosphere is small $\epsilon_{\mathrm{T}} \sim 10 \mathrm{~cm}^{2} / \mathrm{s}^{3}, \mathrm{~K}_{\mathrm{o}}{ }^{\prime}$ is essentially equal to the value used by Otter and Vaughn. As turbulence increases, there is an effective increase in particle diffusion coefficients. At high turbulence levels, $\epsilon_{\mathrm{T}} \sim 3000 \mathrm{~cm}^{2} / \mathrm{s}^{3}, \mathrm{~K}_{\mathrm{o}}{ }^{\prime}$ is about twice the value of $\mathrm{K}_{\mathrm{O}}$.

To account for turbulent inertial coagulation, the factor $\mathrm{g}$ in the various equations can simply be replaced by: 


$$
g+1.8183\left(\frac{\epsilon_{\mathrm{T}}^{3} \rho_{\mathrm{p}}}{\mu_{\mathrm{g}}}\right)^{1 / 4}
$$

To test this treatment of turbulence effects, comparisons were made to results of calculations with the CONTAIN code which solves the aerosol dynamic equation including the effects of turbulent agglomeration. For these calculations, a source of 100 grams per second into a $5 \times 10^{10} \mathrm{~cm}^{3}$ containment $4000 \mathrm{~cm}$ high was assumed to operate for 3600 seconds. The predictions of the time dependence of the suspended aerosol mass in the containment for a situation involving a low level of turbulence (turbulent energy dissipation rate $=10 \mathrm{~cm}^{2} / \mathrm{s}^{3}$ ) are shown in Figure 20. Predictions obtained from the correlations are in good agreement with the predictions obtained with the CONTAIN code. The most significant discrepancies occur at the peak mass concentration. These discrepancies, which are not large, may be caused more by the transition from the steady-state correlation to the decay correlation than by the high mass concentration. The discrepancies that arise in making a selection between the two correlations have been discussed by Otter and Vaughn [159].

The calculations were repeated for a case involving a high level of turbulence (turbulent energy dissipation rate $=1000 \mathrm{~cm}^{2} / \mathrm{s}^{3}$ ). Results obtained with the CONTAIN code and with the correlations including the effects of turbulent agglomeration processes are shown in Figure 21. Again, the agreement between predictions obtained with the CONTAIN code and predictions obtained with the correlation are quite good. Discrepancies between these predictions are probably smaller than uncertainties in the physical processes.

Also shown in the figure are predictions of the suspended aerosol mass that would be obtained from the correlation neglecting turbulent agglomeration processes. It is evident from the comparison of correlation predictions with and without terms for the turbulent processes that these turbulent processes have significant, but not overwhelming, effects on aerosol behavior.

Nearly all tests of aerosol behavior have used a single aerosol source. Certainly, the correlation approach pioneered by Epstein et al. and refined by Otter and Vaughn is geared to treat a single, though perhaps chemically complex, aerosol. This, however, is not the situation created in the containment by severe accidents. As depicted in the proposed revision to the severe accident source term (NUREG-1465, Reference 1), there are four distinct types of aerosol:

- gap release aerosol,

- in-vessel release aerosol,

- ex-vessel release aerosol, and

- late in-vessel release aerosol.

It is assumed here that each of these aerosols has aged sufficiently prior to reaching the containment atmosphere that particles are compositionally homogeneous regardless of particle size. But, after the gap release, each new aerosol will encounter in the atmosphere an aged, preexisting aerosol. There will 


\section{Correlations}

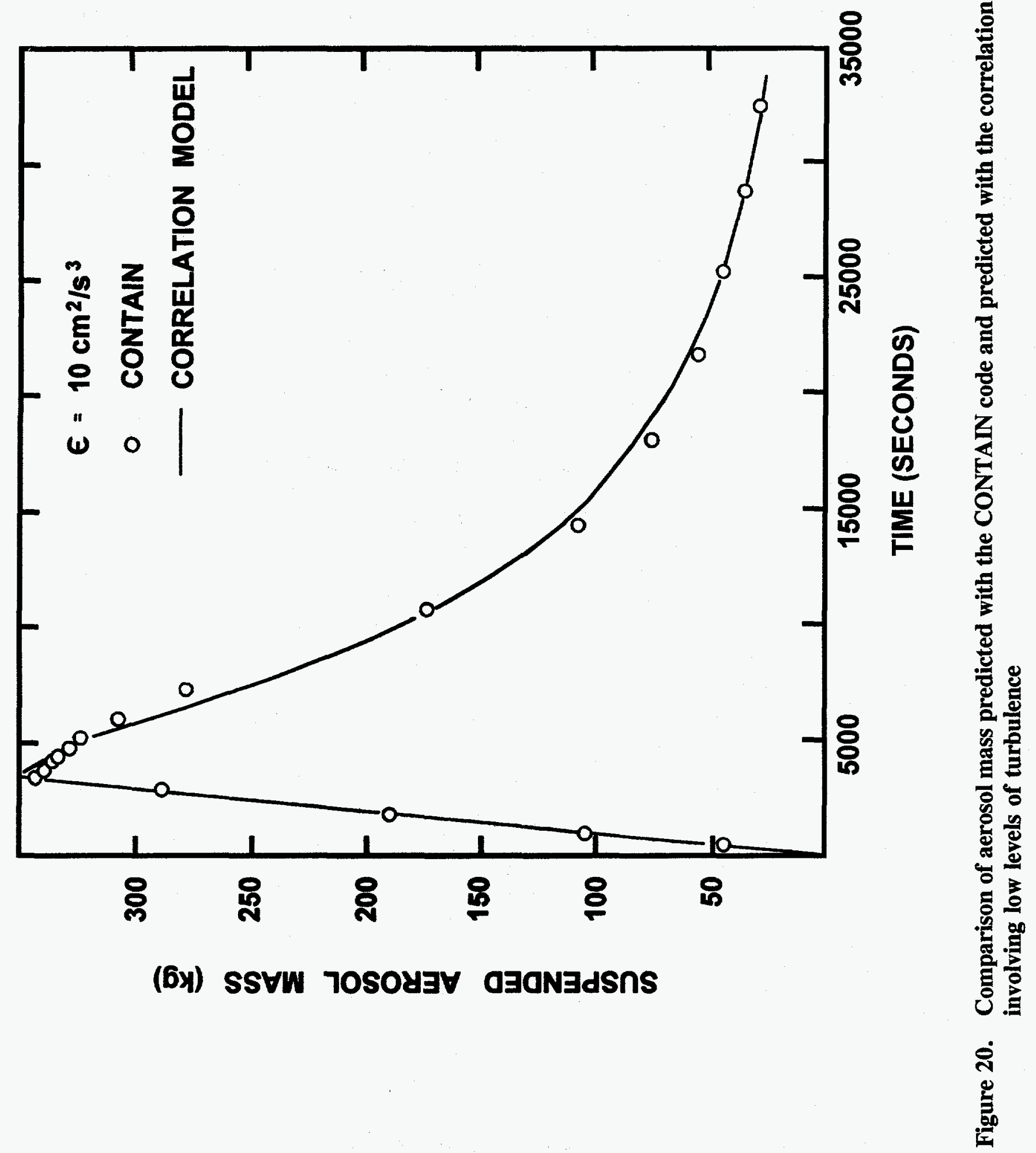




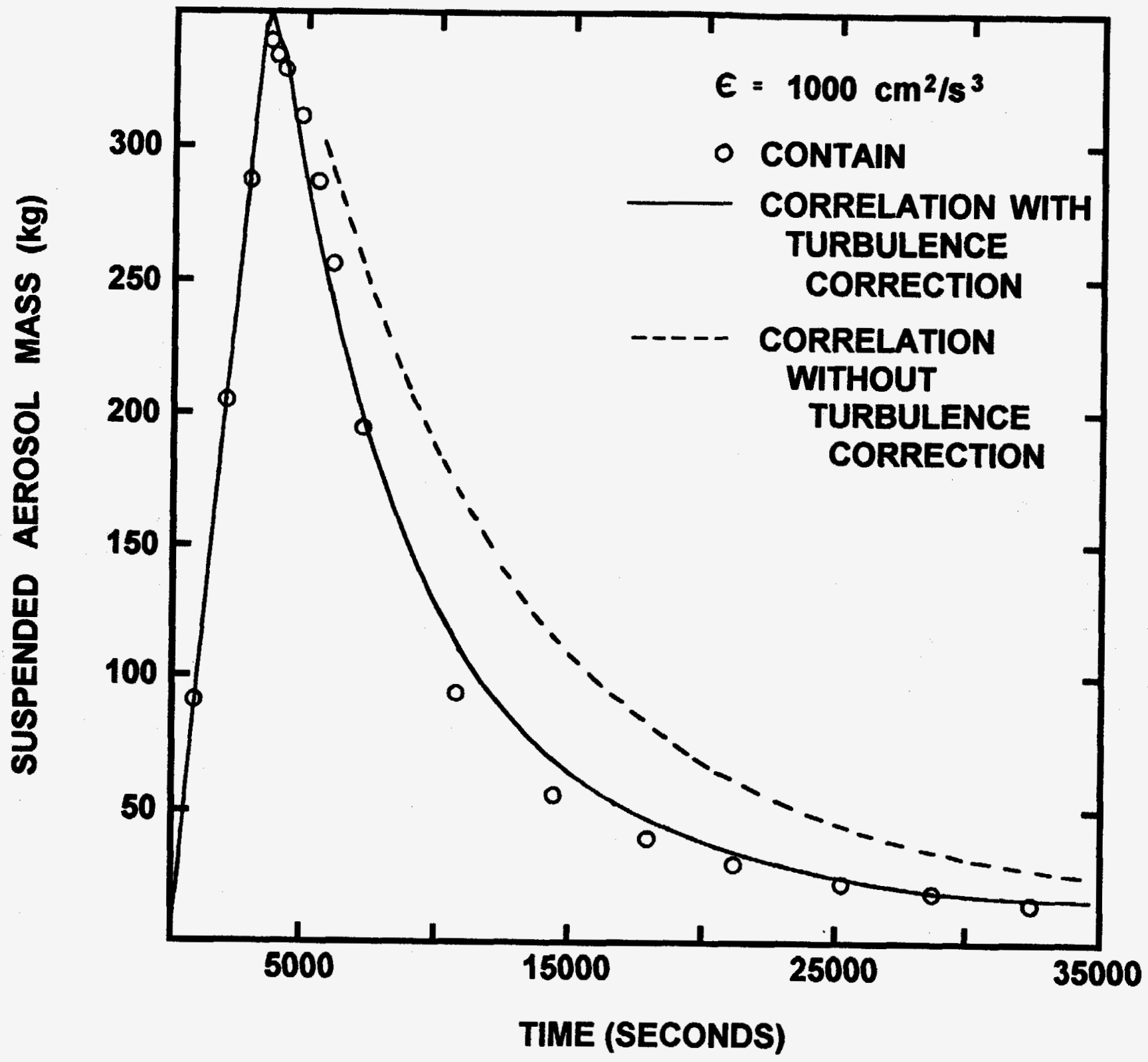

号

TIME (SECONDS)

Figure 21. Comparison of aerosol mass predicted with the CONTAIN code and predicted with the correlation for a situation involving high levels of turbulence. Also shown (dashed line) is the prediction of the correlation if no account is taken of turbulent agglomeration processes. 
be a transient period when the aerosol size distribution in the containment is complicated and the aerosol particles of different sizes will have striking variations in composition. It is assumed here that this transient period is insignificant. Certainly, in the case of the material produced by the in-vessel release encountering the aerosol still present from the gap release, this will be the case since the in-vessel release including the nonradioactive aerosol is huge in comparison to the gap release. Similarly, the intense release during the ex-vessel phase of the accident will totally overwhelm residual aerosol from the invessel release that remains suspended in the containment atmosphere. It is less clear that the lowintensity release during the late in-vessel stage of the accident will have such a profound, immediate effect on aged aerosol encountered in the containment atmosphere.

A modification of the correlation approach is developed below to account for multicomponent aerosols. This modification is then tested by comparison of its predictions of aerosol behavior against predictions obtained with the CONTAIN code.

To modify the correlation to account for multiple aerosol sources, the total aerosol mass suspended in the containment is defined to be:

$$
\mathrm{m}=\sum_{\mathrm{i}=1}^{8} \mathrm{~m}(\mathrm{i})
$$

where

$$
\begin{aligned}
& \mathrm{m}=\text { total suspended mass, } \\
& \mathrm{m}(1)=\text { suspended mass from the gap release of radionuclides, } \\
& \mathrm{m}(2)=\text { suspended mass from the in-vessel release of radionuclides, } \\
& \mathrm{m}(3)=\text { suspended mass from the ex-vessel release of radionuclides, } \\
& \mathrm{m}(4)=\text { suspended mass from the late in-vessel release of radionuclides, } \\
& \mathrm{m}(5)=\text { suspended mass from the release of nonradioactive materials during the gap release } \\
& \mathrm{m}(6)=\begin{array}{l}
\text { suspended mass from the release of nonradioactive materials during the in-vessel phase } \\
\text { of the accident, }
\end{array} \\
& \mathrm{m}(7)=\begin{array}{l}
\text { suspended mass from the release of nonradioactive materials during the ex-vessel phase } \\
\text { of the accident, and }
\end{array} \\
& \mathrm{m}(8)=\begin{array}{l}
\text { suspended mass from the release of nonradioactive materials following the ex-vessel } \\
\text { phase of the accident. }
\end{array}
\end{aligned}
$$

Similarly, the source rate of aerosol to the containment atmosphere is defined to be: 
Correlations

$$
\dot{s}=\sum_{i=1}^{8} \dot{s}(i)
$$

where the component sources, $\dot{\mathrm{s}}(\mathrm{i})$, are defined consistently with the definitions of $\mathrm{m}(\mathrm{i})$ for $\mathrm{i}=1$ to 8 above.

The rate of change of the aerosol mass suspended in the containment is calculated based on the total mass. The results are then apportioned to the various components according to their mass fractions.

To test this treatment of multiple aerosol sources, a comparison was made to the predictions of the CONTAIN code. The comparison involved calculation of suspended aerosol mass from two sources. The first component source operated for 1800 seconds at a rate of 10 grams per second. The second source operated at 170 grams per second for 4680 seconds from 1800 to 6480 seconds. Results are shown in Figure 22. The correlation produces predictions of the suspended mass from the first source (first component of the aerosol) and the suspended mass from the second component that are in good agreement with predictions of the CONTAIN code. Small discrepancies between the two predictions of suspended mass are readily apparent only at the times of highest aerosol concentration which are also times of sudden changes in the source rate. The delay in the attenuation of the first aerosol component as the second aerosol component agglomerates (ages) is quite accurately predicted as is the sharp attenuation of the first component once the second aerosol component has agglomerated sufficiently to begin rapid sedimentation. The long-term decreases in suspended aerosol mass concentrations are quite accurately predicted for both the first and second components.

Note that the comparisons shown in Figures 20 through 22 also test the approach taken here to aerosol aging. The satisfactory agreement between predictions obtained by solving the aerosol dynamic equation in detail and predictions obtained from the correlation over the entire time interval suggests that the correlation approach to aerosol aging is satisfactory. 


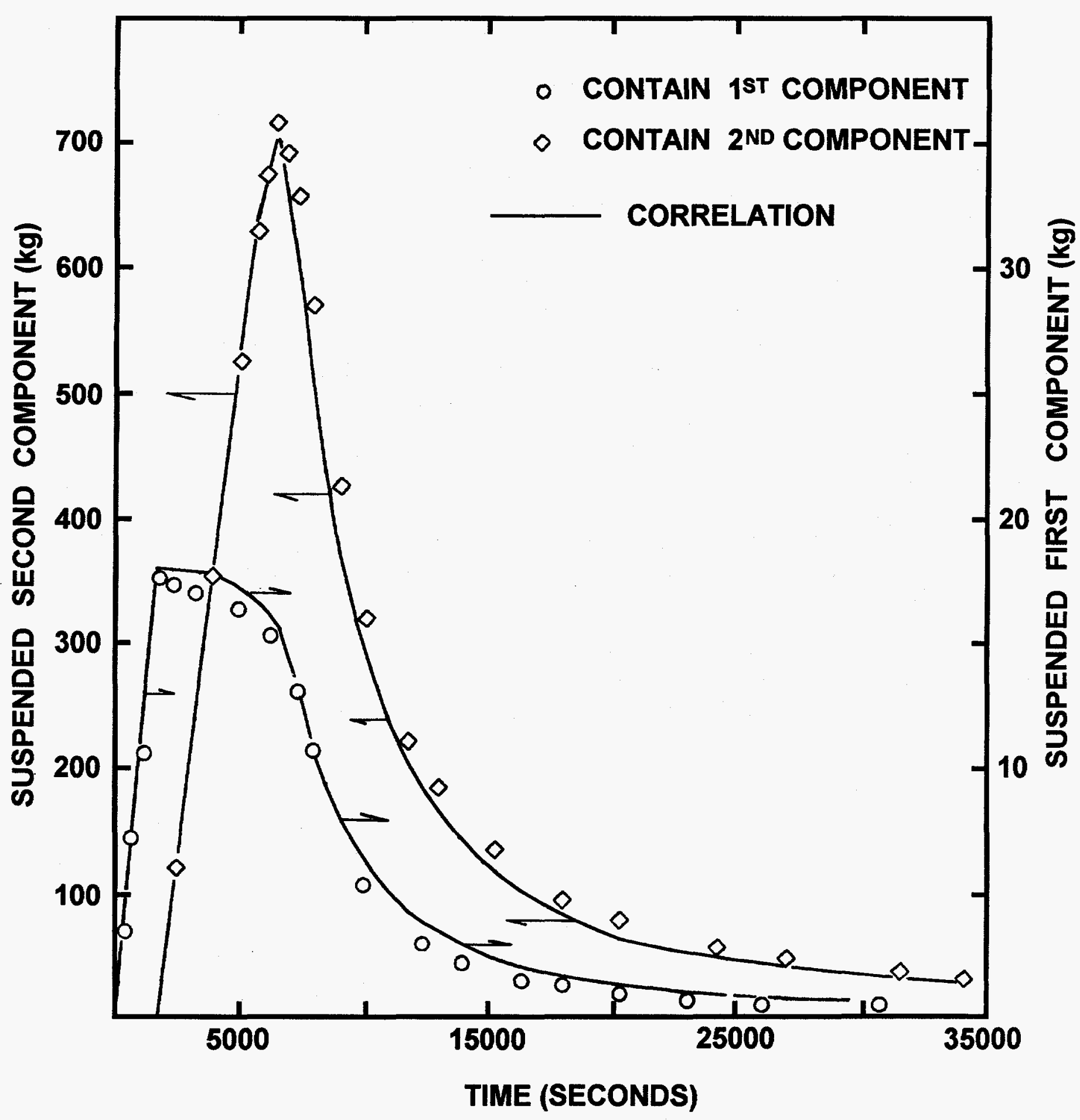

Figure 22. Comparison of the predictions of the CONTAIN code and the predictions of the modified correlation method for a situation involving two aerosol sources 


\section{Monte Carlo Uncertainty Analysis}

The correlation model described in Chapter IV represents one level of simplification over the complete solution of the aerosol dynamic equation. Comparisons presented in Chapter IV show that the correlational model, when properly calibrated against a more detailed model, yields adequately accurate descriptions of the aerosol mass suspended in a containment atmosphere and, consequently, the decontamination of the atmosphere by natural aerosol processes.

The correlational model including multiple components and multiple mechanisms for agglomeration and deposition of aerosol particles is still too complicated to meet the objectives for a simplified model sought here. The simplification sought for this work is a single differential equation for each class of radioactive material specified in the revised severe accident source term. This highly simplified model of natural aerosol decontamination processes is described by:

$$
\frac{d D F_{i}(t)}{d t}=\lambda_{i}(P, t) D F_{i}(+)
$$

where

$$
\begin{aligned}
\mathrm{DF}_{\mathrm{i}}(+)= & \text { decontamination factor for the } \mathrm{i}^{\text {th }} \text { class of radioactive aerosol at time } \mathrm{t} \text { where } \mathrm{i} \\
& \text { indicates material released in the gap, in-vessel, ex-vessel, or late in-vessel phases of } \\
& \text { a severe reactor accident, } \\
\lambda_{\mathrm{i}}(\mathrm{P}, \mathrm{t})= & \text { decontamination coefficient for the } \mathrm{i}^{\text {th }} \text { class of radioactive aerosol, and } \\
\mathrm{P}= & \text { thermal power of the reactor in question }
\end{aligned}
$$

The decontamination factor as used here is the mass of the particular class of radioactive aerosol injected into the containment (or drywell) atmosphere divided by the mass that remains suspended in the atmosphere. Note that the source term for the class of radioactive aerosol is not explicitly denoted as a term in this highly simplified equation. The effects of the source term are subsumed in the effective decontamination coefficient, $\lambda_{\mathbf{i}}(\mathrm{P}, \mathrm{t})$.

In principle, the values of the decontamination coefficients for the highly simplified model will be very complicated functions of time and accident conditions. For the purposes of the simplification sought here, the decontamination coefficients are taken to be piecewise constant over selected time intervals. That is, over a time interval from $t_{1}$ to $t_{2}$, the simplified differential equation can be integrated to yield:

$$
\ln \left[D F_{i}\left(t_{2}\right) / D F_{i}\left(t_{1}\right)\right]=\lambda_{e}\left(t_{2}, t_{1}\right)\left(t_{2}-t_{1}\right)
$$

where $\lambda_{\mathrm{e}}\left(\mathrm{t}_{2}, \mathrm{t}_{1}\right)$ is the average, effective decontamination coefficient over the time interval.

The values of the average, effective decontamination coefficients are obtained from the Monte Carlo uncertainty analysis of the correlational model of aerosol behavior. The Monte Carlo uncertainty analysis is done by accumulating sets of values of the decontamination factors for each of the four classes of radioactive aerosol at selected times. Each member of the set is a result of calculations using particular values of the uncertain parameters described in Chapter III. These uncertain parameters are 
indicative of uncertainties in plant geometry, accident conditions and phenomenological uncertainties concerning aerosol processes. Values of the uncertain parameters are selected randomly according to their respective uncertainty distributions for individual calculations.

Average effective decontamination coefficients over selected time intervals are calculated using the integrated form of the highly simplified aerosol model. The selected time intervals used here are:

- the duration of the gap release phase of an accident (0-1800 $\mathrm{s}$ for pressurized water reactors and 0$3600 \mathrm{~s}$ for boiling water reactors)

- the duration of the in-vessel release phase of an accident (1800-6480 $\mathrm{s}$ for pressurized water reactors and $3600-9000 \mathrm{~s}$ for boiling water reactors)

- the duration of the ex-vessel release phase of an accident (6480-13680 s for pressurized water reactors and $9000-19800 \mathrm{~s}$ for boiling water reactors)

- the interval from the end of ex-vessel release to the end of the late in-vessel release phase of an accident (13680-42480 $\mathrm{s}$ for pressurized water reactors and 19800-45000 $\mathrm{s}$ for boiling water reactors)

Decontamination factors were also calculated at $80,000,100,000$, and 120,000 seconds. Average, effective decontamination coefficients were calculated for the appropriate time intervals.

The accumulated sets of decontamination factors and average, effective decontamination factors were analyzed using nonparametric order statistics as described elsewhere [2,3]. These analyses yield uncertainty distributions for the decontamination factors and average, effective decontamination coefficients. Values of the decontamination factors and decontamination coefficients at selected quantiles of the distribution yield descriptions of the uncertainty in the predicted decontamination that can be achieved by natural aerosol processes. For the purposes of this work, median ( 50 percentile) values are considered best estimates. The 90th percentile and 10th percentile values are considered reasonable upper and lower bounds.

Uncertainty analyses were done for pressurized water reactors having operating powers of 1000,2000 , 3000 , and $4000 \mathrm{MW}$ (th). Analyses were done for boiling water reactors with operating powers of 1500 , 2500 , and $3500 \mathrm{MW}$ (th). Analyses were also done for hypothetical radiological design basis accidents at reactors with operating powers of 2000,3000 , and $4000 \mathrm{MW}$ (th). These radiological design basis accidents involve safety features that prevent ex-vessel and late in-vessel release of radioactive aerosols to the containment atmosphere. In all of the calculations, Monte Carlo calculations were continued until there was a 99 percent confidence that 95 percent of the possible range of decontamination factors had been sampled.

Results of the various calculations are described in the subsections below.

\section{A. Uncertainty Analyses for Pressurized Water Reactors}

Typical results obtained with the correlational model of aerosol behavior for an accident in a $3000 \mathrm{MW}$ (th) pressurized water reactor are shown in Figures 23 to 27. The pressures and temperatures in containment selected from the appropriate uncertainty distributions are shown in Figure 23. These 
in containment selected from the appropriate uncertainty distributions are shown in Figure 23. These pressures and temperatures have, of course, been assumed to be steady during each phase of the accident. This only approximates, in a stepwise fashion, the expected, real conditions in reactor containments during a severe accident. The calculated rate of steam condensation, which is responsible for diffusiophoretic deposition of aerosol, is shown in Figure 24. The rate of steam condensation is quite large during the gap and in-vessel phases of an accident. Usually steam condensation rates are calculated to be larger during gap release than during in-vessel release. For some conditions, steam condensation rates are calculated to be somewhat larger during the in-vessel release phase than during the gap release phase of an accident. Steam condensation rates drop sharply during the ex-vessel release phase. Water evolved from decomposing concrete is largely converted to hydrogen by reaction with residual zirconium in the core debris. In some calculations, the steam condensation rate was predicted to be zero during the ex-vessel release phase. Steam condensation rates increase during the late in-vessel release phase and the post-release phase of an accident though they remain small in comparison with steam condensation rates during the gap and in-vessel release phases of an accident.

The difference between the bulk atmosphere temperature and average surface temperatures in the containment is shown as a function of time in Figure 24. This temperature difference is responsible for the thermophoretic deposition of aerosol. It is apparent that this aerosol deposition mechanism is more important in the later phases of an accident.

The effective particle size of aerosols in the containment is shown as a function of time in Figure 25. The particle size decreases slightly at the start of in-vessel release as relatively large amounts of fresh, unaged aerosol are injected into the containment atmosphere. Coagulation of this material leads to aerosol growth throughout the in-vessel release phase of the accident.

More dramatic particle growth occurs during the ex-vessel release phase of the accident as large quantities of nonradioactive aerosol are injected into the containment atmosphere. Growth of aerosol particles shown in this example is typical of some fraction of the Monte Carlo sample calculations for pressurized water reactors. In others, growth to as much as $6 \mu \mathrm{m}$ was predicted.

Average particle size begins to decrease at the completion of the ex-vessel release as large particles sediment from the atmosphere. The rate of decrease in this particular example is not especially rapid. In this example calculation, late in-vessel release was predicted to include significant quantities of nonradioactive aerosol mass which could partially replenish the inventory of large particles in the atmosphere. Once this material began to coagglomerate, the average aerosol particle size fell more rapidly.

Concentrations of the four classes of radioactive material (gap release, in-vessel release, ex-vessel release, and late in-vessel release) present in the containment atmosphere are shown in Figure 26. Note that nonradioactive aerosol concentrations are not indicated in this figure. These nonradioactive aerosol materials make up most of the aerosol in containment after the start of ex-vessel release. The concentrations of each class of radioactive material rises to maximum while the source of that material is operative. Once the source stops, the concentrations of aerosol decrease. In the case of materials released to the atmosphere during the gap release phase and the in-vessel release phase, the rate of decrease of concentration is slow. Concentrations of total aerosol mass in the containment atmosphere are low enough that it takes time for particles to agglomerate to the point gravitational settling augments particle removal by other mechanisms. 


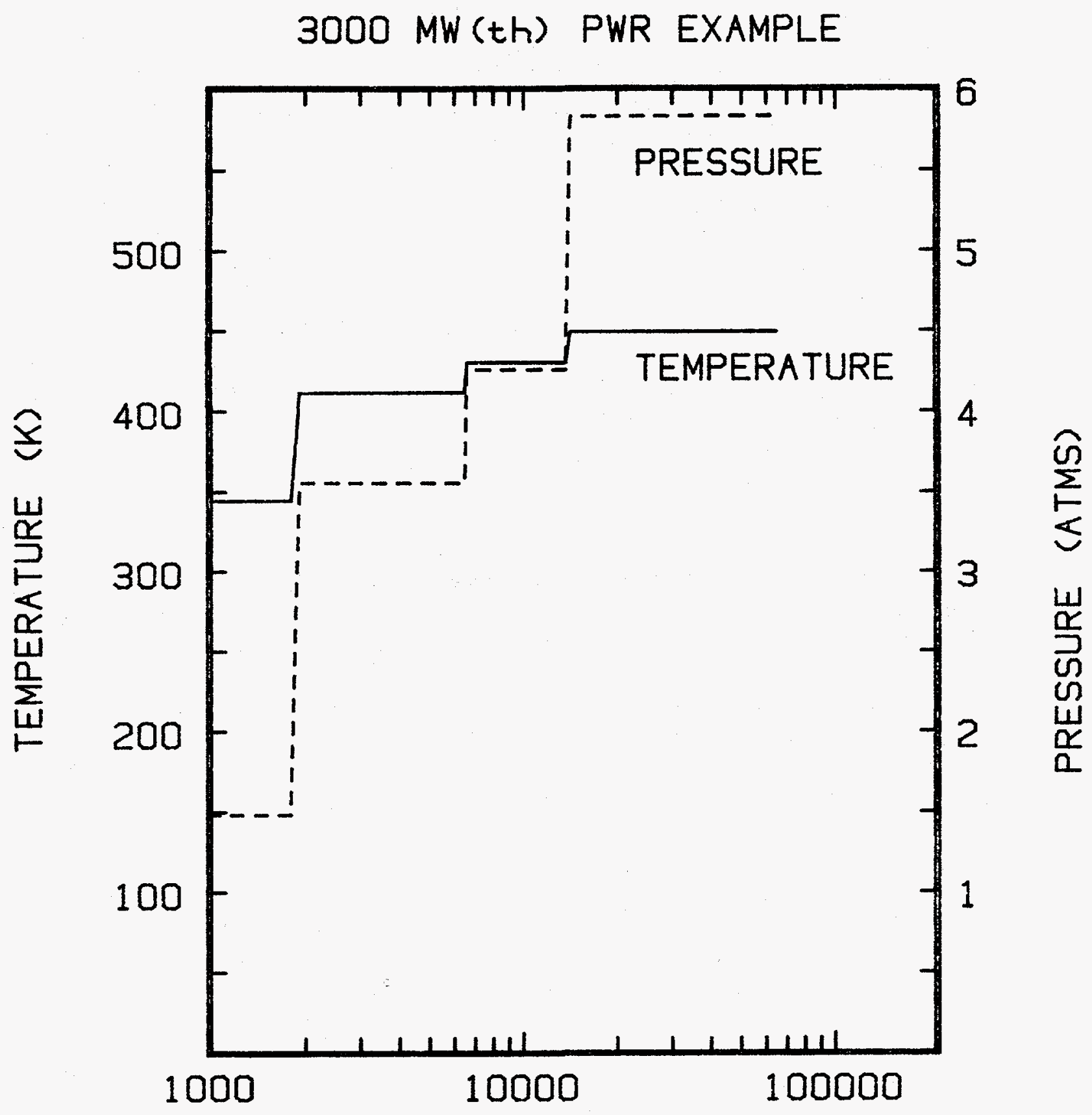

TIME (SECONDS)

Figure 23. Containment temperatures and pressures selected for the various phases of a particular accident at a $3000 \mathrm{MW}(\mathrm{th})$ pressurized water reactor 


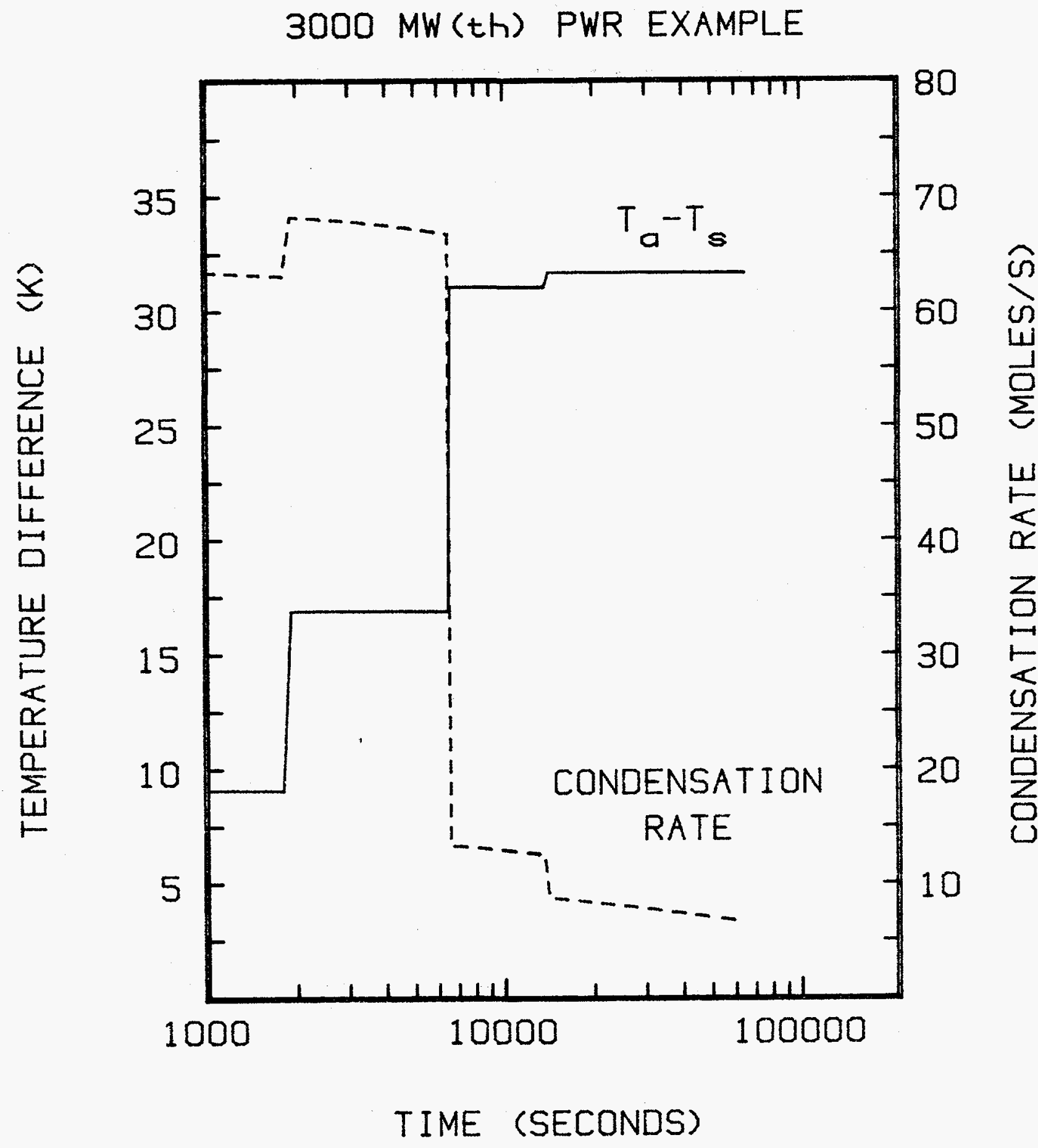

Figure 24. Steam condensation rates and the difference between the atmosphere temperature and structural surface temperatures in a particular accident at a $3000 \mathrm{MW}(\mathrm{th})$ pressurized water reactor 


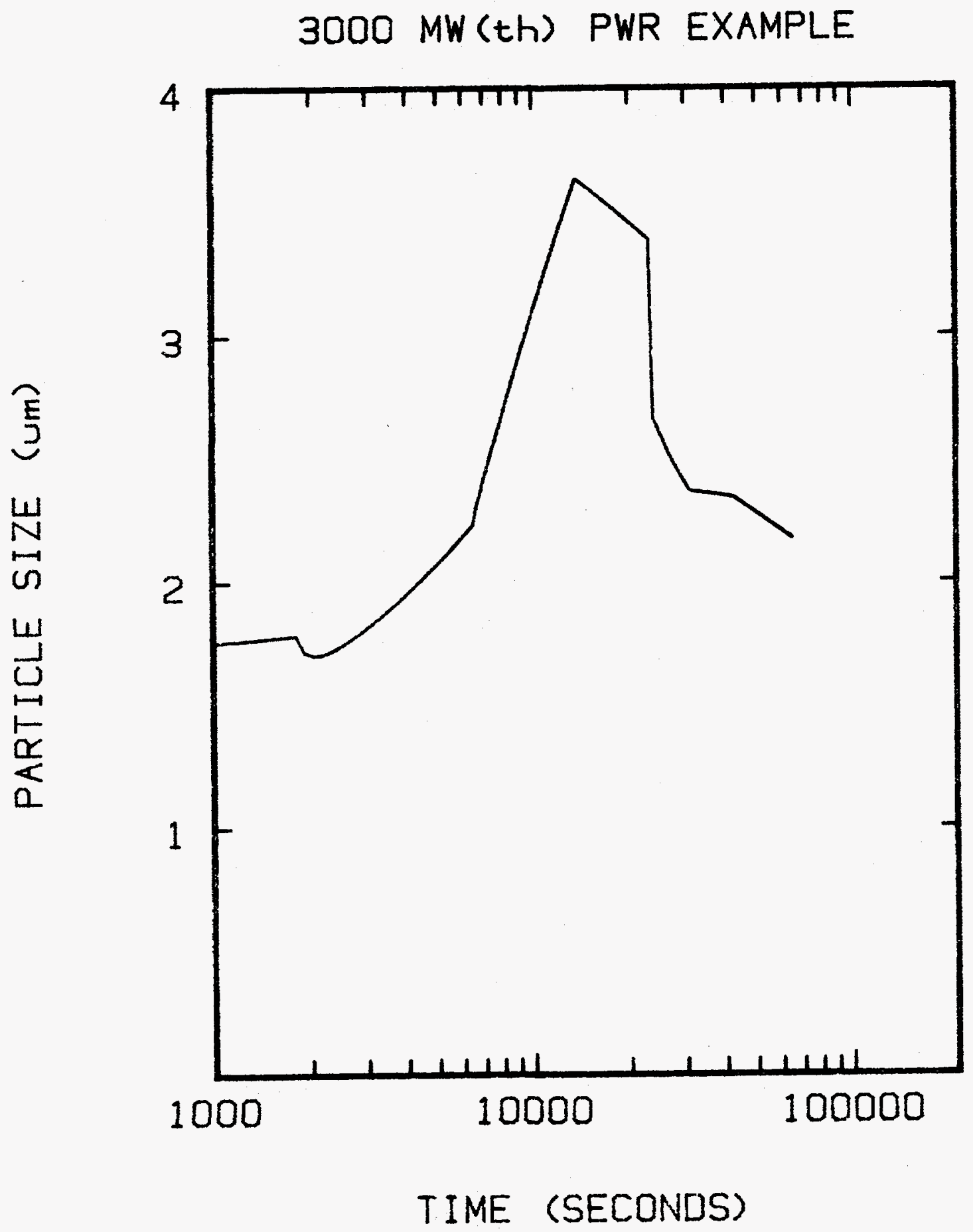

Figure 25. Effective size of aerosol particles in the containment of a $3000 \mathrm{MW}(\mathrm{th})$ pressurized water reactor during a particular accident 


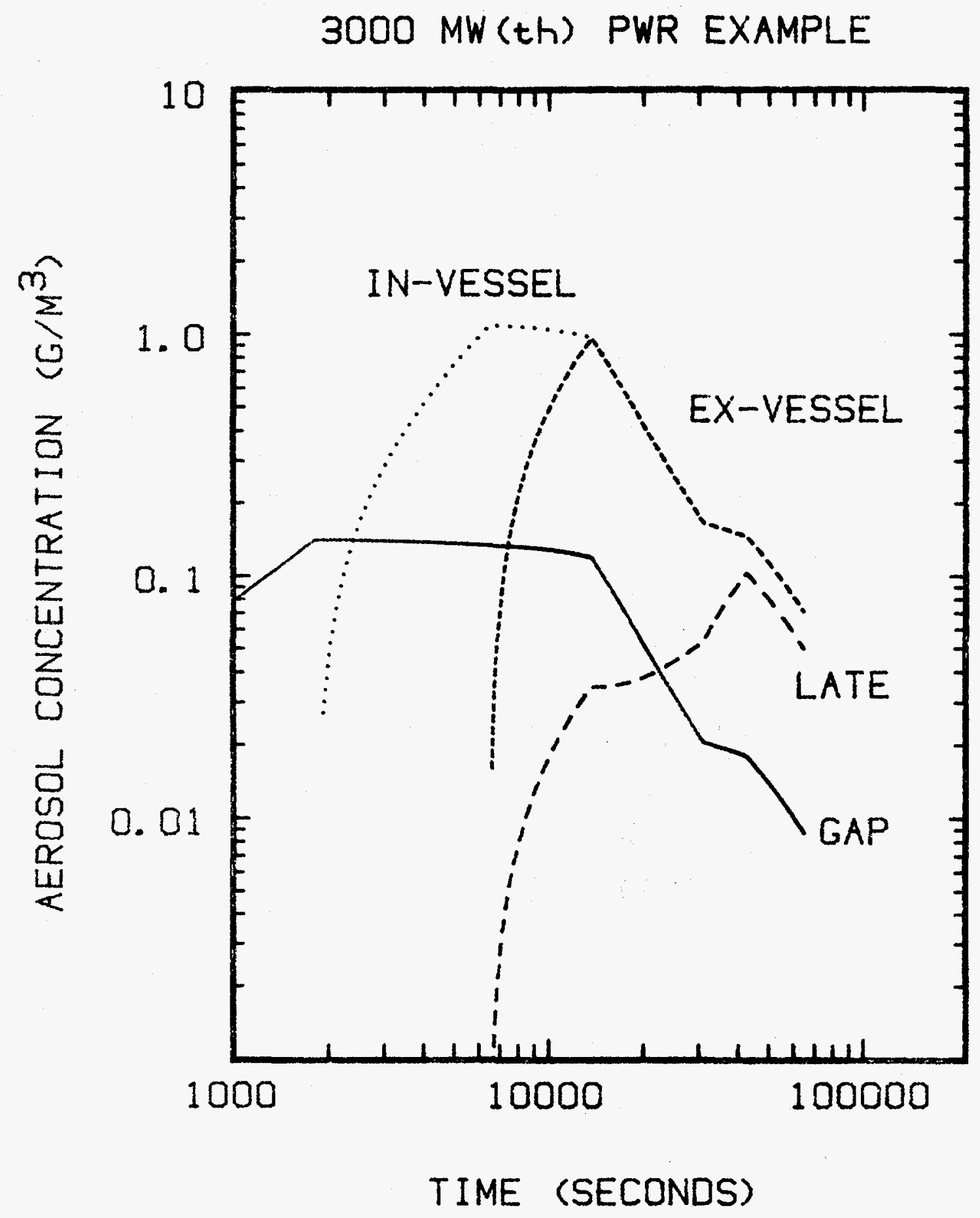

Figure 26. Concentrations of various classes of radioactive materials in the containment atmosphere as a function of time for a particular $3000 \mathrm{MW}(\mathrm{th})$ pressurized water reactor accident 
The concentration of aerosol material released to the containment during the ex-vessel phase of the accident falls rapidly once the source stops. Total aerosol mass in the containment atmosphere, including nonradioactive aerosol mass, is high enough that agglomeration rapidly produces particles that sediment.

The concentration of late in-vessel release is a more complicated function of time than is the case for other classes of radioactive aerosol. This, of course, is because the late in-vessel release overlaps the ex-vessel release. When the ex-vessel release stops, there is still continuing late in-vessel release of aerosol to the atmosphere.

Deposition velocities for aerosol particles by various mechanisms are shown as functions of time in Figure 27. Initially, diffusiophoresis and thermophoresis are the most important mechanisms of aerosol deposition. Gravitational settling does not become the most important deposition mechanism until the ex-vessel release phase of the accident. Turbulent diffusion contributes to particle deposition but its contribution is small in nearly all cases compared with those of other mechanisms.

The time dependence of the diffusiophoretic, thermophoretic and turbulent diffusion mechanisms illustrates how coupled the behavior of aerosols is to thermal hydraulic conditions in the containment. The approximate descriptions of these thermal hydraulic conditions affect the contributions to particle deposition by these phoretic and diffusive mechanisms. Substantial uncertainty has been attributed to predictions of the thermal hydraulic conditions in the Monte Carlo calculations discussed here.

Uncertainty distributions were calculated for decontamination factors and decontamination coefficients for pressurized water reactors having operating powers of 1000, 2000, 3000, and $4000 \mathrm{MW}(\mathrm{th})$. Example distributions at various times for the decontamination factor for aerosol injected into the containment during the in-vessel release of an accident are shown in Figures 28 to 31. The Monte Carlo uncertainty method yields uncertainty distributions that depend on the prescribed level of confidence. Shown in these are the cumulative distributions at a 50 percent confidence level (bars) and at a 90 percent confidence level (dashed lines). At a 50 percent confidence level, there is a 50 percent chance that the decontamination factor indicative of a particular quantile of the distribution lies within the indicated range and a 50 percent chance that it is either larger or smaller than the indicated range. The ranges indicative of the quantiles of the distribution can be narrowed by increasing the number of sampled results used to construct the distribution. Unfortunately, these ranges decrease in size with the square root of the number of samples so there is a practical limit to the narrowing that can be achieved. Sampling was continued for this work until the confidence bounds on the uncertainty distribution were small in comparison with the range of the distribution between the 10th and 90th percentile.

There is a qualitative variation with time in the uncertainty distributions of the decontamination factor for gap release material. Initially, the distribution is narrow and has almost uniform probability density. As time increases, the distribution broadens and develops "tails" at high and low values more reminiscent of lognormal distributions.

Interest here focuses on the median (50 percentile), 10 percentile and 90 percentile values of the distributions. These values are taken to be the best estimate, reasonable lower bound and reasonable upper bound values, respectively. These values are summarized in Tables 18 to 21 . Mean values, which are sometimes used as conservative estimates, are summarized in Table 21. 
Monte Carlo

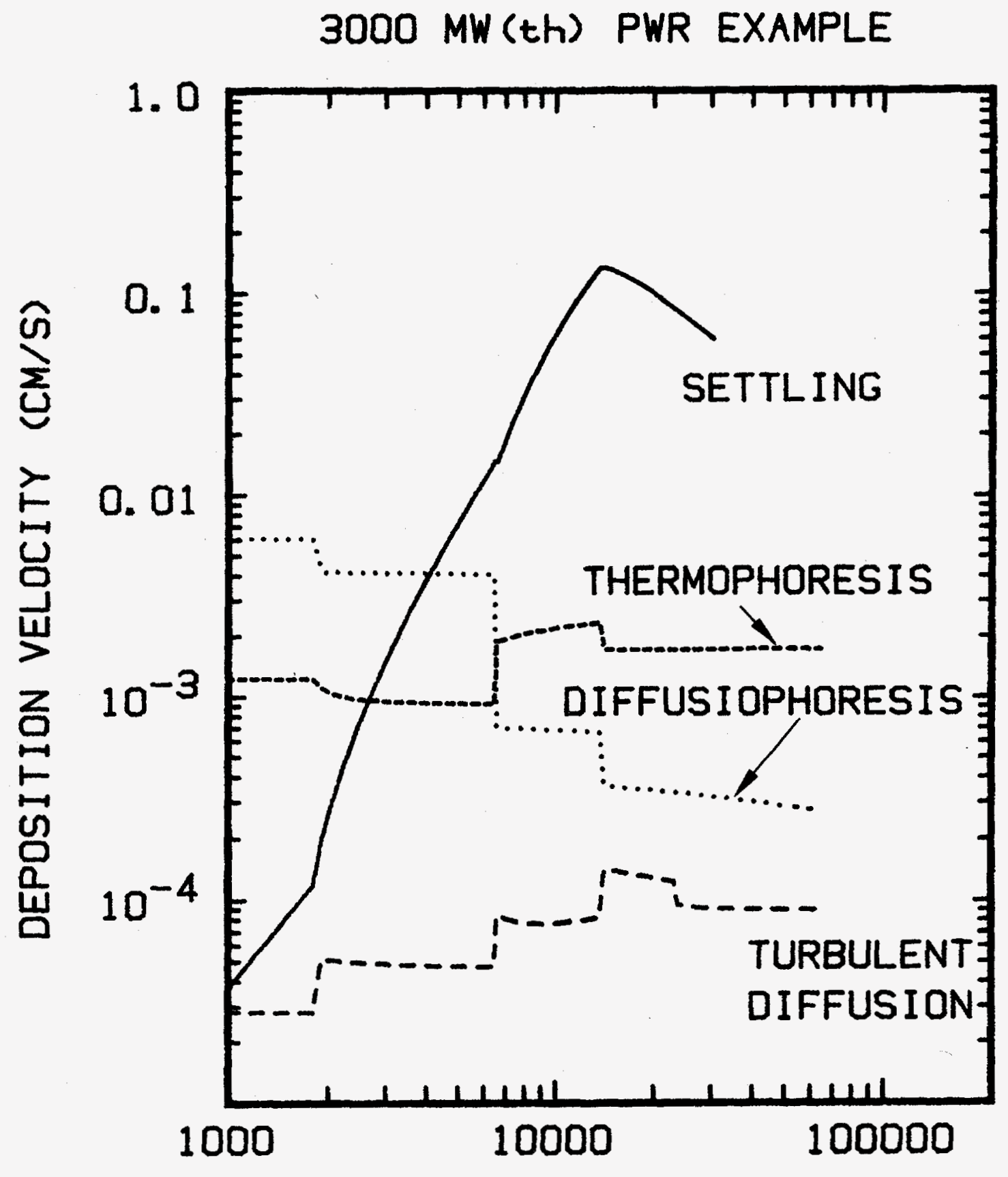

TIME (SECONDS)

Figure 27. Aerosol deposition velocities by various mechanisms during a particular accident at a $3000 \mathrm{MW}$ (th) pressurized water reactor 
3000 MW (th) PWR 6480 SECONDS

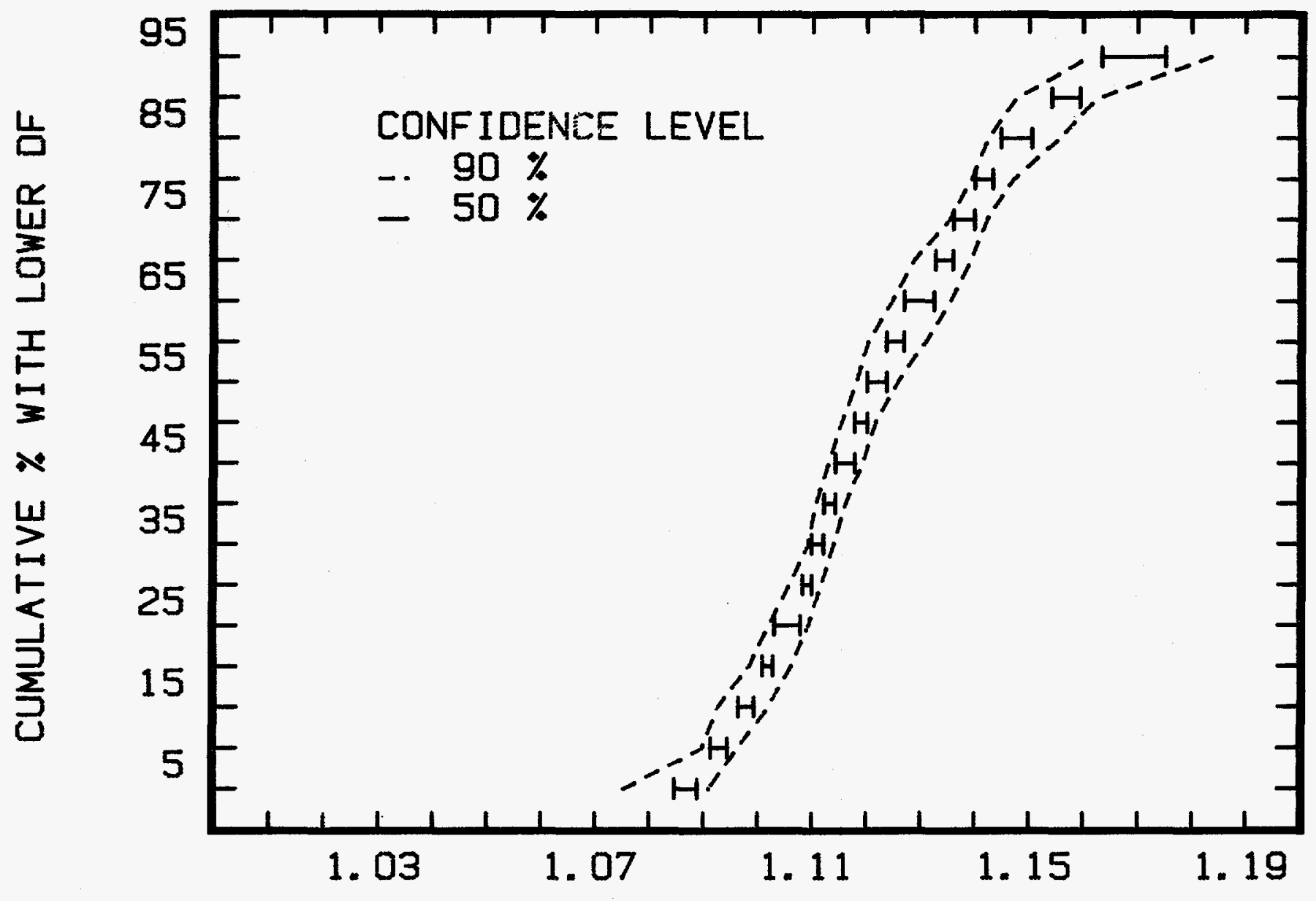

\section{DECONTAMINATION FACTOR}

Figure 28. Uncertainty distribution for the decontamination factor for in-vessel release in a $3000 \mathrm{MW}$ PWR at the end of in-vessel release (6480 seconds). Solid lines indicate the distribution at the 50 percent confidence level. Dashed lines indicate the distribution at the 90 percent confidence level. 


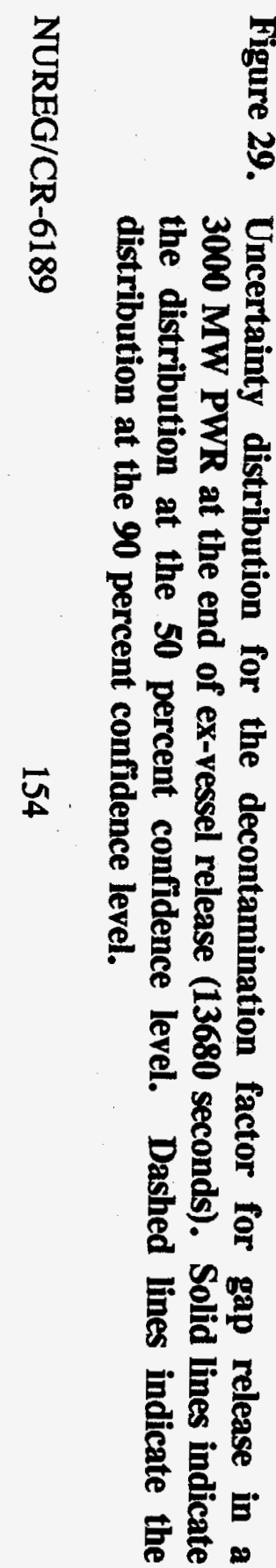

CUMULATIVE \% WITH LOWER DF

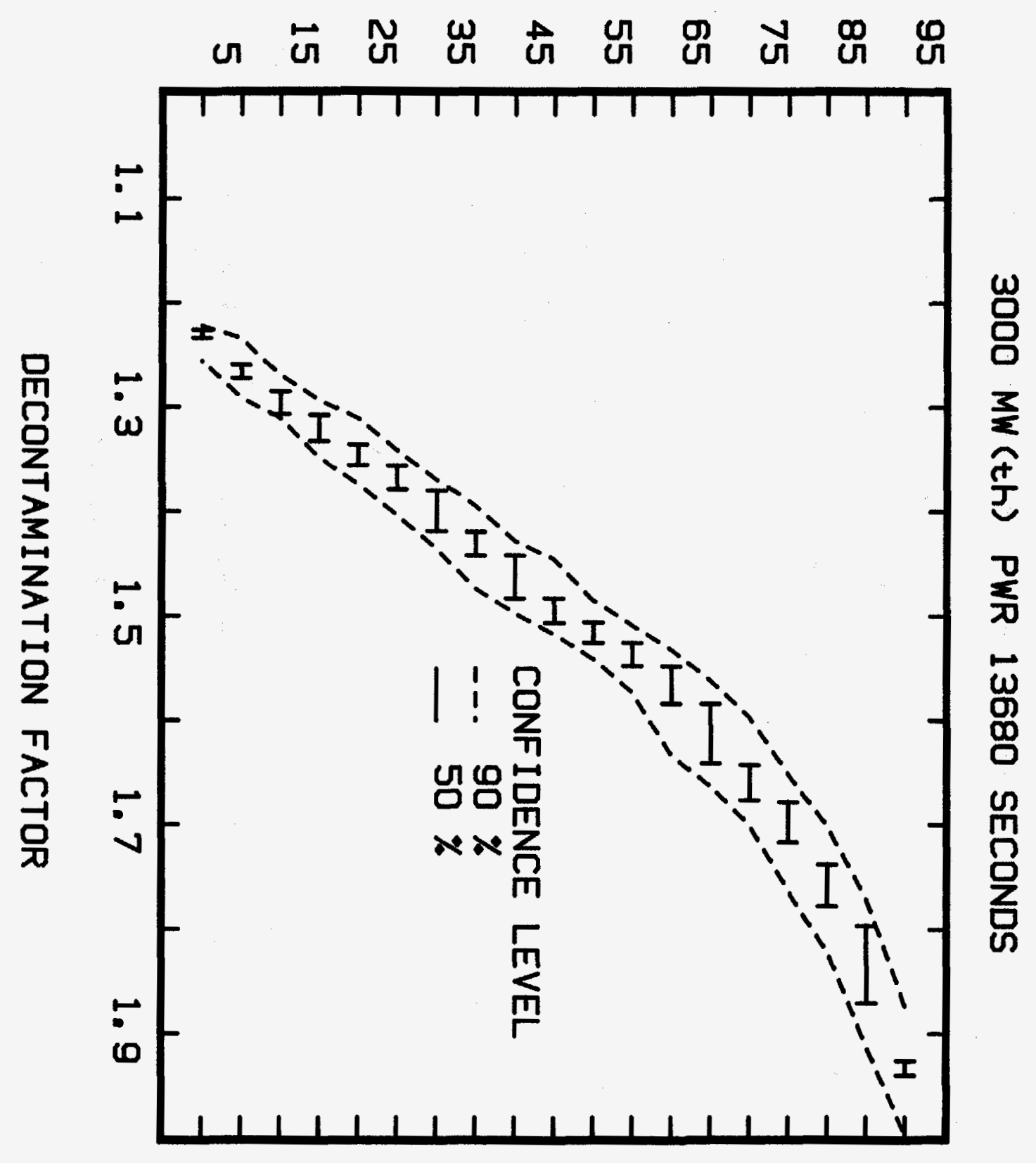


3000 MW (th) PWR 42480 SECONDS

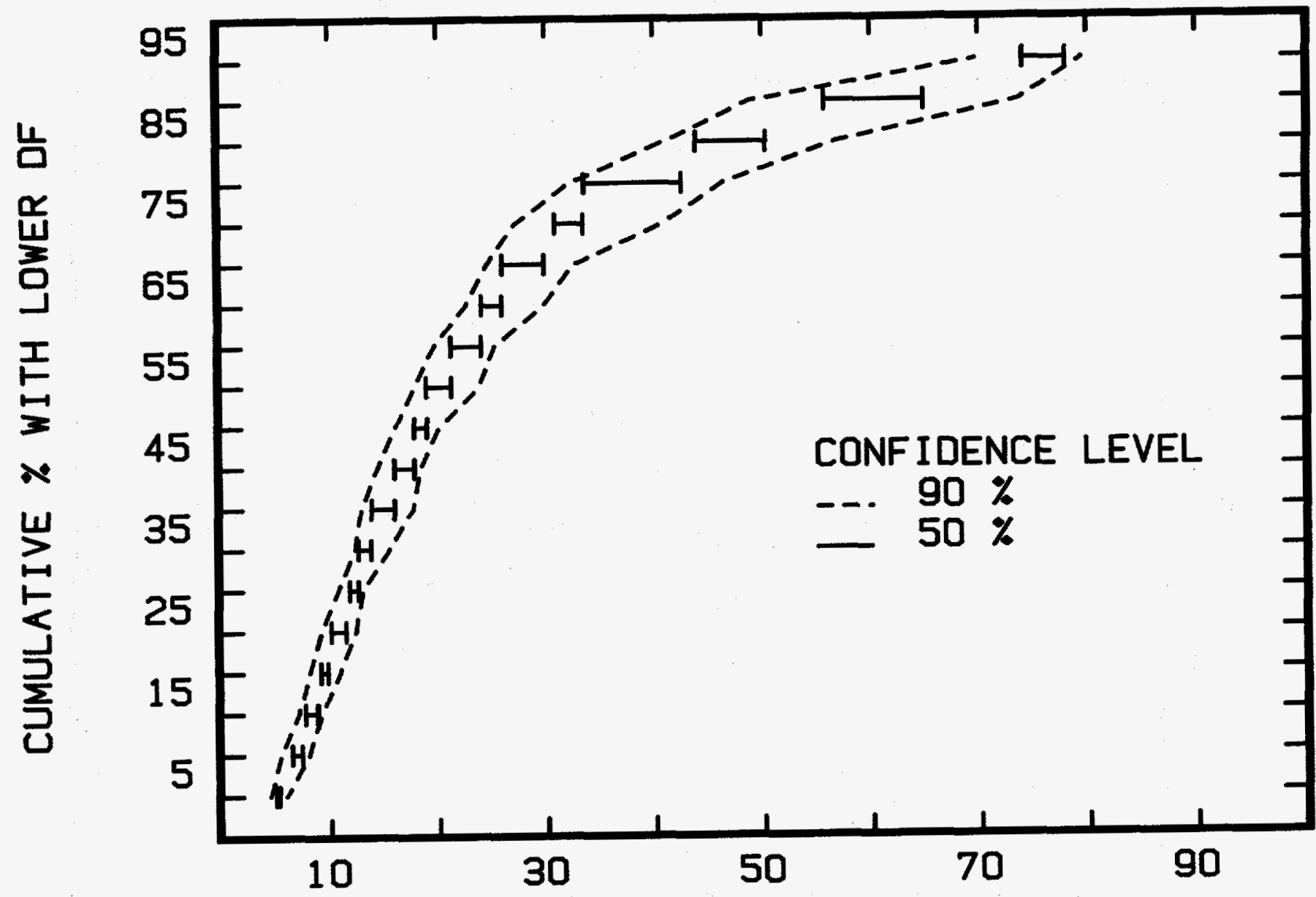

DECONTAMINATION FACTOR

Figure 30. Uncertainty distribution for the decontamination factor for in-vessel release in a 3000 MW PWR at the end of late in-vessel release (42480 seconds). Solid lines indicate the distribution at the 50 percent confidence level. Dashed lines indicate the distribution at the 90 percent confidence level. 


\section{MW(th) PWR 80000 SECONDS}

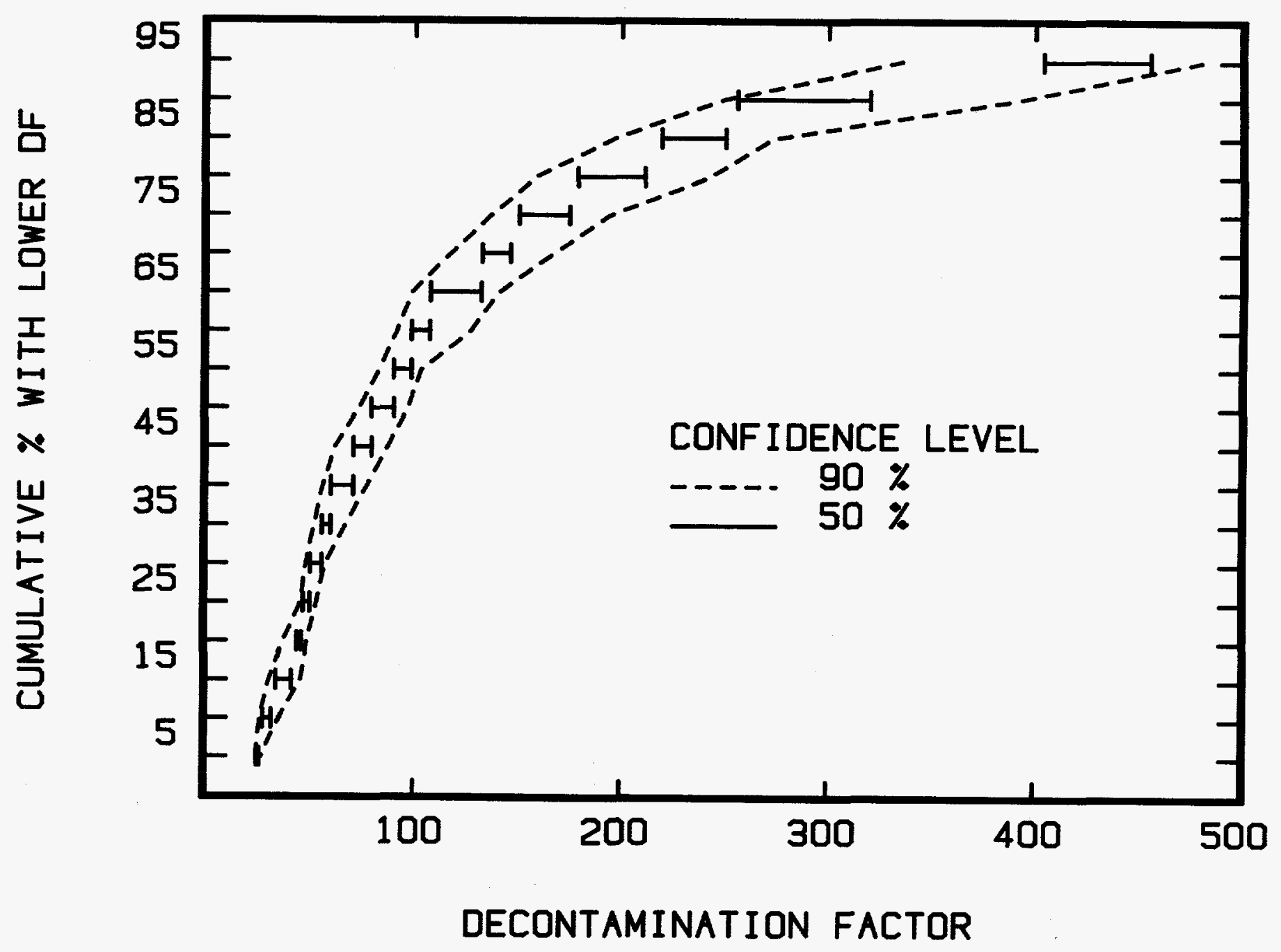

Figure 31. Uncertainty distribution for the decontamination factor for gap release in a $3000 \mathrm{MW}$ PWR at 80000 seconds. Solid lines indicate the distribution at the 50 percent confidence level. Dashed lines indicate the distribution at the 90 percent confidence level. 
Table 18. Median (50 percentile) decontamination factors for pressurized water reactors

\begin{tabular}{|c|c|c|c|c|}
\hline$\underset{\text { (s) }}{\text { Time }}$ & Gap release $^{*}$ & In-vessel release ${ }^{*}$ & Ex-vessel release & $\begin{array}{l}\text { Late in-vessel } \\
\text { release }\end{array}$ \\
\hline \multicolumn{5}{|c|}{$1000 \mathrm{MW}(\mathrm{th})$} \\
\hline $\begin{array}{r}0 \\
1800 \\
6480 \\
13680 \\
42480 \\
80000 \\
100000 \\
120000\end{array}$ & $\begin{array}{c}1.0 \\
1.0139 \text { to } 1.0141 \\
1.0865 \text { to } 1.0921 \\
1.722 \text { to } 1.764 \\
41.864 \text { to } 46.577 \\
190.68 \text { to } 225.78 \\
302.30 \text { to } 364.41 \\
440.65 \text { to } 502.47\end{array}$ & $\begin{array}{c}1.0 \\
1.0 \\
1.0379 \text { to } 1.0396 \\
1.650 \text { to } 1.665 \\
40.054 \text { to } 44.162 \\
176.58 \text { to } 214.29 \\
219.24 \text { to } 344.76 \\
416.65 \text { to } 473.37\end{array}$ & $\begin{array}{c}1.0 \\
1.0 \\
1.0 \\
1.319 \text { to } 1.326 \\
33.445 \text { to } 35.746 \\
142.83 \text { to } 165.78 \\
234.66 \text { to } 247.81 \\
316.37 \text { to } 373.60\end{array}$ & $\begin{array}{c}1.0 \\
1.0 \\
1.0 \\
1.319 \text { to } 1.326 \\
1.966 \text { to } 1.994 \\
8.364 \text { to } 9.039 \\
12.212 \text { to } 13.635 \\
16.769 \text { to } 17.837\end{array}$ \\
\hline \multicolumn{5}{|c|}{$2000 \mathrm{MW}(\mathrm{th})$} \\
\hline $\begin{array}{r}0 \\
1800 \\
6480 \\
13680 \\
42480 \\
80000 \\
100000 \\
120000\end{array}$ & $\begin{array}{c}1.0 \\
1.0166 \text { to } 1.0170 \\
1.106 \text { to } 1.109 \\
1.536 \text { to } 1.562 \\
23.579 \text { to } 25.203 \\
116.14 \text { to } 128.28 \\
183.43 \text { to } 206.29 \\
239.19 \text { to } 296.71\end{array}$ & $\begin{array}{c}1.0 \\
1.0 \\
1.0449 \text { to } 1.0458 \\
1.448 \text { to } 1.478 \\
22.110 \text { to } 23.811 \\
110.98 \text { to } 121.36 \\
167.54 \text { to } 195.85 \\
225.36 \text { to } 281.06\end{array}$ & $\begin{array}{c}1.0 \\
1.0 \\
1.0 \\
1.210 \text { to } 1.224 \\
17.966 \text { to } 19.650 \\
94.262 \text { to } 100.79 \\
144.84 \text { to } 165.66 \\
191.88 \text { to } 224.04\end{array}$ & $\begin{array}{c}1.0 \\
1.0 \\
1.0 \\
1.210 \text { to } 1.224 \\
1.866 \text { to } 1.888 \\
8.334 \text { to } 8.923 \\
12.521 \text { to } 13.478 \\
17.403 \text { to } 19.236\end{array}$ \\
\hline \multicolumn{5}{|c|}{$3000 \mathrm{MW}(\mathrm{th})$} \\
\hline $\begin{array}{r}0 \\
1800 \\
6480 \\
13680 \\
42480 \\
80000 \\
100000 \\
120000\end{array}$ & $\begin{array}{c}1.0 \\
1.0180 \text { to } 1.0188 \\
1.118 \text { to } 1.120 \\
1.483 \text { to } 1.506 \\
17.801 \text { to } 18.980 \\
79.178 \text { to } 90.087 \\
121.24 \text { to } 143.62 \\
167.72 \text { to } 197.89\end{array}$ & $\begin{array}{c}1.0 \\
1.0 \\
1.0484 \text { to } 1.0501 \\
1.376 \text { to } 1.410 \\
16.501 \text { to } 17.823 \\
73.889 \text { to } 83.500 \\
113.34 \text { to } 132.38 \\
158.01 \text { to } 187.39\end{array}$ & $\begin{array}{c}1.0 \\
1.0 \\
1.0 \\
1.176 \text { to } 1.187 \\
14.520 \text { to } 15.326 \\
64.028 \text { to } 68.882 \\
97.223 \text { to } 110.08 \\
126.77 \text { to } 159.44\end{array}$ & $\begin{array}{c}1.0 \\
1.0 \\
1.0 \\
1.176 \text { to } 1.187 \\
1.824 \text { to } 1.842 \\
7.408 \text { to } 7.706 \\
11.480 \text { to } 12.100 \\
15.627 \text { to } 17.059\end{array}$ \\
\hline \multicolumn{5}{|c|}{$4000 \mathrm{MW}(\mathrm{th})$} \\
\hline $\begin{array}{r}0 \\
1800 \\
6480 \\
13680 \\
42480 \\
80000 \\
100000 \\
120000\end{array}$ & $\begin{array}{c}1.0 \\
1.0198 \text { to } 1.0204 \\
1.127 \text { to } 1.135 \\
1.451 \text { to } 1.475 \\
15.073 \text { to } 17.136 \\
72.474 \text { to } 79.694 \\
105.31 \text { to } 122.55 \\
141.80 \text { to } 175.12\end{array}$ & $\begin{array}{c}1.0 \\
1.0 \\
1.0535 \text { to } 1.0566 \\
1.348 \text { to } 1.372 \\
14.222 \text { to } 15.575 \\
68.818 \text { to } 74.647 \\
97.921 \text { to } 112.73 \\
130.48 \text { to } 163.47\end{array}$ & $\begin{array}{c}1.0 \\
1.0 \\
1.0 \\
1.159 \text { to } 1.167 \\
12.295 \text { to } 12.952 \\
58.153 \text { to } 61.597 \\
82.022 \text { to } 95.739 \\
105.30 \text { to } 140.80\end{array}$ & $\begin{array}{c}1.0 \\
1.0 \\
1.0 \\
1.159 \text { to } 1.167 \\
1.793 \text { to } 1.807 \\
8.115 \text { to } 8.709 \\
12.185 \text { to } 13.296 \\
17.137 \text { to } 18.797\end{array}$ \\
\hline $50 \mathrm{p}$ & & & & \\
\hline
\end{tabular}


Monte Carlo

Table 19. Reasonable upper bound ( 90 percentile) decontamination factors for pressurized water reactors

\begin{tabular}{|c|c|c|c|c|}
\hline $\begin{array}{c}\text { Time } \\
\text { (s) }\end{array}$ & Gap release ${ }^{*}$ & In-vessel release & Ex-vessel release ${ }^{*}$ & $\begin{array}{l}\text { Late in-vessel } \\
\text { release }\end{array}$ \\
\hline \multicolumn{5}{|c|}{$1000 \mathrm{MW}(\mathrm{th})$} \\
\hline $\begin{array}{r}0 \\
1800 \\
6480 \\
13680 \\
42480 \\
80000 \\
100000 \\
120000\end{array}$ & $\begin{array}{c}1.0 \\
1.0183 \text { to } 1.0212 \\
1.129 \text { to } 1.158 \\
2.703 \text { to } 3.415 \\
182.02 \text { to } 251.23 \\
881.98 \text { to } 1984 \\
1471 \text { to } 3298 \\
1942 \text { to } 4039\end{array}$ & $\begin{array}{c}1.0 \\
1.0 \\
1.0567 \text { to } 1.0708 \\
2.557 \text { to } 3.124 \\
173.79 \text { to } 241.10 \\
839.92 \text { to } 1779 \\
1378 \text { to } 3058 \\
1824 \text { to } 3834\end{array}$ & $\begin{array}{c}1.0 \\
1.0 \\
1.0 \\
1.615 \text { to } 1.760 \\
109.08 \text { to } 143.65 \\
545.32 \text { to } 966.99 \\
841.14 \text { to } 1573 \\
1231 \text { to } 2275\end{array}$ & $\begin{array}{c}1.0 \\
1.0 \\
1.0 \\
1.615 \text { to } 1.760 \\
2.448 \text { to } 2.602 \\
26.298 \text { to } 36.512 \\
41.367 \text { to } 62.949 \\
57.410 \text { to } 100.02\end{array}$ \\
\hline \multicolumn{5}{|c|}{$2000 \mathrm{MW}(\mathrm{th})$} \\
\hline $\begin{array}{r}0 \\
1800 \\
6480 \\
13680 \\
42480 \\
80000 \\
100000 \\
120000\end{array}$ & $\begin{array}{c}1.0 \\
1.0204 \text { to } 1.0218 \\
1.135 \text { to } 1.152 \\
1.927 \text { to } 2.040 \\
66.046 \text { to } 94.890 \\
314.96 \text { to } 519.47 \\
489.15 \text { to } 771.55 \\
698.76 \text { to } 1136.3\end{array}$ & $\begin{array}{c}1.0 \\
1.0 \\
1.0573 \text { to } 1.0652 \\
1.816 \text { to } 1.911 \\
62.438 \text { to } 88.867 \\
299.49 \text { to } 486.10 \\
461.45 \text { to } 715.04 \\
657.17 \text { to } 1064.9\end{array}$ & $\begin{array}{c}1.0 \\
1.0 \\
1.0 \\
1.368 \text { to } 1.408 \\
48.321 \text { to } 67.606 \\
229.08 \text { to } 355.88 \\
355.47 \text { to } 521.18 \\
509.43 \text { to } 753.04\end{array}$ & $\begin{array}{c}1.0 \\
1.0 \\
1.0 \\
1.368 \text { to } 1.408 \\
2.209 \text { to } 2.477 \\
18.942 \text { to } 30.101 \\
31.614 \text { to } 49.200 \\
46.191 \text { to } 74.616\end{array}$ \\
\hline \multicolumn{5}{|c|}{$3000 \mathrm{MW}(\mathrm{th})$} \\
\hline $\begin{array}{r}0 \\
1800 \\
6480 \\
13680 \\
42480 \\
80000 \\
100000 \\
120000\end{array}$ & $\begin{array}{c}1.0 \\
1.0225 \text { to } 1.0241 \\
1.148 \text { to } 1.163 \\
1.771 \text { to } 1.912 \\
48.882 \text { to } 73.749 \\
249.38 \text { to } 390.59 \\
370.08 \text { to } 633.76 \\
537.28 \text { to } 909.14\end{array}$ & $\begin{array}{c}1.0 \\
1.0 \\
1.0614 \text { to } 1.0684 \\
1.657 \text { to } 1.773 \\
45.017 \text { to } 68.597 \\
231.88 \text { to } 361.67 \\
341.22 \text { to } 589.89 \\
498.94 \text { to } 847.37\end{array}$ & $\begin{array}{c}1.0 \\
1.0 \\
1.0 \\
1.296 \text { to } 1.350 \\
36.403 \text { to } 53.345 \\
182.47 \text { to } 275.40 \\
262.50 \text { to } 443.27 \\
386.37 \text { to } 642.99\end{array}$ & $\begin{array}{c}1.0 \\
1.0 \\
1.0 \\
1.296 \text { to } 1.350 \\
2.028 \text { to } 2.246 \\
16.542 \text { to } 24.483 \\
27.807 \text { to } 41.678 \\
40.889 \text { to } 62.364\end{array}$ \\
\hline \multicolumn{5}{|c|}{$4000 \mathrm{MW}(\mathrm{th})$} \\
\hline $\begin{array}{r}0 \\
1800 \\
6480 \\
13680 \\
42480 \\
80000 \\
100000 \\
120000\end{array}$ & $\begin{array}{c}1.0 \\
1.0245 \text { to } 1.0263 \\
1.173 \text { to } 1.187 \\
1.717 \text { to } 1.832 \\
37.184 \text { to } 50.376 \\
188.96 \text { to } 284.55 \\
295.22 \text { to } 430.96 \\
411.39 \text { to } 572.71\end{array}$ & $\begin{array}{c}1.0 \\
1.0 \\
1.0682 \text { to } 1.0794 \\
1.572 \text { to } 1.674 \\
34.471 \text { to } 47.011 \\
175.35 \text { to } 266.82 \\
276.71 \text { to } 400.32 \\
381.73 \text { to } 524.15\end{array}$ & $\begin{array}{c}1.0 \\
1.0 \\
1.0 \\
1.261 \text { to } 1.292 \\
28.374 \text { to } 35.705 \\
142.30 \text { to } 205.23 \\
222.14 \text { to } 311.90 \\
310.58 \text { to } 407.19\end{array}$ & $\begin{array}{c}1.0 \\
1.0 \\
1.0 \\
1.261 \text { to } 1.292 \\
1.954 \text { to } 2.104 \\
15.056 \text { to } 17.592 \\
24.561 \text { to } 26.624 \\
36.858 \text { to } 43.798\end{array}$ \\
\hline & & & & \\
\hline
\end{tabular}


Table 20. Reasonable lower bound (10 percentile) decontamination factors for pressurized water reactors

\begin{tabular}{|c|c|c|c|c|}
\hline $\begin{array}{c}\text { Time } \\
\text { (s) }\end{array}$ & Gap release & In-vessel release & Ex-vessel release & $\begin{array}{c}\text { Late in-vessel } \\
\text { release }\end{array}$ \\
\hline \multicolumn{5}{|c|}{$1000 \mathrm{MW}(\mathrm{th})$} \\
\hline $\begin{array}{r}0 \\
1800 \\
6480 \\
13680 \\
42480 \\
80000 \\
100000 \\
120000\end{array}$ & $\begin{array}{c}1.0 \\
1.0090 \text { to } 1.0100 \\
1.0566 \text { to } 1.0630 \\
1.296 \text { to } 1.354 \\
9.172 \text { to } 11.875 \\
43.173 \text { to } 71.588 \\
59.249 \text { to } 109.07 \\
81.756 \text { to } 140.22\end{array}$ & $\begin{array}{c}1.0 \\
1.0 \\
1.0228 \text { to } 1.0254 \\
1.257 \text { to } 1.302 \\
8.709 \text { to } 11.392 \\
41.798 \text { to } 69.039 \\
56.130 \text { to } 103.96 \\
77.437 \text { to } 132.81\end{array}$ & $\begin{array}{c}1.0 \\
1.0 \\
1.0 \\
1.135 \text { to } 1.158 \\
7.680 \text { to } 10.201 \\
39.181 \text { to } 61.051 \\
49.681 \text { to } 91.557 \\
72.140 \text { to } 117.70\end{array}$ & $\begin{array}{c}1.0 \\
1.0 \\
1.0 \\
1.135 \text { to } 1.158 \\
1.812 \text { to } 1.842 \\
4.428 \text { to } 5.765 \\
6.047 \text { to } 8.015 \\
8.022 \text { to } 9.682\end{array}$ \\
\hline \multicolumn{5}{|c|}{$2000 \mathrm{MW}$ (th) } \\
\hline $\begin{array}{r}0 \\
1800 \\
6480 \\
13680 \\
42480 \\
80000 \\
100000 \\
120000\end{array}$ & $\begin{array}{c}1.0 \\
1.0116 \text { to } 1.0127 \\
1.0790 \text { to } 1.0861 \\
1.268 \text { to } 1.328 \\
6.792 \text { to } 9.358 \\
37.833 \text { to } 47.019 \\
49.734 \text { to } 72.033 \\
69.248 \text { to } 92.634\end{array}$ & $\begin{array}{c}1.0 \\
1.0 \\
1.0323 \text { to } 1.0355 \\
1.196 \text { to } 1.257 \\
62.438 \text { to } 88.867 \\
35.377 \text { to } 44.433 \\
47.258 \text { to } 68.355 \\
65.270 \text { to } 86.639\end{array}$ & $\begin{array}{c}1.0 \\
1.0 \\
1.0 \\
1.0943 \text { to } 1.119 \\
5.518 \text { to } 7.854 \\
32.030 \text { to } 39.161 \\
42.908 \text { to } 57.528 \\
58.341 \text { to } 77.048\end{array}$ & $\begin{array}{c}1.0 \\
1.0 \\
1.0 \\
1.0943 \text { to } 1.119 \\
1.713 \text { to } 1.756 \\
5.371 \text { to } 5.759 \\
6.979 \text { to } 8.509 \\
8.643 \text { to } 10.163\end{array}$ \\
\hline \multicolumn{5}{|c|}{$3000 \mathrm{MW}(\mathrm{th})$} \\
\hline $\begin{array}{r}0 \\
1800 \\
6480 \\
13680 \\
42480 \\
80000 \\
100000 \\
120000\end{array}$ & $\begin{array}{c}1.0 \\
1.0134 \text { to } 1.0141 \\
1.0899 \text { to } 1.0964 \\
1.235 \text { to } 1.292 \\
5.484 \text { to } 8.028 \\
26.033 \text { to } 35.055 \\
38.433 \text { to } 51.203 \\
49.375 \text { to } 66.840\end{array}$ & $\begin{array}{c}1.0 \\
1.0 \\
1.0361 \text { to } 1.0389 \\
1.166 \text { to } 1.214 \\
5.141 \text { to } 7.451 \\
24.620 \text { to } 32.786 \\
36.631 \text { to } 47.891 \\
46.267 \text { to } 62.427\end{array}$ & $\begin{array}{c}1.0 \\
1.0 \\
1.0 \\
1.074 \text { to } 1.100 \\
4.622 \text { to } 6.686 \\
22.628 \text { to } 29.449 \\
33.800 \text { to } 43.691 \\
41.879 \text { to } 56.023\end{array}$ & $\begin{array}{c}1.0 \\
1.0 \\
1.0 \\
1.074 \text { to } 1.100 \\
1.683 \text { to } 1.725 \\
4.998 \text { to } 5.620 \\
6.237 \text { to } 7.811 \\
7.876 \text { to } 9.902\end{array}$ \\
\hline \multicolumn{5}{|c|}{$4000 \mathrm{MW}(\mathrm{th})$} \\
\hline $\begin{array}{r}0 \\
1800 \\
6480 \\
13680 \\
42480 \\
80000 \\
100000 \\
120000\end{array}$ & $\begin{array}{c}1.0 \\
1.0138 \text { to } 1.0151 \\
1.0931 \text { to } 1.0996 \\
1.244 \text { to } 1.285 \\
4.499 \text { to } 6.880 \\
27.493 \text { to } 37.999 \\
34.177 \text { to } 49.384 \\
49.156 \text { to } 64.782\end{array}$ & $\begin{array}{c}1.0 \\
1.0 \\
1.0365 \text { to } 1.0404 \\
1.168 \text { to } 1.203 \\
4.227 \text { to } 6.467 \\
22.522 \text { to } 29.763 \\
32.170 \text { to } 46.203 \\
46.294 \text { to } 61.022\end{array}$ & $\begin{array}{c}1.0 \\
1.0 \\
1.0 \\
1.0662 \text { to } 1.0824 \\
3.815 \text { to } 5.812 \\
20.116 \text { to } 26.921 \\
29.718 \text { to } 41.195 \\
41.890 \text { to } 55.353\end{array}$ & $\begin{array}{c}1.0 \\
1.0 \\
1.0 \\
1.0662 \text { to } 1.0824 \\
1.610 \text { to } 1.669 \\
5.269 \text { to } 6.002 \\
6.847 \text { to } 7.861 \\
8.484 \text { to } 9.966\end{array}$ \\
\hline & anfiden intarn & & & \\
\hline
\end{tabular}


Table 21. Mean decontamination factors for pressurized water reactors

\begin{tabular}{|c|c|c|c|c|}
\hline $\begin{array}{c}\text { Time } \\
\text { (s) }\end{array}$ & Gap release & In-vessel release & Ex-vessel release & $\begin{array}{c}\text { Late in-vessel } \\
\text { release }\end{array}$ \\
\hline \multicolumn{5}{|c|}{$1000 \mathrm{MW}(\mathrm{th})$} \\
\hline $\begin{array}{r}0 \\
1800 \\
6480 \\
13680 \\
42480 \\
80000 \\
100000 \\
120000\end{array}$ & $\begin{array}{c}1.0 \\
1.0148 \\
1.101 \\
2.478 \\
395.12 \\
28779 \\
80534 \\
162843\end{array}$ & $\begin{array}{c}1.0 \\
1.0 \\
1.0426 \\
2.260 \\
324.70 \\
22904 \\
64011 \\
129365\end{array}$ & $\begin{array}{c}1.0 \\
1.0 \\
1.0 \\
1.384 \\
65.740 \\
1732 \\
4503 \\
8809\end{array}$ & $\begin{array}{l}1.0 \\
1.0 \\
1.0 \\
1.384 \\
2.085 \\
16.724 \\
30.378 \\
47.884\end{array}$ \\
\hline \multicolumn{5}{|c|}{$2000 \mathrm{MW}(\mathrm{th})$} \\
\hline $\begin{array}{r}0 \\
1800 \\
6480 \\
13680 \\
42480 \\
80000 \\
100000 \\
120000\end{array}$ & $\begin{array}{l}1.0 \\
1.0168 \\
1.111 \\
1.602 \\
34.265 \\
189.69 \\
297.44 \\
417.92\end{array}$ & $\begin{array}{c}1.0 \\
1.0 \\
1.046 \\
1.508 \\
32.237 \\
178.23 \\
279.37 \\
392.46\end{array}$ & $\begin{array}{c}1.0 \\
1.0 \\
1.0 \\
1.232 \\
25.412 \\
137.16 \\
214.80 \\
301.98\end{array}$ & $\begin{array}{l}1.0 \\
1.0 \\
1.0 \\
1.232 \\
1.946 \\
12.152 \\
19.449 \\
27.821\end{array}$ \\
\hline \multicolumn{5}{|c|}{$3000 \mathrm{MW}$ (th) } \\
\hline $\begin{array}{r}0 \\
1800 \\
6480 \\
13680 \\
42480 \\
80000 \\
100000 \\
120000\end{array}$ & $\begin{array}{l}1.0 \\
1.0185 \\
1.122 \\
1.518 \\
25.612 \\
128.43 \\
199.26 \\
279.01\end{array}$ & $\begin{array}{l}1.0 \\
1.0 \\
1.0506 \\
1.420 \\
23.951 \\
120.15 \\
186.40 \\
261.01\end{array}$ & $\begin{array}{c}1.0 \\
1.0 \\
1.0 \\
1.189 \\
19.448 \\
96.412 \\
149.50 \\
209.54\end{array}$ & $\begin{array}{l}1.0 \\
1.0 \\
1.0 \\
1.189 \\
1.873 \\
10.355 \\
16.247 \\
23.003\end{array}$ \\
\hline \multicolumn{5}{|c|}{$4000 \mathrm{MW}(\mathrm{th})$} \\
\hline $\begin{array}{r}0 \\
1800 \\
6480 \\
13680 \\
42480 \\
80000 \\
100000 \\
120000\end{array}$ & $\begin{array}{l}1.0 \\
1.0201 \\
1.135 \\
1.492 \\
20.467 \\
107.09 \\
167.19 \\
236.95\end{array}$ & $\begin{array}{c}1.0 \\
1.0 \\
1.0556 \\
1.387 \\
19.009 \\
99.394 \\
155.14 \\
219.84\end{array}$ & $\begin{array}{c}1.0 \\
1.0 \\
1.0 \\
1.169 \\
15.633 \\
80.287 \\
125.22 \\
177.37\end{array}$ & $\begin{array}{l}1.0 \\
1.0 \\
1.0 \\
1.169 \\
1.818 \\
9.902 \\
15.578 \\
22.200\end{array}$ \\
\hline
\end{tabular}


Selected quantiles of the distributions for the average, effective decontamination coefficients calculated from the decontamination factors are summarized in Tables 22 to 24 . Mean values are listed in Table 25. Inspection of the tables shows that there is a unique decontamination factor for a class of material while the source of material is operative. When the source of a particular class of material stops, the decontamination coefficient increases to a value that is the same for all materials that do not have an operative source. This uniformity is shown by the plot of decontamination coefficients as a function of time in Figure 32. There are, then, just 10 average effective decontamination factors that are needed to describe the behavior of the aerosol. These are the coefficients for materials while they are being released and the decontamination coefficients for gap release material at times later than $1800 \mathrm{~s}$.

The decontamination coefficients for material released during the late in-vessel release phase are somewhat more complicated than other decontamination coefficients. The late in-vessel release and the ex-vessel release overlap for some time ( 2 hours). While both the ex-vessel release and the late in-vessel release occur, these materials have the same decontamination coefficient. When ex-vessel release stops, the decontamination coefficient for aerosol produced by the ex-vessel release rises to the values for aerosols produced during gap release. The decontamination coefficient for aerosol produced by late invessel release remains small as long as the late in-vessel release is occurring. When late in-vessel release stops, the decontamination coefficient rises to be the same as the decontamination coefficients for aerosol produced by gap release, in-vessel release and ex-vessel release.

The average, effective decontamination coefficients calculated for aerosol produced during the gap release phases of accidents have an unusual significance. These are the same as effective decontamination coefficients calculated for other classes of materials after their respective sources cease. The median ( 50 percentile), upper bound ( 90 percentile) and lower bound (10 percentile) effective decontamination coefficients for gap release material are shown as functions of time in Figure 33.

Median values of the gap release decontamination coefficients for various reactor powers are shown as functions of time in Figure 34. The dependencies of the decontamination coefficients on reactor power during various time intervals are complicated. During the gap releases and the in-vessel release, the decontamination coefficient decreases with decreasing power. During the ex-vessel release, the opposite occurs. Decontamination coefficients increase with decreasing reactor power. During the late stages of accidents, the decontamination coefficients are nearly independent of reactor power.

The dependencies of the ten important decontamination coefficients on reactor power are more clearly shown in Figures 35 and 37 . The dependencies during the middle stages of accidents appear to be described by expressions of the form:

$$
\lambda_{\mathrm{e}}=\mathrm{A}+\mathrm{B} / \mathrm{P}
$$

where A and B are parameters that depend on time. The dependencies on power during early stages of accidents are essentially linear:

$$
\lambda_{\mathrm{e}}=\mathrm{A}+\mathrm{BP}
$$

Correlations for the average, effective decontamination coefficients with power were formulated by fitting the above expressions to calculated values of the decontamination coefficients. Parameter values derived from these fits are summarized in Table 26. 
Monte Carlo

Table 22. Median (50 percentile) effective decontamination coefficients for pressurized water reactors

\begin{tabular}{|c|c|c|c|c|}
\hline Time interval (s) & $\begin{array}{c}\text { Gap release } \\
\left(\mathbf{h r} \mathbf{r}^{-1}\right)\end{array}$ & $\begin{array}{c}\text { In-vessel release } \\
\left(\mathbf{h r} \mathbf{r}^{-1}\right)\end{array}$ & $\begin{array}{c}\text { Ex-vessel release } \\
\left(\mathbf{h r}^{-1}\right)\end{array}$ & $\begin{array}{l}\text { Late in-vessel } \\
\text { release }\left(\mathrm{hr}^{-1}\right)\end{array}$ \\
\hline \multicolumn{5}{|l|}{$1000 \mathrm{MW}($ th) } \\
\hline $\begin{array}{c}0-1800 \\
1800-6480 \\
6480-13680 \\
13680-42480 \\
42480-80000 \\
80000-100000 \\
100000-120000\end{array}$ & $\begin{array}{c}0.0276 \text { to } 0.0280 \\
0.0532 \text { to } 0.0558 \\
0.233 \text { to } 0.237 \\
0.406 \text { to } 0.411 \\
0.134 \text { to } 0.147 \\
0.0832 \text { to } 0.0849 \\
0.0658 \text { to } 0.0682\end{array}$ & $\begin{array}{c}0.0 \\
0.0286 \text { to } 0.0299 \\
0.233 \text { to } 0.237 \\
0.406 \text { to } 0.411 \\
0.134 \text { to } 0.147 \\
0.0832 \text { to } 0.0849 \\
0.0658 \text { to } 0.0682\end{array}$ & $\begin{array}{c}0.0 \\
0.0 \\
0.138 \text { to } 0.141 \\
0.406 \text { to } 0.411 \\
0.134 \text { to } 0.147 \\
0.0832 \text { to } 0.0849 \\
0.0658 \text { to } 0.0682\end{array}$ & $\begin{array}{c}0.0 \\
0.0 \\
0.138 \text { to } 0.141 \\
0.0526 \text { to } 0.0547 \\
0.134 \text { to } 0.147 \\
0.0832 \text { to } 0.0849 \\
0.0658 \text { to } 0.0682\end{array}$ \\
\hline \multicolumn{5}{|l|}{$2000 \mathrm{MW}(\mathrm{th})$} \\
\hline $\begin{array}{c}0-1800 \\
1800-6480 \\
6480-13680 \\
13680-42480 \\
42480-80000 \\
80000-100000 \\
100000-120000\end{array}$ & $\begin{array}{c}0.0329 \text { to } 0.0337 \\
0.0653 \text { to } 0.0673 \\
0.164 \text { to } 0.173 \\
0.338 \text { to } 0.348 \\
0.144 \text { to } 0.152 \\
0.0835 \text { to } 0.0843 \\
0.0669 \text { to } 0.0677\end{array}$ & $\begin{array}{c}0.0 \\
0.0338 \text { to } 0.0334 \\
0.164 \text { to } 0.173 \\
0.338 \text { to } 0.348 \\
0.144 \text { to } 0.152 \\
0.0835 \text { to } 0.0843 \\
0.0669 \text { to } 0.0677\end{array}$ & $\begin{array}{c}0.0 \\
0.0 \\
0.0951 \text { to } 0.101 \\
0.338 \text { to } 0.348 \\
0.144 \text { to } 0.152 \\
0.0835 \text { to } 0.0843 \\
0.0669 \text { to } 0.0677\end{array}$ & $\begin{array}{c}0.0 \\
0.0 \\
0.0951 \text { to } 0.101 \\
0.0525 \text { to } 0.0544 \\
0.144 \text { to } 0.152 \\
0.0835 \text { to } 0.0843 \\
0.0669 \text { to } 0.0677\end{array}$ \\
\hline \multicolumn{5}{|l|}{$3000 \mathrm{MW}(\mathrm{th})$} \\
\hline $\begin{array}{c}0-1800 \\
1800-6480 \\
6480-13680 \\
13680-42480 \\
42480-80000 \\
80000-100000 \\
100000-120000\end{array}$ & $\begin{array}{c}0.0357 \text { to } 0.0373 \\
0.0713 \text { to } 0.0728 \\
0.140 \text { to } 0.144 \\
0.311 \text { to } 0.324 \\
0.134 \text { to } 0.138 \\
0.0824 \text { to } 0.0837 \\
0.0662 \text { to } 0.0673\end{array}$ & $\begin{array}{c}0.0 \\
0.0363 \text { to } 0.0376 \\
0.140 \text { to } 0.144 \\
0.311 \text { to } 0.324 \\
0.134 \text { to } 0.138 \\
0.0824 \text { to } 0.0837 \\
0.0662 \text { to } 0.0673\end{array}$ & $\begin{array}{c}0.0 \\
0.0 \\
0.0811 \text { to } 0.0859 \\
0.311 \text { to } 0.324 \\
0.134 \text { to } 0.138 \\
0.0824 \text { to } 0.0837 \\
0.0662 \text { to } 0.0673\end{array}$ & $\begin{array}{c}0.0 \\
0.0 \\
0.0811 \text { to } 0.0859 \\
0.0535 \text { to } 0.0548 \\
0.134 \text { to } 0.138 \\
0.0824 \text { to } 0.0837 \\
0.0662 \text { to } 0.0673\end{array}$ \\
\hline \multicolumn{5}{|l|}{$4000 \mathrm{MW}(\mathrm{th})$} \\
\hline $\begin{array}{c}0-1800 \\
1800-6480 \\
6480-13680 \\
13680-42480 \\
42480-80000 \\
80000-100000 \\
100000-120000\end{array}$ & $\begin{array}{c}0.0392 \text { to } 0.0403 \\
0.0793 \text { to } 0.0818 \\
0.125 \text { to } 0.131 \\
0.296 \text { to } 0.304 \\
0.147 \text { to } 0.154 \\
0.0836 \text { to } 0.0850 \\
0.0663 \text { to } 0.0667\end{array}$ & $\begin{array}{c}0.0 \\
0.0401 \text { to } 0.0423 \\
0.125 \text { to } 0.131 \\
0.296 \text { to } 0.304 \\
0.147 \text { to } 0.155 \\
0.0836 \text { to } 0.0850 \\
0.0663 \text { to } 0.0667\end{array}$ & $\begin{array}{c}0.0 \\
0.0 \\
0.0740 \text { to } 0.0773 \\
0.296 \text { to } 0.304 \\
0.147 \text { to } 0.155 \\
0.0836 \text { to } 0.0850 \\
0.0663 \text { to } 0.0667\end{array}$ & $\begin{array}{c}0.0 \\
0.0 \\
0.0740 \text { to } 0.0773 \\
0.0508 \text { to } 0.0519 \\
0.147 \text { to } 0.155 \\
0.0836 \text { to } 0.0850 \\
0.0663 \text { to } 0.0667\end{array}$ \\
\hline
\end{tabular}


Table 23. Reasonable upper bound ( 90 percentile) effective decontamination coefficients for pressurized water reactors

\begin{tabular}{|c|c|c|c|c|}
\hline Time interval (s) & $\begin{array}{c}\text { Gap release } \\
\left(\mathrm{hr}^{-1}\right)\end{array}$ & $\begin{array}{c}\text { In-vessel release } \\
\left(\mathrm{hr}^{-1}\right)\end{array}$ & $\begin{array}{c}\text { Ex-vessel release } \\
\left(\mathrm{hr}^{-1}\right)\end{array}$ & $\begin{array}{l}\text { Late in-vessel } \\
\text { release }^{*}\left(\mathbf{h r}^{-1}\right)\end{array}$ \\
\hline \multicolumn{5}{|l|}{$1000 \mathrm{MW}$ (th) } \\
\hline $\begin{array}{c}0-1800 \\
1800-6480 \\
6480-13680 \\
13680-42480 \\
42480-80000 \\
80000-100000 \\
100000-120000\end{array}$ & $\begin{array}{c}0.0362 \text { to } 0.0420 \\
0.0816 \text { to } 0.0989 \\
0.444 \text { to } 0.535 \\
0.518 \text { to } 0.554 \\
0.243 \text { to } 0.273 \\
0.102 \text { to } 0.109 \\
0.0803 \text { to } 0.0854\end{array}$ & $\begin{array}{c}0.0 \\
0.0424 \text { to } 0.0526 \\
0.444 \text { to } 0.535 \\
0.518 \text { to } 0.554 \\
0.243 \text { to } 0.273 \\
0.102 \text { to } 0.109 \\
0.0803 \text { to } 0.0854\end{array}$ & $\begin{array}{c}0.0 \\
0.0 \\
0.240 \text { to } 0.283 \\
0.518 \text { to } 0.554 \\
0.243 \text { to } 0.273 \\
0.102 \text { to } 0.109 \\
0.0803 \text { to } 0.0854\end{array}$ & $\begin{array}{c}0.0 \\
0.0 \\
0.240 \text { to } 0.283 \\
0.0714 \text { to } 0.0855 \\
0.243 \text { to } 0.273 \\
0.102 \text { to } 0.109 \\
0.0803 \text { to } 0.0854\end{array}$ \\
\hline \multicolumn{5}{|l|}{$2000 \mathrm{MW}(\mathrm{th})$} \\
\hline $\begin{array}{c}0-1800 \\
1800-6480 \\
6480-13680 \\
13680-42480 \\
42480-80000 \\
80000-100000 \\
100000-120000\end{array}$ & $\begin{array}{c}0.0405 \text { to } 0.0431 \\
0.0832 \text { to } 0.0951 \\
0.274 \text { to } 0.306 \\
0.449 \text { to } 0.485 \\
0.223 \text { to } 0.260 \\
0.0973 \text { to } 0.101 \\
0.0753 \text { to } 0.0778\end{array}$ & $\begin{array}{c}0.0 \\
0.0429 \text { to } 0.0486 \\
0.274 \text { to } 0.306 \\
0.449 \text { to } 0.485 \\
0.223 \text { to } 0.260 \\
0.0973 \text { to } 0.101 \\
0.0753 \text { to } 0.0778\end{array}$ & $\begin{array}{c}0.0 \\
0.0 \\
0.156 \text { to } 0.171 \\
0.449 \text { to } 0.485 \\
0.223 \text { to } 0.260 \\
0.0973 \text { to } 0.101 \\
0.0753 \text { to } 0.0778\end{array}$ & $\begin{array}{c}0.0 \\
0.0 \\
0.156 \text { to } 0.171 \\
0.0700 \text { to } 0.0904 \\
0.223 \text { to } 0.260 \\
0.0973 \text { to } 0.101 \\
0.0753 \text { to } 0.0778\end{array}$ \\
\hline \multicolumn{5}{|l|}{$3000 \mathrm{MW}(\mathrm{th})$} \\
\hline $\begin{array}{c}0-1800 \\
1800-6480 \\
6480-13680 \\
13680-42480 \\
42480-80000 \\
80000-100000 \\
100000-120000\end{array}$ & $\begin{array}{c}0.0445 \text { to } 0.0476 \\
0.0899 \text { to } 0.101 \\
0.227 \text { to } 0.258 \\
0.422 \text { to } 0.463 \\
0.214 \text { to } 0.247 \\
0.0944 \text { to } 0.0990 \\
0.0731 \text { to } 0.0755\end{array}$ & $\begin{array}{c}0.0 \\
0.0458 \text { to } 0.0509 \\
0.227 \text { to } 0.0258 \\
0.422 \text { to } 0.463 \\
0.214 \text { to } 0.247 \\
0.0944 \text { to } 0.0990 \\
0.0731 \text { to } 0.0755\end{array}$ & $\begin{array}{c}0.0 \\
0.0 \\
0.130 \text { to } 0.150 \\
0.422 \text { to } 0.463 \\
0.214 \text { to } 0.247 \\
0.0944 \text { to } 0.0990 \\
0.0731 \text { to } 0.0755\end{array}$ & $\begin{array}{c}0.0 \\
0.0 \\
0.130 \text { to } 0.150 \\
0.0643 \text { to } 0.0711 \\
0.214 \text { to } 0.247 \\
0.0944 \text { to } 0.0990 \\
0.0731 \text { to } 0.0755\end{array}$ \\
\hline \multicolumn{5}{|l|}{$4000 \mathrm{MW}(\mathrm{th})$} \\
\hline $\begin{array}{c}0-1800 \\
1800-6480 \\
6480-13680 \\
13680-42480 \\
42480-80000 \\
80000-100000 \\
100000-120000\end{array}$ & $\begin{array}{c}0.0484 \text { to } 0.0520 \\
0.102 \text { to } 0.114 \\
0.200 \text { to } 0.222 \\
0.389 \text { to } 0.419 \\
0.209 \text { to } 0.221 \\
0.0954 \text { to } 0.0987 \\
0.0741 \text { to } 0.0773\end{array}$ & $\begin{array}{c}0.0 \\
0.0507 \text { to } 0.0588 \\
0.200 \text { to } 0.222 \\
0.389 \text { to } 0.419 \\
0.209 \text { to } 0.221 \\
0.954 \text { to } 0.987 \\
0.741 \text { to } 0.0773\end{array}$ & $\begin{array}{c}0.0 \\
0.0 \\
0.116 \text { to } 0.128 \\
0.389 \text { to } 0.419 \\
0.209 \text { to } 0.221 \\
0.0954 \text { to } 0.0987 \\
0.0741 \text { to } 0.0773\end{array}$ & $\begin{array}{c}0.0 \\
0.0 \\
0.116 \text { to } 0.128 \\
0.0647 \text { to } 0.0779 \\
0.209 \text { to } 0.221 \\
0.0954 \text { to } 0.0987 \\
0.0741 \text { to } 0.0773\end{array}$ \\
\hline 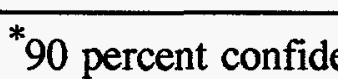 & ce intervals & & & \\
\hline
\end{tabular}


Monte Carlo

Table 24. Reasonable lower bound (10 percentile) effective decontamination coefficients for pressurized water reactors

\begin{tabular}{|c|c|c|c|c|}
\hline Time interval (s) & $\begin{array}{c}\text { Gap release } \\
\left(\mathbf{h r} \mathbf{r}^{-1}\right)\end{array}$ & $\begin{array}{c}\text { In-vessel release } \\
\left(\mathrm{hr}^{-1}\right)\end{array}$ & $\begin{array}{c}\text { Ex-vessel release } \\
\left(\mathrm{hr}^{-1}\right)\end{array}$ & $\begin{array}{l}\text { Late in-vessel } \\
\text { release }\left(h r^{-1}\right)\end{array}$ \\
\hline \multicolumn{5}{|l|}{$1000 \mathrm{MW}$} \\
\hline $\begin{array}{c}0-1800 \\
1800-6480 \\
6480-13680 \\
13680-42480 \\
42480-80000 \\
80000-100000 \\
100000-120000\end{array}$ & $\begin{array}{c}0.0180 \text { to } 0.0199 \\
0.0347 \text { to } 0.0381 \\
0.100 \text { to } 0.116 \\
0.237 \text { to } 0.277 \\
0.0756 \text { to } 0.0890 \\
0.0340 \text { to } 0.0470 \\
0.0254 \text { to } 0.0321\end{array}$ & $\begin{array}{c}0.0 \\
0.0173 \text { to } 0.0193 \\
0.100 \text { to } 0.116 \\
0.237 \text { to } 0.277 \\
0.756 \text { to } 0.0890 \\
0.0340 \text { to } 0.0470 \\
0.0254 \text { to } 0.0321\end{array}$ & $\begin{array}{c}0.0 \\
0.0 \\
0.0635 \text { to } 0.0733 \\
0.237 \text { to } 0.277 \\
0.0756 \text { to } 0.0890 \\
0.0340 \text { to } 0.0470 \\
0.0254 \text { to } 0.0321\end{array}$ & $\begin{array}{c}0.0 \\
0.0 \\
0.0635 \text { to } 0.0733 \\
0.0219 \text { to } 0.0267 \\
0.0756 \text { to } 0.0890 \\
0.0340 \text { to } 0.0470 \\
0.0254 \text { to } 0.0321\end{array}$ \\
\hline \multicolumn{5}{|l|}{$2000 \mathrm{MW}$} \\
\hline $\begin{array}{c}0-1800 \\
1800-6480 \\
6480-13680 \\
13680-42480 \\
42480-80000 \\
80000-100000 \\
100000-120000\end{array}$ & $\begin{array}{c}0.0231 \text { to } 0.0253 \\
0.0473 \text { to } 0.0521 \\
0.0726 \text { to } 0.0909 \\
0.200 \text { to } 0.241 \\
0.0802 \text { to } 0.0941 \\
0.0315 \text { to } 0.0434 \\
0.0243 \text { to } 0.0282\end{array}$ & $\begin{array}{c}0.0 \\
0.0245 \text { to } 0.0268 \\
0.0726 \text { to } 0.0909 \\
0.200 \text { to } 0.241 \\
0.0802 \text { to } 0.0941 \\
0.0315 \text { to } 0.0434 \\
0.0243 \text { to } 0.0247\end{array}$ & $\begin{array}{c}0.0 \\
0.0 \\
0.0451 \text { to } 0.0562 \\
0.200 \text { to } 0.241 \\
0.0802 \text { to } 0.0941 \\
0.0315 \text { to } 0.0434 \\
0.0243 \text { to } 0.0282\end{array}$ & $\begin{array}{c}0.0 \\
0.0 \\
0.0451 \text { to } 0.0562 \\
0.0382 \text { to } 0.0427 \\
0.0802 \text { to } 0.0941 \\
0.0315 \text { to } 0.0434 \\
0.0243 \text { to } 0.0282\end{array}$ \\
\hline \multicolumn{5}{|l|}{$3000 \mathrm{MW}$} \\
\hline $\begin{array}{c}0-1800 \\
1800-6480 \\
6480-13680 \\
13680-42480 \\
42480-80000 \\
80000-100000 \\
100000-120000\end{array}$ & $\begin{array}{c}0.0267 \text { to } 0.0279 \\
0.0529 \text { to } 0.0589 \\
0.0575 \text { to } 0.0781 \\
0.177 \text { to } 0.223 \\
0.0804 \text { to } 0.0955 \\
0.0314 \text { to } 0.0392 \\
0.0238 \text { to } 0.0287\end{array}$ & $\begin{array}{c}0.0 \\
0.0273 \text { to } 0.0293 \\
0.0575 \text { to } 0.0781 \\
0.177 \text { to } 0.223 \\
0.0804 \text { to } 0.0955 \\
0.0314 \text { to } 0.0392 \\
0.0238 \text { to } 0.0287\end{array}$ & $\begin{array}{c}0.0 \\
0.0 \\
0.0357 \text { to } 0.0474 \\
0.177 \text { to } 0.223 \\
0.0804 \text { to } 0.0955 \\
0.0314 \text { to } 0.0392 \\
0.0238 \text { to } 0.0287\end{array}$ & $\begin{array}{c}0.0 \\
0.0 \\
0.0357 \text { to } 0.0474 \\
0.0422 \text { to } 0.0454 \\
0.0804 \text { to } 0.0955 \\
0.0314 \text { to } 0.0392 \\
0.0238 \text { to } 0.0287\end{array}$ \\
\hline \multicolumn{5}{|l|}{$4000 \mathrm{MW}$} \\
\hline $\begin{array}{c}0-1800 \\
1800-6480 \\
6480-13680 \\
13680-42480 \\
42480-80000 \\
80000-100000 \\
100000-120000\end{array}$ & $\begin{array}{l}0.0275 \text { to } 0.0300 \\
0.0551 \text { to } 0.0613 \\
0.0543 \text { to } 0.0664 \\
0.0157 \text { to } 0.0212 \\
0.0907 \text { to } 0.0104 \\
0.0344 \text { to } 0.0406 \\
0.0257 \text { to } 0.0335\end{array}$ & $\begin{array}{c}0.0 \\
0.0276 \text { to } 0.0305 \\
0.0543 \text { to } 0.0664 \\
0.157 \text { to } 0.212 \\
0.0907 \text { to } 0.104 \\
0.0344 \text { to } 0.0406 \\
0.0257 \text { to } 0.0335\end{array}$ & $\begin{array}{c}0.0 \\
0.0 \\
0.0321 \text { to } 0.0396 \\
0.157 \text { to } 0.212 \\
0.907 \text { to } 0.104 \\
0.0344 \text { to } 0.0406 \\
0.0257 \text { to } 0.0335\end{array}$ & $\begin{array}{c}0.0 \\
0.0 \\
0.0321 \text { to } 0.0396 \\
0.0437 \text { to } 0.0456 \\
0.0907 \text { to } 0.104 \\
0.0344 \text { to } 0.0406 \\
0.0257 \text { to } 0.0335\end{array}$ \\
\hline & & & & \\
\hline
\end{tabular}


Table 25. Mean effective decontamination coefficients for pressurized water reactors

\begin{tabular}{|c|c|c|c|c|}
\hline Time interval (s) & $\begin{array}{l}\text { Gap release } \\
\left(\mathbf{h r}^{-1}\right)\end{array}$ & $\begin{array}{c}\text { In-vessel release } \\
\left(\mathbf{h r}^{-1}\right)\end{array}$ & $\begin{array}{c}\text { Ex-vessel release } \\
\left(\mathbf{h r}^{-1}\right)\end{array}$ & $\begin{array}{l}\text { Late in-vessel } \\
\text { release }\left(\mathrm{hr}^{-1}\right)\end{array}$ \\
\hline \multicolumn{5}{|l|}{$1000 \mathrm{MW}$ (th) } \\
\hline $\begin{array}{c}0-1800 \\
1800-6480 \\
6480-13680 \\
13680-42480 \\
42480-80000 \\
80000-100000 \\
100000-120000\end{array}$ & $\begin{array}{l}0.0294 \\
0.0616 \\
0.275 \\
0.402 \\
0.157 \\
0.0784 \\
0.0607\end{array}$ & $\begin{array}{l}0 \\
0.0318 \\
0.275 \\
0.402 \\
0.157 \\
0.0784 \\
0.0607\end{array}$ & $\begin{array}{l}0 \\
0 \\
0.153 \\
0.402 \\
0.157 \\
0.0784 \\
0.0607\end{array}$ & $\begin{array}{l}0 \\
0 \\
0.153 \\
0.0522 \\
0.157 \\
0.0784 \\
0.0607\end{array}$ \\
\hline \multicolumn{5}{|l|}{$2000 \mathrm{MW}$ (th) } \\
\hline $\begin{array}{c}0-1800 \\
1800-6480 \\
6480-13680 \\
13680-42480 \\
42480-80000 \\
80000-100000 \\
100000-120000\end{array}$ & $\begin{array}{l}0.0333 \\
0.0681 \\
0.176 \\
0.343 \\
0.157 \\
0.0766 \\
0.0584\end{array}$ & $\begin{array}{l}0 \\
0.0348 \\
0.176 \\
0.343 \\
0.157 \\
0.0766 \\
0.0584\end{array}$ & $\begin{array}{l}0 \\
0 \\
0.103 \\
0.343 \\
0.157 \\
0.0766 \\
0.0584\end{array}$ & $\begin{array}{l}0 \\
0 \\
0.103 \\
0.0568 \\
0.0157 \\
0.0766 \\
0.0584\end{array}$ \\
\hline \multicolumn{5}{|l|}{$3000 \mathrm{MW}$ (th) } \\
\hline $\begin{array}{c}0-1800 \\
1800-6480 \\
6480-13680 \\
13680-42480 \\
42480-80000 \\
80000-100000 \\
100000-120000\end{array}$ & $\begin{array}{l}0.0367 \\
0.0745 \\
0.146 \\
0.316 \\
0.149 \\
0.0741 \\
0.0574\end{array}$ & $\begin{array}{l}0.0 \\
0.0379 \\
0.146 \\
0.316 \\
0.149 \\
0.0741 \\
0.0574\end{array}$ & $\begin{array}{l}0.0 \\
0.0 \\
0.0854 \\
0.316 \\
0.149 \\
0.0741 \\
0.0574\end{array}$ & $\begin{array}{l}0.0 \\
0.0 \\
0.0854 \\
0.0566 \\
0.149 \\
0.0741 \\
0.0574\end{array}$ \\
\hline \multicolumn{5}{|l|}{$4000 \mathrm{MW}(\mathrm{th})$} \\
\hline $\begin{array}{c}0-1800 \\
1800-6480 \\
6480-13680 \\
13680-42480 \\
42480-80000 \\
80000-100000 \\
100000-120000\end{array}$ & $\begin{array}{l}0.0398 \\
0.0820 \\
0.133 \\
0.295 \\
0.152 \\
0.0755 \\
0.0587\end{array}$ & $\begin{array}{l}0.0 \\
0.0416 \\
0.133 \\
0.295 \\
0.152 \\
0.0755 \\
0.0587\end{array}$ & $\begin{array}{l}0.0 \\
0.0 \\
0.0771 \\
0.295 \\
0.152 \\
0.0755 \\
0.0587\end{array}$ & $\begin{array}{l}0.0 \\
0.0 \\
0.0771 \\
0.0550 \\
0.152 \\
0.0755 \\
0.0587\end{array}$ \\
\hline
\end{tabular}




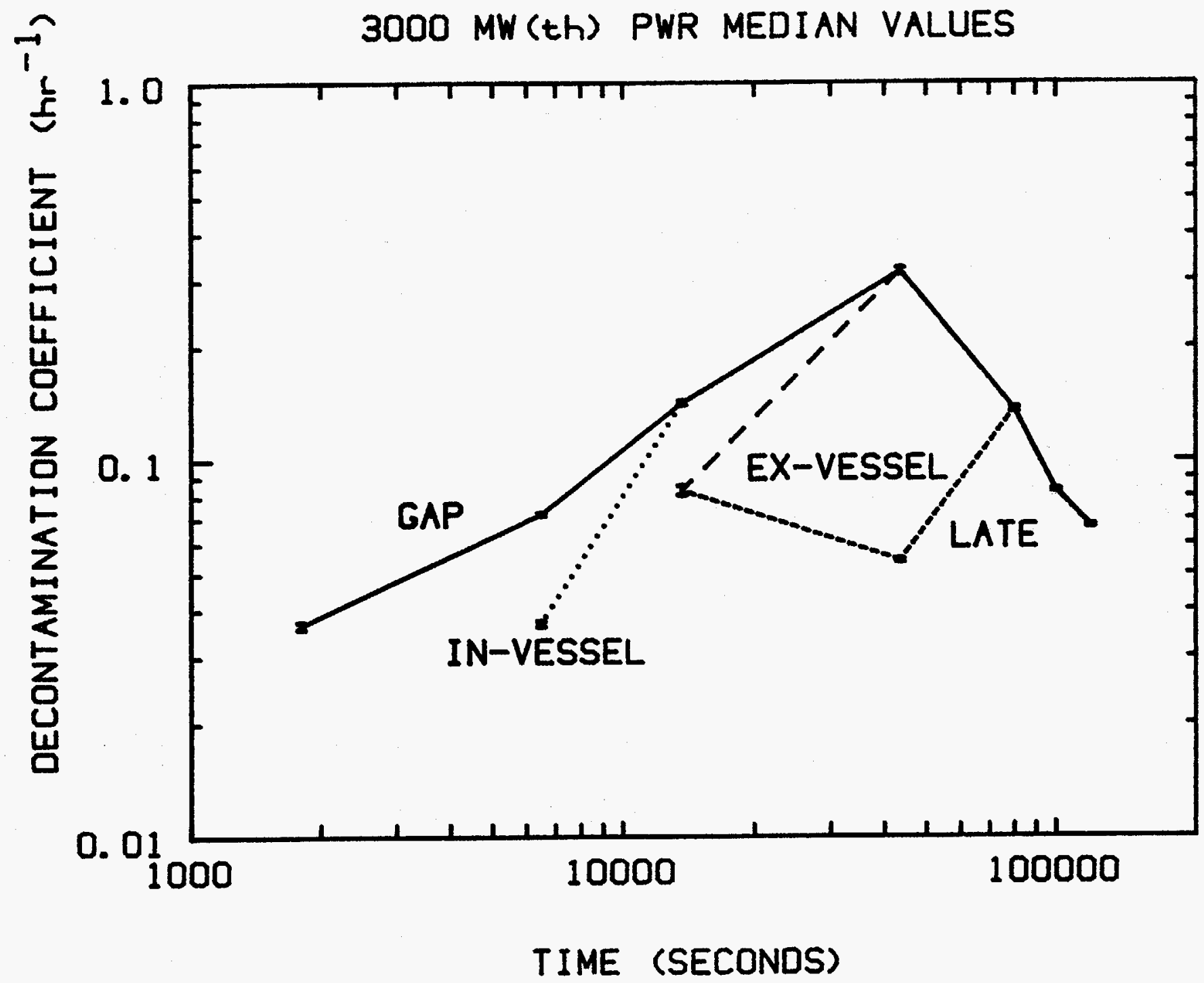

Figure 32. Median values of the average effective decontamination coefficients for four classes of radioactive material released during accidents at a $3000 \mathrm{MW}$ (th) pressurized water reactor 
ชี

$\omega$

$\$$

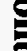

要

.

을

8

일

$\frac{7}{8}$

8

콩

$\infty$

$\stackrel{w}{\xi}$

胥

量

0

․ㅡㄹ

옹

률
DECONTAMINATION COEFFICIENT $\left(\mathrm{hr}^{-1}\right)$

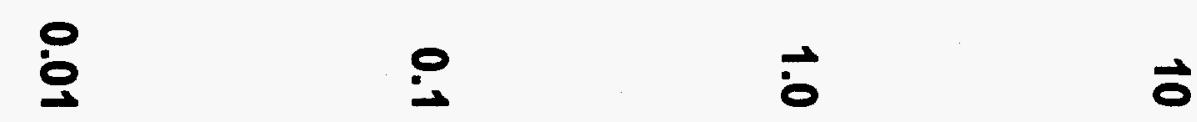

$\Omega$

2

ㅈ.

m

8

m 
PWR MEDIAN VALUES GAP RELEASE

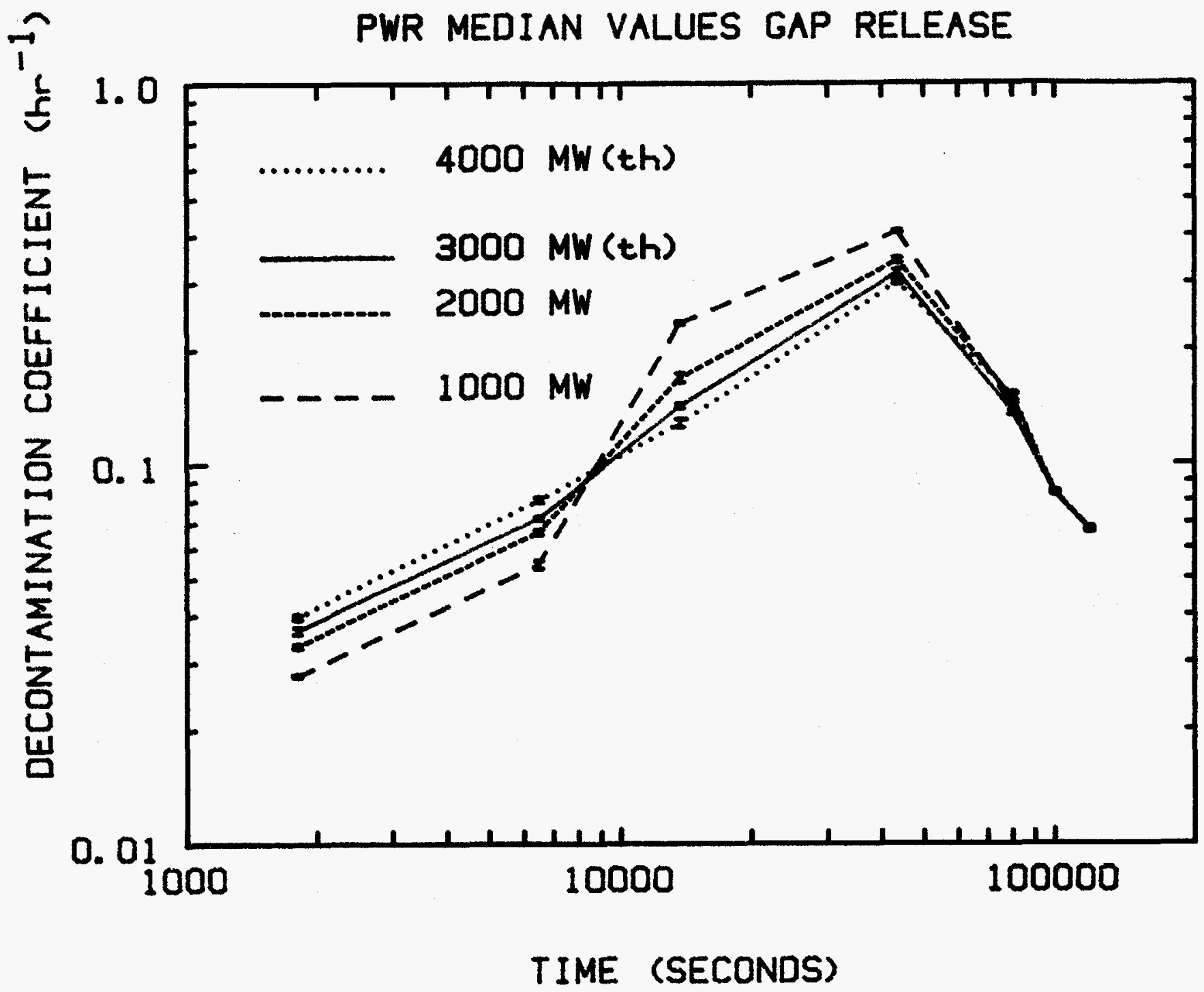

TIME (SECONDS)

Figure 34. Time dependencies of median effective decontamination coefficients for gap release during accidents at pressurized water reactors of various powers 


\section{PWR MEDIAN VALUES GAP RELEASE}

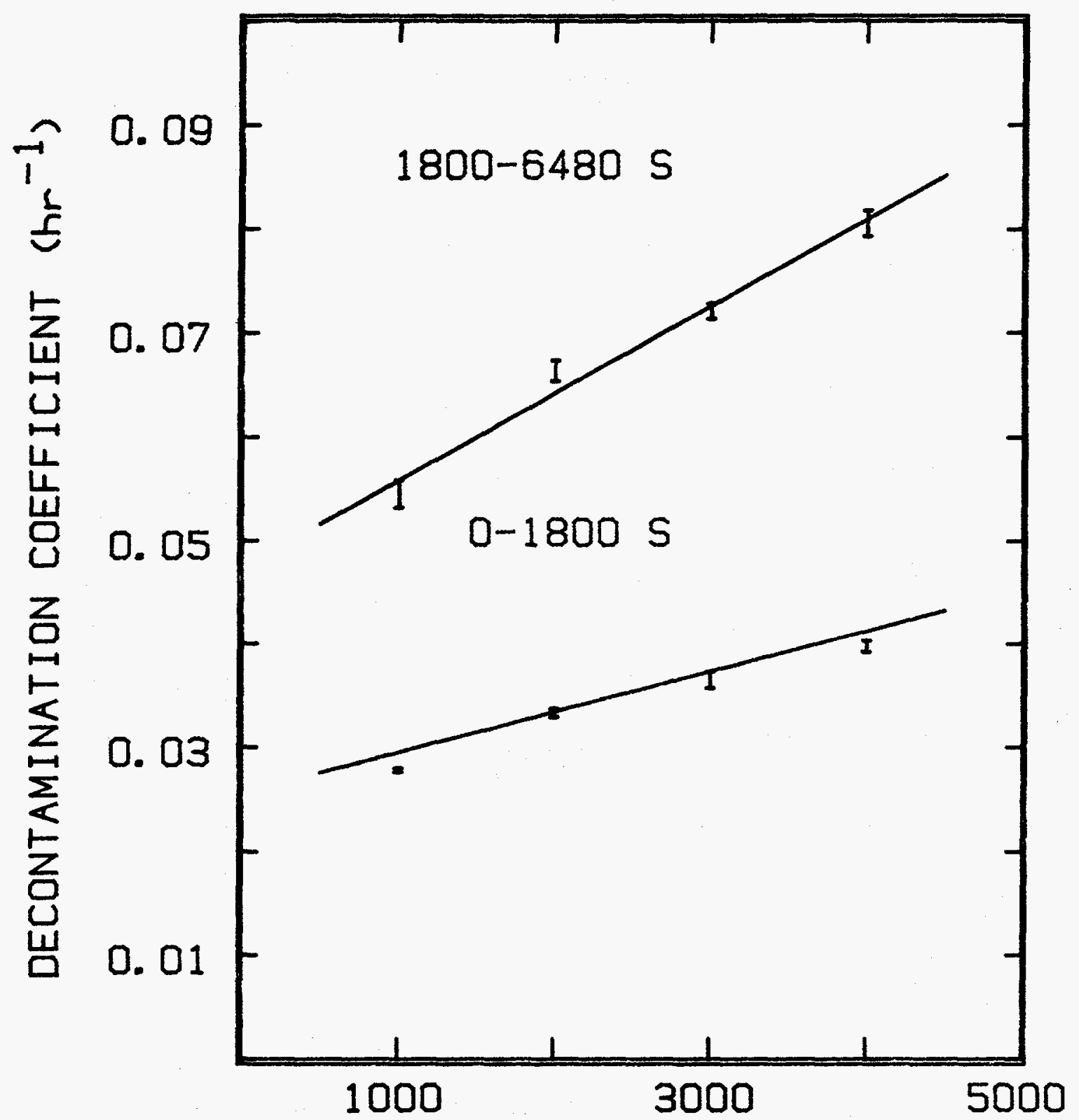

REACTOR THERMAL POWER (MW)

Figure 35. Dependencies of various effective decontamination coefficients for gap release on reactor power 


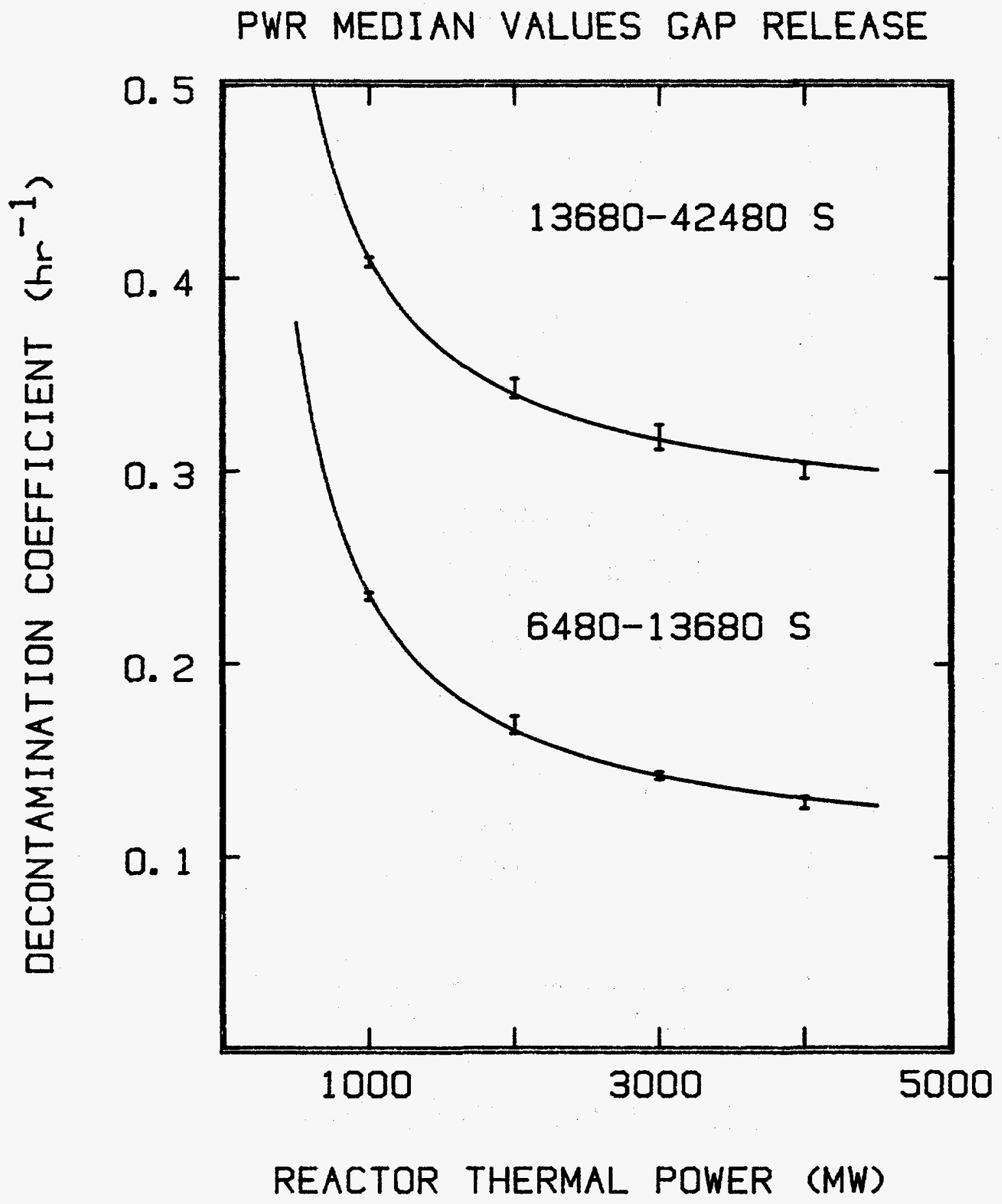

Figure 36. Dependencies of various effective decontamination coefficients on reactor power 
PWR MEDIAN VALUES

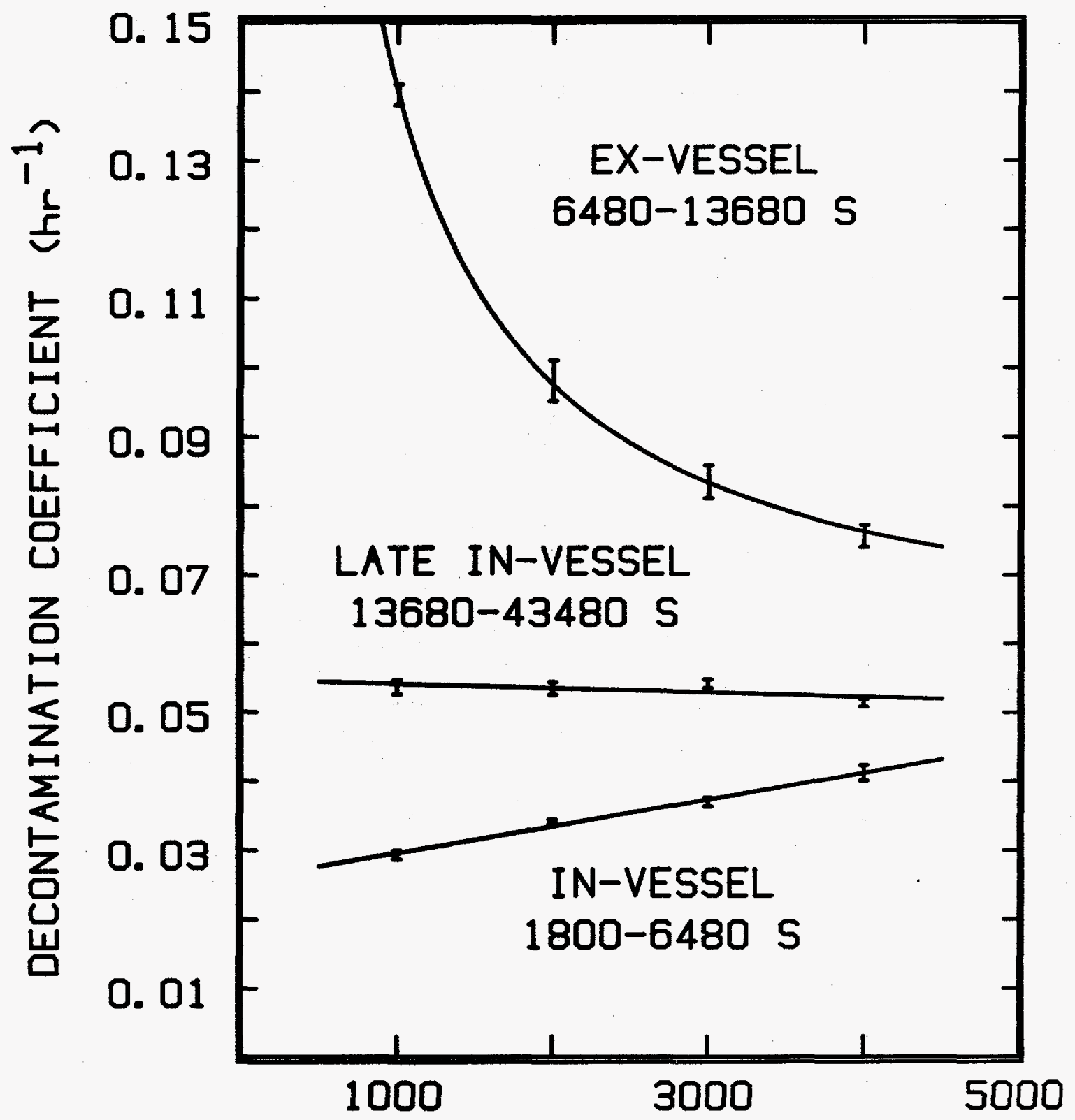

REACTOR THERMAL POWER (MW)

Figure 37. Dependencies of various effective decontamination coefficients on reactor power 
Monte Carlo

Table 26. Correlation of important PWR decontamination coefficients with reactor thermal power

\begin{tabular}{|c|c|c|}
\hline Material & Time Interval (s) & Correlations ${ }^{*}\left(\mathrm{hr}^{-1}\right)$ \\
\hline gap & $0-1800$ & $\begin{array}{l}\lambda_{\mathrm{e}}(90)=0.0349+3.755 \times 10^{-6} \mathrm{P}(\mathrm{MW}) \\
\lambda_{\mathrm{e}}(50)=0.0256+3.90 \times 10^{-6} \mathrm{P}(\mathrm{MW}) \\
\lambda_{\mathrm{e}}(10)=0.0167+3.25 \times 10^{-6} \mathrm{P}(\mathrm{MW})\end{array}$ \\
\hline gap & $1800-6480$ & $\begin{array}{l}\lambda_{\mathrm{e}}(90)=0.0808+5.955 \times 10^{-6} \mathrm{P}(\mathrm{MW}) \\
\lambda_{\mathrm{e}}(50)=0.0474+8.39 \times 10^{-6} \mathrm{P}(\mathrm{MW}) \\
\lambda_{\mathrm{e}}(10)=0.0322+7.16 \times 10^{-6} \mathrm{P}(\mathrm{MW})\end{array}$ \\
\hline gap & $6480-13680$ & $\begin{array}{l}\lambda_{\mathrm{e}}(90)=0.1146+371.9 / \mathrm{P}(\mathrm{MW}) \\
\lambda_{\mathrm{e}}(50)=0.0948+141.2 / \mathrm{P}(\mathrm{MW}) \\
\lambda_{\mathrm{e}}(10)=0.0472+62.0 / \mathrm{P}(\mathrm{MW})\end{array}$ \\
\hline gap & $13680-42480$ & $\begin{array}{l}\lambda_{\mathrm{e}}(90)=0.378+161.6 / \mathrm{P}(\mathrm{MW}) \\
\lambda_{\mathrm{e}}(50)=0.269+141.2 / \mathrm{P}(\mathrm{MW}) \\
\lambda_{\mathrm{e}}(10)=0.068+81.8 / \mathrm{P}(\mathrm{MW})\end{array}$ \\
\hline gap & $42480-80000$ & $\begin{array}{l}\lambda_{\mathrm{e}}(90)=0.210+50.6 / \mathrm{P}(\mathrm{MW}) \\
\lambda_{\mathrm{e}}(50)=0.144 \\
\lambda_{\mathrm{e}}(10)=0.0915[1-\exp (-2.216 \mathrm{P}(\mathrm{MW}) / 1000)]\end{array}$ \\
\hline gap & $80000-100000$ & $\begin{array}{l}\lambda_{\mathrm{e}}(90)=0.0933+12.0 / \mathrm{P}(\mathrm{MW}) \\
\lambda_{\mathrm{e}}(50)=0.0838 \\
\lambda_{\mathrm{e}}(10)=0.0377\end{array}$ \\
\hline gap & $100000-120000$ & $\begin{array}{l}\lambda_{\mathrm{e}}(90)=0.0717+10.8 / \mathrm{P}(\mathrm{MW}) \\
\lambda_{\mathrm{e}}(50)=0.0669 \\
\lambda_{\mathrm{e}}(10)=0.0277\end{array}$ \\
\hline in-vessel & $1800-6480$ & $\begin{array}{l}\lambda_{\mathrm{e}}(90)=0.0505+0.94 \times 10^{-6} \mathrm{P}(\mathrm{MW}) \\
\lambda_{\mathrm{e}}(50)=0.0257+3.87 \times 10^{-6} \mathrm{P}(\mathrm{MW}) \\
\lambda_{\mathrm{e}}(10)=0.0166+3.49 \times 10^{-6} \mathrm{P}(\mathrm{MW})\end{array}$ \\
\hline ex-vessel & $6480-13680$ & $\begin{array}{l}\lambda_{\mathrm{e}}(90)=0.0754+184.9 / \mathrm{P}(\mathrm{MW}) \\
\lambda_{\mathrm{e}}(50)=0.0551+84.65 / \mathrm{P}(\mathrm{MW}) \\
\lambda_{\mathrm{e}}(10)=0.0272+42.0 / \mathrm{P}(\mathrm{MW})\end{array}$ \\
\hline late in-vessel & $13680-42480$ & $\begin{array}{l}\lambda_{\mathrm{e}}(90)=0.0829-3.40 \times 10^{-6} \mathrm{P}(\mathrm{MW}) \\
\lambda_{\mathrm{e}}(50)=0.0547-0.62 \times 10^{-6} \mathrm{P}(\mathrm{MW}) \\
\lambda_{\mathrm{e}}(10)=0.0222+6.44 \times 10^{-6} \mathrm{P}(\mathrm{MW})\end{array}$ \\
\hline \multicolumn{3}{|c|}{$\begin{array}{l}* \lambda_{\mathrm{e}}(50) \text { is the median of the uncertainty distribution. The } 90^{\text {th }} \text { and } 10^{\text {th }} \text { percentile values are } \\
\lambda_{\mathrm{e}}(90) \text { and } \lambda_{\mathrm{e}}(10) \text {, respectively. }\end{array}$} \\
\hline
\end{tabular}




\section{B. Uncertainty Analyses for Radiological Design-Basis Accidents}

Advanced light water reactors are being designed to have the capabilities to terminate the later stages of severe reactor accidents. This is done by flooding the reactor cavity with water. Even if this flooding does not quench the core debris, the deep water pool produced by flooding will sharply attenuate the massive production of radioactive and nonradioactive aerosols produced during the ex-vessel phase of a severe accident. Water pools are envisaged to be so deep that the reactor vessel may be immersed in water and this will prevent late in-vessel release.

The massive generation of nonradioactive aerosol during the ex-vessel release phase of an accident has a very significant effect on the behaviors of radioactive aerosols injected into the containment at earlier times during the gap release and in-vessel release phases of an accident. The deposition of aerosols by sedimentation becomes a dominant process as the massive production of nonradioactive aerosol takes place and aerosol particles coagulate to very large sizes. This important mitigating effect is not available for accidents at advanced reactors in which the important generation of aerosol during ex-vessel interactions of core debris is either attenuated or prevented altogether. Consequently, the effective decontamination coefficients and decontamination factors derived above are not applicable after the in-vessel release is complete.

Additional sets of decontamination factors were calculated for situations in which the aerosol sources to the reactor containment were stopped after the in-vessel release phase of an accident. For the purposes of identification, these decontamination factors are labelled here as being for "radiological design basis accidents." No significance aside from labeling should be ascribed to this name. Conditions in the containment were taken to be the same as for the calculations described above for pressurized water reactor accidents except:

- the ex-vessel release source term was taken to be zero,

- the late in-vessel release source term was taken to be zero,

- the chemical energy that had to be dissipated after the completion of the in-vessel phase of the accident was taken to be zero, and

- the containment atmosphere was taken to be steam-saturated during the gap release phase of the accident and superheated by less than $15 \mathrm{~K}$ during the rest of the accident.

Pressure in the containment during the gap release phase of the accident was assumed to be uniformly distributed over the range of 1.16 to $1.79 \mathrm{~atm}$. During the rest of the accident, pressure was assumed to be uniformly distributed over the range of 1.12 to $3.96 \mathrm{~atm}$. Hydrogen production occurred only during the in-vessel release phase. No carbon dioxide or carbon monoxide sources to the containment were considered.

\footnotetext{
* Recently, arguments have been advanced suggesting that immersion of the reactor vessel may prevent vessel rupture and thus prevent ex-vessel release or late in-vessel release.
} 
The median (50 percentile), 90 percentile and 10 percentile values of the decontamination factors are summarized in Tables 27 to 29 for reactors operating at powers of 1000, 2000, 3000, and 4000 MW. Mean values of the decontamination factors are shown in Table 30. Decontamination factors are, of course, shown in these tables only for gap release and in-vessel release. Ex-vessel release and late invessel release, by hypothesis, do not occur. As expected, decontamination factors shown in these tables are similar to values found for the pressurized water reactors at early times (compare results shown in Tables 18 to 21 with results shown in Tables 27 to 29). At later times ( $>6480 \mathrm{~s}$ ), decontamination factors found for aerosols introduced into the containment during the gap release and the in-vessel release phase are smaller for the advanced reactors than the corresponding values found for pressurized water reactors. The smaller decontamination factors are calculated because the aerosol particles in the containment do not grow as large as they are calculated to do in the pressurized water reactor accidents. There is not the massive release of nonradioactive aerosol mass during an ex-vessel release phase to prompt growth of aerosol particles suspended in the atmosphere during the gap release and in-vessel release phases of the accident. Sedimentation of aerosol particles is not as efficient a decontamination mechanism as it is in the pressurized water reactor accidents that include all four release phases.

On the other hand, the containment atmospheres during the radiological design basis accidents are nearly saturated. Even though steam condensation on particles has been discounted here, as have hygroscopic effects, the high steam concentrations do facilitate aerosol particle removal by diffusiophoresis. Though sedimentation is the dominant aerosol removal process after 6480 seconds, diffusiophoresis (and to a lesser extent thermophoresis) contributes to the natural removal of aerosol particles. The diffusiophoretic deposition depends on steam condensation rates. As part of the Monte Carlo uncertainty analyses for the radiological design basis accidents, uncertainty distributions for the steam condensation rates were developed. Distributions for condensation rates at 1800 and 80000 seconds are shown in Figure 38 . Median (50 percentile), reasonable upper bound ( 90 percentile) and lower bound (10 percentile) values of the molar rate of steam condensation are listed in Table 31. Steam condensation rates found for early times are quite similar to rates predicted for the early stages of pressurized water reactor accidents. Steam condensation rates calculated for later times in the radiological design basis accidents are somewhat higher than condensation rates calculated for later stages of accidents in pressurized water reactors. More heat must be dissipated from containments by condensation since temperature differences between the atmosphere and structural surfaces are not as large as in the case of accidents at pressurized water reactors. There is, then, less heat loss by convection. On the other hand, there is less chemically produced heat to dissipate since there is no ex-vessel phase of the radiological design basis accidents.

Median (50 percentile), upper bound ( 90 percentile) and lower bound (10 percentile) decontamination coefficients calculated for radiological design basis accidents are listed in Tables 32 to 34 . Mean values are shown in Table 35. These decontamination coefficients are, of course, entirely similar to those found for pressurized water reactors for times less than 6480 seconds. The median decontamination coefficients for materials released during the gap and in-vessel phases of radiological design basis accidents at a $3000 \mathrm{MW}(\mathrm{th})$ reactor are shown as functions of time in Figure 39. The median, upper bound and lower bound decontamination coefficients are shown as functions of time in Figure 40.

The dependencies of the decontamination coefficients on the thermal power are not as complicated as in the case of pressurized water reactors (see Figure 41). The decontamination coefficients increase with 
Table 27. Median ( 50 percentile) decontamination factors for radiological design basis accidents

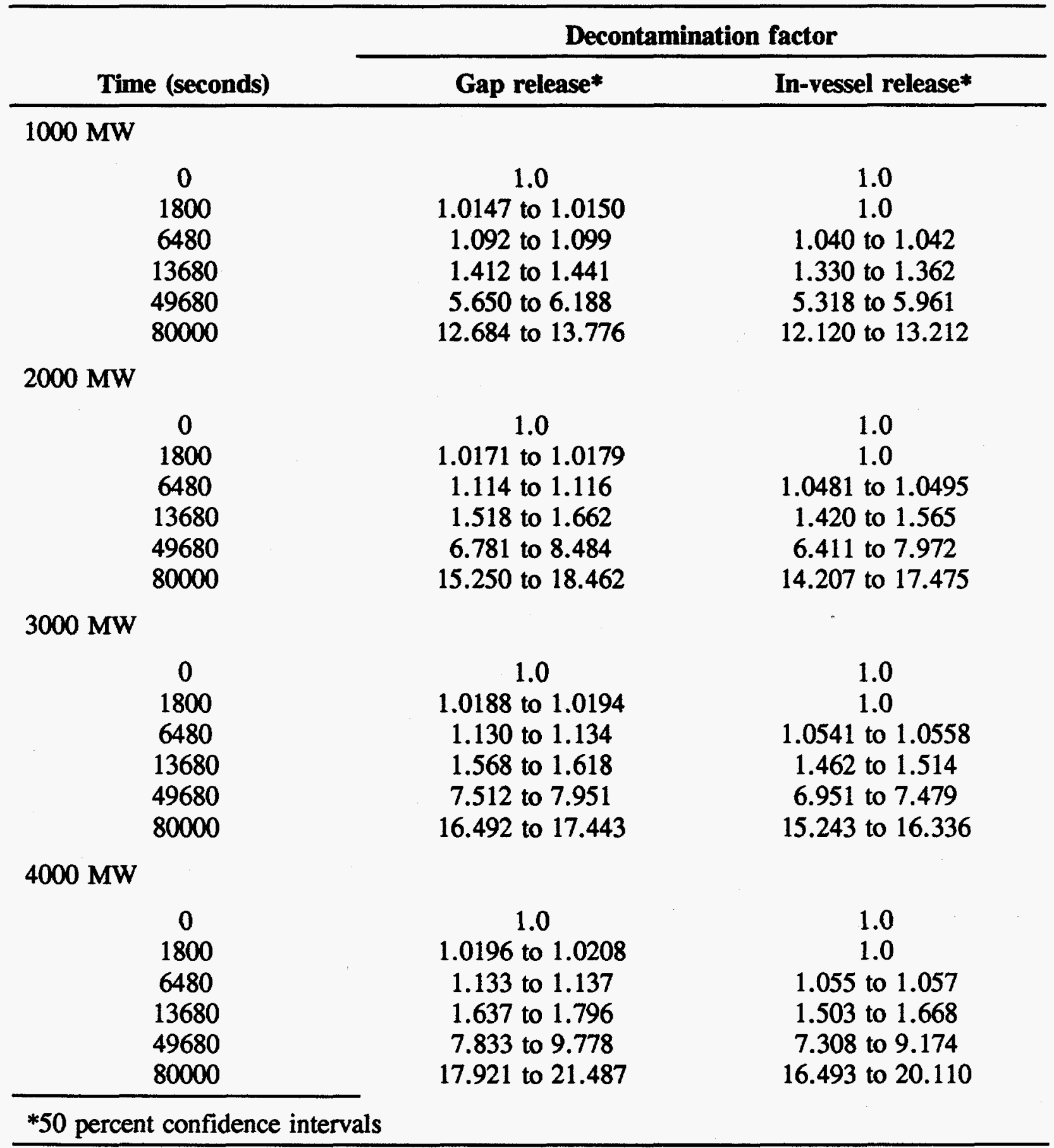


Monte Carlo

Table 28. Reasonable upper bound ( 90 percentile) decontamination factors for radiological design basis accidents

\begin{tabular}{|c|c|c|}
\hline \multirow[b]{2}{*}{ Time (seconds) } & \multicolumn{2}{|c|}{ Decontamination factor } \\
\hline & Gap release* & In-vessel release* \\
\hline \multicolumn{3}{|l|}{$1000 \mathrm{MW}$} \\
\hline $\begin{array}{c}0 \\
1800 \\
6480 \\
13680 \\
49680 \\
80000\end{array}$ & $\begin{array}{c}1.0 \\
1.0191 \text { to } 1.0212 \\
1.138 \text { to } 1.162 \\
2.348 \text { to } 2.685 \\
14.446 \text { to } 18.812 \\
31.503 \text { to } 44.160\end{array}$ & $\begin{array}{c}1.0 \\
1.0 \\
1.060 \text { to } 1.070 \\
2.145 \text { to } 2.502 \\
13.719 \text { to } 17.258 \\
29.519 \text { to } 40.640\end{array}$ \\
\hline \multicolumn{3}{|l|}{$2000 \mathrm{MW}$} \\
\hline $\begin{array}{c}0 \\
1800 \\
6480 \\
13680 \\
49680 \\
80000\end{array}$ & $\begin{array}{c}1.0 \\
1.0214 \text { to } 1.0231 \\
1.147 \text { to } 1.167 \\
2.390 \text { to } 2.810 \\
15.354 \text { to } 17.696 \\
33.111 \text { to } 37.552\end{array}$ & $\begin{array}{c}1.0 \\
1.0 \\
1.620 \text { to } 1.0690 \\
2.240 \text { to } 2.600 \\
14.129 \text { to } 16.742 \\
30.989 \text { to } 35.034\end{array}$ \\
\hline \multicolumn{3}{|l|}{$3000 \mathrm{MW}$} \\
\hline $\begin{array}{c}0 \\
1800 \\
6480 \\
13680 \\
49680 \\
80000\end{array}$ & $\begin{array}{c}1.0 \\
1.0225 \text { to } 1.0251 \\
1.160 \text { to } 1.178 \\
2.164 \text { to } 2.882 \\
12.864 \text { to } 19.488 \\
28.063 \text { to } 40.047\end{array}$ & $\begin{array}{c}1.0 \\
1.0 \\
1.0664 \text { to } 1.0722 \\
1.995 \text { to } 2.320 \\
11.843 \text { to } 18.347 \\
25.877 \text { to } 37.700\end{array}$ \\
\hline \multicolumn{3}{|l|}{$4000 \mathrm{MW}$} \\
\hline $\begin{array}{c}0 \\
1800 \\
6480 \\
13680 \\
49680 \\
80000\end{array}$ & $\begin{array}{c}1.0 \\
1.0248 \text { to } 1.0267 \\
1.173 \text { to } 1.194 \\
2.644 \text { to } 3.113 \\
17.443 \text { to } 20.504 \\
38.352 \text { to } 43.324\end{array}$ & $\begin{array}{c}1.0 \\
1.0 \\
1.070 \text { to } 1.080 \\
2.464 \text { to } 2.858 \\
15.972 \text { to } 19.313 \\
35.165 \text { to } 40.043\end{array}$ \\
\hline
\end{tabular}


Table 29. Reasonable lower bound (10 percentile) decontamination factors for radiological design basis accidents

\begin{tabular}{|c|c|c|}
\hline \multirow[b]{2}{*}{ Time (seconds) } & \multicolumn{2}{|c|}{ Decontamination factor } \\
\hline & Gap release* & In-vessel release* \\
\hline \multicolumn{3}{|l|}{$1000 \mathrm{MW}$} \\
\hline $\begin{array}{c}0 \\
1800 \\
6480 \\
13680 \\
49680 \\
80000\end{array}$ & $\begin{array}{c}1.0 \\
1.0096 \text { to } 1.0108 \\
1.0598 \text { to } 1.0680 \\
1.175 \text { to } 1.218 \\
2.538 \text { to } 3.110 \\
4.861 \text { to } 6.131\end{array}$ & $\begin{array}{c}1.0 \\
1.0 \\
1.025 \text { to } 1.027 \\
1.127 \text { to } 1.173 \\
2.452 \text { to } 3.004 \\
4.721 \text { to } 5.904\end{array}$ \\
\hline \multicolumn{3}{|l|}{$2000 \mathrm{MW}$} \\
\hline $\begin{array}{c}0 \\
1800 \\
6480 \\
13680 \\
49680 \\
80000\end{array}$ & $\begin{array}{c}1.0 \\
1.0126 \text { to } 1.0139 \\
1.0846 \text { to } 1.0928 \\
1.275 \text { to } 1.329 \\
3.418 \text { to } 4.083 \\
7.100 \text { to } 8.889\end{array}$ & $\begin{array}{c}1.0 \\
1.0 \\
1.0338 \text { to } 1.0376 \\
1.199 \text { to } 1.247 \\
3.255 \text { to } 3.823 \\
6.736 \text { to } 8.289\end{array}$ \\
\hline \multicolumn{3}{|l|}{$3000 \mathrm{MW}$} \\
\hline $\begin{array}{c}0 \\
1800 \\
6480 \\
13680 \\
49680 \\
80000\end{array}$ & $\begin{array}{c}1.0 \\
1.0134 \text { to } 1.0148 \\
1.0944 \text { to } 1.106 \\
1.322 \text { to } 1.373 \\
3.927 \text { to } 4.716 \\
8.292 \text { to } 10.380\end{array}$ & $\begin{array}{c}1.0 \\
1.0 \\
1.0378 \text { to } 1.0423 \\
1.238 \text { to } 1.269 \\
3.644 \text { to } 4.494 \\
7.694 \text { to } 9.848\end{array}$ \\
\hline \multicolumn{3}{|l|}{$4000 \mathrm{MW}$} \\
\hline $\begin{array}{c}0 \\
1800 \\
6480 \\
13680 \\
49680 \\
80000\end{array}$ & $\begin{array}{c}1.0 \\
1.0146 \text { to } 1.0161 \\
1.100 \text { to } 1.109 \\
1.332 \text { to } 1.387 \\
3.932 \text { to } 4.685 \\
9.254 \text { to } 11.802\end{array}$ & $\begin{array}{c}1.0 \\
1.0 \\
1.040 \text { to } 1.045 \\
1.236 \text { to } 1.286 \\
3.677 \text { to } 4.372 \\
7.890 \text { to } 9.560\end{array}$ \\
\hline 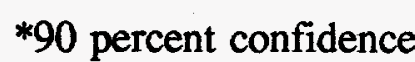 & & \\
\hline
\end{tabular}


Monte Carlo

Table 30. Mean decontamination factors for radiological design basis accidents

\begin{tabular}{|c|c|c|}
\hline \multirow[b]{2}{*}{ Time (seconds) } & \multicolumn{2}{|c|}{ Mean decontamination factor } \\
\hline & Gap release* & In-vessel release* \\
\hline \multicolumn{3}{|l|}{$1000 \mathrm{MW}$} \\
\hline $\begin{array}{c}0 \\
1800 \\
6480 \\
13680 \\
49680 \\
80000\end{array}$ & $\begin{array}{c}1.0 \\
1.0151 \\
1.101 \\
1.684 \\
8.425 \\
18.497\end{array}$ & $\begin{array}{c}1.0 \\
1.0 \\
1.042 \\
1.590 \\
7.918 \\
17.365\end{array}$ \\
\hline \multicolumn{3}{|l|}{$2000 \mathrm{MW}$} \\
\hline $\begin{array}{c}0 \\
1800 \\
6480 \\
13680 \\
49680 \\
80000\end{array}$ & $\begin{array}{c}1.0 \\
1.0178 \\
1.120 \\
1.777 \\
9.107 \\
19.653\end{array}$ & $\begin{array}{c}1.0 \\
1.0 \\
1.0496 \\
1.665 \\
8.525 \\
18.390\end{array}$ \\
\hline \multicolumn{3}{|l|}{$3000 \mathrm{MW}$} \\
\hline $\begin{array}{c}0 \\
1800 \\
6480 \\
13680 \\
49680 \\
80000\end{array}$ & $\begin{array}{c}1.0 \\
1.019 \\
1.133 \\
1.764 \\
8.917 \\
19.382\end{array}$ & $\begin{array}{c}1.0 \\
1.0 \\
1.0548 \\
1.642 \\
8.303 \\
18.042\end{array}$ \\
\hline \multicolumn{3}{|l|}{$4000 \mathrm{MW}$} \\
\hline $\begin{array}{c}0 \\
1800 \\
6480 \\
13680 \\
49680 \\
80000\end{array}$ & $\begin{array}{c}1.0 \\
1.0205 \\
1.140 \\
1.919 \\
10.466 \\
22.820\end{array}$ & $\begin{array}{c}1.0 \\
1.0 \\
1.058 \\
1.779 \\
9.693 \\
21.125\end{array}$ \\
\hline
\end{tabular}




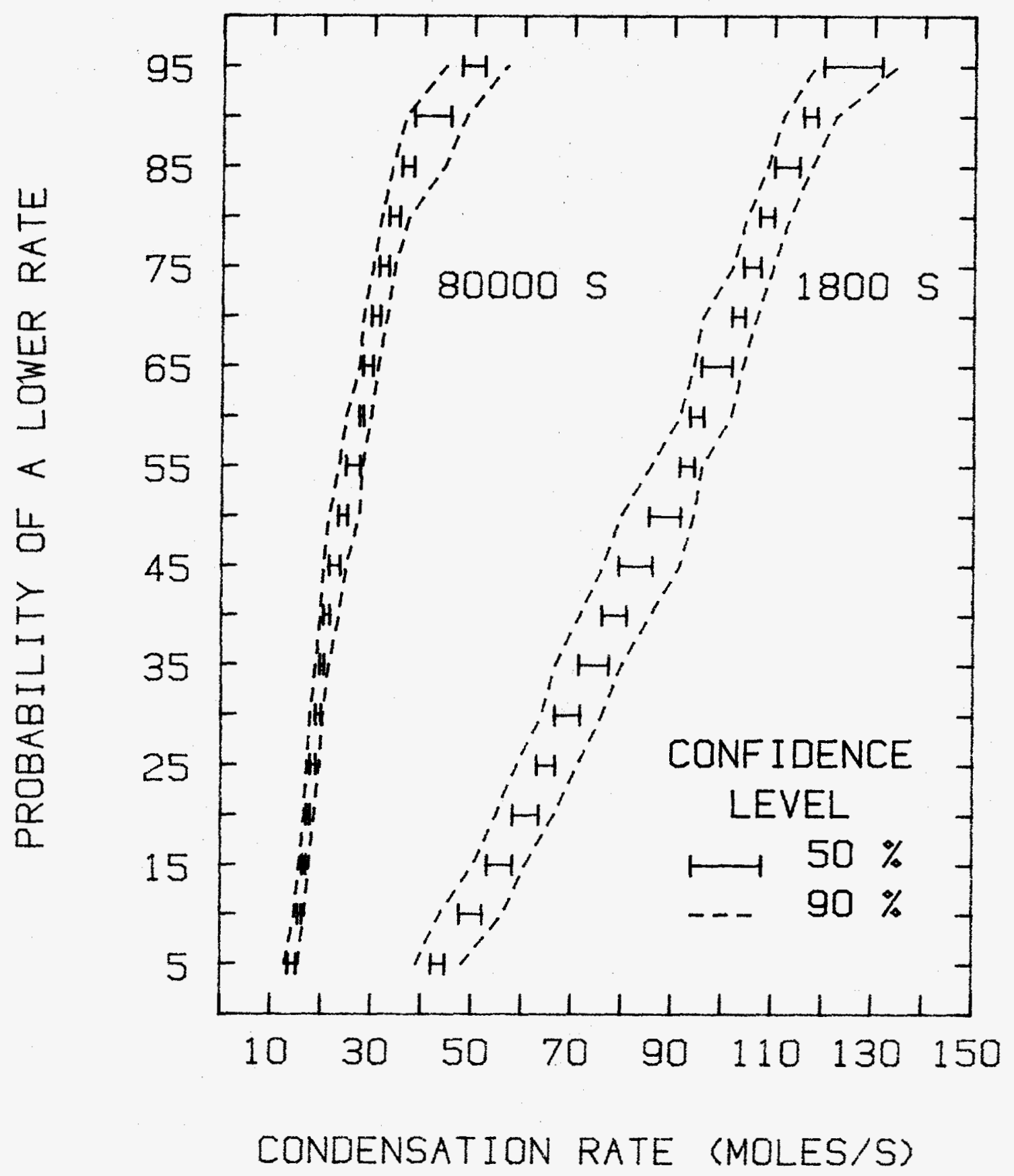

Figure 38. Uncertainty distributions for steam condensation rates at $1800 \mathrm{~s}$ and $80000 \mathrm{~s}$ during accidents at a $3000 \mathrm{MW}(\mathrm{th})$ advanced reactor 
Monte Carlo

Table 31. Characteristic values of uncertainty distributions for steam condensation rates during radiological design basis accidents at a $3000 \mathrm{MW}(\mathrm{th})$ reactor

\begin{tabular}{cccc}
\hline & \multicolumn{2}{c}{ Molar rate of steam condensation (moles/s) } \\
\cline { 2 - 4 } Time (s) & $\begin{array}{c}\text { Median }^{*} \\
\mathbf{( 5 0} \text { percentile) }\end{array}$ & $\begin{array}{c}\text { Upper bound } \\
\text { (90 percentile) }\end{array}$ & $\begin{array}{c}\text { Lower bound } \\
\text { (10 percentile) }\end{array}$ \\
\hline 1800 & $85.28-91.57$ & $111.85-122.27$ & $43.75-56.39$ \\
6480 & $53.20-56.08$ & $78.00-92.01$ & $32.13-39.96$ \\
13680 & $39.46-43.66$ & $59.18-80.14$ & $26.13-30.32$ \\
49680 & $26.23-28.95$ & $39.74-52.49$ & $16.48-18.93$ \\
80000 & $23.23-25.03$ & $36.42-48.40$ & $14.80-16.80$ \\
\hline$* 50$ percent confidence intervals & & \\
*** percent confidence intervals & & \\
\hline
\end{tabular}


Table 32. Median (50 percentile) decontamination coefficients for radiological design basis accidents

\begin{tabular}{|c|c|c|}
\hline \multirow{2}{*}{$\begin{array}{c}\text { Time } \\
\text { interval(s) }\end{array}$} & \multicolumn{2}{|c|}{ Decontamination coefficient $\left(h r^{-1}\right)$} \\
\hline & Gap release* & In-vessel release* \\
\hline \multicolumn{3}{|l|}{$1000 \mathrm{MW}$} \\
\hline $\begin{array}{c}0-1800 \\
1800-6480 \\
6480-13680 \\
13680-49680 \\
49680-80000\end{array}$ & $\begin{array}{c}0.0291 \text { to } 0.0298 \\
0.0566 \text { to } 0.0595 \\
0.120 \text { to } 0.133 \\
0.140 \text { to } 0.144 \\
0.0888 \text { to } 0.0905\end{array}$ & $\begin{array}{c}0 \\
0.0298 \text { to } 0.0315 \\
0.120 \text { to } 0.133 \\
0.140 \text { to } 0.144 \\
0.0888 \text { to } 0.0905\end{array}$ \\
\hline \multicolumn{3}{|l|}{$2000 \mathrm{MW}$} \\
\hline $\begin{array}{c}0-1800 \\
1800-6480 \\
6480-13680 \\
13680-49680 \\
49680-80000\end{array}$ & $\begin{array}{c}0.0339 \text { to } 0.0354 \\
0.0691 \text { to } 0.0711 \\
0.150 \text { to } 0.201 \\
0.151 \text { to } 0.163 \\
0.0904 \text { to } 0.0912\end{array}$ & $\begin{array}{c}0 \\
0.0361 \text { to } 0.0372 \\
0.150 \text { to } 0.201 \\
0.151 \text { to } 0.163 \\
0.0904 \text { to } 0.0912\end{array}$ \\
\hline \multicolumn{3}{|l|}{$3000 \mathrm{MW}$} \\
\hline $\begin{array}{c}0-1800 \\
1800-6480 \\
6480-13680 \\
13680-49680 \\
49680-80000\end{array}$ & $\begin{array}{c}0.0373 \text { to } 0.0385 \\
0.0802 \text { to } 0.0826 \\
0.166 \text { to } 0.183 \\
0.156 \text { to } 0.160 \\
0.0921 \text { to } 0.0928\end{array}$ & $\begin{array}{c}0 \\
0.0405 \text { to } 0.0418 \\
0.166 \text { to } 0.183 \\
0.156 \text { to } 0.160 \\
0.0921 \text { to } 0.928\end{array}$ \\
\hline \multicolumn{3}{|l|}{$4000 \mathrm{MW}$} \\
\hline $\begin{array}{c}0-1800 \\
1800-6480 \\
6480-13680 \\
13680-49680 \\
49680-80000\end{array}$ & $\begin{array}{c}0.0388 \text { to } 0.0411 \\
0.0803 \text { to } 0.0828 \\
0.175 \text { to } 0.226 \\
0.159 \text { to } 0.170 \\
0.0915 \text { to } 0.0922\end{array}$ & $\begin{array}{c}0 \\
0.0415 \text { to } 0.0425 \\
0.175 \text { to } 0.226 \\
0.159 \text { to } 0.170 \\
0.0915 \text { to } 0.0922\end{array}$ \\
\hline *50 percent confidence & & \\
\hline
\end{tabular}


Monte Carlo

Table 33. Reasonable upper bound ( 90 percentile) decontamination coefficients for radiological design basis accidents

\begin{tabular}{|c|c|c|}
\hline \multirow{2}{*}{$\begin{array}{c}\text { Time } \\
\text { interval(s) }\end{array}$} & \multicolumn{2}{|c|}{ Decontamination coefficient $\left(\mathrm{hr}^{-1}\right)$} \\
\hline & Gap release* & In-vessel release* \\
\hline \multicolumn{3}{|l|}{$1000 \mathrm{MW}$} \\
\hline $\begin{array}{c}0-1800 \\
1800-6480 \\
6480-13680 \\
13680-49680 \\
49680-80000\end{array}$ & $\begin{array}{c}0.0379 \text { to } 0.0419 \\
0.0871 \text { to } 0.1011 \\
0.349 \text { to } 0.428 \\
0.190 \text { to } 0.197 \\
0.0989 \text { to } 0.1082\end{array}$ & $\begin{array}{c}0 \\
0.0447 \text { to } 0.0519 \\
0.349 \text { to } 0.428 \\
0.190 \text { to } 0.197 \\
0.0989 \text { to } 0.1082\end{array}$ \\
\hline \multicolumn{3}{|l|}{$2000 \mathrm{MW}$} \\
\hline $\begin{array}{c}0-1800 \\
1800-6480 \\
6480-13680 \\
13680-49680 \\
49680-80000\end{array}$ & $\begin{array}{c}0.0423 \text { to } 0.0456 \\
0.0896 \text { to } 0.1015 \\
0.380 \text { to } 0.452 \\
0.185 \text { to } 0.190 \\
0.0980 \text { to } 0.1027\end{array}$ & $\begin{array}{c}0 \\
0.0463 \text { to } 0.0513 \\
0.380 \text { to } 0.452 \\
0.185 \text { to } 0.190 \\
0.0980 \text { to } 0.100\end{array}$ \\
\hline \multicolumn{3}{|l|}{$3000 \mathrm{MW}$} \\
\hline $\begin{array}{c}0-1800 \\
1800-6480 \\
6480-13680 \\
13680-49680 \\
49680-80000\end{array}$ & $\begin{array}{c}0.0445 \text { to } 0.0496 \\
0.0975 \text { to } 0.108 \\
0.314 \text { to } 0.462 \\
0.180 \text { to } 0.186 \\
0.0987 \text { to } 0.100\end{array}$ & $\begin{array}{c}0 \\
0.0495 \text { to } 0.0536 \\
0.314 \text { to } 0.462 \\
0.180 \text { to } 0.186 \\
0.0987 \text { to } 0.100\end{array}$ \\
\hline \multicolumn{3}{|l|}{$4000 \mathrm{MW}$} \\
\hline $\begin{array}{c}0-1800 \\
1800-6480 \\
6480-13680 \\
13680-49680 \\
49680-80000\end{array}$ & $\begin{array}{c}0.0490 \text { to } 0.0526 \\
0.104 \text { to } 0.116 \\
0.419 \text { to } 0.492 \\
0.189 \text { to } 0.192 \\
0.0991 \text { to } 0.102\end{array}$ & $\begin{array}{c}0 \\
0.0519 \text { to } 0.0590 \\
0.419 \text { to } 0.492 \\
0.189 \text { to } 0.192 \\
0.0991 \text { to } 0.102\end{array}$ \\
\hline *90 percent confidenc & & \\
\hline
\end{tabular}


Table 34. Reasonable lower bound (10 percentile) decontamination coefficients for radiological design basis accidents

\begin{tabular}{|c|c|c|}
\hline \multirow{2}{*}{$\begin{array}{c}\text { Time } \\
\text { interval(s) }\end{array}$} & \multicolumn{2}{|c|}{ Decontamination coefficient $\left(\mathrm{hr}^{-1}\right)$} \\
\hline & Gap release* & In-vessel release* \\
\hline \multicolumn{3}{|l|}{$1000 \mathrm{MW}$} \\
\hline $\begin{array}{c}0-1800 \\
1800-6480 \\
6480-13680 \\
13680-49680 \\
49680-80000\end{array}$ & $\begin{array}{l}0.0190 \text { to } 0.0214 \\
0.0378 \text { to } 0.0419 \\
0.0469 \text { to } 0.0614 \\
0.0764 \text { to } 0.0949 \\
0.0771 \text { to } 0.0792\end{array}$ & $\begin{array}{c}0 \\
0.0189 \text { to } 0.0207 \\
0.0469 \text { to } 0.0614 \\
0.0764 \text { to } 0.0949 \\
0.0771 \text { to } 0.0792\end{array}$ \\
\hline \multicolumn{3}{|l|}{$2000 \mathrm{MW}$} \\
\hline $\begin{array}{c}0-1800 \\
1800-6480 \\
6480-13680 \\
13680-49680 \\
49680-80000\end{array}$ & $\begin{array}{c}0.0251 \text { to } 0.0276 \\
0.0515 \text { to } 0.0573 \\
0.0690 \text { to } 0.0870 \\
0.101 \text { to } 0.113 \\
0.0839 \text { to } 0.0863\end{array}$ & $\begin{array}{c}0 \\
0.0255 \text { to } 0.0284 \\
0.0690 \text { to } 0.0870 \\
0.101 \text { to } 0.113 \\
0.0839 \text { to } 0.0884\end{array}$ \\
\hline \multicolumn{3}{|l|}{$3000 \mathrm{MW}$} \\
\hline $\begin{array}{c}0-1800 \\
1800-6480 \\
6480-13680 \\
13680-49680 \\
49680-80000\end{array}$ & $\begin{array}{c}0.0267 \text { to } 0.0294 \\
0.0553 \text { to } 0.0630 \\
0.0810 \text { to } 0.0965 \\
0.108 \text { to } 0.127 \\
0.0845 \text { to } 0.0866\end{array}$ & $\begin{array}{c}0 \\
0.0286 \text { to } 0.0318 \\
0.0810 \text { to } 0.0965 \\
0.108 \text { to } 0.127 \\
0.0845 \text { to } 0.0866\end{array}$ \\
\hline \multicolumn{3}{|l|}{$4000 \mathrm{MW}$} \\
\hline $\begin{array}{c}0-1800 \\
1800-6480 \\
6480-13680 \\
13680-49680 \\
49680-80000\end{array}$ & $\begin{array}{c}0.0291 \text { to } 0.0319 \\
0.0609 \text { to } 0.0678 \\
0.0804 \text { to } 0.100 \\
0.109 \text { to } 0.123 \\
0.0860 \text { to } 0.0872\end{array}$ & $\begin{array}{c}0 \\
0.0301 \text { to } 0.0341 \\
0.0804 \text { to } 0.100 \\
0.109 \text { to } 0.123 \\
0.0860 \text { to } 0.0872\end{array}$ \\
\hline *90 percent confidence & & \\
\hline
\end{tabular}


Monte Carlo

Table 35. Mean decontamination coefficients for radiological design basis accidents

\begin{tabular}{ccc}
\hline & \multicolumn{2}{c}{ Decontamination coefficient $\left(\mathbf{h r}^{-\mathbf{1}}\right)$} \\
\cline { 2 - 3 } interval(s) & Gap release* & In-vessel release* \\
\hline $1000 \mathrm{MW}$ & & \\
$0-1800$ & 0.0299 & 0 \\
$1800-6480$ & 0.0623 & 0.0318 \\
$6480-13680$ & 0.1872 & 0.1872 \\
$13680-49680$ & 0.1418 & 0.1418 \\
$49680-80000$ & 0.08973 & 0.0897 \\
$2000 \mathrm{MW}$ & & \\
$0-1800$ & 0.0352 & 0 \\
$1800-6480$ & 0.0732 & 0.0372 \\
$6480-13680$ & 0.212 & 0.212 \\
$13680-49680$ & 0.152 & 0.152 \\
$49680-80000$ & 0.0914 & 0.0914 \\
$3000 \mathrm{MW}$ & & \\
$0-1800$ & 0.0378 & 0 \\
$1800-6480$ & 0.0814 & 0.0410 \\
$6480-13680$ & 0.207 & 0.207 \\
$13680-49680$ & 0.154 & 0.154 \\
$49680-80000$ & 0.0927 & 0.0927 \\
$4000 \mathrm{MW}$ & & \\
$0-1800$ & & 0 \\
$1800-6480$ & 0.0406 & 0.0432 \\
$6480-13680$ & 0.0851 & 0.159 \\
$13680-49680$ & 0.239 & 0.0927 \\
$49680-80000$ & 0.159 &
\end{tabular}




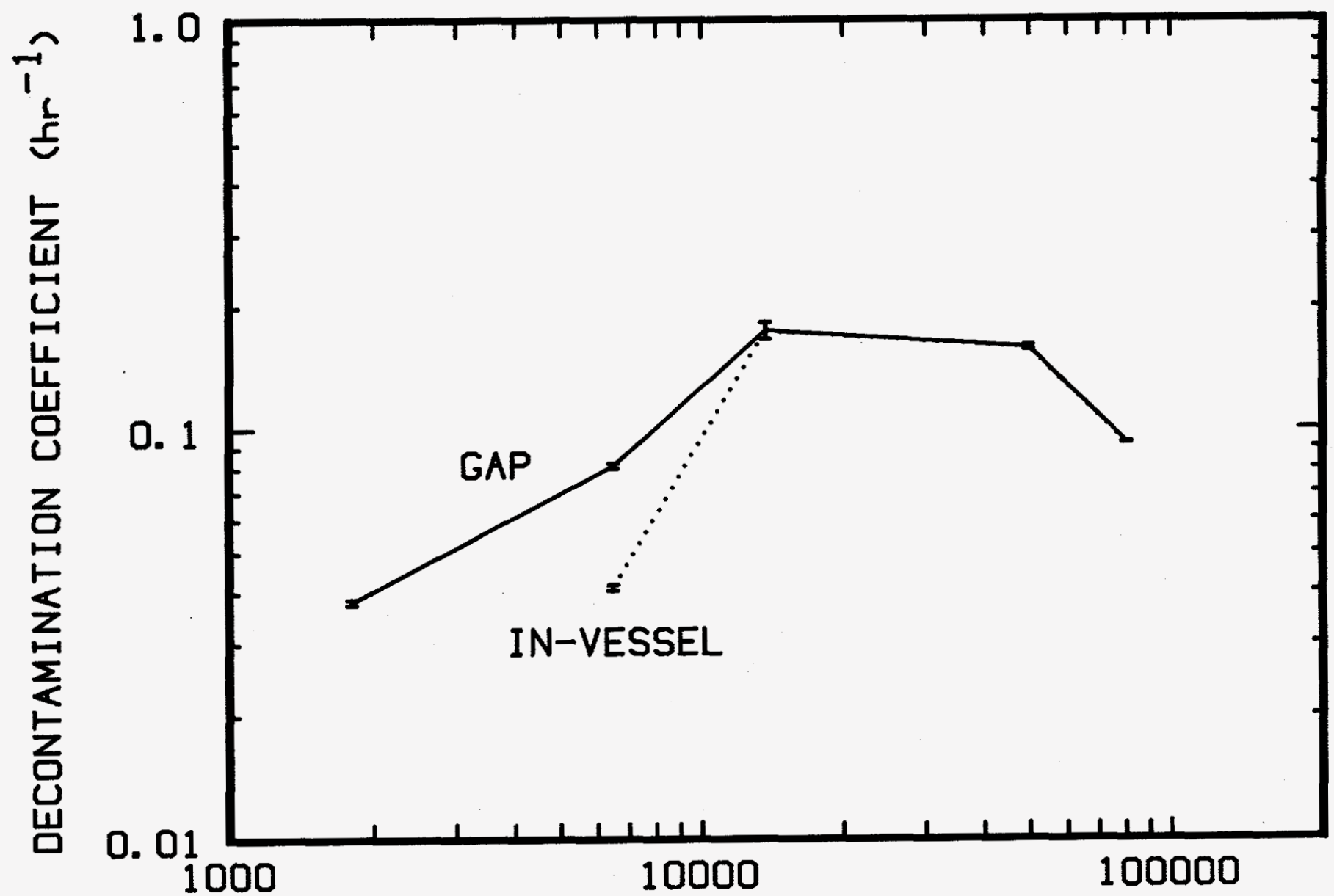

TIME (SECONDS)

Figure 39. Median decontamination coefficients calculated for gap and in-vessel releases during accidents at a $3000 \mathrm{MW}$ (th) advanced water reactor 
Monte Carlo

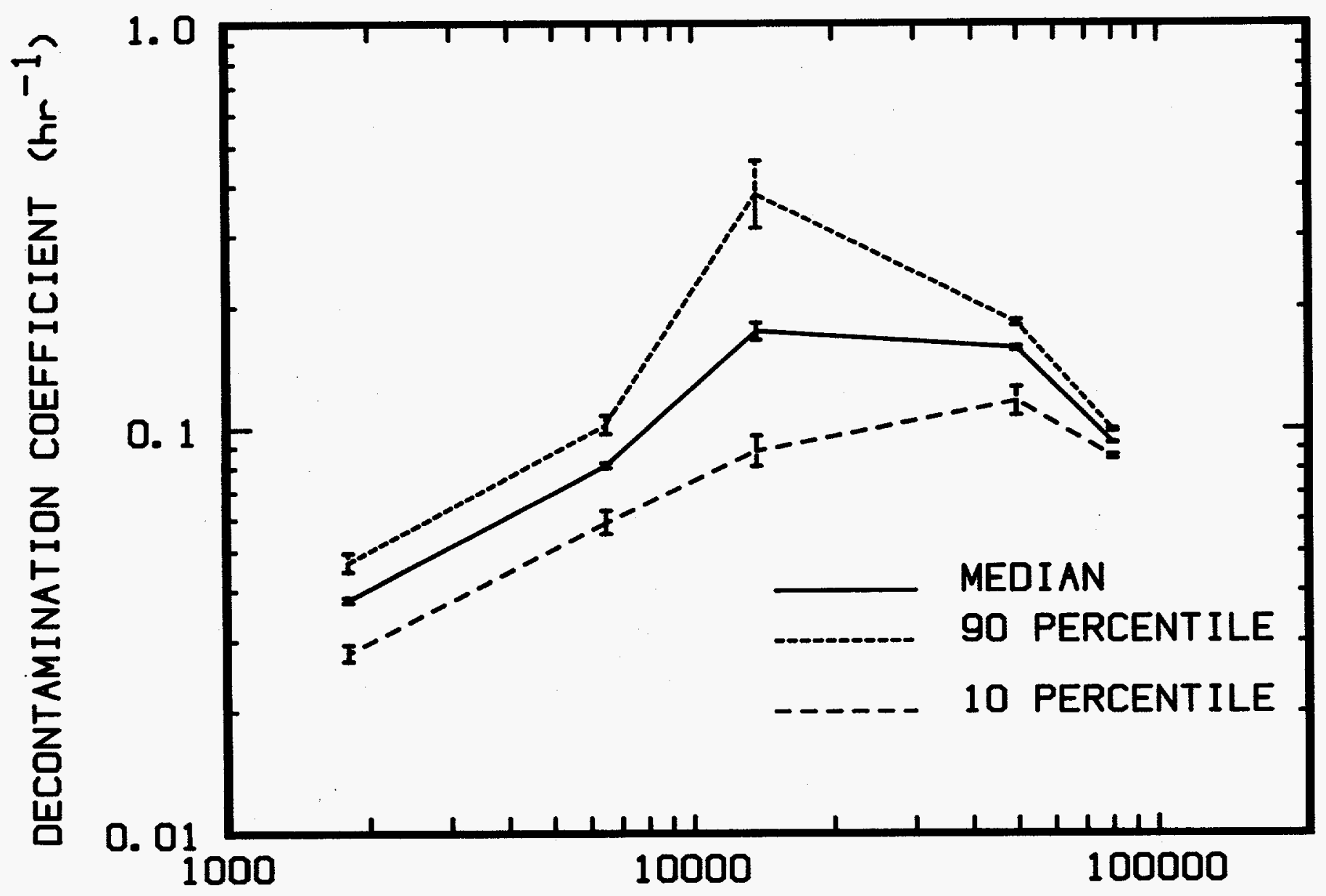

TIME (SECONDS)

Figure 40. Median ( 50 percentile), upper bound ( 90 percentile), and lower bound (10 percentile) decontamination coefficients for gap releases during accidents at a $3000 \mathrm{MW}$ (th) advanced reactor 
Monte Carlo

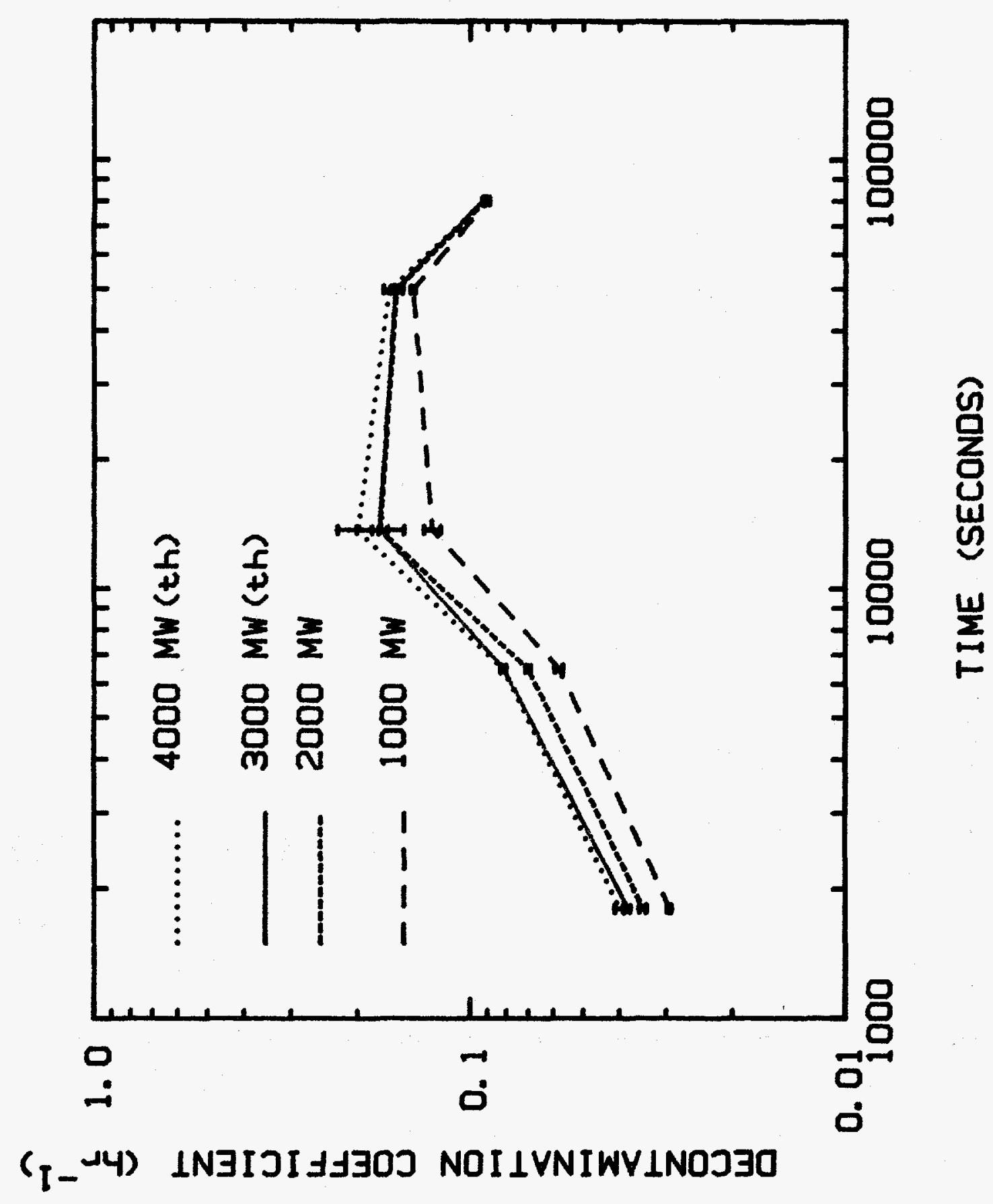

$\frac{3}{8}$

를

\%

옹

e

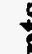

ก

0
0
$\omega$

$\sum_{1}^{4}$

8

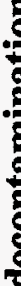




\section{Monte Carlo}

increasing reactor power. The dependence on reactor power is most pronounced at early times. By 80000 seconds after the start of gap release, decontamination coefficients are sensibly independent of reactor power (see Figures 42 and 43). Correlations for the six unique, important decontamination coefficient with power are listed in Table 36.

The simplified model developed here for radiological design basis accidents may be of some use for safety analysis of advanced reactors. The model should be useful for analysis of advanced reactor accidents in which the containment thermal hydraulics are similar to thermal hydraulics in existing pressurized water reactors during accidents without spray actuation. Advanced reactor containments with external containment cooling create additional driving forces for aerosol deposition that are not considered in the simplified model. Consequently, the simplified model for radiological design basis accidents may underpredict by perhaps an order of magnitude the rates of aerosol deposition in advanced reactor containments with external cooling.

\section{Uncertainty Analysis For Boiling Water Reactors}

Monte Carlo uncertainty analyses were done for 1500,2500 , and $3500 \mathrm{MW}($ th) boiling water reactors. Results of a particular calculation of aerosol behavior in the drywell of a $2500 \mathrm{MW}$ reactor during a severe accident are shown in Figures 44 to 50. These example results are shown just to illustrate some of the general features of the predicted aerosol behavior. Detailed quantitative predictions vary, of course, among the many calculations which use different values of the uncertain parameters.

Pressures and temperatures in the drywell selected as described in Chapter IV for the various phases of the particular accident are shown in Figure 44. Again, it should be noted that for this work, temperatures and pressures were assumed constant in each phase of an accident but they varied among the accident phases. This only approximately describes the temperature and pressure conditions expected to actually arise in a drywell during a severe accident.

The calculated difference between the atmosphere temperature and the average temperature of structural surfaces in the drywell is shown as a function of time in Figure 45. This temperature difference is, of course, responsible for thermophoretic deposition of aerosol particles in the drywell. This temperature difference becomes quite large during the ex-vessel release and late in-vessel release phases of the accident when core debris expelled from the reactor coolant system is interacting with structural concrete in the drywell.

Also shown in Figure 45 is the difference between the atmosphere temperature and the saturation temperature. By assumption, the drywell atmosphere is at steam saturation throughout the gap release phase of the accident. The atmosphere becomes superheated during the in-vessel release phase of the accident. Relative humidities in the drywell atmosphere become low after the gap release phase as first hydrogen and then a hydrogen, carbon monoxide and carbon dioxide mixture are injected into the atmosphere during the in-vessel and subsequent phases of the accident (see Figure 46). These noncondensible gases are produced by metal-water reactions and concrete decomposition.

Molar rates of steam condensation and gas flow from the drywell to the steam suppression pool are shown as functions of time in Figure 47. Molar rates of steam condensation are quite high during the gap release and in-vessel release phases of this accident and drop dramatically during the ex-vessel release phase. That steam condensation rates are higher during the in-vessel release phase than during 


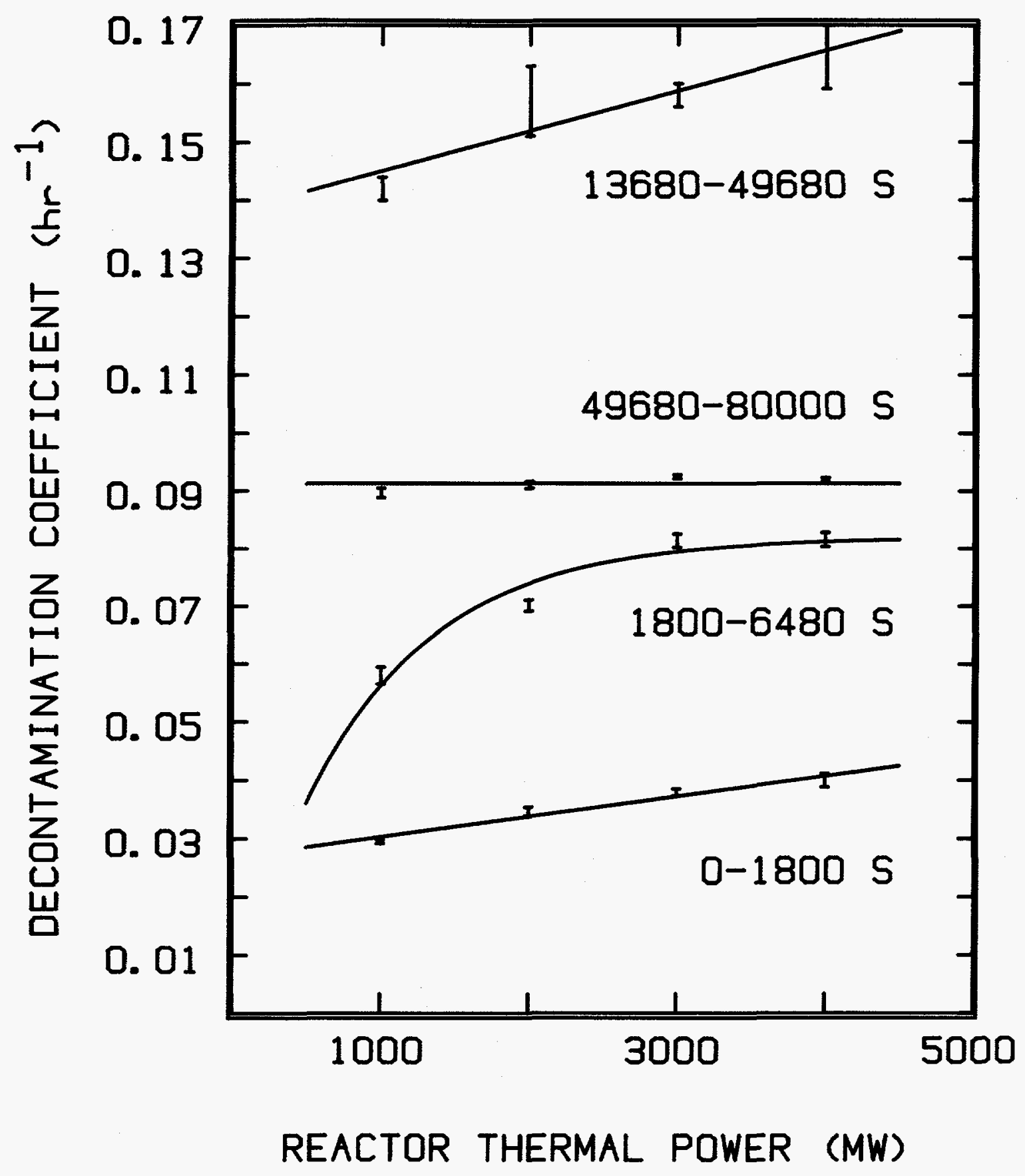

Figure 42. Average, effective decontamination coefficients for gap releases during radiological design basis accidents 


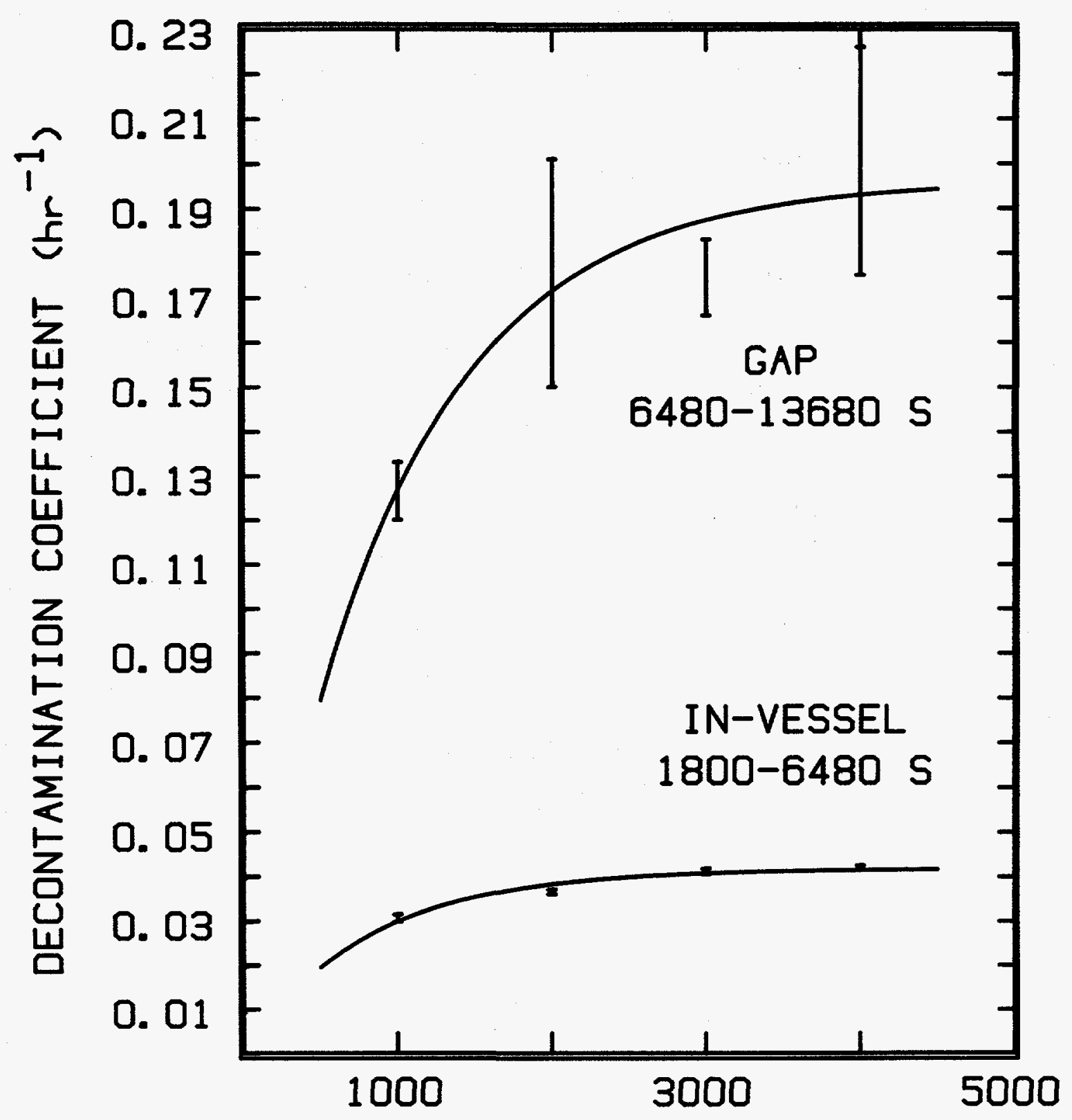

REACTOR THERMAL POWER (MW)

Figure 43. Effective decontamination coefficients for gap releases and in-vessel releases during radiological design basis accidents at reactors of various thermal powers 
Table 36. Correlation of effective decontamination coefficients for radiological design basis accidents with reactor thermal power

\begin{tabular}{|c|c|c|}
\hline Material & Time Interval (s) & Correlation ${ }^{*}$ \\
\hline gap & $0-1800$ & $\begin{array}{l}\lambda_{\mathrm{e}}(90)=0.0365+3.580 \times 10^{-6} \mathrm{P}(\mathrm{MW}) \\
\lambda_{\mathrm{e}}(50)=0.0268+3.475 \times 10^{-6} \mathrm{P}(\mathrm{MW}) \\
\lambda_{\mathrm{e}}(10)=0.0182+3.260 \times 10^{-6} \mathrm{P}(\mathrm{MW})\end{array}$ \\
\hline gap & $1800-6480$ & $\begin{array}{l}\lambda_{\mathrm{e}}(90)=0.1036[1-\exp (-2.239 \mathrm{P}(\mathrm{MW}) / 1000)] \\
\lambda_{\mathrm{e}}(50)=0.0820[1-\exp (-1.159 \mathrm{P}(\mathrm{MW}) / 1000)] \\
\lambda_{\mathrm{e}}(10)=0.0645[1-\exp (-0.938 \mathrm{P}(\mathrm{MW}) / 1000)]\end{array}$ \\
\hline gap & $6480-13680$ & $\begin{array}{l}\lambda_{\mathrm{e}}(90)=0.421[1-\exp (-2.530 \mathrm{P}(\mathrm{MW}) / 1000)] \\
\lambda_{\mathrm{e}}(50)=0.196[1-\exp (-1.040 \mathrm{P}(\mathrm{MW}) / 1000)] \\
\lambda_{\mathrm{e}}(10)=0.094[1-\exp (-0.869 \mathrm{P}(\mathrm{MW}) / 1000)]\end{array}$ \\
\hline gap & $13680-49680$ & $\begin{array}{l}\lambda_{\mathrm{e}}(90)=0.1920-1.35 \times 10^{-6} \mathrm{P}(\mathrm{MW}) \\
\lambda_{\mathrm{e}}(50)=0.1382+6.85 \times 10^{-6} \mathrm{P}(\mathrm{MW}) \\
\lambda_{\mathrm{e}}(10)=0.0811+10.15 \times 10^{-6} \mathrm{P}(\mathrm{MW})\end{array}$ \\
\hline gap & $49680-80000$ & $\begin{array}{l}\lambda_{\mathrm{e}}(90)=0.1010 \\
\lambda_{\mathrm{e}}(50)=0.0912 \\
\lambda_{\mathrm{e}}(10)=0.0860[1-\exp (-2.384 \mathrm{P}(\mathrm{MW}) / 1000)]\end{array}$ \\
\hline in-vessel & $1800-6480$ & $\begin{array}{l}\lambda_{\mathrm{e}}(90)=0.0522[1-\exp (-2.458 \mathrm{P}(\mathrm{MW}) / 1000)] \\
\lambda_{\mathrm{e}}(50)=0.0417[1-\exp (-1.258 \mathrm{P}(\mathrm{MW}) / 1000)] \\
\lambda_{\mathrm{e}}(10)=0.0326[1-\exp (-0.910 \mathrm{P}(\mathrm{MW}) / 1000)]\end{array}$ \\
\hline \multicolumn{3}{|c|}{$\begin{array}{l}* \lambda_{\mathrm{e}}(50) \text { is the } 50 \text { percentile or median effective decontamination coefficient. } \lambda_{\mathrm{e}}(90) \text { and } \lambda_{\mathrm{e}}(10) \text { ar } \\
\text { the } 90^{\text {th }} \text { and } 10^{\text {th }} \text { percentile values, respectively. }\end{array}$} \\
\hline
\end{tabular}


TEMPERATURE (K)

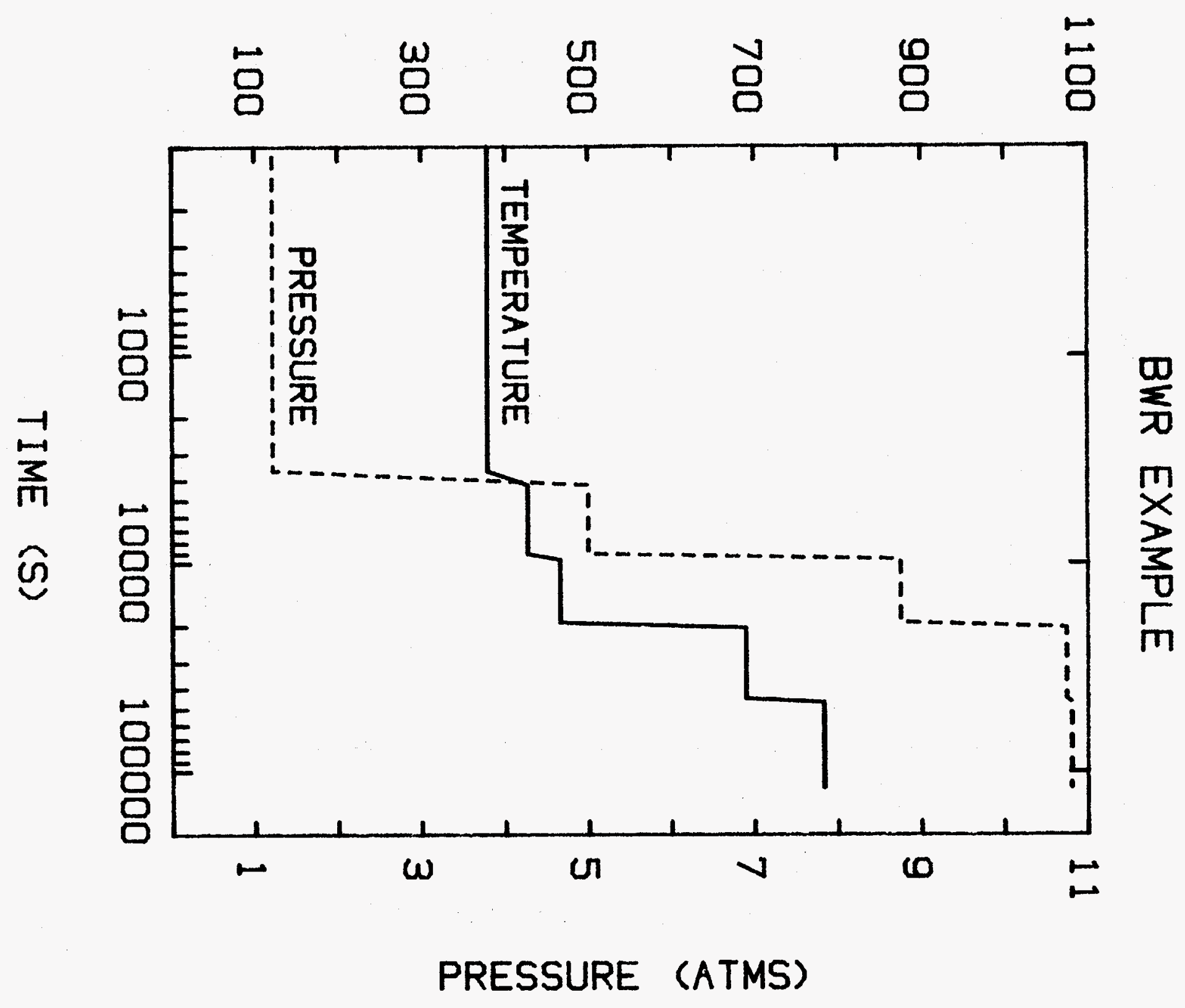


BWR EXAMPLE

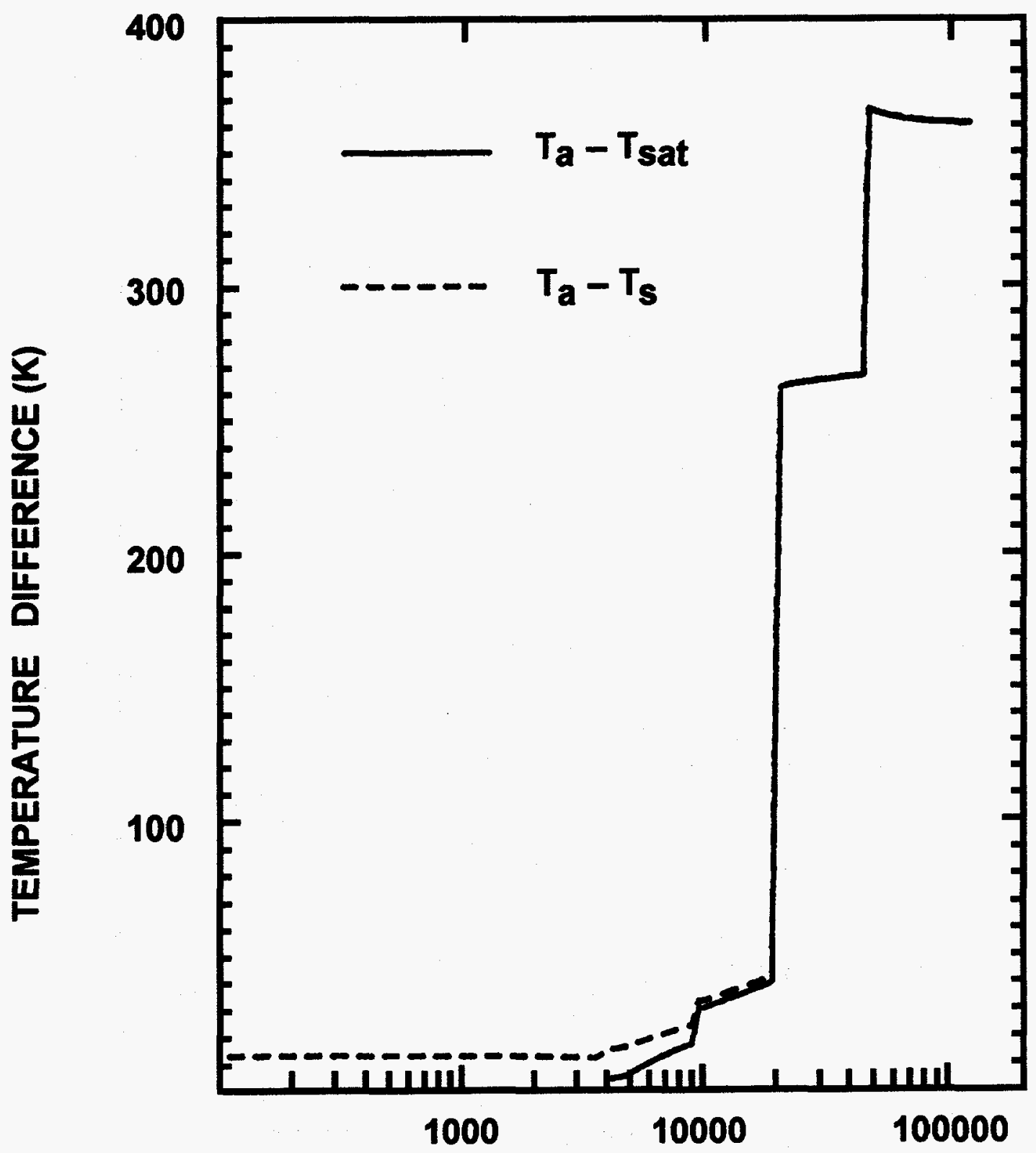

TIME (S)

Figure 45. Temperature differences between the atmosphere and structural surfaces (dashed line) and between the atmosphere and the steam saturation temperature (solid line) during a particular accident in a $2500 \mathrm{MW}$ (th) boiling water reactor 
Monte Carlo

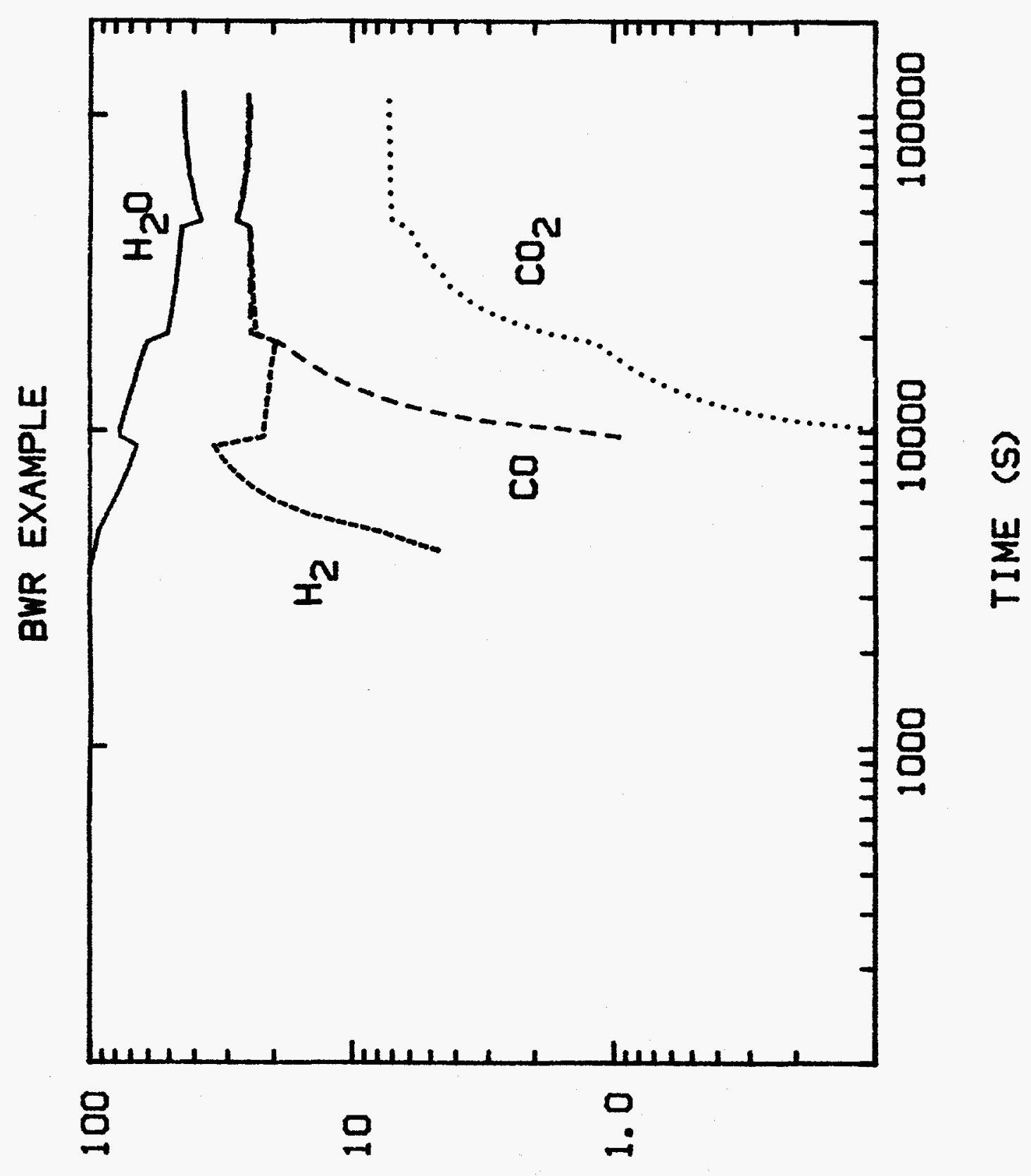

(\% ヨา0W) NOILISOdWOJ sVJ 


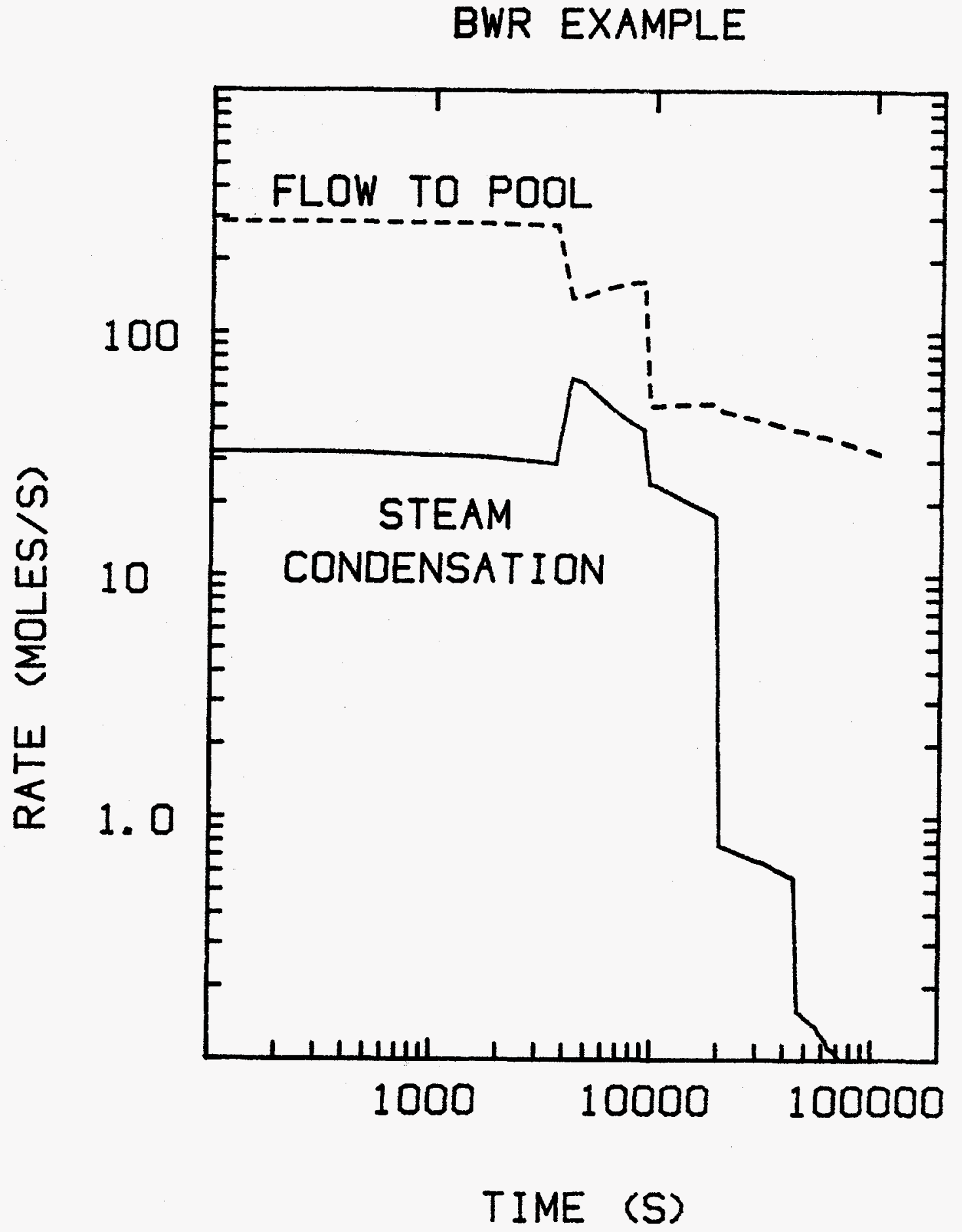

Figure 47. Molar rate of gas flow from the drywell to the suppression pool and the molar rate of steam condensation during a particular accident at a 2500 MW(th) boiling water reactor 


\section{Monte Carlo}

the gap release phase this is not always the case. In other calculations with less steam production during the in-vessel release phase of the accident, steam condensation rates decrease from the gap release to the in-vessel release phase of the accident. A drop in the condensation rate during the ex-vessel release phase is generally calculated. This decrease in steam condensation occurs because of the low steam production. Much of the water vaporized from concrete is converted to hydrogen during the ex-vessel release phase by reaction with residual zirconium in the core debris. Further decreases in the steam condensation rate are calculated to occur during the late in-vessel release phase of the accident, largely because of high temperatures in the drywell.

The effective aerosol particle size is shown as a function of time in Figure 48. The aerosol particle size is nearly constant throughout the gap release phase of the accident when particle concentrations are low. The particle size increases some during the in-vessel release phase when additional radioactive and nonradioactive masses are added to the atmosphere and accelerate particle coagulation. The dramatic increase in aerosol particle size during the ex-vessel release phase of the accident is due to the enormous amounts of nonradioactive aerosol mass injected into the drywell atmosphere during this phase of the accident. At 19800 seconds, this large source of aerosol mass is sharply attenuated to the more modest levels ascribed to the late in-vessel release phase. Particle size of the aerosol remaining suspended in the drywell atmosphere decreases as large particles sediment and are not replenished by a large aerosol source.

Concentrations of radioactive materials released to the drywell during the gap release, in-vessel release, ex-vessel release and late in-vessel release phases of the accident are shown as functions of time in Figure 49. Note that the concentrations of nonradioactive aerosol are not shown in this figure. Even so, it is apparent that aerosol concentrations in the drywell of a boiling water reactor can be much larger than concentrations typically calculated to exist in more voluminous pressurized water reactor containments. Note the unusual time dependence of the concentrations of radioactive material released to the drywell during the late in-vessel release phase of the accident. This late in-vessel release overlaps in time the ex-vessel release. At first, the concentration of late in-vessel release materials is strongly affected by the massive amounts of nonradioactive aerosol produced by ex-vessel release. When the exvessel release stops and conditions in the drywell change, the late in-vessel release material goes through complicated changes in composition. These complicated changes are challenging to treat in developing a simplified model.

Particle deposition velocities due to gravitational settling, diffusiophoresis, thermophoresis and turbulent diffusion are shown as functions of time in Figure 50. During the gap release phase, diffusiophoresis is the only really important aerosol removal process aside from the removal that occurs because of gas flow from the drywell to the steam suppression pool. As aerosol particles agglomerate, gravitational settling becomes a more important deposition mechanism. Because gravitational settling operates over smaller surface areas than does diffusiophoresis, gravitational settling does not account for most of the aerosol removal until the later stages of the in-vessel release phase of the accident. Gravitational settling is by far the most important deposition mechanism during the ex-vessel release phase.

As the drywell atmosphere heats, thermophoresis becomes a more important aerosol deposition mechanism. Late in the accident it exceeds gravitational settling in importance as a deposition mechanism. 


\section{BWR EXAMPLE}

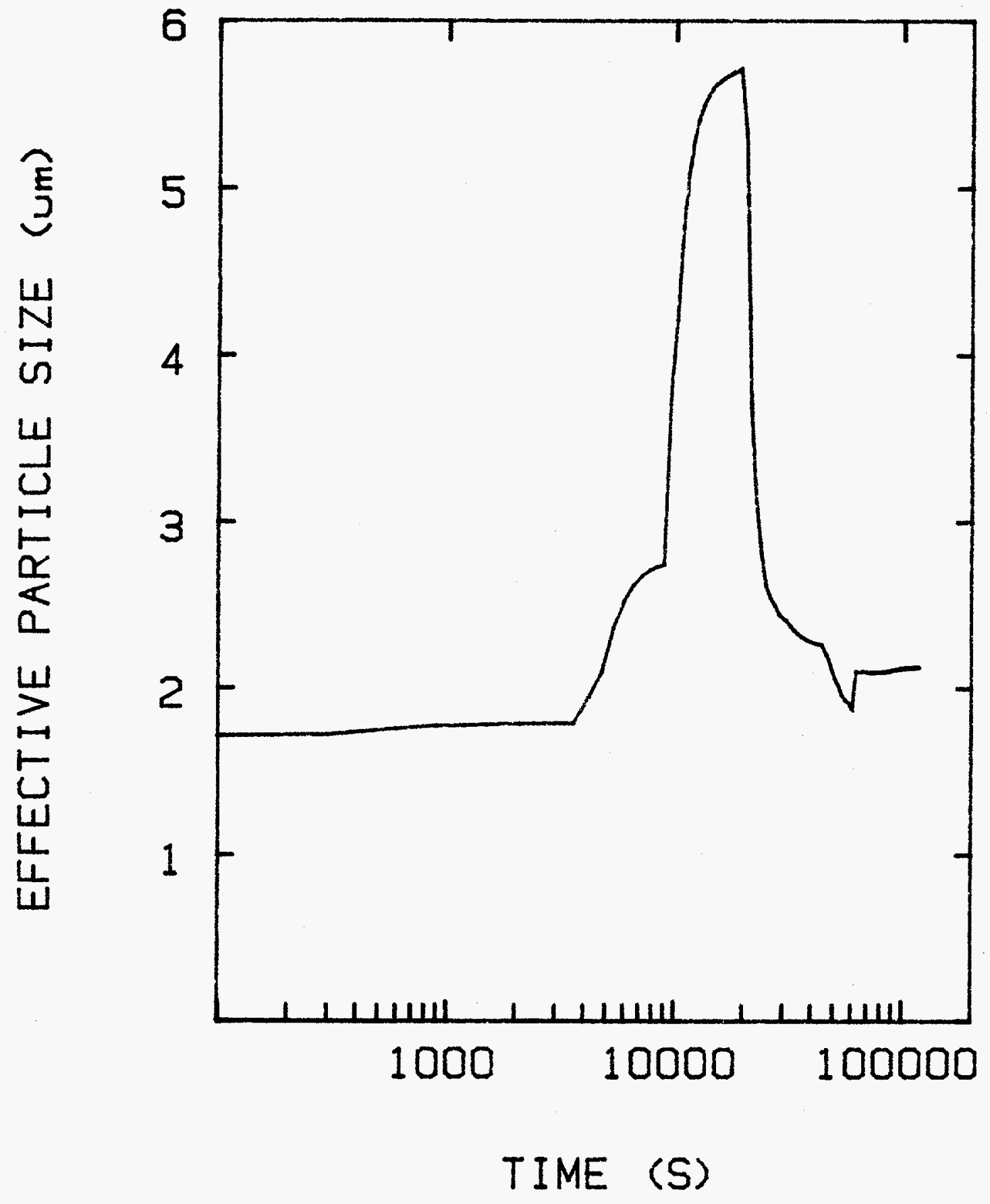

Figure 48. Effective size of aerosol particles in the drywell of a $2500 \mathrm{MW}$ (th) boiling water reactor during a particular accident 


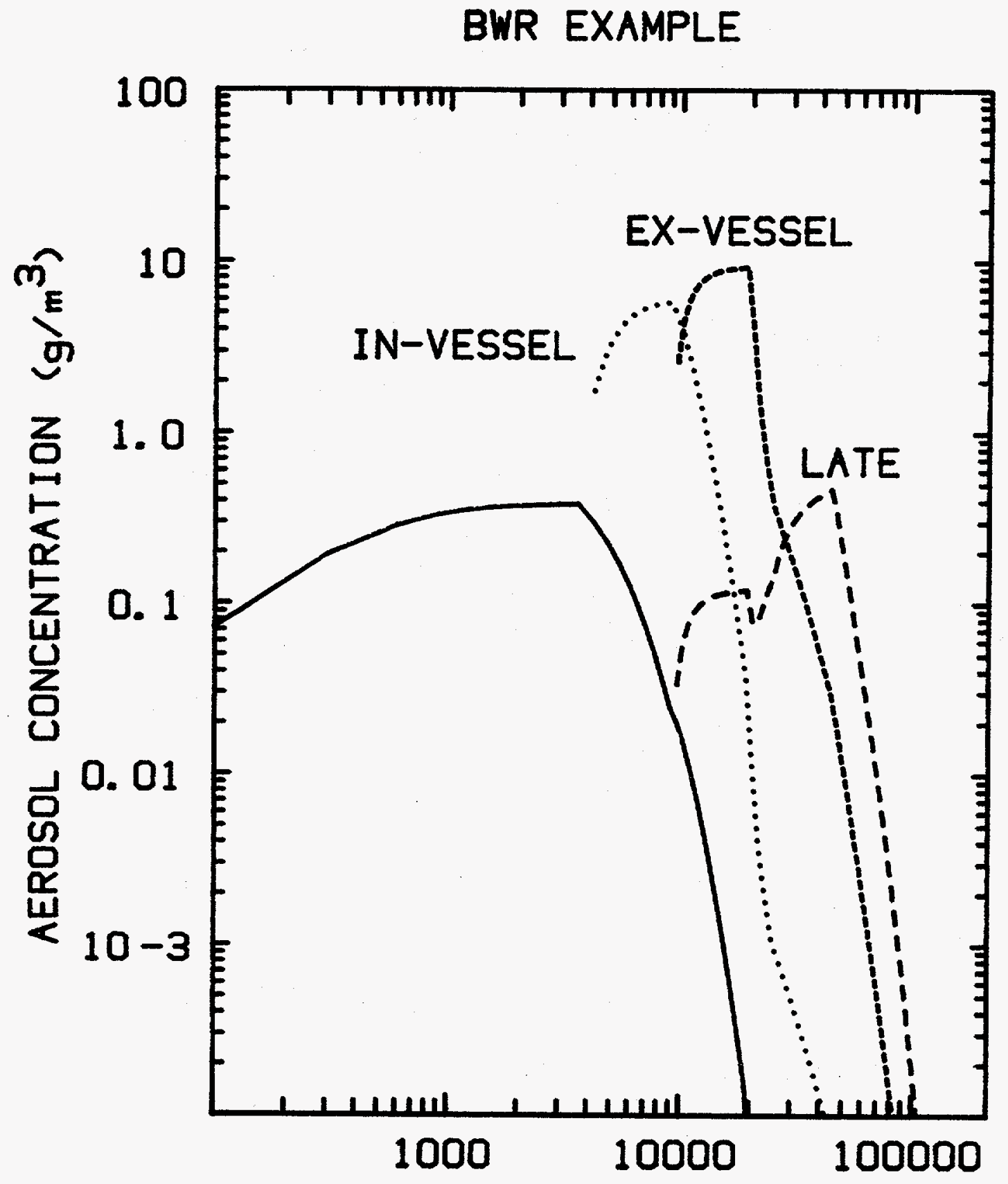

TIME (SECONDS)

Figure 49. Concentrations of radioactive aerosols released to the drywell during various phases of a particular accident at a $2500 \mathrm{MW}$ (th) boiling water reactor 


\section{BWR EXAMPLE}

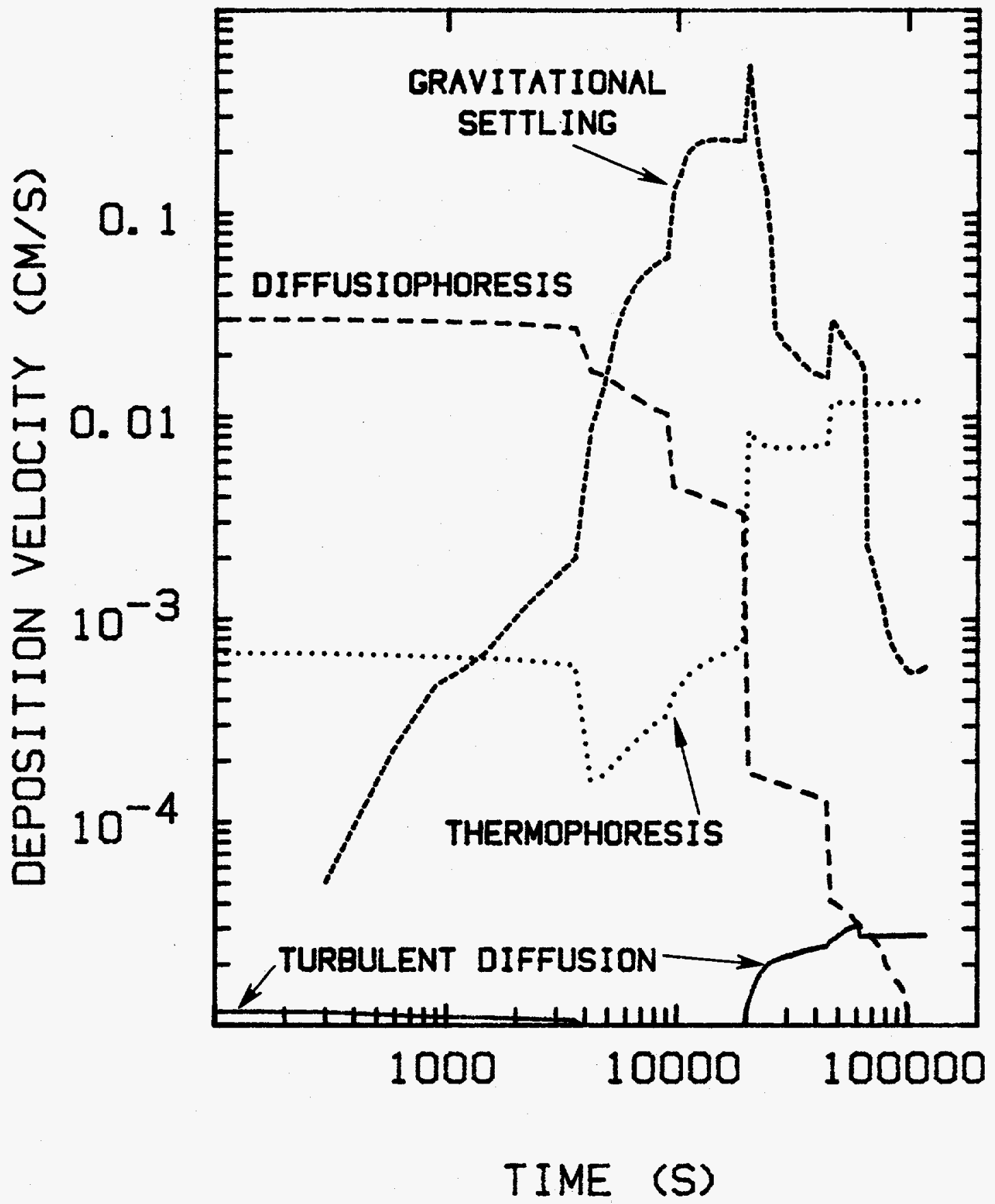

Figure 50. Aerosol deposition velocities by various mechanisms during a particular accident at a 2500 MW(th) boiling water reactor 


\section{Monte Carlo}

Turbulent diffusion was not calculated to be the cause of significant mass removal in this example calculation. In fact, turbulent diffusion was not found to be important in any of the calculations of aerosol behavior in boiling water reactor drywells.

Results of calculations similar to those described above were accumulated in the Monte Carlo uncertainty analyses. Decontamination factors for radioactive materials released during the gap release, in-vessel release, ex-vessel release and late in-vessel release were calculated at the times $3600,9000,19800$, $45000,80000,100000$, and 120000 seconds after the start of gap release. The first four of these times correspond to the end of gap release, the end of in-vessel release, the end of ex-vessel release and the end of late in-vessel release, respectively. Later times were selected to show the long term aerosol behavior during the post-release phase of accidents. Uncertainty distributions for the various decontamination factors were constructed. Median (50 percentile) reasonable upper bound ( 90 percentile) and reasonable lower bound (10 percentile) values of the decontamination factors are listed in Tables 37 to 39 .

The most notable feature of decontamination factors calculated for boiling water reactors is that they are much larger than decontamination factors calculated for pressurized water reactor containments. Larger decontamination factors are calculated largely because drywells of boiling water reactors are smaller than containments of pressurized water reactors. As a result, aerosol concentrations in the drywell are higher. Particles more rapidly agglomerate to sizes that sediment. Flow of aerosol laden gas from the drywell to the suppression pool also accentuates decontamination of drywells in a way that is not possible in pressurized water reactors. In some cases, decontamination factors in excess of $10^{6}$ were calculated. The authors are not persuaded, however, that the models they have used account for sufficient phenomena to justify such complete decontamination. Consequently, decontamination factors larger than $10^{6}$ are listed in the tables as $>10^{6}$.

Uncertainty distributions were calculated for the average, effective decontamination coefficients as discussed above in connection with the Monte Carlo uncertainty analysis of aerosol behavior in pressurized water reactors. Median (50 percentile), reasonable upper bound ( 90 percentile) and reasonable lower bound ( 10 percentile) values of the decontamination coefficient are listed in Tables 40 to 42. Mean values of the decontamination coefficients are listed in Table 43.

Qualitative features of the decontamination coefficients are similar to what was found for decontamination coefficients for pressurized water reactors and advanced reactors. That is, there are unique values of the decontamination coefficient for a particular material while the source of that material is operative. When the source stops, the decontamination coefficient rises to values applicable to all materials without operative sources (see Figure 51). The gap release decontamination coefficients are then particularly significant. The time dependence of these average, effective decontamination coefficients is shown in Figure 52.

The decontamination coefficient for the late in-vessel release material over the period 19800 to 45000 seconds is unusual. During this time interval the ex-vessel release has stopped but the late in-vessel release is still taking place. The late in-vessel decontamination coefficient can become quite small. When the rate of aerosol production during this time interval exceeds the rate of particle deposition, the effective decontamination coefficient assumes negative values! This is, of course, just an exaggerated form of the behavior found for the late in-vessel decontamination coefficients in the case of pressurized 
Table 37. Median decontamination factors for BWR drywells

\begin{tabular}{|c|c|c|c|c|}
\hline Time (s) & Gap release & In-vessel release ${ }^{*}$ & Ex-vessel release ${ }^{*}$ & $\begin{array}{l}\text { Late in-vessel } \\
\text { release }\end{array}$ \\
\hline \multicolumn{5}{|l|}{$3500 \mathrm{MW}$} \\
\hline $\begin{array}{r}0 \\
3600 \\
9000 \\
19800 \\
45000 \\
80000 \\
100000 \\
120000\end{array}$ & $\begin{array}{c}1.0 \\
4.459 \text { to } 4.817 \\
67.619 \text { to } 106.80 \\
5845 \text { to } 8772 \\
>10^{6} \\
>10^{6} \\
>10^{6} \\
>10^{6}\end{array}$ & $\begin{array}{c}1.0 \\
1.0 \\
3.066 \text { to } 3.303 \\
209.6 \text { to } 303.8 \\
42142 \text { to } 83089 \\
>10^{6} \\
>10^{6} \\
>10^{6}\end{array}$ & $\begin{array}{c}1.0 \\
1.0 \\
1.0 \\
4.541 \text { to } 4.806 \\
902.8 \text { to } 1364 \\
44634 \text { to } 72742 \\
252259 \text { to } 643750 \\
>10^{6}\end{array}$ & $\begin{array}{c}1.0 \\
1.0 \\
1.0 \\
4.541 \text { to } 4.806 \\
4.543 \text { to } 4.929 \\
239.6 \text { to } 393.9 \\
1616 \text { to } 2711 \\
8788 \text { to } 15968\end{array}$ \\
\hline \multicolumn{5}{|l|}{$2500 \mathrm{MW}$} \\
\hline $\begin{array}{r}0 \\
3600 \\
9000 \\
19800 \\
45000 \\
80000 \\
100000 \\
120000\end{array}$ & $\begin{array}{c}1.0 \\
3.578 \text { to } 3.754 \\
44.858 \text { to } 56.760 \\
3070 \text { to } 5294 \\
708936 \text { to }>10^{6} \\
>10^{6} \\
>10^{6} \\
>10^{6}\end{array}$ & $\begin{array}{c}1.0 \\
1.0 \\
2.740 \text { to } 2.939 \\
211.2 \text { to } 261.5 \\
47916 \text { to } 64697 \\
>10^{6} \\
>10^{6} \\
>10^{6}\end{array}$ & $\begin{array}{c}1.0 \\
1.0 \\
1.0 \\
4.749 \text { to } 4.875 \\
950.9 \text { to } 1147 \\
59498 \text { to } 89199 \\
346938 \text { to } 654710 \\
>10^{6}\end{array}$ & $\begin{array}{c}1.0 \\
1.0 \\
1.0 \\
4.749 \text { to } 4.875 \\
4.475 \text { to } 4.692 \\
238.7 \text { to } 380.9 \\
1413 \text { to } 2210 \\
8695 \text { to } 14072\end{array}$ \\
\hline \multicolumn{5}{|l|}{$1500 \mathrm{MW}$} \\
\hline $\begin{array}{r}0 \\
3600 \\
9000 \\
19800 \\
45000 \\
80000 \\
100000 \\
120000\end{array}$ & $\begin{array}{c}1.0 \\
1.900 \text { to } 1.975 \\
5.233 \text { to } 5.771 \\
113.5 \text { to } 209.9 \\
12226 \text { to } 24474 \\
340438 \text { to }>10^{6} \\
899183 \text { to }>10^{6} \\
>10^{6}\end{array}$ & $\begin{array}{c}1.0 \\
1.0 \\
1.590 \text { to } 1.674 \\
41.410 \text { to } 53.139 \\
4119 \text { to } 5828 \\
88931 \text { to } 127160 \\
268838 \text { to } 683750 \\
>10^{6}\end{array}$ & $\begin{array}{c}1.0 \\
1.0 \\
1.0 \\
3.622 \text { to } 3.915 \\
379.4 \text { to } 466.1 \\
6261 \text { to } 9916 \\
27633 \text { to } 41051 \\
90869 \text { to } 168530\end{array}$ & $\begin{array}{c}1.0 \\
1.0 \\
1.0 \\
3.622 \text { to } 3.915 \\
3.560 \text { to } 3.694 \\
80.782 \text { to } 99.572 \\
284.3 \text { to } 393.0 \\
965.2 \text { to } 1464\end{array}$ \\
\hline percent $c$ & e intervals & & & \\
\hline
\end{tabular}


Table 38. 90 percentile decontamination factors for BWR drywells

\begin{tabular}{|c|c|c|c|c|}
\hline Time (s) & Gap release & In-vessel release & Ex-vessel release & $\begin{array}{l}\text { Late in-vessel } \\
\text { release }\end{array}$ \\
\hline \multicolumn{5}{|l|}{$3500 \mathrm{MW}$} \\
\hline $\begin{array}{r}0 \\
3600 \\
9000 \\
19800 \\
45000 \\
80000 \\
100000 \\
120000\end{array}$ & $\begin{array}{c}1.0 \\
12.560 \text { to } 18.424 \\
21270 \text { to } 988348 \\
>10^{6} \\
>10^{6} \\
>10^{6} \\
>10^{6} \\
>10^{6}\end{array}$ & $\begin{array}{c}1.0 \\
1.0 \\
7.731 \text { to } 11.383 \\
50364 \text { to } 821207 \\
>10^{6} \\
>10^{6} \\
>10^{6} \\
>10^{6}\end{array}$ & $\begin{array}{c}1.0 \\
1.0 \\
1.0 \\
\text { to } \\
111122 \text { to }>10^{6} \\
>10^{6} \\
>10^{6} \\
>10^{6}\end{array}$ & $\begin{array}{c}1.0 \\
1.0 \\
1.0 \\
9.016 \text { to } 11.501 \\
9.912 \text { to } 14.762 \\
118550 \text { to }>10^{6} \\
>10^{6} \\
>10^{6}\end{array}$ \\
\hline \multicolumn{5}{|l|}{$2500 \mathrm{MW}$} \\
\hline $\begin{array}{r}0 \\
3600 \\
9000 \\
19800 \\
45000 \\
80000 \\
100000 \\
120000\end{array}$ & $\begin{array}{c}1.0 \\
10.812 \text { to } 14.826 \\
6416 \text { to } 284912 \\
>10^{6} \\
>10^{6} \\
>10^{6} \\
>10^{6} \\
>10^{6}\end{array}$ & $\begin{array}{c}1.0 \\
1.0 \\
6.459 \text { to } 10.076 \\
31213 \text { to } 466437 \\
>10^{6} \\
>10^{6} \\
>10^{6} \\
>10^{6}\end{array}$ & $\begin{array}{c}1.0 \\
1.0 \\
1.0 \\
8.488 \text { to } 10.980 \\
55153 \text { to } 592256 \\
>10^{6} \\
>10^{6} \\
>10^{6}\end{array}$ & $\begin{array}{c}1.0 \\
1.0 \\
1.0 \\
8.488 \text { to } 10.980 \\
9.470 \text { to } 13.299 \\
76740 \text { to }>10^{6} \\
>10^{6} \\
>10^{6}\end{array}$ \\
\hline \multicolumn{5}{|l|}{$3000 \mathrm{MW}$} \\
\hline $\begin{array}{r}0 \\
3600 \\
9000 \\
19800 \\
45000 \\
80000 \\
100000 \\
120000\end{array}$ & $\begin{array}{c}1.0 \\
5.284 \text { to } 10.822 \\
288.4 \text { to } 403368 \\
697961 \text { to }>10^{6} \\
>10^{6} \\
>10^{6} \\
>10^{6} \\
>10^{6}\end{array}$ & $\begin{array}{c}1.0 \\
1.0 \\
4.739 \text { to } 9.259 \\
12409 \text { to } 162267 \\
>10^{6} \\
>10^{6} \\
>10^{6} \\
>10^{6}\end{array}$ & $\begin{array}{c}1.0 \\
1.0 \\
1.0 \\
8.193 \text { to } 12.135 \\
17264 \text { to } 577580 \\
>10^{6} \\
>10^{6} \\
>10^{6}\end{array}$ & $\begin{array}{c}1.0 \\
1.0 \\
1.0 \\
8.193 \text { to } 12.135 \\
7.306 \text { to } 12.328 \\
5903 \text { to }>10^{6} \\
161627 \text { to }>10^{6} \\
>10^{6}\end{array}$ \\
\hline
\end{tabular}


Table 39. 10 percentile decontamination factors for BWR drywells

\begin{tabular}{|c|c|c|c|c|}
\hline Time (s) & Gap release* & In-vessel release" & Ex-vessel release ${ }^{*}$ & $\begin{array}{l}\text { Late in-vessel } \\
\text { release }\end{array}$ \\
\hline \multicolumn{5}{|l|}{$3500 \mathrm{MW}$} \\
\hline $\begin{array}{r}0 \\
3600 \\
9000 \\
19800 \\
45000 \\
80000 \\
100000 \\
120000\end{array}$ & $\begin{array}{c}1.0 \\
2.058 \text { to } 2.334 \\
6.267 \text { to } 10.244 \\
84.855 \text { to } 166.01 \\
3571 \text { to } 10086 \\
63677 \text { to } 225076 \\
191732 \text { to } 764708 \\
522243 \text { to }>10^{6}\end{array}$ & $\begin{array}{c}1.0 \\
1.0 \\
1.622 \text { to } 1.820 \\
18.655 \text { to } 27.391 \\
783.6 \text { to } 1825 \\
10948 \text { to } 36396 \\
32556 \text { to } 128476 \\
89974 \text { to } 266589\end{array}$ & $\begin{array}{c}1.0 \\
1.0 \\
1.0 \\
\text { to } \\
134.7 \text { to } 189.9 \\
1423 \text { to } 3674 \\
3848 \text { to } 9485 \\
10574 \text { to } 24040\end{array}$ & $\begin{array}{c}1.0 \\
1.0 \\
1.0 \\
2.774 \text { to } 3.025 \\
2.922 \text { to } 3.172 \\
30.58 \text { to } 49.70 \\
81.67 \text { to } 169.4 \\
194.6 \text { to } 453.1\end{array}$ \\
\hline \multicolumn{5}{|l|}{$2500 \mathrm{MW}$} \\
\hline $\begin{array}{r}0 \\
3600 \\
9000 \\
19800 \\
45000 \\
80000 \\
100000 \\
120000\end{array}$ & $\begin{array}{c}1.0 \\
1.964 \text { to } 2.268 \\
5.814 \text { to } 8.930 \\
107.6 \text { to } 243.2 \\
5439 \text { to } 22739 \\
97709 \text { to } 355305 \\
327473 \text { to }>10_{6} \\
>10^{6}\end{array}$ & $\begin{array}{c}1.0 \\
1.0 \\
1.612 \text { to } 1.795 \\
20.602 \text { to } 43.169 \\
856.5 \text { to } 3365 \\
18644 \text { to } 69419 \\
47846 \text { to } 186474 \\
115996 \text { to } 725063\end{array}$ & $\begin{array}{c}1.0 \\
1.0 \\
1.0 \\
2.871 \text { to } 3.403 \\
124.7 \text { to } 274.9 \\
2689 \text { to } 4599 \\
7151 \text { to } 15273 \\
14615 \text { to } 45573\end{array}$ & $\begin{array}{c}1.0 \\
1.0 \\
1.0 \\
2.870 \text { to } 3.403 \\
2.933 \text { to } 3.349 \\
24.997 \text { to } 50.167 \\
62.257 \text { to } 185.6 \\
150.0 \text { to } 456.3\end{array}$ \\
\hline \multicolumn{5}{|l|}{$1500 \mathrm{MW}$} \\
\hline $\begin{array}{r}0 \\
3600 \\
9000 \\
19800 \\
45000 \\
80000 \\
100000 \\
120000 \\
\end{array}$ & $\begin{array}{c}1.0 \\
1.326 \text { to } 1.435 \\
1.970 \text { to } 2.404 \\
13.458 \text { to } 23.810 \\
465.1 \text { to } 1039 \\
4380 \text { to } 12697 \\
11787 \text { to } 34662 \\
23031 \text { to } 68166\end{array}$ & $\begin{array}{c}1.0 \\
1.0 \\
1.189 \text { to } 1.272 \\
7.980 \text { to } 11.609 \\
254.4 \text { to } 438.3 \\
2585 \text { to } 6364 \\
6741 \text { to } 16013 \\
13679 \text { to } 29115\end{array}$ & $\begin{array}{c}1.0 \\
1.0 \\
1.0 \\
2.427 \text { to } 2.640 \\
70.115 \text { to } 104.57 \\
766.8 \text { to } 1276 \\
1674 \text { to } 2748 \\
3686 \text { to } 5618\end{array}$ & $\begin{array}{c}1.0 \\
1.0 \\
1.0 \\
2.427 \text { to } 2.640 \\
2.686 \text { to } 2.808 \\
12.284 \text { to } 17.657 \\
31.098 \text { to } 55.633 \\
57.572 \text { to } 117.64\end{array}$ \\
\hline percent $\mathrm{c}$ & e intervals & & & \\
\hline
\end{tabular}


Monte Carlo

Table 40. Median decontamination coefficients for BWR drywells

\begin{tabular}{|c|c|c|c|c|}
\hline Time interval (s) & $\begin{array}{c}\text { Gap release } \\
\left(\mathbf{h} \mathbf{r}^{-1}\right)\end{array}$ & $\begin{array}{c}\text { In-vessel release } \\
\left(\mathbf{h r} \mathbf{r}^{-1}\right)\end{array}$ & $\begin{array}{c}\text { Ex-vessel release } \\
\left(\mathrm{hr}^{-1}\right)\end{array}$ & $\begin{array}{c}\text { Late in-vessel release } \\
\left(\mathbf{h r}^{-1}\right)\end{array}$ \\
\hline \multicolumn{5}{|l|}{$3500 \mathrm{MW}$} \\
\hline $\begin{array}{c}0-3600 \\
3600-9000 \\
9000-19800 \\
19800-45000 \\
45000-80000 \\
80000-100000 \\
100000-120000\end{array}$ & $\begin{array}{l}1.495 \text { to } 1.572 \\
1.859 \text { to } 2.027 \\
1.390 \text { to } 1.504 \\
0.751 \text { to } 0.793 \\
0.416 \text { to } 0.443 \\
0.339 \text { to } 0.364 \\
0.332 \text { to } 0.358\end{array}$ & $\begin{array}{c}0.0 \\
0.747 \text { to } 0.797 \\
1.390 \text { to } 1.503 \\
0.750 \text { to } 0.792 \\
0.416 \text { to } 0.443 \\
0.339 \text { to } 0.364 \\
0.332 \text { to } 0.358\end{array}$ & $\begin{array}{c}0.0 \\
0.0 \\
0.504 \text { to } 0.523 \\
0.750 \text { to } 0.792 \\
0.416 \text { to } 0.443 \\
0.339 \text { to } 0.364 \\
0.332 \text { to } 0.358\end{array}$ & $\begin{array}{c}0.0 \\
0.0 \\
0.504 \text { to } 0.523 \\
0.0053 \text { to } 0.0093 \\
0.416 \text { to } 0.443 \\
0.339 \text { to } 0.364 \\
0.332 \text { to } 0.358\end{array}$ \\
\hline \multicolumn{5}{|l|}{$2500 \mathrm{MW}$} \\
\hline $\begin{array}{c}0-3600 \\
3600-9000 \\
9000-19800 \\
19800-45000 \\
45000-80000 \\
80000-100000 \\
100000-120000\end{array}$ & $\begin{array}{l}1.275 \text { to } 1.323 \\
1.625 \text { to } 1.734 \\
1.460 \text { to } 1.498 \\
0.760 \text { to } 0.776 \\
0.417 \text { to } 0.449 \\
0.326 \text { to } 0.358 \\
0.320 \text { to } 0.353\end{array}$ & $\begin{array}{c}0.0 \\
0.672 \text { to } 0.719 \\
1.460 \text { to } 1.498 \\
0.759 \text { to } 0.775 \\
0.417 \text { to } 0.449 \\
0.326 \text { to } 0.358 \\
0.320 \text { to } 0.353\end{array}$ & $\begin{array}{c}0.0 \\
0.0 \\
0.519 \text { to } 0.528 \\
0.759 \text { to } 0.775 \\
0.417 \text { to } 0.448 \\
0.326 \text { to } 0.358 \\
0.320 \text { to } 0.353\end{array}$ & $\begin{array}{c}0.0 \\
0.0 \\
0.519 \text { to } 0.528 \\
0.0039 \text { to } 0.0086 \\
0.417 \text { to } 0.448 \\
0.326 \text { to } 0.358 \\
0.320 \text { to } 0.353\end{array}$ \\
\hline \multicolumn{5}{|l|}{$1500 \mathrm{MW}$} \\
\hline $\begin{array}{c}0-3600 \\
3600-9000 \\
9000-19800 \\
19800-45000 \\
45000-80000 \\
80000-100000 \\
100000-120000\end{array}$ & $\begin{array}{l}0.642 \text { to } 0.680 \\
0.644 \text { to } 0.707 \\
1.072 \text { to } 1.165 \\
0.658 \text { to } 0.691 \\
0.322 \text { to } 0.341 \\
0.236 \text { to } 0.252 \\
0.232 \text { to } 0.253\end{array}$ & $\begin{array}{c}0.0 \\
0.309 \text { to } 0.343 \\
1.072 \text { to } 1.165 \\
0.657 \text { to } 0.691 \\
0.322 \text { to } 0.341 \\
0.235 \text { to } 0.252 \\
0.232 \text { to } 0.253\end{array}$ & $\begin{array}{c}0.0 \\
0.0 \\
0.429 \text { to } 0.455 \\
0.657 \text { to } 0.691 \\
0.322 \text { to } 0.341 \\
0.235 \text { to } 0.252 \\
0.232 \text { to } 0.253\end{array}$ & $\begin{array}{c}0.0 \\
0.0 \\
0.429 \text { to } 0.454 \\
-0.0011 \text { to } 0.0044 \\
0.321 \text { to } 0.341 \\
0.235 \text { to } 0.252 \\
0.232 \text { to } 0.253\end{array}$ \\
\hline & & & & \\
\hline
\end{tabular}


Table 41. 90 percentile decontamination coefficients for BWR drywells

\begin{tabular}{|c|c|c|c|c|}
\hline Time interval (s) & $\begin{array}{c}\text { Gap release } \\
\left(\mathrm{hr}^{-1}\right)\end{array}$ & $\begin{array}{c}\text { In-vessel release } \\
\left(\mathbf{h r}^{-1}\right)\end{array}$ & $\begin{array}{c}\text { Ex-vessel release } \\
\left(\mathbf{h r}^{-1}\right)\end{array}$ & $\begin{array}{c}\text { Late in-vessel release } \\
\left(\mathbf{h r}^{-1}\right)\end{array}$ \\
\hline \multicolumn{5}{|l|}{$3500 \mathrm{MW}$} \\
\hline $\begin{array}{c}0-3600 \\
3600-9000 \\
9000-19800 \\
19800-45000 \\
45000-80000 \\
80000-100000 \\
100000-120000\end{array}$ & $\begin{array}{l}2.530 \text { to } 2.913 \\
5.077 \text { to } 6.805 \\
2.922 \text { to } 3.791 \\
1.338 \text { to } 1.816 \\
0.961 \text { to } 1.454 \\
0.830 \text { to } 1.356 \\
0.805 \text { to } 1.302\end{array}$ & $\begin{array}{c}0.0 \\
1.364 \text { to } 1.621 \\
2.914 \text { to } 3.771 \\
1.338 \text { to } 1.816 \\
0.961 \text { to } 1.454 \\
0.830 \text { to } 1.356 \\
0.805 \text { to } 1.302\end{array}$ & $\begin{array}{c}0.0 \\
0.0 \\
0.733 \text { to } 0.814 \\
1.334 \text { to } 1.811 \\
0.960 \text { to } 1.454 \\
0.830 \text { to } 1.356 \\
0.805 \text { to } 1.302\end{array}$ & $\begin{array}{c}0.0 \\
0.0 \\
0.733 \text { to } 0.814 \\
0.0533 \text { to } 0.0684 \\
0.957 \text { to } 1.450 \\
0.830 \text { to } 1.356 \\
0.805 \text { to } 1.302\end{array}$ \\
\hline \multicolumn{5}{|l|}{$2500 \mathrm{MW}$} \\
\hline $\begin{array}{c}0-3600 \\
3600-9000 \\
9000-19800 \\
19800-45000 \\
45000-80000 \\
80000-100000 \\
100000-120000\end{array}$ & $\begin{array}{l}2.380 \text { to } 2.696 \\
4.372 \text { to } 6.616 \\
2.797 \text { to } 3.702 \\
1.270 \text { to } 1.584 \\
0.895 \text { to } 1.167 \\
0.781 \text { to } 1.094 \\
0.767 \text { to } 1.065\end{array}$ & $\begin{array}{c}0.0 \\
1.244 \text { to } 1.540 \\
2.785 \text { to } 3.694 \\
1.271 \text { to } 1.580 \\
0.895 \text { to } 1.167 \\
0.781 \text { to } 1.094 \\
0.787 \text { to } 1.065\end{array}$ & $\begin{array}{c}0.0 \\
0.0 \\
0.713 \text { to } 0.799 \\
1.269 \text { to } 1.570 \\
0.895 \text { to } 1.167 \\
0.781 \text { to } 1.094 \\
0.767 \text { to } 1.065\end{array}$ & $\begin{array}{c}0.0 \\
0.0 \\
0.713 \text { to } 0.799 \\
0.0557 \text { to } 0.0678 \\
0.892 \text { to } 1.163 \\
0.781 \text { to } 1.094 \\
0.767 \text { to } 1.065\end{array}$ \\
\hline \multicolumn{5}{|l|}{$1500 \mathrm{MW}$} \\
\hline $\begin{array}{c}0-3600 \\
3600-9000 \\
9000-19800 \\
19800-45000 \\
45000-80000 \\
80000-100000 \\
100000-120000\end{array}$ & $\begin{array}{l}1.655 \text { to } 2.379 \\
3.067 \text { to } 4.047 \\
2.643 \text { to } 4.047 \\
1.083 \text { to } 1.573 \\
0.690 \text { to } 1.237 \\
0.617 \text { to } 1.134 \\
0.610 \text { to } 1.108\end{array}$ & $\begin{array}{c}0.0 \\
1.037 \text { to } 1.483 \\
2.634 \text { to } 4.030 \\
1.082 \text { to } 1.572 \\
0.690 \text { to } 1.237 \\
0.616 \text { to } 1.134 \\
0.610 \text { to } 1.108\end{array}$ & $\begin{array}{c}0.0 \\
0.0 \\
0.701 \text { to } 0.832 \\
1.078 \text { to } 1.569 \\
0.688 \text { to } 1.237 \\
0.616 \text { to } 1.134 \\
0.610 \text { to } 1.108\end{array}$ & $\begin{array}{c}0.0 \\
0.0 \\
0.701 \text { to } 0.832 \\
0.0450 \text { to } 0.0514 \\
0.688 \text { to } 1.233 \\
0.616 \text { to } 1.134 \\
0.610 \text { to } 1.108\end{array}$ \\
\hline *on nercent confid & dence intervals & & & \\
\hline
\end{tabular}


Monte Carlo

Table 42. 10 percentile decontamination coefficients for BWR drywells

\begin{tabular}{|c|c|c|c|c|}
\hline Time interval (s) & $\begin{array}{c}\text { Gap release } \\
\left(\mathrm{hr}^{-1}\right)\end{array}$ & $\begin{array}{c}\text { In-vessel release } \\
\left(\mathbf{h r}^{-1}\right)\end{array}$ & $\begin{array}{c}\text { Ex-vessel release } \\
\left(\mathrm{hr}^{-1}\right)\end{array}$ & $\begin{array}{c}\text { Late in-vessel release } \\
\left(\mathbf{h r}^{-1}\right)\end{array}$ \\
\hline \multicolumn{5}{|l|}{$3500 \mathrm{MW}$} \\
\hline $\begin{array}{c}0-3600 \\
3600-9000 \\
9000-19800 \\
19800-45000 \\
45000-80000 \\
80000-100000 \\
100000-120000\end{array}$ & $\begin{array}{l}0.722 \text { to } 0.848 \\
0.647 \text { to } 0.833 \\
0.777 \text { to } 0.884 \\
0.547 \text { to } 0.587 \\
0.238 \text { to } 0.281 \\
0.169 \text { to } 0.195 \\
0.141 \text { to } 0.182\end{array}$ & $\begin{array}{c}0.0 \\
0.332 \text { to } 0.399 \\
0.777 \text { to } 0.884 \\
0.547 \text { to } 0.587 \\
0.238 \text { to } 0.281 \\
0.169 \text { to } 0.195 \\
0.141 \text { to } 0.182\end{array}$ & $\begin{array}{c}0.0 \\
0.0 \\
0.340 \text { to } 0.369 \\
0.547 \text { to } 0.587 \\
0.238 \text { to } 0.281 \\
0.170 \text { to } 0.195 \\
0.141 \text { to } 0.182\end{array}$ & $\begin{array}{c}0.0 \\
0.0 \\
0.340 \text { to } 0.369 \\
-0.0591 \text { to } 0.0430 \\
0.238 \text { to } 0.281 \\
0.170 \text { to } 0.195 \\
0.141 \text { to } 0.182\end{array}$ \\
\hline \multicolumn{5}{|l|}{$2500 \mathrm{MW}$} \\
\hline $\begin{array}{c}0-3600 \\
3600-9000 \\
9000-19800 \\
19800-45000 \\
45000-80000 \\
80000-100000 \\
100000-120000\end{array}$ & $\begin{array}{l}0.675 \text { to } 0.809 \\
0.626 \text { to } 0.811 \\
0.801 \text { to } 1.002 \\
0.556 \text { to } 0.626 \\
0.222 \text { to } 0.277 \\
0.140 \text { to } 0.183 \\
0.129 \text { to } 0.164\end{array}$ & $\begin{array}{c}0.0 \\
0.318 \text { to } 0.390 \\
0.801 \text { to } 1.002 \\
0.556 \text { to } 0.626 \\
0.222 \text { to } 0.277 \\
0.140 \text { to } 0.183 \\
0.129 \text { to } 0.164\end{array}$ & $\begin{array}{c}0.0 \\
0.0 \\
0.352 \text { to } 0.408 \\
0.556 \text { to } 0.626 \\
0.222 \text { to } 0.277 \\
0.140 \text { to } 0.182 \\
0.129 \text { to } 0.164\end{array}$ & $\begin{array}{c}0.0 \\
0.0 \\
0.351 \text { to } 0.408 \\
-0.0725 \text { to }-0.0535 \\
0.222 \text { to } 0.277 \\
0.140 \text { to } 0.182 \\
0.129 \text { to } 0.164\end{array}$ \\
\hline \multicolumn{5}{|l|}{$1500 \mathrm{MW}$} \\
\hline $\begin{array}{c}0-3600 \\
3600-9000 \\
9000-19800 \\
19800-45000 \\
45000-80000 \\
80000-100000 \\
100000-120000\end{array}$ & $\begin{array}{c}0.282 \text { to } 0.361 \\
0.225 \text { to } 0.318 \\
0.624 \text { to } 0.698 \\
0.465 \text { to } 0.520 \\
0.185 \text { to } 0.217 \\
0.108 \text { to } 0.135 \\
0.0937 \text { to } 0.118\end{array}$ & $\begin{array}{c}0.0 \\
0.115 \text { to } 0.160 \\
0.624 \text { to } 0.689 \\
0.465 \text { to } 0.520 \\
0.185 \text { to } 0.217 \\
0.108 \text { to } 0.135 \\
0.0937 \text { to } 0.118\end{array}$ & $\begin{array}{c}0.0 \\
0.0 \\
0.296 \text { to } 0.324 \\
0.465 \text { to } 0.520 \\
0.185 \text { to } 0.217 \\
0.108 \text { to } 0.135 \\
0.0937 \text { to } 0.188\end{array}$ & $\begin{array}{c}0.0 \\
0.0 \\
0.296 \text { to } 0.324 \\
-0.0868 \text { to }-0.0582 \\
0.185 \text { to } 0.217 \\
0.108 \text { to } 0.135 \\
0.0937 \text { to } 0.118\end{array}$ \\
\hline${ }^{*} 90$ percent confic & lence intervals & & & \\
\hline
\end{tabular}


Table 43. Mean decontamination coefincients for BWR drywells

\begin{tabular}{|c|c|c|c|c|}
\hline Time interval (s) & $\begin{array}{c}\text { Gap release } \\
\left(\mathbf{h r}^{-1}\right)\end{array}$ & $\begin{array}{c}\text { In-vessel release } \\
\left(\mathbf{h r} \mathbf{r}^{-1}\right)\end{array}$ & $\begin{array}{c}\text { Ex-vessel release } \\
\left(\mathbf{h r} \mathbf{r}^{-1}\right)\end{array}$ & $\begin{array}{c}\text { Late in-vessel release } \\
\left(\mathbf{h r}^{-1}\right)\end{array}$ \\
\hline \multicolumn{5}{|l|}{$3500 \mathrm{MW}$} \\
\hline $\begin{array}{c}0-3600 \\
3600-9000 \\
9000-19800 \\
19800-45000 \\
45000-80000 \\
80000-100000 \\
100000-120000\end{array}$ & $\begin{array}{l}1.671 \\
2.633 \\
1.838 \\
0.924 \\
0.592 \\
0.516 \\
0.499\end{array}$ & $\begin{array}{c}0 \\
0.860 \\
1.834 \\
0.923 \\
0.592 \\
0.516 \\
0.499\end{array}$ & $\begin{array}{c}0 \\
0 \\
0.544 \\
0.922 \\
0.592 \\
0.516 \\
0.499\end{array}$ & $\begin{array}{c}0 \\
0 \\
0.544 \\
0.00575 \\
0.591 \\
0.516 \\
0.499\end{array}$ \\
\hline \multicolumn{5}{|l|}{$2500 \mathrm{MW}$} \\
\hline $\begin{array}{c}0-3600 \\
3600-9000 \\
9000-19800 \\
19800-45000 \\
45000-80000 \\
80000-100000 \\
100000-120000\end{array}$ & $\begin{array}{l}1.472 \\
2.400 \\
1.792 \\
0.904 \\
0.562 \\
0.471 \\
0.458\end{array}$ & $\begin{array}{c}0 \\
0.781 \\
1.790 \\
0.903 \\
0.562 \\
0.471 \\
0.458\end{array}$ & $\begin{array}{c}0 \\
0 \\
0.548 \\
0.902 \\
0.562 \\
0.471 \\
0.458\end{array}$ & $\begin{array}{c}0 \\
0 \\
0.548 \\
0.00233 \\
0.561 \\
0.471 \\
0.458\end{array}$ \\
\hline \multicolumn{5}{|l|}{$1500 \mathrm{MW}$} \\
\hline $\begin{array}{c}0-3600 \\
3600-9000 \\
9000-19800 \\
19800-45000 \\
45000-80000 \\
80000-100000 \\
100000-120000\end{array}$ & $\begin{array}{l}0.943 \\
1.648 \\
1.653 \\
0.813 \\
0.471 \\
0.389 \\
0.378\end{array}$ & $\begin{array}{c}0 \\
0.521 \\
1.650 \\
0.812 \\
0.471 \\
0.389 \\
0.378\end{array}$ & $\begin{array}{c}0 \\
0 \\
0.497 \\
0.811 \\
0.470 \\
0.389 \\
0.378\end{array}$ & $\begin{array}{c}0 \\
0 \\
0.497 \\
-0.0040 \\
0.470 \\
0.389 \\
0.378\end{array}$ \\
\hline
\end{tabular}


Monte Carlo

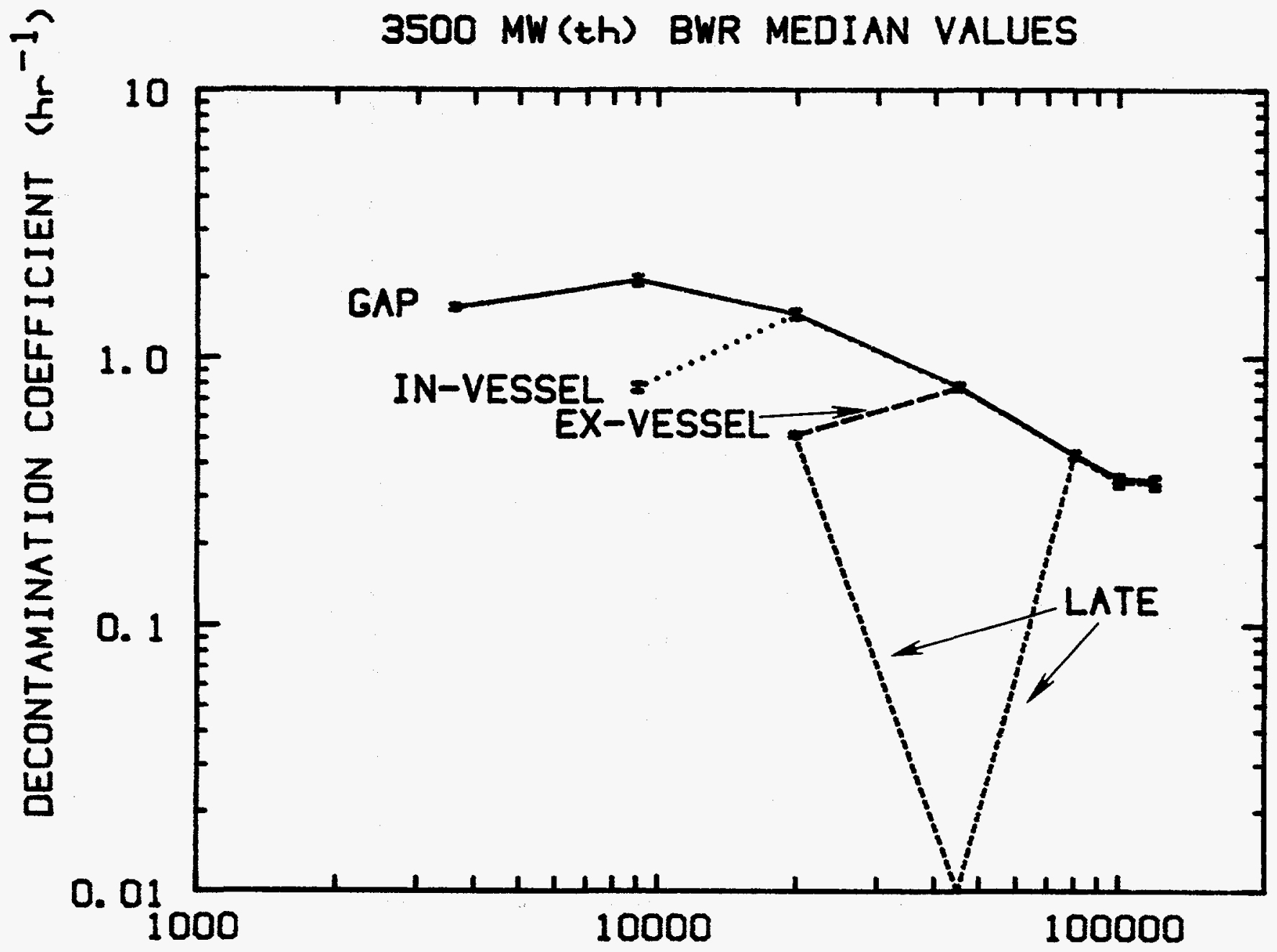

TIME (SECONDS)

Figure 51. Median values of the decontamination coefficients for the four classes of radioactive material released to the drywell during accidents at a $3500 \mathrm{MW}(\mathrm{th})$ boiling water reactor 
Monte Carlo

$\infty$

6

$\overline{\bar{g}}$

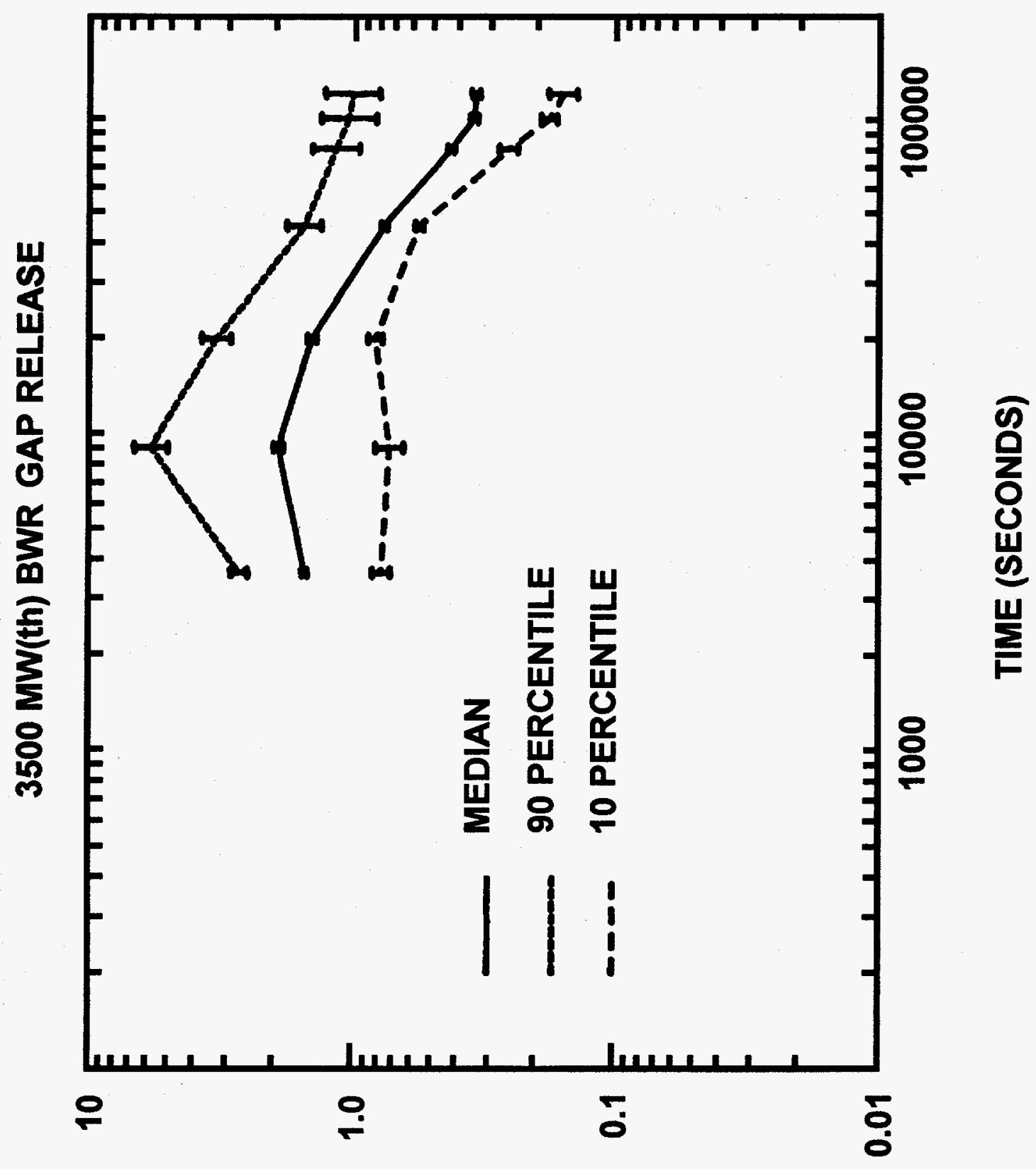

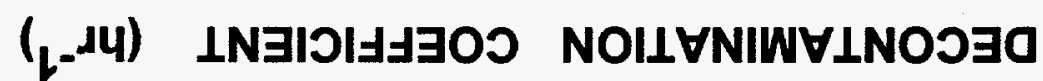

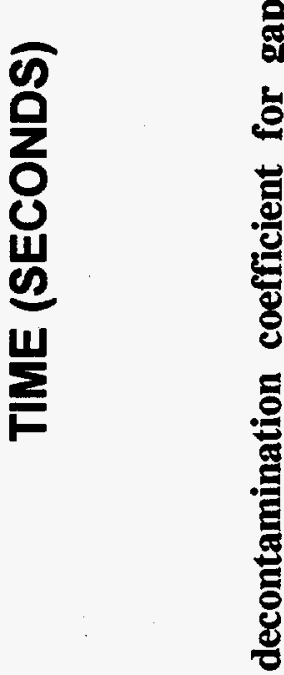


water reactors. It is the expected consequence of subsuming the source term into the effective decontamination coefficient.

The average, effective decontamination coefficients for boiling water reactors are larger during most periods of time than the average, effective decontamination coefficients found for pressurized water reactors or advanced reactors. At very late times, however, similar values are approached for all reactors. This is because aerosol particle concentrations are reduced at these late times to similar values in drywells and in containments.

The dependence of the average decontamination coefficients on reactor power is somewhat different than the dependencies found in the case of pressurized water reactors or advanced reactors. The ten critical types of decontamination coefficients are plotted against reactor thermal power in Figures 53 to 56 . The dependence on power is quite pronounced at early times (time $<19800$ seconds). The dependence on power is largely the result of values calculated for a $1500 \mathrm{MW}$ (th) reactor. The authors have not attempted to develop a complete rationalization for the relatively lower values of the decontamination coefficients for the low power reactor. The low values do seem to be associated with lower flows from the drywell to the suppression pool. The dependence of all decontamination coefficients on reactor power becomes small at late times.

The dependencies of the average, effective decontamination coefficients on reactor power can be approximately described by the general expression:

$$
\lambda_{\mathrm{e}}=\mathrm{A}[1-\exp (-\beta \mathrm{P})]
$$

or by expressions linear in reactor thermal power. The parameters in this expression, $A$ and $\beta$, were found by fitting the expression to the calculated values of the 10 unique average effective decontamination coefficients. Results are listed in Table 44. 


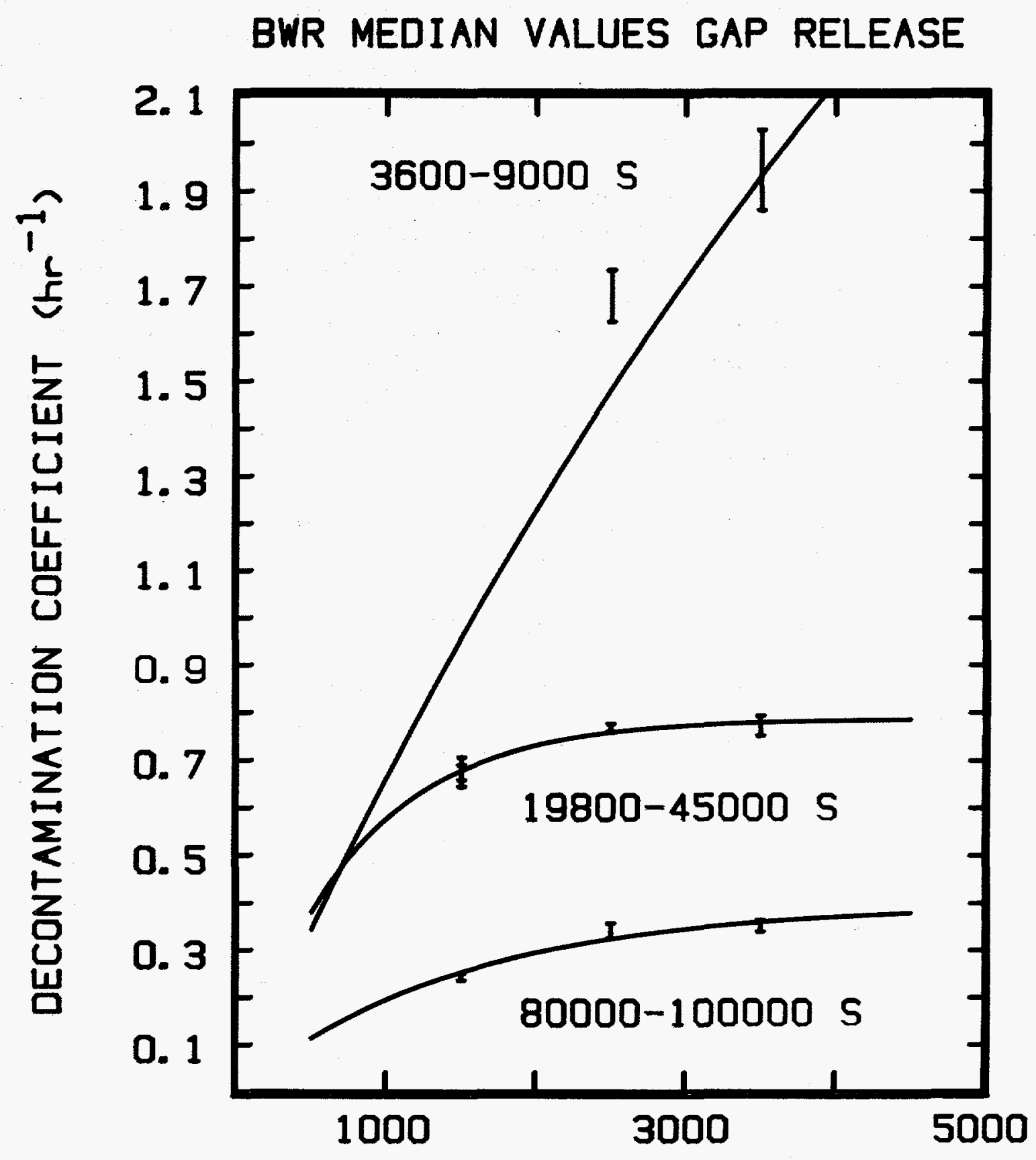

REACTOR THERMAL POWER (MW)

Figure 53. Dependence of gap release decontamination coefficients on boiling water reactor power 
Monte Carlo

BWR MEDIAN VALUES GAP RELEASE

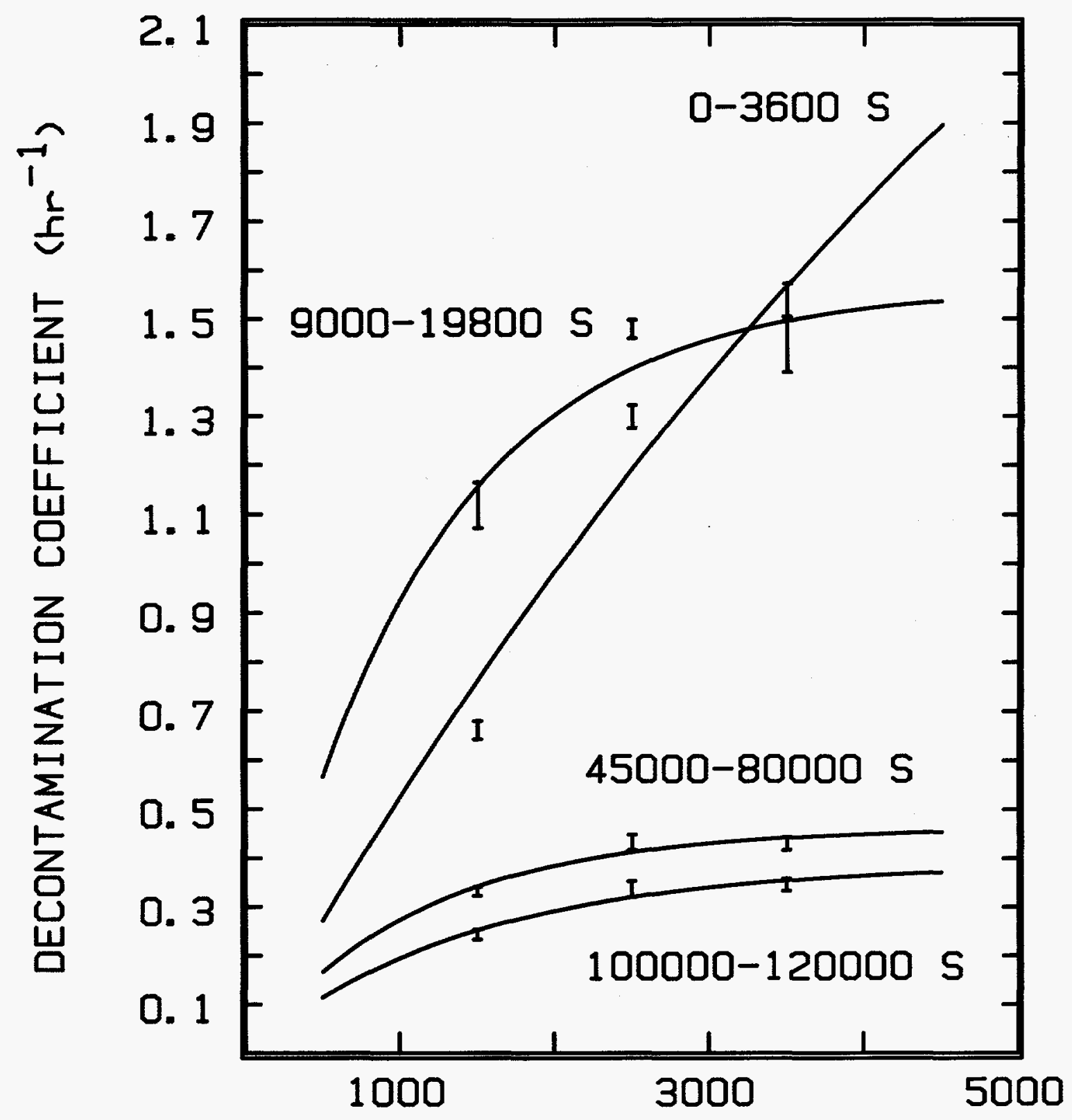

REACTOR THERMAL POWER (MW)

Figure 54. Dependence of gap release decontamination coefficients on boiling water reactor power 
Monte Carlo

BWR MEDIAN VALUES

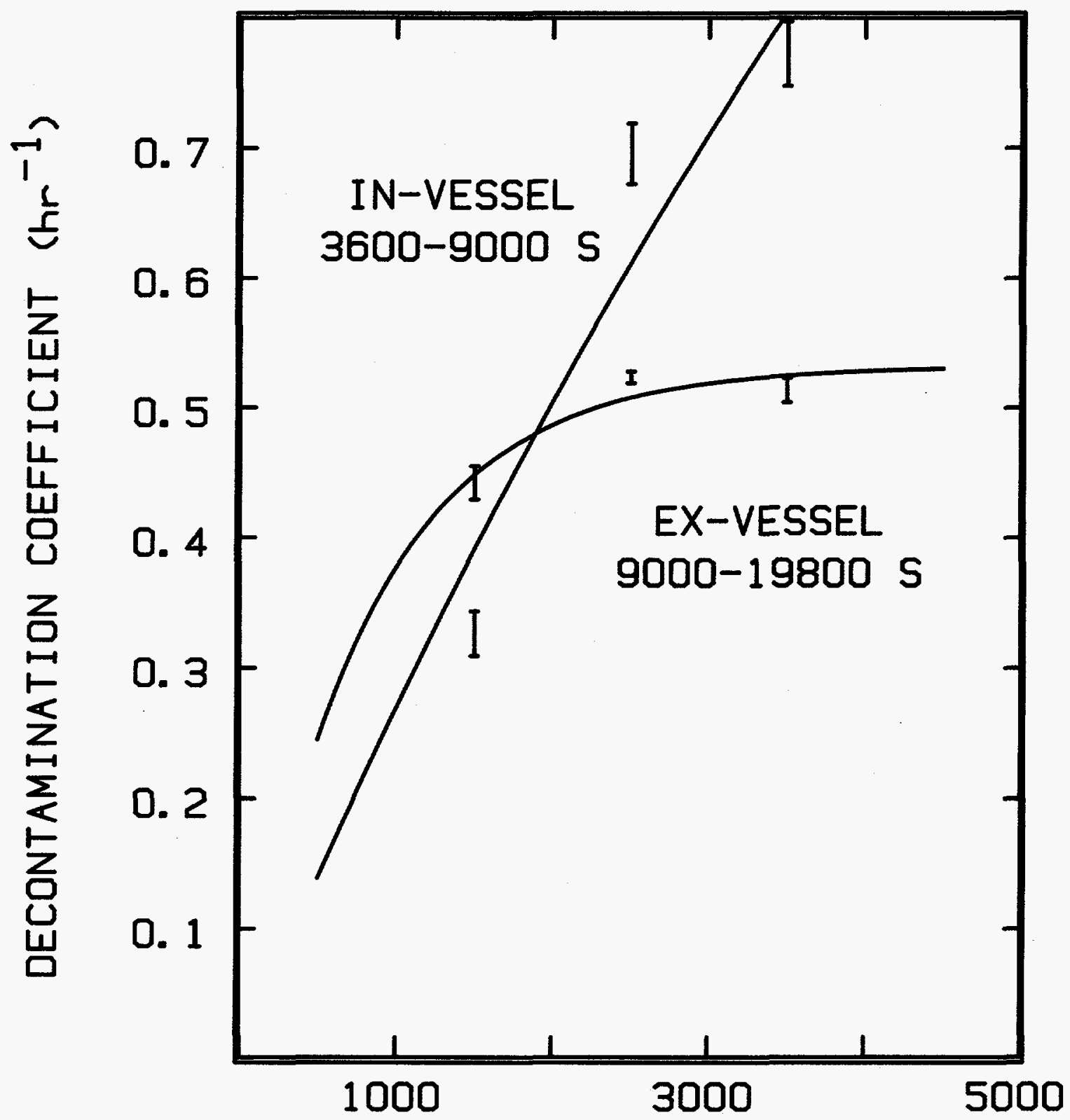

REACTOR THERMAL POWER (MW)

Figure 55. Dependence of gap release decontamination coefficients on boiling water reactor power 


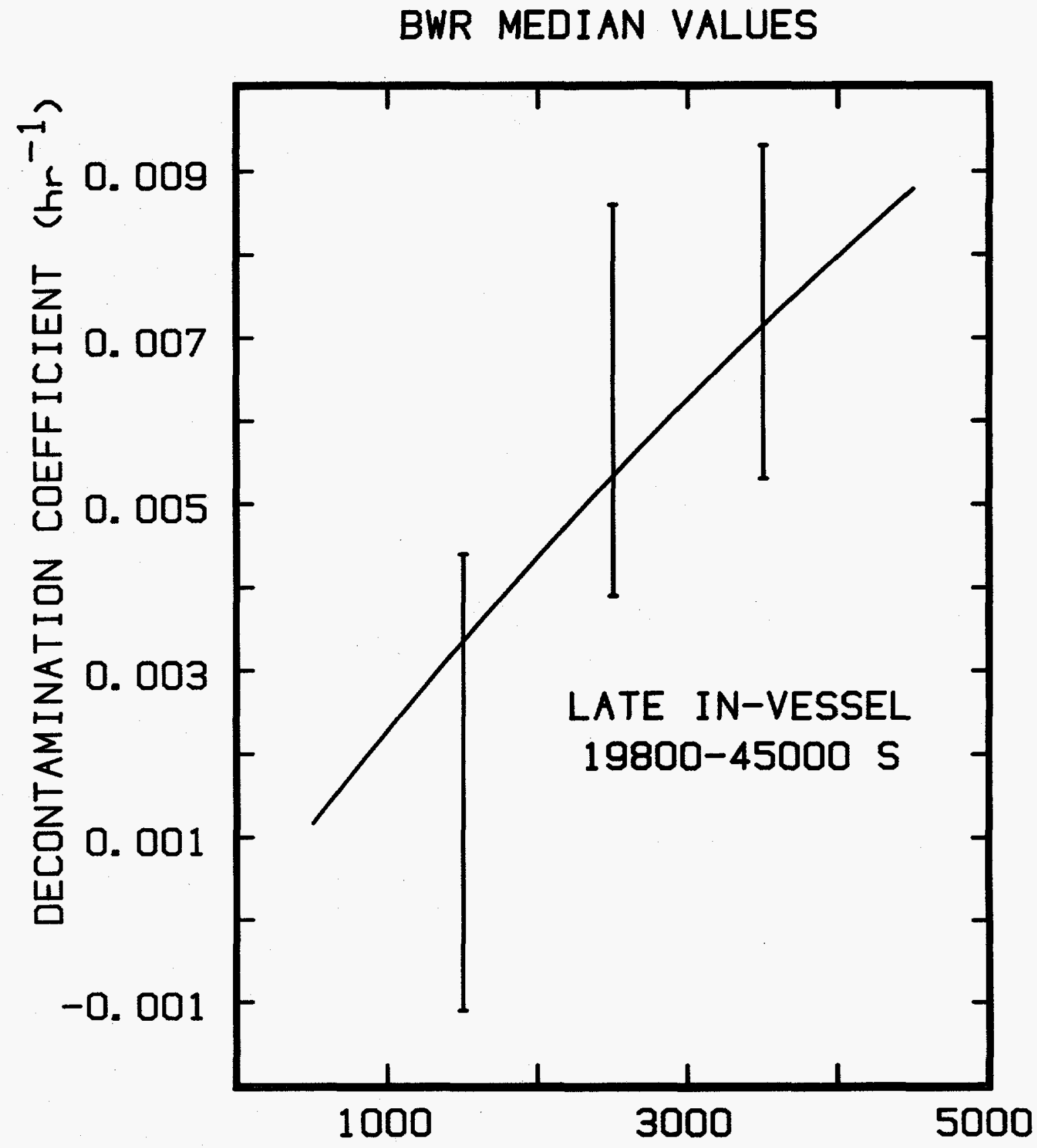

REACTOR THERMAL POWER (MW)

Figure 56. Dependence of the late in-vessel release decontamination coefficient for the period from 19800 to $45000 \mathrm{~s}$ on boiling water reactor power 
Table 44. Correlations of decontamination coefficients with boiling water reactor thermal power

\begin{tabular}{|c|c|c|}
\hline Material & Time interval (s) & Correlation ${ }^{*}\left(h r^{-1}\right)$ \\
\hline gap & $0-3600$ & $\begin{array}{l}\lambda_{\mathrm{e}}(90)=2.912[1-\exp (-0.798 \mathrm{P}(\mathrm{MW}) / 1000)] \\
\lambda_{\mathrm{e}}(50)=4.186[1-\exp (-0.134 \mathrm{P}(\mathrm{MW}) / 1000)] \\
\lambda_{\mathrm{e}}(10)=2.131[1-\exp (-0.140 \mathrm{P}(\mathrm{MW}) / 1000)]\end{array}$ \\
\hline gap & $3600-9000$ & $\begin{array}{l}\lambda_{\mathrm{e}}(90)=6.201[1-\exp (-0.887 \mathrm{P}(\mathrm{MW}) / 1000)] \\
\lambda_{\mathrm{e}}(50)=4.611[1-\exp (-0.155 \mathrm{P}(\mathrm{MW}) / 1000)] \\
\lambda_{\mathrm{e}}(10)=2.217[1-\exp (-0.124 \mathrm{P}(\mathrm{MW}) / 1000)]\end{array}$ \\
\hline gap & $9000-19800$ & $\begin{array}{l}\lambda_{\mathrm{e}}(90)=3.303+5.75 \times 10^{-6} \mathrm{P}(\mathrm{MW}) \\
\lambda_{\mathrm{e}}(50)=1.563[1-\exp (-0.897 \mathrm{P}(\mathrm{MW}) / 1000)] \\
\lambda_{\mathrm{e}}(10)=0.579+87.0 \times 10^{-6} \mathrm{P}(\mathrm{MW})\end{array}$ \\
\hline gap & $19800-45000$ & $\begin{array}{l}\lambda_{\mathrm{e}}(90)=1.561[1-\exp (-1.210 \mathrm{P}(\mathrm{MW}) / 1000)] \\
\lambda_{\mathrm{e}}(50)=0.787[1-\exp (-1.318 \mathrm{P}(\mathrm{MW}) / 1000)] \\
\lambda_{\mathrm{e}}(10)=0.591[1-\exp (-1.255 \mathrm{P}(\mathrm{MW}) / 1000)]\end{array}$ \\
\hline gap & $45000-80000$ & $\begin{array}{l}\lambda_{\mathrm{e}}(90)=1.200[1-\exp (-1.004 \mathrm{P}(\mathrm{MW}) / 1000)] \\
\lambda_{\mathrm{e}}(50)=0.462[1-\exp (-0.893 \mathrm{P}(\mathrm{MW}) / 1000)] \\
\lambda_{\mathrm{e}}(10)=0.274[1-\exp (-0.902 \mathrm{P}(\mathrm{MW}) / 1000)]\end{array}$ \\
\hline gap & $80000-100000$ & $\begin{array}{l}\lambda_{\mathrm{e}}(90)=1.085[1-\exp (-1.018 \mathrm{P}(\mathrm{MW}) / 1000)] \\
\lambda_{\mathrm{e}}(50)=0.398[1-\exp (-0.673 \mathrm{P}(\mathrm{MW}) / 1000)] \\
\lambda_{\mathrm{e}}(10)=0.210[1-\exp (-0.579 \mathrm{P}(\mathrm{MW}) / 1000)]\end{array}$ \\
\hline gap & $100000-120000$ & $\begin{array}{l}\lambda_{\mathrm{e}}(90)=1.041[1-\exp (-1.084 \mathrm{P}(\mathrm{MW}) / 1000)] \\
\lambda_{\mathrm{e}}(50)=0.388[1-\exp (-0.695 \mathrm{P}(\mathrm{MW}) / 1000)] \\
\lambda_{\mathrm{e}}(10)=0.190[1-\exp (-0.558 \mathrm{P}(\mathrm{MW}) / 1000)]\end{array}$ \\
\hline in-vessel & $3600-9000$ & $\begin{array}{l}\lambda_{\mathrm{e}}(90)=4.495[1-\exp (-0.120 \mathrm{P}(\mathrm{MW}) / 1000)] \\
\lambda_{\mathrm{e}}(50)=2.188[1-\exp (-0.131 \mathrm{P}(\mathrm{MW}) / 1000)] \\
\lambda_{\mathrm{e}}(10)=1.089[1-\exp (-0.124 \mathrm{P}(\mathrm{MW}) / 1000)]\end{array}$ \\
\hline ex-vessel & $9000-19800$ & $\begin{array}{l}\lambda_{\mathrm{e}}(90)=0.756+3.50 \times 10^{-6} \mathrm{P}(\mathrm{MW}) \\
\lambda_{\mathrm{e}}(50)=0.532[1-\exp (-1.232 \mathrm{P}(\mathrm{MW}) / 1000)] \\
\lambda_{\mathrm{e}}(10)=0.374[1-\exp (-1.263 \mathrm{P}(\mathrm{MW}) / 1000)]\end{array}$ \\
\hline late in-vessel & $19800-45000$ & $\begin{array}{l}\lambda_{\mathrm{e}}(90)=0.0648[1-\exp (-0.959 \mathrm{P}(\mathrm{MW}) / 1000)] \\
\lambda_{\mathrm{e}}(50)=0.0254[1-\exp (-0.0943 \mathrm{P}(\mathrm{MW}) / 1000)] \\
\lambda_{\mathrm{e}}(10)=-0.089+10.72 \times 10^{-6} \mathrm{P}(\mathrm{MW})\end{array}$ \\
\hline \multicolumn{3}{|c|}{$\begin{array}{l}* \lambda_{e}(50) \text { is the median value of the effective decontamination coefficient. } \lambda_{e}(90) \text { and } \lambda_{e}(10) \text { are the } \\
90^{\text {th }} \text { and } 10^{\text {th }} \text { percentile values, respectively. }\end{array}$} \\
\hline
\end{tabular}




\section{Example Application of the Simplified Models of Decontamination by Natural Aerosol Processes}

The average effective decontamination coefficients derived from the Monte Carlo uncertainty analyses constitute a highly simplified model of containment and drywell decontamination by natural aerosol processes. They can be used as piecewise constant to calculate decontamination factors for the various classes of radioactive material releases defined in the revised severe accident source term. Thus for a time $t$ after the start of gap release the decontamination factor for material of the $\mathrm{j}^{\text {th }}$ class is given by:

$$
D F_{j}(t)=\prod_{i=1}^{k-1} \exp \left[+\lambda_{e}\left(t_{i}, t_{i+1}\right) \Delta t_{i}\right] \exp \left[+\lambda_{e}\left(t_{k}, t_{N+1}\right) \Delta t\right]
$$

Because values of the decontamination coefficients at various percentiles of the uncertainty distributions for these parameters are available, best-estimate predictions of aerosol behavior and the uncertainty in these predictions can be made.

This highly simplified model can, perhaps, be better appreciated by means of some example applications. Three such examples are presented below:

\section{Example 1:}

Calculate the best estimate and lower bound decontamination of gap releases from a $3000 \mathrm{MW}$ (th) pressurized water reactor 10 hours after the start of radionuclide release.

\section{Solution:}

For this work, "best estimate" is identified as the median value whereas "lower bound" is identified as the 10th percentile. Thus, the median and 90 th percentile decontamination factors should be used. At 10 hours, gap release is complete. From the correlations for pressurized water reactor decontamination coefficients (Table 26), the needed parameter values are:

\begin{tabular}{ccc} 
& \multicolumn{2}{c}{$\lambda\left(\mathrm{hr}^{-1}\right)$} \\
$0-1800 \mathrm{~s}$ & $\underline{\text { Median }}$ & $\underline{\text { Lower bound }}$ \\
$1800-6480 \mathrm{~s}$ & 0.0773 & 0.0264 \\
$6480-13680 \mathrm{~s}$ & 0.1419 & 0.0537 \\
$13680-43480 \mathrm{~s}$ & 0.3161 & 0.0679 \\
& & 0.1953
\end{tabular}

The time intervals are $0.5,1.3,2$, and 6.2 hours. Then, the best-estimate decontamination factors are: 


$\begin{array}{lc}\underline{\mathrm{t}(\mathrm{hr})} & \mathrm{DF}(\mathrm{t}) \text { for gap release } \\ 0 & 1.0 \\ 0.5 & 1.0 \exp (0.0373 \times 0.5)=1.0188 \\ 1.8 & 1.0188 \exp (0.0726 \times 1.3)=1.120 \\ 3.8 & 1.120 \exp (0.1419 \times 2.0)=1.487 \\ 10 & 1.487 \exp (0.3161 \times 6.2)=10.56\end{array}$

Similarly, the lower bound decontamination factors are:

$\begin{array}{lc}\frac{\mathrm{t}(\mathrm{hr})}{0} & \mathrm{DF}(\mathrm{t}) \text { for gap release } \\ 0.5 & 1.0 \\ 1.8 & 1.0133 \exp (0.0264 \times 0.5)=1.0133 \\ 3.8 & 1.0865 \exp (0.0537 \times 1.3)=1.0865 \\ 10 & 1.244 \exp (0.1953 \times 6.2)=4.177\end{array}$

An upper bound estimate of the decontamination factor for gap release material at 10 hours is 27.3 . These three estimates provide a fairly useful description of the uncertainty in decontamination by natural aerosol processes.

\section{Example 2}

Compute fractions of the core inventories of iodine and barium suspended in the containment atmosphere of a $3000 \mathrm{MW}$ (th) pressurized water reactor 10 hours after the start of radionuclide release.

\section{Solution:}

At 10 hours after the start of gap release, the gap release, in-vessel release and ex-vessel release have been completed, but only 6.2 hours of the 10 -hour late in-vessel release has been completed. From Table 1, the amounts of iodine and barium released to the containment are

Percent of core inventory released

\begin{tabular}{|c|c|c|}
\hline Accident Phase & I & $\mathrm{Ba}$ \\
\hline Gap & $5 \%$ & 0 \\
\hline In-vessel & $35 \%$ & 4 \\
\hline Ex-vessel & $29 \%$ & 10 \\
\hline $62 \%$ of Late in-vessel & $4.34 \%$ & 0 \\
\hline
\end{tabular}

From the correlations (Table 26), the best-estimate values of the decontamination coefficients for the materials released during various phases of the accident are 
Example

$\lambda_{e}(\mathrm{hr}-1)$

\begin{tabular}{|c|c|c|c|c|}
\hline Time period (s) & Gap & In-vessel & Ex-vessel & Late \\
\hline $0-1800$ & 0.0373 & 0 & 0 & 0 \\
\hline $1800-6480$ & 0.0726 & 0.0373 & 0 & 0 \\
\hline $6480-13680$ & 0.1419 & 0.1419 & 0.0833 & 0.0833 \\
\hline $13680-43480$ & 0.3161 & 0.3161 & 0.3161 & 0.0566 \\
\hline
\end{tabular}

The decontamination factors at 10 hours for the various classes of materials are:

$\begin{array}{cc}\text { Material class } & \text { DF (10 hrs) } \\ \text { Gap } & 10.56 \\ \text { In-vessel } & 9.90 \\ \text { Ex-vessel } & 8.38 \\ \text { Late in-vessel } & 1.68\end{array}$

Then, the fraction of core inventory of iodine suspended in the containment atmosphere is:

$$
\frac{0.05}{10.56}+\frac{0.35}{9.90}+\frac{0.29}{8.38}+\frac{0.0434}{1.68}=0.1005
$$

The fraction of the core inventory of barium suspended in the containment atmosphere is:

$$
\frac{0.04}{9.90}+\frac{0.10}{8.38}=0.016
$$

\section{Example 3:}

Repeat the calculation of Example 2 for a radiological design basis accident at a $3000 \mathrm{MW}(\mathrm{th})$ reactor.

\section{Solution:}

Release fractions for iodine and barium during the gap release and in-vessel release phases of radiological design basis accidents are taken to be the same as in the case of pressurized water reactors. There is neither an ex-vessel release phase or a late in-vessel release phase of radiological design basis accidents.

From the correlations for decontamination coefficients for radiological design basis accidents (Table 36), the appropriate decontamination coefficients are: 


\begin{tabular}{cccc} 
& \multicolumn{2}{c}{$\lambda\left(\mathrm{hr}^{-1}\right)$} \\
Time period(s) & & Gap & In-vessel \\
$0-1800$ & & 0.0372 & 0 \\
$1800-6480$ & 0.0795 & 0.0407 \\
$6480-13680$ & 0.1873 & 0.1873 \\
$13680-49680$ & 0.1588 & 0.1588
\end{tabular}

The decontamination factors at 10 hours for the two classes of radioactive materials released to the containment during radiological design basis accidents are:

$\begin{array}{cc}\text { Material class } & \mathrm{DF}(10 \mathrm{hr}) \\ \text { Gap } & 4.40 \\ \text { In-vessel } & 4.10\end{array}$

It is immediately noticeable that the decontamination factors for the radiological design basis accidents case are smaller than for the pressurized water reactor case in Example 2. This, of course, is because there is no massive injection of nonradioactive aerosol associated with the ex-vessel phase and late in-vessel phase of pressurized water reactor accidents. Without this additional mass, aerosol removal by natural processes is slower.

The inventory of iodine suspended in the containment atmosphere of the reactor at 10 hours is:

$$
\frac{0.05}{4.40}+\frac{0.35}{4.10}=0.0967
$$

This fraction of the core inventory suspended in the reactor containment atmosphere during a radiological design basis accident is only slightly less than the amount calculated to be suspended in a similar pressurized water reactor even though only about half as much iodine is thought to be released to the containment during such accidents. This is because the advanced radiological design basis accidents do not include the enhanced decontamination effects produced when large quantities of nonradioactive aerosol are injected into the containment.

The inventory of barium suspended in the reactor containment at 10 hours is:

$$
\frac{0.04}{4.10}=0.0098
$$

This fraction of the core inventory of barium in the reactor containment during a radiological design basis accident is substantially less than was predicted to be suspended in the containment of a pressurized water reactor at the same time. This is because in such a reactor accident, ex-vessel releases of barium to the containment do not occur. 


\section{Example}

Some analysts will be more interested in the total amounts of each radioactive element that remains suspended in the containment as a function of time than in the decontamination factors for various classes of released materials. Such element inventories are readily calculated from the proposed releases and the correlations for the various decontamination factors. Results of such calculations for iodine, cesium, tellurium, and strontium for severe accidents at a $3000 \mathrm{MW}(\mathrm{th})$ pressurized water reactor are shown in Figures 57 through 60 . The solid curves in these figures were calculated using the median (bestestimate) values of the decontamination coefficients. Dotted and dashed curves were calculated using reasonable upper bound ( 90 percentile) and reasonable lower bound (10 percentile) values of the decontamination coefficients, respectively.

There is little spread in median, 90 th and 10th percentile predictions of the percentages of the core inventories of cesium and iodine suspended in the reactor containment during the period of the gap release and the early stages of the in-vessel release. Aerosol concentrations in the containment atmosphere during these early phases of a severe accident are low, so releases of iodine and cesium to the containment atmosphere overwhelm deposition from the atmosphere. The large releases of nonradioactive materials during the ex-vessel release phase of the accident greatly accentuates deposition of materials from the atmosphere. Greater spread becomes apparent among the amounts of iodine and cesium suspended in containment predicted using median, 90th percentile and 10th percentile values of the decontamination coefficients. Factors of 10 differences develop among predictions at about $100000 \mathrm{~s}$. Also, at such late times concentrations become quite low.

Results of similar calculations for the time dependence of the amounts of iodine, cesium, tellurium, and strontium suspended in the drywell of a $3000 \mathrm{MW}$ (th) boiling water reactor are shown in Figures 61 to 64. The volume of a drywell is smaller than the containment of a pressurized water reactor. Aerosol concentrations are, then, high and the predictions of the amount of a radioactive element suspended in the drywell atmosphere vary more dramatically with release rates and decontamination rates. Variations in the amounts of suspended elements as a result of changes in the rates of release are apparent in Figures 61 through 64 . Also, decontamination rates are larger in the confined drywell than in the larger volume containment of a pressurized water reactor. The rapid decontamination and the sensitivity to release rates give rise to the complicated predictions of the amounts of radioactive elements suspended in containments. 


\section{IODINE}

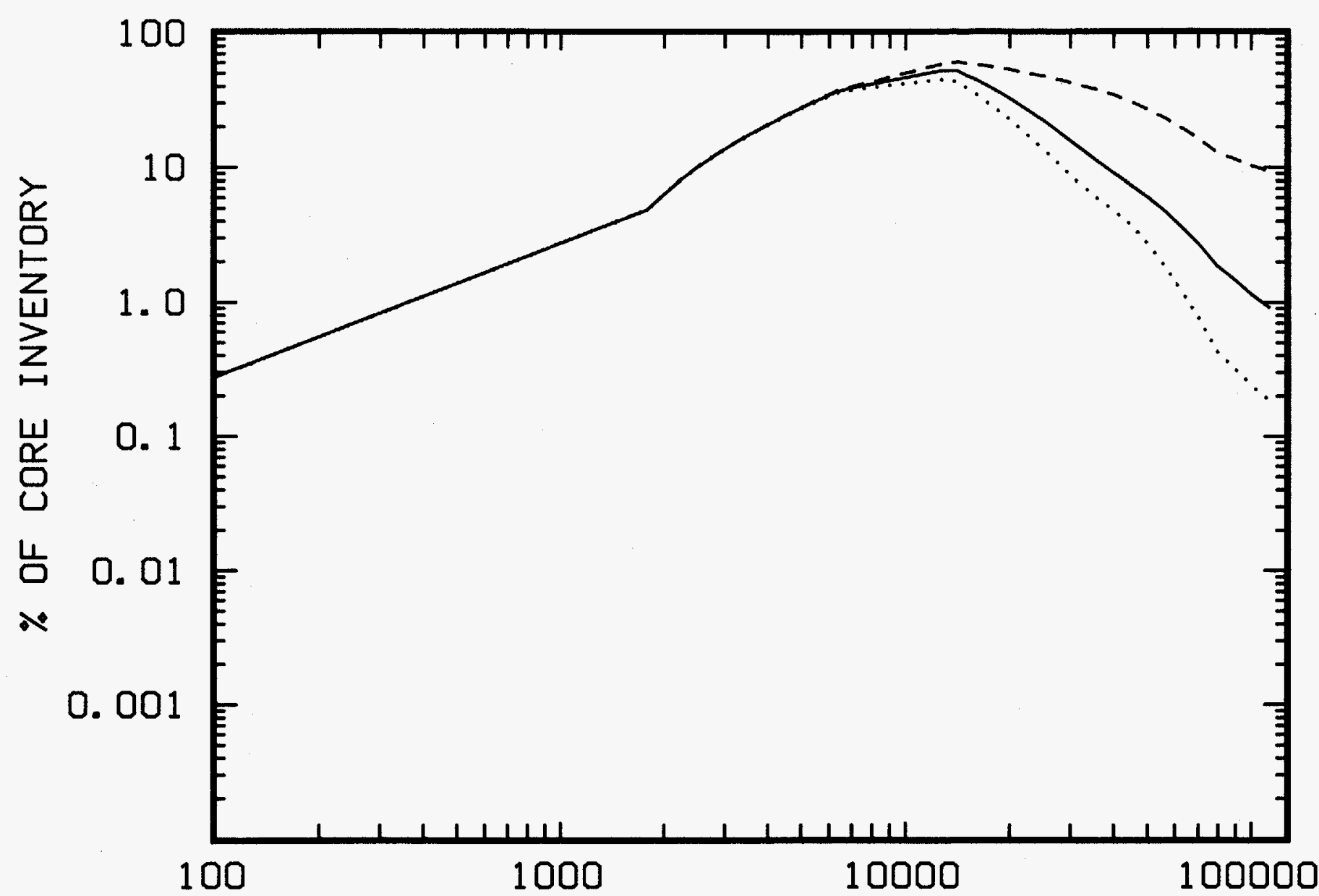

a function of time. The solid curve is the median value. Dotted and dashed curves were calculated using the 90th and 10th percentile values of the decontamination coefficients. 


\section{CESIUM}

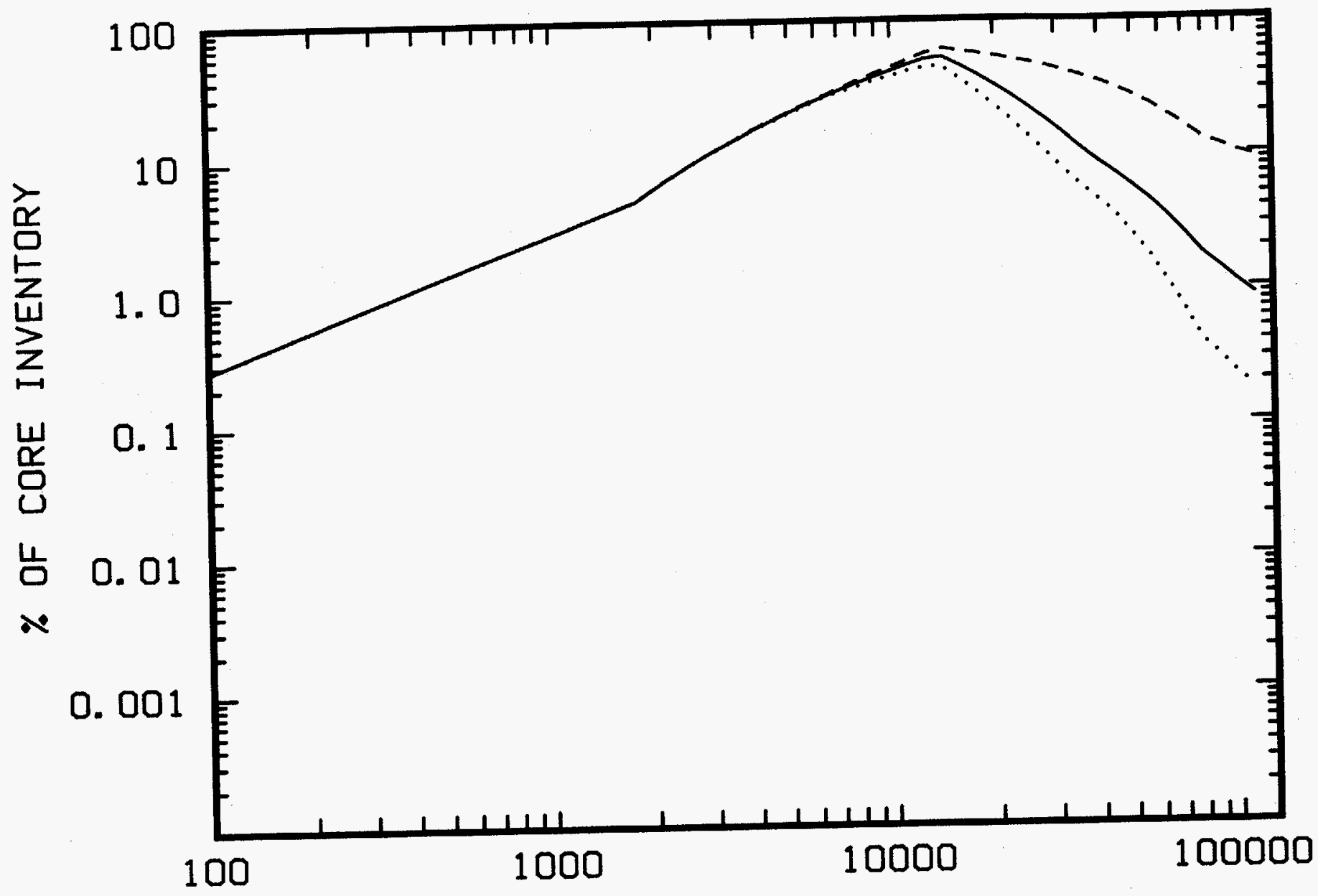

TIME (SECONDS)

Figure 58. Percent of core inventory of cesium suspended in the containment of a $3000 \mathrm{MW}(\mathrm{th})$ pressurized water reactor as a function of time. The solid curve is the median value. Dotted and dashed curves were calculated using the $90 t h$ and 10th percentile values of the decontamination coefficients. 


\section{TELLURIUM}

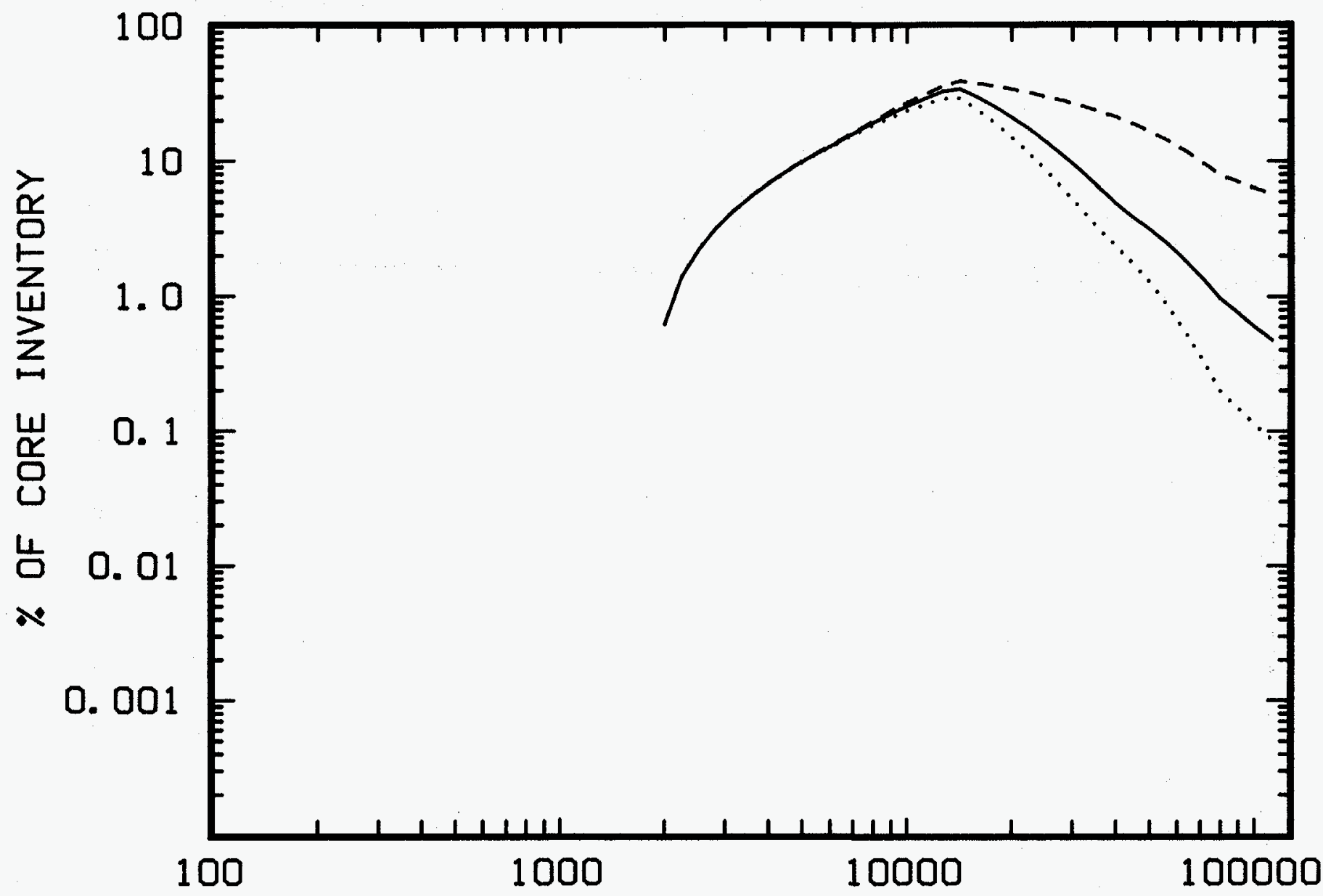

TIME (SECONDS)

Figure 59. Percent of core inventory of tellurium suspended in the containment of a $3000 \mathrm{MW}$ (th) pressurized water reactor as a function of time. The solid curve is the median value. Dotted and dashed curves were calculated using the 90th and 10th percentile values of the decontamination coefficients. 


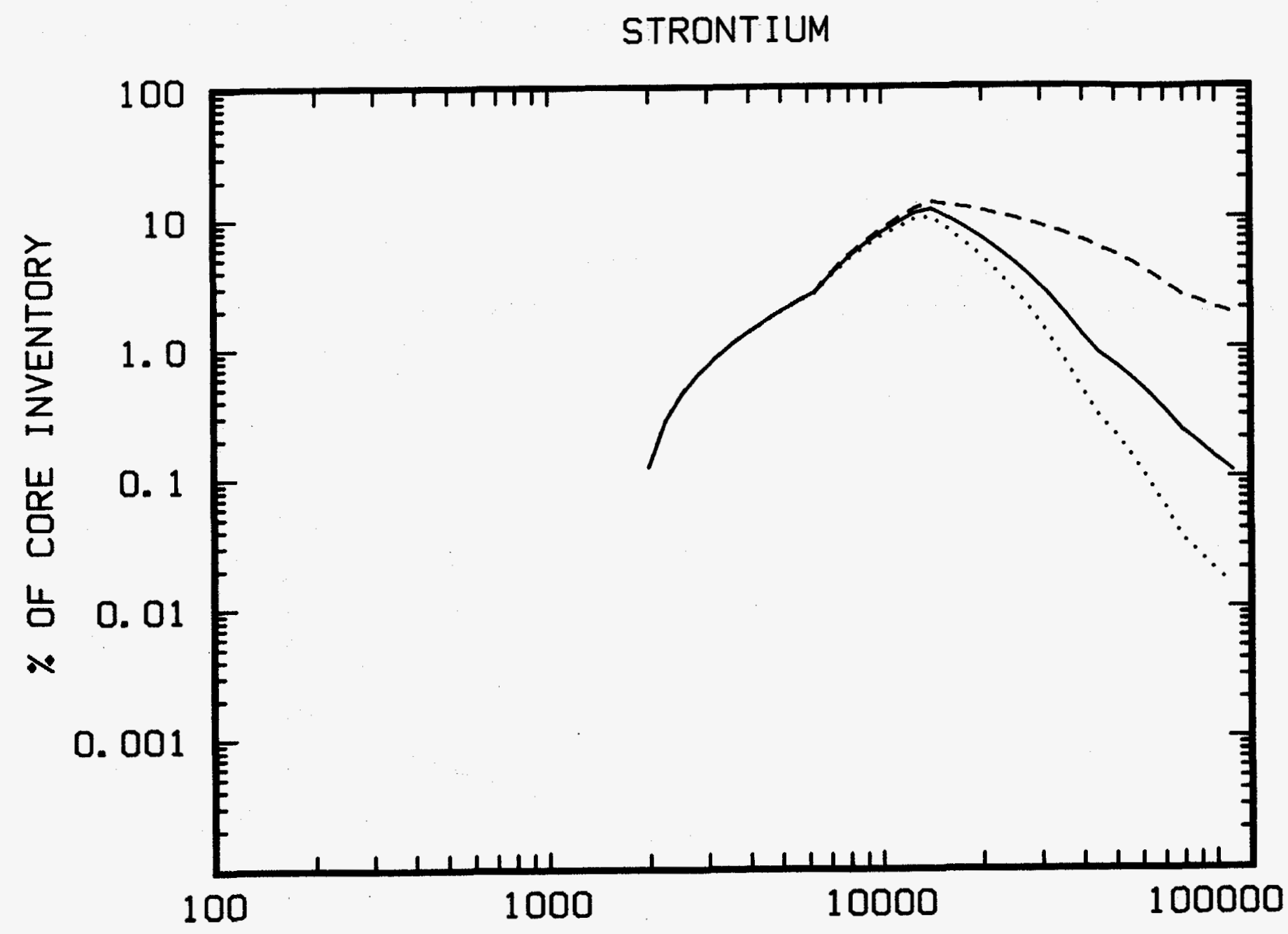

TIME (SECONDS)

Figure 60. Percent of core inventory of strontium suspended in the containment of a $3000 \mathrm{MW}$ (th) pressurized water reactor as a function of time. The solid curve is the median value. Dotted and dashed curves were calculated using the 90th and 10th percentile values of the decontamination coefficients. 

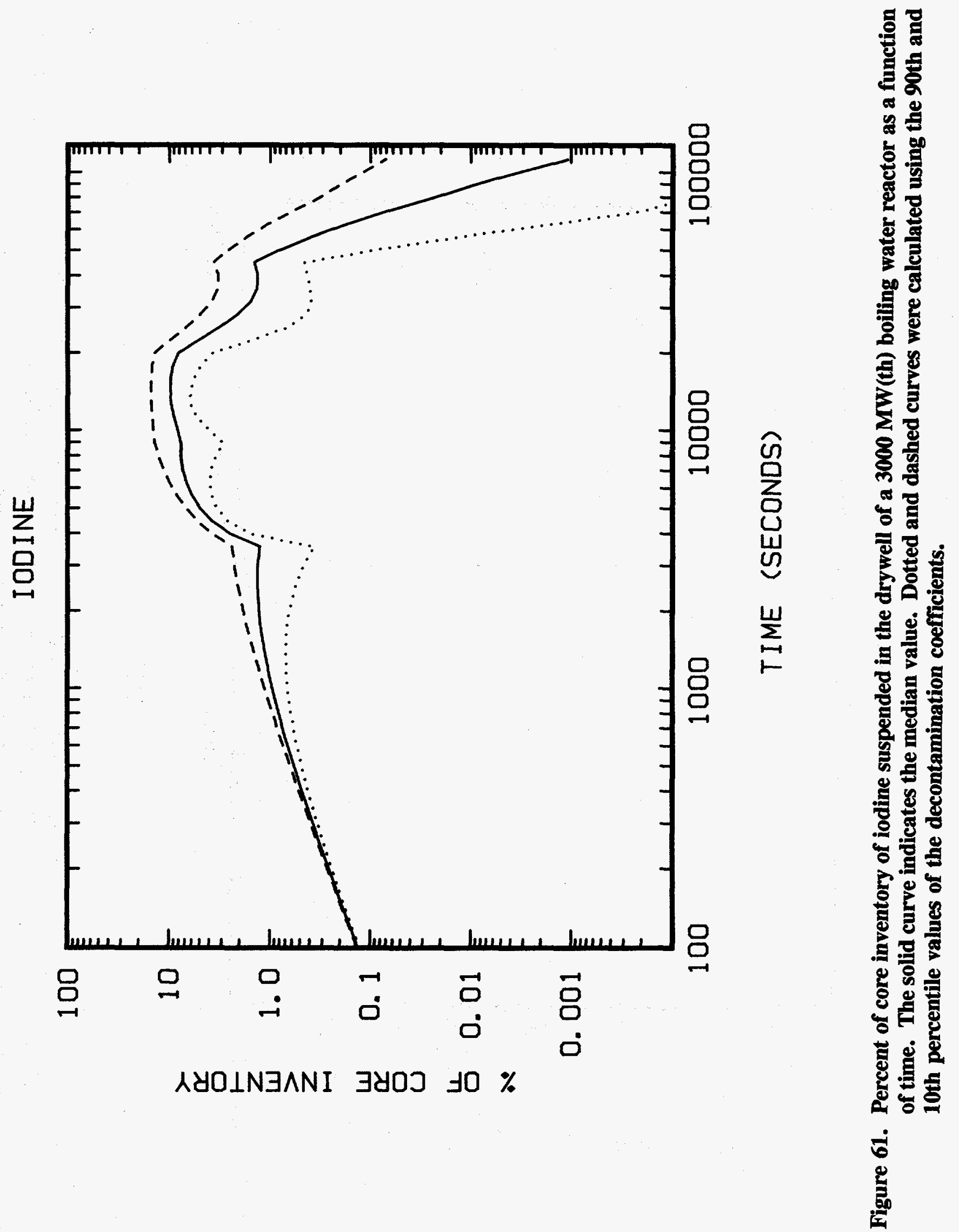
Example
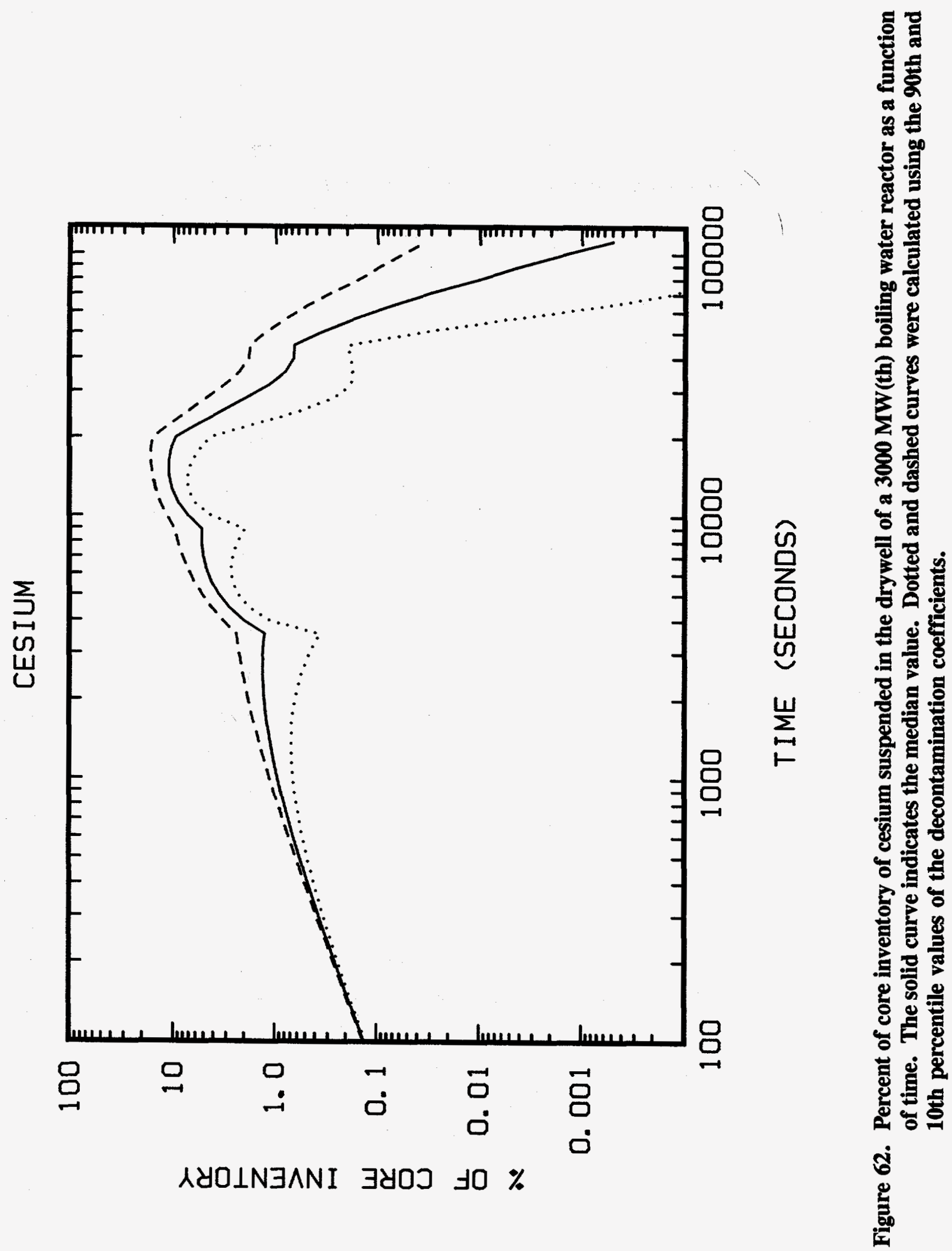


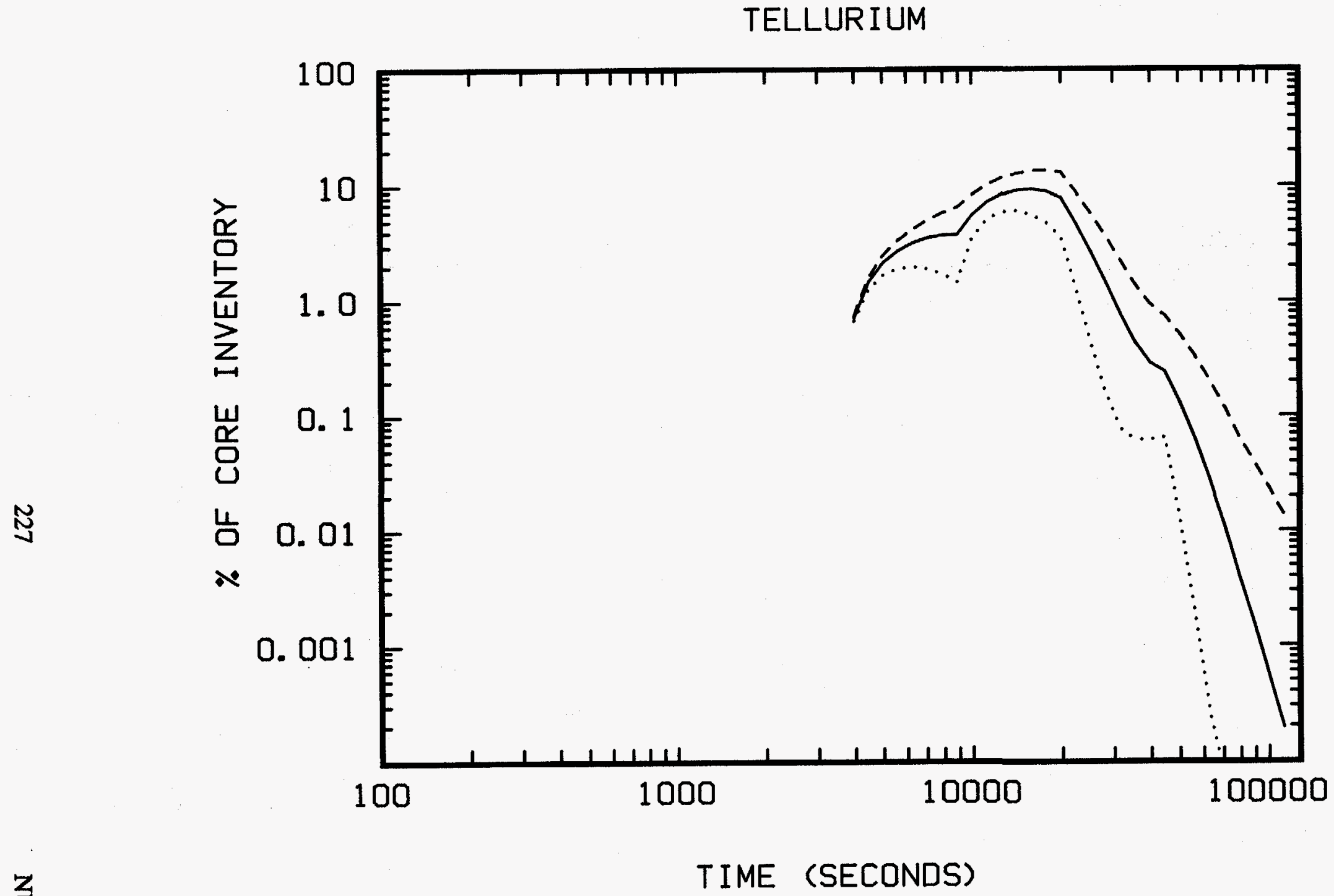

Figure 63. Percent of core inventory of tellurium suspended in the drywell of a $3000 \mathrm{MW}$ (th) boiling water reactor as a function of time. The solid curve indicates the median value. Dotted and dashed curves were calculated using the 90th and 10th percentile values of the decontamination coefficients. 


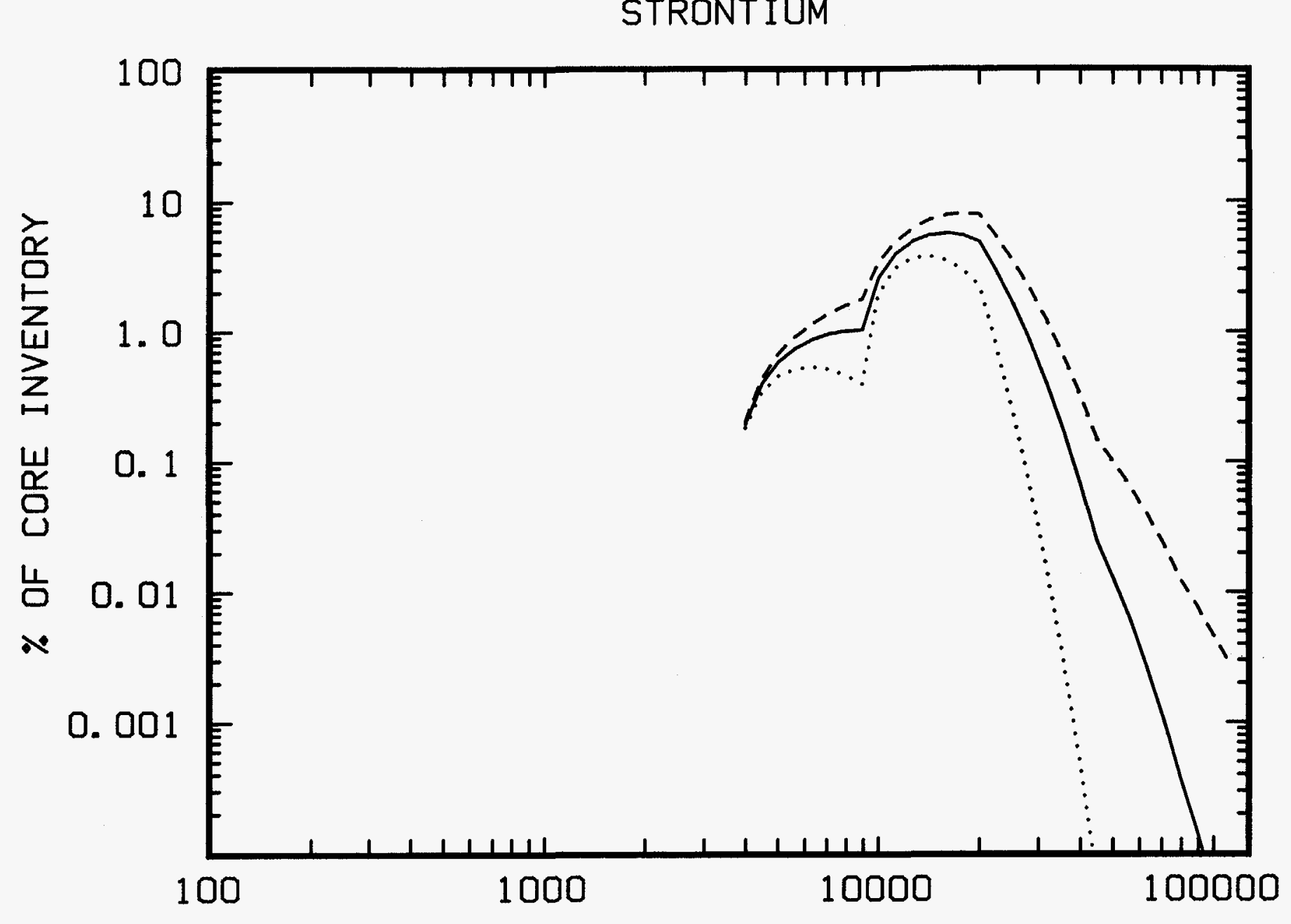

TIME (SECONDS)

Figure 64. Percent of core inventory of strontium suspended in the drywell of a $3000 \mathrm{MW}$ (th) boiling water reactor as a function of time. The solid curve indicates the median value. Dotted and dashed curves were calculated using the 90th and 10th percentile values of the decontamination coefficients. 


\section{Conclusions}

An extended review of the physical phenomena that affect the behavior of aerosols in reactor containments has been presented. Among the phenomenological issues discussed in this review were the quite uncertain topics of:

- definition of coagulation kernels and deposition velocities when multiple coagulation or deposition processes are operative,

- estimation of particle deposition from turbulent flows, and

- the effects of electrostatic charging on the agglomeration and deposition of aerosols.

Analyses found in the literature suggest that simple summation methods for accounting for multiple mechanisms of aerosol coagulation may underestimate the specific rate of coagulation by at most 30 percent. The effects of synergism among the mechanisms are partially compensated in integral calculations because of the time variation in particle concentrations.

An alternative means for predicting the diffusive deposition of aerosol particles has been derived. Such diffusive deposition is, however, found to be a relatively unimportant mechanism for aerosol deposition in the case of aerosol behavior in reactor containments under accident conditions. Overall, gravitational sedimentation is the most important aerosol deposition mechanism in reactor containments. Especially during the gap release and the in-vessel release phases of severe accidents, diffusiophoresis and thermophoresis can augment or even exceed sedimentation as mechanisms for aerosol deposition. The importance of diffusiophoresis and thermophoresis in reactor accident analyses is largely dictated by the uncertain thermal hydraulic conditions in the reactor containment.

Exploratory estimates of the extent of aerosol charging in reactor containments under accident conditions suggest that the aerosol particles will acquire an electrostatic charge if mobilities of positive and negative ions in the atmosphere are different. Ionization of the atmosphere by the radioactive decay of noble gases is a predominant effect that makes it likely aerosol particles will be charged if there is a difference between the mobilities of positive ions and the mobilities of negative ions.

The effects of electrostatic charging of the aerosol particles are harder to estimate. Large particles will have broad charge distributions that will ameliorate some of the effects of electrostatic repulsion that inhibit the agglomeration of particles. Relative mobilities of atmosphere ions will dictate whether electrostatic charging of aerosol particles enhances or inhibits aerosol deposition on structural surfaces in the reactor containment. Experience in atmospheric sciences suggests that negative ions will be more mobile than positive ions. This would indicate that aerosols produced in reactor accidents will be electrostatically charged, but it is far from clear that the findings from atmospheric studies are applicable to the environments created in containments and drywells during reactor accidents. If free electrons in the atmosphere can be discounted, there may be sufficient information available to predict mobilities of gas phase ions under reactor accident conditions. The effort needed to make such predictions exceeded the resources available for this work.

Empirical correlations can be used to simulate well the behavior of aerosols in reactor containments predicted by models that solve the aerosol dynamic equation. The empirical correlations have been used in Monte Carlo uncertainty analyses of aerosol behavior in pressurized water reactors and in boiling 
water reactors. The uncertainty analyses considered uncertainties in phenomenological issues associated with aerosol behavior and gas-aerosol interactions. The uncertainty analyses also considered uncertainties in the geometry of reactor containments, especially internal surface areas, and the progression of severe accidents as they affect thermal hydraulic conditions.

The uncertainty analyses show that gravitational settling is not always the predominant mechanism of aerosol deposition. In fact, diffusiophoresis and thermophoresis can be dominant mechanisms of aerosol deposition during early and very late stages of severe reactor accidents. This makes prediction of the decontamination of atmospheres by natural aerosol processes very dependent on predictions of thermal hydraulic conditions in the reactor containment. This is especially true in the analysis of decontamination of boiling water reactor drywells since flow from the drywell to the suppression pool also contributes to decontamination. The extent to which uncertainties in the thermal hydraulic conditions in containments and drywells have been adequately characterized affects directly results reported here on natural decontamination by aerosol processes.

During and immediately following ex-vessel release, gravitational settling is nearly always the dominant mechanism for aerosol deposition. Particles suspended in containment or drywell atmospheres grow to sizes such that they settle rapidly because of the large amounts of nonradioactive aerosol mass created in the ex-vessel phase of an accident. Accurate predictions of aerosol behavior in containments depend, then, on having good predictions of the nonradioactive aerosol masses produced in various stages of a reactor accident. Substantial allowances have been made in the studies reported here for uncertainties about the amounts of nonradioactive aerosol mass created in all stages of reactor accidents.

The uncertainty analyses conducted here have yielded uncertainty distributions for the decontamination factors for radioactive materials released to the containment atmosphere according to the draft NUREG1465 source term [1]. These decontamination factors have been used to derive piecewise constant, effective decontamination coefficients. These decontamination coefficients exhibit a similarity for radioactive materials released during the gap release phase, the in-vessel release phase and the ex-vessel release phase of an accident. Simple expressions for the reasonable upper bound (90 percentile), reasonable lower bound (10 percentile) and median values of the decontamination coefficient have been derived. Decontamination coefficients for the late in-vessel release defined in NUREG-1465 exhibit a more complicated behavior because this release:

- overlaps for 2 to 3 hours with the ex-vessel release, and

- there is a protracted period ( 7 to 8 hours) of continuing release of this material.

A more heuristic approach has been adopted to systematize results of the uncertainty analyses for the late in-vessel release phase.

The correlations of the results of the uncertainty analyses constitute a simplified model of containment decontamination by natural aerosol processes. Examples are provided to illustrate how this simplified model can be used to estimate the decontamination achieved by natural aerosol processes. Over a sufficient period, substantial decontamination of containment atmospheres can occur by these processes. 


\section{References}

1. L. Soffer, S. B. Burson, C. M. Ferrell, R. Y. Lee, and J. N. Ridgely, Accident Source Terms for Light-Water Nuclear Power Plants, (Draft Report for Comment). NUREG-1465, U.S. Nuclear Regulatory Commission, Washington, D.C., June 1992.

2. D. J. Alpert, D. I. Chanin, and L. T. Ritchie, Relative Importance of Individual Elements to Reactor Accident Consequences Assuming Equal Release Fraction, NUREG/CR-4467, SAND85-2575, Sandia National Laboratories, Albuquerque, NM, March 1988.

3. D. A. Powers and J. L. Sprung, A Simplified Model of Aerosol Scrubbing by a Water Pool Overlying Core Debris Interacting with Concrete, NUREG/CR-5901, SAND92-1422, Sandia National Laboratories, Albuquerque, NM, October 1992.

4. D. A. Powers and S. B. Burson, A Simplified Model of Aerosol Removal by Containment Sprays, NUREG/CR-5966, SAND92-2689, Sandia National Laboratories, Albuquerque, NM, June 1993.

5. D. A. Powers and S. B. Burson, A Simplified Model of Decontamination by Boiling Water Reactor Steam Suppression Pools, NUREG/CR-6153, SAND93-2588, Sandia National Laboratories, Albuquerque, NM, 1995.

6. U.S. Nuclear Regulatory Commission, Reactor Safety Study: An Assessment of Accident Risks in U.S. Commercial Nuclear Power Plants, WASH-1400 (NUREG-75/014), Washington D.C., December 1975.

7. R. L. Koontz et al., Aerosol Modeling of Hypothetical LMFBR Accidents, AI-AEC-12977, Atomics International, August 1970.

8. H. Bunz, PARDISEKO-IV, Ein Computerprogram zur Berechnug des Aerosoluerhaltens in geschlessenen Berhaltern, Kfk-3545, Kerforschungszentrum Karlsruhe, Karlsruhe, Germany, 1983.

9. S. A. Ramsdale, AEROSIM - M User Manual, SRD R401, United Kingdom Atomic Energy Authority Safety and Reliability Directorate, United Kingdom, 1987.

10. F. Gelbard and J. H. Seinfeld, J. Coll. Interfacial Science, 76 (1980) 541.

11. J. A. Gieseke et al., Source Term Code Package: A User's Guide, NUREG/CR-4587, Battelle Columbus Laboratory, Columbus, OH, July 1986.

12. H. Bunz, NAUA4, A Code for Calculating Aerosol Behavior in LWR Core Melt Accidents, Code Description and User's Manual, KfK-353, Kernforschungszentrum Karlsruhe, Karlsruhe, Germany, August 1983.

13. R. M. Summers et al., MELCOR 1.8.0: A Computer Code for Nuclear Reactor Severe Accident Source Term and Risk Assessment Analysis, NUREG/CR-5531, SAND90-0364, Sandia National Laboratories, Albuquerque, NM, January 1991. 
14. F. Gelbard, MAEROS User's Manual, NUREG/CR-1391, SAND80-0822, Sandia National Laboratories, Albuquerque, NM, December 1982.

15. K. E. Washington, K. K. Murata, R. G. Gido, F. Gelbard, N. A. Russell, S. C. Billups, D. E. Carroll, R. O. Griffith, and D. L. Y. Louie, Reference Manual for the CONTAIN 1.1 Code for Containment Severe Accident Analysis, NUREG/CR-5715, SAND91-0835, Sandia National Laboratories, Albuquerque, NM, July 1991.

16. S. K. Loyalka, Progress in Nuclear Energy, 12 (1983) 1.

17. N. Ketchell, I. H. Dunbar, and C. J. Wheatley, "ITHACA - A Coupled Aerosol and ThermalHydraulic Containment Code," p. 70, Proceedings Workshop on Aerosol Behavior and Thermal Hydraulics in the Containment, Committee on the Safety of Nuclear Installations, Paris, France, November 1990.

18. R. E. Adams et al., Sodium Oxide Aerosol Study: NSPP Runs 101-105, Data Record Report, ORNL/NUREG/TM-179, Oak Ridge National Laboratory, Oak Ridge, TN, April 1978.

19. R. E. Adams et al., Sodium Oxide and Uranium Oxide Aerosol Experiments: NSPP Tests 106108 and Tests 204-207, Data Record Report, NUREG/CR-1767, Oak Ridge National Laboratory, Oak Ridge, TN, March 1981.

20. M. L. Tobias and R. E. Adams, Limestone Concrete Aerosol Experiments in Steam-Air Atmospheres: NSPP Tests 521, 522, and 531, Data Record Report, NUREG/CR-5017, ORNL/TM-10587, Oak Ridge National Laboratory, Oak Ridge, TN, October 1987.

21. R. K. Hilliard et al., Aerosol Behavior During Sodium Pool Fires in a Large Vessel - CSTF Tests AB1 and AB2, HEDL-TME 83-16, Hanford Engineering and Development Laboratory, Richland, WA, June 1979.

22. R. K. Hillard, J. D. McCormack, and L. D. Muhlestein, Results and Code Predictions for ABCOVE Aerosol Code Validation with Low Concentration $\mathrm{NaOH}$ and NaI Aerosol - CSTF Test AB7, HEDL-TME 85-1, Hanford Engineering and Development Laboratory, Richland, WA, October 1985.

23. R. K. Hilliard et al., Results and Code Predictions for ABCOVE Aerosol Code Validation - Test AB6 with Two Aerosol Species, HEDL-TME 84-19, Hanford Engineering and Development Laboratory, Richland, WA, December 1984.

24. L. N. Kmetyk, MELCOR 1.8.1 Assessment: MARVIKEN-V Aerosol Transport Tests ATT-26/Att-4, SAND92-2243, Sandia National Laboratories, Albuquerque, NM, January 1993 (and references therein).

25. T. K. Kanzleiter, Demona Experiments Final Report, BleV R65.523-01 Battelle Institute E.V., Frankfurt am Main, Germany, September 1987. 
26. F. J. Rahn, Summary of the LWR Aerosol Containment Experiments (LACE) Program Interim Report, LACE TR-012, Electric Power Research Institute, Palo Alto, CA, January 15, 1987.

27. J. C. Helton, R. L. Iman, J. D. Johnston, and C. D. Leigh, Nuclear Science and Engineering, 102 (1989) 22.

28. J. C. Helton, R. L. Iman, J. D. Johnston, and C. D. Leigh, Nuclear Technology, 73 (1986) 320.

29. J. C. Helton, R. C. Iman, J. D. Johnston, and C. D. Leigh, Uncertainty and Sensitivity Analysis of a Dry Containment Test Problem for the MAEROS Aerosol Model, NUREG/CR-4487 SAND85-2795, Sandia National Laboratories Albuquerque, NM, June 1986.

30. J. C. Helton, R. L. Iman, J. D. Johnston, and C. D. Leigh, Uncertainty and Sensitivity Analysis of a Model for Multicomponent Aerosol Dynamics, NUREG/CR-4342, SAND84-1307, Sandia National Laboratories, Albuquerque, NM, September 1985.

31. J. C. Helton, R. L. Iman, J. D. Johnson, and C. D. Leigh, Uncertainty and Sensitivity Analysis of an Upper Plenum Test Problem for the MAEROS Aerosol Model, NUREG/CR-4460 SAND85-2196, Sandia National Laboratories, Albuquerque, NM, January 1986.

32. S. K. Loyalka, Progress in Nuclear Energy, 12 (1983) 1.

33. F. Beonio-Brocchieri, et al., Nuclear Technology, 81 (1988) 193.

34. B. H. McDonald, "Assessing Numerical Methods Used in Nuclear Aerosol Transport Models," in Proceedings of Water-cooled Reactor Aerosol Code Evaluation and Uncertainty Assessment, E. della Loggia and J. Royen, editors, EUR-11351 EX, Commission of the European Communities, Luxembourg, 1988.

35. R. J. Lipinski et al., Uncertainty in Radionuclide Release Under Specific LWR Accident Conditions Volume II, TMLB ${ }^{1}$ Analyses, SAND84-4100, Vol. 2, Sandia National Laboratories, Albuquerque, NM, February 1985.

36. J. H. Wilson and P. C. Atwood, Comparison of (Posttest) Predictions of Aerosol Codes with Measurements in LWR Aerosol Containment Experiments (LACE) LAT., LACE TR-084, ORNL/M-991, Oak Ridge National Laboratory, Oak Ridge, TN, February 1987.

37. I. H. Dunbar, "A General Review of Aerosol Modeling," in Workshop on Aerosol Behavior and Thermal-Hydraulics in the Containment, Committee on the Safety of Nuclear Installations OECD Nuclear Energy Agency, Paris, France, 1990.

38. P. Fynbo, H. Haggblom, and J. Jokiniemi, Aerosol Transport in Severe Reactor Accidents, Studsvik AB, Nykoping, Sweden, March 1990.

39. OECD, Nuclear Aerosols in Reactor Safety, Supplementary Report, Paris, France, 1985. 
References

40. S. K. Loyalka, "Models for Aerosol Rate Processes in Nuclear Reactor Source Term Studies," p. 5-29, Proceedings of the Symposium on Chemical Phenomena Associated with Radioactivity Releases During Severe Nuclear Plant Accidents, S. J. Niemczyk, editor, NUREG/CP-0078, U.S. Nuclear Regulatory Commission, Washington, D.C., June 1987.

41. M. M. R. Williams and S. K. Loyalka, Aerosol Science Theory and Practice, Pergamon Press, 1989.

42. N. A. Fuchs, Dokl. Akad. Nauk. SSSR, 81 (1951) 1043.

43. H. R. Pruppacher and J. D. Klett, Microphysics of Clouds, Reidel Publ. Co., 1978.

44. P. N. Smith and G. J. Roberts, "Application of the CONTAIN Code to the Analysis of the Large-scale Aerosol Experiments," Water-cooled Reactor Aerosol Code Evaluation and Uncertainty Assessment, E. della Loggia and J. Royen, editors, EUR 11351 EX, Commission of the European Communities, Brussels, Belgium, 1988.

45. J. D. Klett and M. H. Davis, J. Atmospheric Sci., 30 (1973) 107.

46. F. Gelbard, L. A. Mondy, and S. E. Ohrt, J. Statistical Physics 62 (1991) 945.

47. G. A. Pertmer and S. K. Loyalka, Nuclear Technology, 47 (1980) 70.

48. V-M. Kerminen, Aerosol Science and Technology, 20 (1994) 207.

49. M. K. Alam, Aerosol Science and Technology, 6 (1987) 41.

50. P. G. Saffman and J. S. Turner, J. Fluid Mechanics, 1 (1956) 16.

51. T. Alty and C. A. Mackay, Proc. Roy. Soc. London, A149 (1935) 104.

52. H. R. Pruppacher and J. D. Klett, Microphysics of Clouds, Reidel Publ. Co., 1978.

53. Y. Y. Hsu and R. W. Graham, Transport Processes in Boiling and Two-Phase Systems, Hemisphere, 1976.

54. P. E. Wagner, "Aerosol Growth by Condensation," Aerosol Microphysics II - Chemical Physics of Microparticles, W. H. Marlow, editor, Springer-Verlag, 1982.

55. N. E. Levine, J. Geophys. Research, 78 (1973) 6266.

56. J. C. Barrett and C. F. Clement, J. Aerosol Science, 19 (1988) 223.

57. J. C. Barrett and C. F. Clement, J. Aerosol Science, 21 (1990) 761.

58. K. S. Pitzer, "Theory: Ion Interaction Approach," Chapter 7 in Activity Coefficients in Electrolyte Solutions, Volume 1, R. M. Pytkowicz, editor, CRC Press. 
59. M. Kulmala and T. Vesla, J. Aerosol Science, 22 (1991) 337.

60. N. B. Vargaftik, Handbook of Physical Properties of Liquids and Gases - Pure Substances and Mixtures, Second edition, Hemisphere Publishing Co., 1975.

61. S. K. Loyalka and J. H. Ferziger, Phys. of Fluids, 11 (1968) 1668.

62. S. K. Dua, P. Brand, E. Karg, and J. Heyder, Aerosol Science and Technology, 21 (1994) 170.

63. L. Waldmann and K. H. Schmitt, "Thermophoresis and Diffusiophoresis," Chapter VI in Aerosol Science, C. N. Davies, editor, Academic Press, 1966.

64. M. M. R. Williams, Z. Naturforsch., 27 (1972) 1798.

65. M. M. R. Williams, Z. Naturforsch., 27 (1972) 1804.

66. As cited in M. M. R. Williams, Z. Naturforsch., 27a (1972) 1798.

67. P. Goldsmith and F. G. May, "Diffusiophoresis and Thermophoresis in Water Vapour Systems," Chapter VII in Aerosol Science, C. N. Davies, editor, Academic Press, 1966.

68. M. L. Corradini, Nuclear Technology, 64 (1984) 1186.

69. S. P. Bakanov, Aerosol Science and Technology, 15 (1991) 77.

70. L. Talbot, R. K. Cheng, R. W. Schefer, and D. R. Willis, J. Fluid Mechanics, 101 (1980) 737.

71. S. K. Loyalka, Physica, A 163 (1990) 813.

72. N. A. Fuchs, The Mechanics of Aerosols, Pergamon Press, 1964.

73. J. F. van de Vate, Investigations into the Dynamics of Aerosols in Enclosures as Used for Air Pollution Studies, ECN-86, Netherlands Energy Research Foundation, Petten, The Netherlands, July, 1980.

74. S. K. Friedlander and H. F. Johnstone, Industrial and Engineering Chemistry, 49 (1957) 1151.

75. B. Y. H. Liu and J. K. Agarwal, J. Aerosol Science, 5 (1974) 145.

76. A. C. Wells and A. C. Chamberlain, Brit. J. Appl. Phys., 18 (1967) 1793.

77. P. O. Rouhiainen and J. W. Stachiewicz, J. Heat Transfer, (1970) 169.

78. A. L. Hines and R. N. Maddock, Mass Transfer Fundamental and Applications, Prentice-Hall, 1985.

79. G. A. Sehmel, J. Aerosol Science, 4 (1973) 125. 
References

80. A. Willers, "Determination of Turbulent Particle Deposition Rates by Use of the Frequency Response Method," p.242, Nuclear Science and Technology-Water-Cooled Reactor Aerosol Code Evaluation and Uncertainty Assessment, E. della Loggia and J. Royen, editors, EUR-11351 Commission of the European Communities, Luxembourg, 1988.

81. S. K. Beal, Nuclear Science and Engineering, 40 (1970) 1.

82. H. Sauter and H. Bunz, J. Aerosol Science, 15 (1984) 350.

83. N. B. Wood, J. Aerosol Science, 12 (1981) 275.

84. J. E. Brockmann, "Range of Possible Dynamic and Collision Shape Factors," Appendix F, R. J. Lipinski et al., Uncertainty in Radionulide Release Under Specific LWR Accident Conditions, Volume II. TMLB' Accident Conditions, SAND84-0410, Vol. 2, Sandia National Laboratories, Albuquerque, NM, February 1985.

85. F. Lesaffre, J. Aerosol Sci., 20 (1989) 857.

86. P. Meakin, B. Donn, and G. W. Mulholland, Langmuir, 5 (1989) 510.

87. R. A. Millikan, Phys. Rev., 22 (1923) 1.

88. M. D. Allen and O. G. Raabe, Aerosol Science and Technology, 4 (1985) 269.

89. C. N. Davies, Proc. Phys. Soc., 57 (1949) 259.

90. B. K. Annis, A. P. Malinauskus, and E. A. Mason, J. Aerosol Science, 3 (1972) 55.

91. S. G. Jennings, J. Aerosol Science, 19 (1988) 159.

92. W. F. Phillips, Physics of Fluids, 18 (1975) 1069.

93. B. E. Dahneke, J. Aerosol Science, 4 (1973) 163.

94. B. E. Dahneke, J. Aerosol Science, 4 (1973) 147.

95. B. E. Dahneke, J. Aerosol Science, 4 (1973) 139.

96. J. Jokiniemi, "Steam Condensation on Containment Aerosols," p.27, Proceedings of Workshop on Aerosol Behavior and Thermal-Hydraulics in the Containment, Committee on the Safety of Nuclear Installations Paris, France.

97. J. Jokiniemi, Nuclear Technology, 83 (1988) 16.

98. A. Drozd and J. Baron, "Hygroscopic Aerosol Growth at Near Saturated Conditions," Proceedings of OECD/NEA Workshop on Water-cooled Reactor Aerosol Code Evaluation and Uncertainty Assessment, EUR 11351, OECD, Brussels, Belgium 1988. 
99. J. Jokiniemi, K. Koistinen, and T. Raunemaa, Nuclear Technology, 90 (1990) 394.

100. Y. S. Touloukian et al., Thermal Conductivity, Volumes 1 and 2, IFI Plenum, 1970.

101. J. A. Gieseke et al., Radionuclide Release Under Specific LWR Accident Conditions, Volume V. PWR-Large Dry Containment Design (Surry Plant Recalculations), BMI-2104 Draft, Volume V, Battelle Columbus Laboratory, Columbus, OH, July 1984.

102. M. T. Leonard et al., Supplemental Radionuclide Release Calculations for Selected Severe Accident Scenarios, NUREG/CR-5062, BMI-2160, Battelle Columbus Laboratory, Columbus, OH, July 1986.

103. R. S. Denning et al., Radionuclide Release Calculations for Selected Severe Accident Scenarios-PWR, Large Dry Containment Design, NUREG/CR-4624 Volume 5, BMI-2139, Battelle Columbus Laboratory, Columbus, OH, July 1986.

104. J. A. Gieseke et al., Radionuclide Release Under Specific LWR Accident Conditions, Volume VI. PWR-Large, Dry Containment Design (Zion Plant), BMI-2104, Battelle Columbus Laboratory, Columbus, OH, July 1986.

105. J. A. Gieseke et al., Radionuclide Release Under Specific LWR Accident Conditions, Volume IV PWR, Ice Condenser Containment Design, BMI-2104, Battelle Columbus Laboratory, Columbus, OH, July 1984.

106. R. S. Denning et al., Radionuclide Release Calculations for Selected Severe Accident Scenarios, BWR, Mark I Design, NUREG/CR-4624, BMI-2139, Vol.1, Battelle's Columbus Division, Columbus, OH, July 1986.

107. R. S. Denning et al., Radionuclide Release Calculations for Selected Severe Accident Scenarios, BWR, Mark III Design, NUREG/CR-4624, BMI-2139, Vol. 4, Battelle's Columbus Division, Columbus, OH, July 1986.

108. D. J. Rader, J. Aerosol Science, 21 (1990) 161.

109. S. C. Saxena and R. K. Joshi, Thermal Accommodation and Adsorption Coefficients, Hemisphere Publishing Co., 1991.

110. G. M. Rossenblatt, Accounts of Chemical Research, 14 (1981) 4.

111. R. E. Riley and D. J. Diestler, Surface Science, 175 (1986) 579.

112. F. O. Goldman and H. Y. Wachman, J. Chem. Phys., 46 (1967) 2376.

113. R. C. Reid, J. M. Prausnitz, and B. E. Poling, The Properties of Gases and Liquids, 4th Edition, McGraw-Hill Book Co., 1987. 
References

114. E. N. Fuller, P. D. Schettler, and J. C. Giddings, Industrial and Engineering Chemistry, 58 (1966) 18.

115. E. N. Fuller, K. Ensley, and J. C. Giddings, J. Phys. Chem, 75 (1969) 3679.

116. B. K. Pathak, V. N. Singh, and P. C. Singh, Canad. J. Chem. Eng., 59 (1991) 362.

117. C. R. Wilke and C. Y. Lee, Industrial and Engineering Chemistry, 47 (1955) 1253.

118. E. A. Mason and S. C. Saxena, Physics of Fluids, 1 (1958) 361.

119. Y. S. Touloukian, S. C. Saxena, P. Hestermans, Thermophysical Properties of Matter Volume II Viscosity, IFI/Plenum, 1975.

120. A. Boushehri, J. Bzowski, J. Kestin, and E. A. Mason, J. Phys. Chem. Ref. Data, 16 (1987) 445.

121. C. F. Clement and R. G. Harrison, J. Aerosol Science, 23 (1992) 481.

122. V. D. Ivanov, V. N. Kirichenko, and I. V. Petryanov, Soviet Physics, 13 (1969) 902.

123. E. P. Emets, V. A. Kascheev, and P. P. Poluektov, J. Aerosol Science, 24 (1993) 867.

124. J. Bricard and J. Pradel, "Electric Charge and Radioactivity of Naturally Occurring Aerosols," Chapter IV in Aerosol Science, C. N. Davies, editor, Academic Press, 1966.

125. L. D. Reed, H. Jordan, and J. A. Gieseke, J. Aerosol Science, 8 (1977) 457.

126. W. A. Hoppel and G. M. Frick, Aerosol Science and Technology, 5 (1986) 1.

127. H. W. Ellis, et al., Atomic Data and Nuclear Data Tables, 22 (1978) 179.

128. H. W. Ellis, P. Y. Pal, and E. W. McDaniel, Atomic Data and Nuclear Data Tables, 17 (1976) 177.

129. D. A. Armstrong, "The Radiation Chemistry of Gases," Chapter 9 in Radiation Chemistry Principles and Practices, Farhataziz and M. A. J. Rodgers, editors, VCH Publishers, 1987.

130. A. Wiedensohler and H. J. Fissan, J. Aerosol Science, 19 (1988) 867.

131. M. Ashadi, R. Yandagmi, and P. Kebarle, J. Phys. Chem., 74 (1970) 1475.

132. G. Y. Kolomeitsev, I. E. Nakhutin, and P. P. Poluektov, Soviet Atomic Energy, 55 (1983) 628.

133. M. D. Muhlheim and E. G. Silver, Nuclear Safety, 32 (1991) 275. 
134. P. Lobner, C. Donahoe, and C. Cavallin, Overview and Comparison of U. S. Commercial Nuclear Power Plants, NUREG/CR-5640, SAIC-89/1541, Science Applications International Corp., San Diego, CA, September 1990.

135. M. R. Kuhlman, D. J. Lehmicke, and R. O. Meyer, CORSOR User's Manual, NUREG/CR4173, BMI-2122, Battelle Memorial Laboratory, Columbus, OH, March 1985.

136. T. S. Kress, Review of the Status of Validation of the Computer Codes Used in the Severe Accident Source Term Assessment Study, (BMI-2104), ORNL/TM-8842, Oak Ridge National Laboratory, Oak Ridge, TN, April 1985.

137. D. A. Powers, J. E. Brockmann, and A. W. Shiver, VANESA: A Mechanistic Model of Radionuclide Release and Aerosol Generation During Core Debris Interactions with Concrete, NUREG/CR-4308, SAND85-1370, Sandia National Laboratories, Albuquerque, NM, July 1986.

138. E. R. Copus and D. R. Bradley, Interaction of Hot Solid Core Debris with Concrete, NUREG/CR-4558, SAND85-1739, Sandia National Laboratories, Albuquerque, NM, June 1986.

139. K. D. Bergeron, A. L. Camp, and D. A. Powers, "Some Unresolved Issues in the Analysis of Severe Accident Phenomena," Paper XXVII, Volume 5, Proceedings of ANS Topical Meeting on Thermal Reactor Safety, American Nuclear Society, La Grange, IL, 1986.

140. Advanced Light Water Reactor Utility Requirements Document, Electric Power Research Institute, Palo Alto, CA, 1990.

141. D. A. Powers and F. E. Arellano, Large-scale, Transient Test of the Interaction of Molten Steel with Concrete, NUREG/CR-2282, SAND81-1753, Sandia National Laboratories, Albuquerque, NM, January 1982.

142. R. K. Cole, Jr., D. P. Kelly, and M. A. Ellis, CORCON Mod 2: A Computer Code for Analysis of Molten Core-Concrete Interactions, NUREG/CR-3920, SAND84-1246, Sandia National Laboratories, Albuquerque, NM, August 1984.

143. I. Kataoka and M. Ishii, Int. J. Heat Mass Transfer, 27 (1984) 1999.

144. D. Azbel et al., "Acoustic Resonance Theory for the Rupture of Film Cap of a Gas Bubble at a Horizontal Gas-Liquid Interface," pp. 159-170 in Two Phase Momentum, Heat and Mass Transfer in Chemical Process and Energy Engineering Systems, Volume 1, Hemisphere Publ. Co., 1978.

145. A. Russell, Proc. Phys. Soc., (London), 35 (1922) 10.

146. D. C. Williams, "Range of Possible Turbulent-Energy-Dissipation Values," Appendix E in, R. J. Lipinski et al., Uncertainty in Radionuclide Release Under Specific Accident Conditions Volume II TMLB ${ }^{1}$ Analyses, SAND84-0410, Vol. 2, Sandia National Laboratories, Albuquerque, NM, February 1985. 
References

147. K. E. Washington, K. K. Murata, R. G. Gido, F. Gelbard, N. A. Russell, S. C. Billups, D. E. Carroll, R. O. Griffith, and D. L. Y. Louie, Reference Manual for the CONTAIN 1.1 Code for Containment Severe Accident Analysis, NUREG/CR-5715, SAND91-0835, Sandia National Laboratories, Albuquerque, NM, July 1991.

148. R. Sher and J. Jokiniemi, NAUAHYGROS 1.0: A Code for Calculating the Behavior of Aerosols in Nuclear Plant Containments Following a Severe Accident, EPRI TR-102775, Electric Power Research Institute, Palo Alto, CA, July 1993.

149. S. K. Friedlander, J. Meteorol., 17 (1960) 479.

150. D. L. Swift and S. K. Friedlander, J. Colloid Sci., 19 (1964) 621.

151. S. K. Friedlander and C. S. Wang, J. Colloid Interface Sci., 22 (1966) 126.

152. G. M. Hidy, J. Colloid Sci., 20 (1965) 123.

153. G. C. Lindauer and A. W. Castleman, Jr., J. Nucl. Sci. Eng., 43 (1971) 85.

154. G. C. Lindauer and A. W. Castleman, Jr., J. Aerosol Science, 2 (1971) 85.

155. K. Takahashi and M. Kasahara, Atmos. Environ., 2 (1968) 441.

156. L. F. Mookros, J. E. Quon, and A. T. Hjelfelt, Jr., J. Colloid Interface Sci., 23 (1967) 90.

157. M. Epstein, P. G. Ellison, and R. E. Henry, J. Colloid Interface Sci., 113 (1987) 168.

158. M. Epstein and P. G. Ellison, Nuclear Engineering and Design, 107 (1988) 327.

159. J. M. Otter and E. U. Vaughan, Evaluation of Empirical Aerosol Correlations, EPRI NP-4974, Rockwell International Corporation, Canoga Park, CA, December 1986.

160. E. U. Vaughn and A. V. von Arx, Evaluation of Aerosol Correlations, EPRI-NP-5602, Rockwell International Corporation, Canoga Park, CA, January 1988.

161. M. Epstein and P. G. Ellison, J. Colloid Interface Sci., 119 (1987) 168. 


\section{DISTRIBUTION:}

6 U.S. Nuclear Regulatory Commission Office of Nuclear Regulatory Research Attn: C. Tinkler, T10K8 J. N. Ridgely, T10K8

J. H. Schaperow, T10K8

R. Y. Lee, T10K8

A. Rubin, T10K8

M. A. Cunningham, T10E50

Washington, DC 20555

3 U.S. Nuclear Regulatory Commission Office of Nuclear Reactor Regulation

Attn: R. Palla, O8H7

C. Miller, O10D4

J. Lee, O10D4

Washington, DC 20555

1 U.S. Nuclear Regulatory Commission Office of the Director for Operations Attn: L. Soffer, O17G21

Washington, DC 20555

1 U.S. Department of Energy NE-42

Attn: S. Sorrell 19901 Germantown Rd.

Germantown, MD 20585

2 U.S. Department of Energy

Albuquerque Operations Office

Attn: C. E. Garcia, Director

For: C. B. Quinn

R. L. Holton

P.O. Box 5400

Albuquerque, NM 87185

1 Electric Power Research Institute

Attn: M. Merilo

3412 Hillview Avenue

Palo Alto, CA 94303
5 Brookhaven National Laboratory

Attn: V. Mubayi

R. Davis

G. A. Greene

H. Nourbakhsh

T. Ginsberg

Upton, NY 11973

1 U.S. Department of Energy

Office of Nuclear Safety Coordination

Attn: R. W. Barber

Washington, DC 20545

1 U.S. Department of Energy

EM-38

Attn: D. Pepson

12800 Middlebrook Road

Germantown, MD 20874

1 University of California Los Angeles

Nuclear Energy Laboratory

Attn: D. Okrent

405 Hilgaard Avenue

Los Angeles, CA 90024

1 Tennessee Valley Authority

Attn: Wang Lu

400 Commerce, WGC157-CK

Knoxville, TN 37902

1 Battelle Pacific Northwest Laboratory

Attn: M. Freshley

P.O. Box 999

Richland, WA 99352

1 Professor R. Seale

Department of Nuclear Engineering

University of Arizona

Tucson, AZ 85721 
5 Oak Ridge National Laboratory

Attn: A. L. Wright

E. Beahm

S. Hodge

C. Hyman

C. Weber

P.O. Box 2009

Oak Ridge, TN 37831

1 Battelle Columbus Laboratory

Attn: R. Denning

505 King Avenue

Columbus, OH 43201

1 D. Osetek

Los Alamos Technical Associates

Building 1, Suite 400

2400 Louisiana NE

Albuquerque, NM 87110

1 David Leaver

POLESTAR

4 Main St.

Los Altos, CA 94022
1 S. Rosen

Nuclear Fuel Engineering

ABB Combustion Engineering Nuclear Power 1000 Prospect Hill Road

P.O. Box 500

Windsor, CT 06095-0500

1 Professor T. G. Theofanous

University of California-Santa Barbara

Chemical and Nuclear Engineering Dept.

UC-Santa Barbara

Santa Barbara, CA 93106

1 T. S. Kress

102-B Newridge Rd.

Oak Ridge, TN 37830 
DISTRIBUTION (Continued):

\section{FOREIGN DISTRIBUTION}

1 M. Jankowski

International Atomic Energy Agency

Division of Nuclear Reactor Safety

Wagranerstrasse 5

P.O. Box 100

A/1400 Vienna

AUSTRIA

1 H. Bairiot, Chief

Department LWR Fuel

Belgonucleair

Reu de Champde Mars. 25

B-1050 Brussels

BELGIUM

1 P. Fehrenbach

Atomic Energy Canada, Ltd.

Chalk River, Ontario

CANADA KOJ IJO

$1 \mathrm{Mm}$. C. Lecomte

CEN FAR

60-68 Av. du G. Leclerc-B.P.6

92265 Fontenay aux Roses Cedex

FRANCE

1 Kernforschungszentrum Karlsruhe

Attn: H. Alsmeyer

Postfach 3640

75 Karlsruhe

GERMANY

1 Technische Universitat Munchen

Attn: Professor H. Karwat

8046 Garching, Forschungagelande

Munich

GERMANY

1 Alan Jones

ISPRA

CEC Joint Research Center

21020 Varese

ITALY
2 Japan Atomic Energy Research Institute Severe Accident Research Laboratory

Attn: N. Yamano

Y. Maruyama

Tokai-mura, Naka-gun, Ibaraki-ken

319-11

JAPAN

4 Japan Atomic Energy Research Institute Reactor Accident Laboratory

Attn: Dr. T. Fujishiro, Head

Tokai-mura, Naka-gun, Ibaraki-ken

319-11

JAPAN

1 Japan Atomic Energy Research Institute Tokai Research Establishment

Attn: Dr. S. Matsuura, Deputy Director General

Tokai-mura, Naka-gun, Ibaraki-ken

319-11

JAPAN

1 Itaru Kaneko

Chemical Technology Group

Nuclear Engineering Laboratory

Toshiba Corporation

4-1 Ukishima Cho, Kawasaki Ku

Kawasaki 210

JAPAN

1 Japan Atomic Energy Research Institute

Attn: K. Sato

Fukoku Seime Building

2-2-2, Uchisaiwai-cho, Chiyoda-ku, Tokyo JAPAN

1 Korea Advanced Energy Research Institute

Attn: H. R. Jun

P.O. Box 7

Daeduk-Danji

Choong-Nam

KOREA 
DISTRIBUTION (Continued):

FOREIGN DISTRIBUTION

1 POSTECH

Dept. of Mechnical Eng.

Attn: Moo Hwan Kim

P.O. Box 125

Kyungbuk 790-600

KOREA

1 Dr. K. J. Brinkman

Reactor Centrum Nederland

1755 ZG Petten

THE NETHERLANDS

1 Luis E. Herranz Puebla

Instituto de Tecnologia Nuclear

Proyecto Tecnologia de la Contencion

Ministerio de Industria y Energia

Avda Complutense

22-28040 Madrid

SPAIN

1 Stratens Karnfraftinspektion

Attn: L. Hammer

P.O. Box 27106

S-10252 Stockholm

SWEDEN
1 J. E. Antill

Berkeley Nuclear Laboratory

Berkeley GL 139 PB

Gloucestershire, England

UNITED KINGDOM

1 W. G. Cunliffe

Bldg. 396

British Nuclear Fuels, Ltd.

Springfield Works

Salwick, Preston

Lancashire, England

UNITED KINGDOM

5 AEA Technology

Attn: B. Bowsher, 105A/A50

S. Dickinson, 105A/A50

P. Smith, 215/A23

D. Sweet, 210/A32

D. Williams, 210/A32

Winfrith, Dorchester

Dorset DT2 8DH, England

UNITED KINGDOM 


\section{SANDIA DISTRIBUTION}

1 MS-0736 N. R. Ortiz 6400

1 MS-0744 W. A. von Riesemann 6403

5 MS-0744 D. A. Powers 6404

1 MS-0748 F. T. Harper $\quad 6413$

1 MS-0748 T. D. Brown 6413

1 MS-0739 K. D. Bergeron 6421

1 MS-1137 M. D. Allen 6422

1 MS-1137 N. Bixler 6422

1 MS-1137 J. E. Brockmann 6422

1 MS-1137 T. K. Blanchat 6422

1 MS-1137 T. Y. Chu 6422

1 MS-1137 R. M. Elrick 6422

1 MS-1137 T. J. Heames 6422

1 MS-0739 D. C. Williams 6429

1 MS-0738 K. K. Murata 6429

1 MS-1175 L. A. Miller 6513

1 MS-0718 J. L. Sprung 6641

1 MS-0722 K. E. Washington 6913

1 MS-9018 Central Technical Files 8523

1 MS-0619 Technical Publications 12615

5 MS-0899 Technical Library 13414 
(See instructions on the reverse)

NUREG/CR-6189

SAND94-0407

\section{TITLE AND SUBTITLE}

A Simplified Model of Aerosol Removal by Natural Processes in Reactor Containments

\begin{tabular}{|l|r|}
\hline 3. & \multicolumn{2}{|c|}{ DATE REPORT PUBLISHED } \\
\hline MONTH & YEAR \\
July & 1996 \\
\hline $\begin{array}{l}\text { 4. FIN OR GRANT NUMBER } \\
\text { L2035 }\end{array}$ \\
\hline 6. TYPE OF REPORT
\end{tabular}

5. AUTHOR(S)

D.A. Powers, K.E. Washington, S.B. Burson,* J.L. Sprung

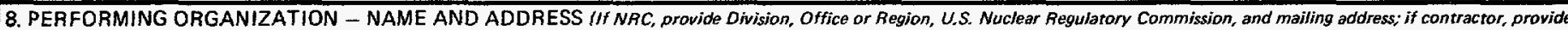
name and mailing address.

Sandia Nationa1 Laboratories

*U.S. Nuclear Regulatory Commission

Albuquerque, NM 87185-0744

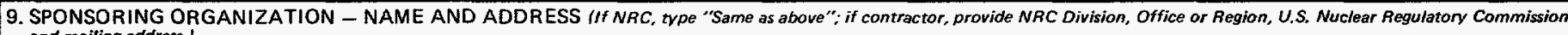
and mailing address.)

Division of Systems Technology

Office of Nuclear Regulatory Research

U.S. Nuclear Regulatory Commission

Washington, DC 20555-0001

10. SUPPLEMENTARY NOTES

J.H. Schaperow, NRC Project Manager

11. ABSTRACT (200 words or less)

Simplified formulae are developed for estimating the aerosol decontamination that can be achieved by natural processes in the containments of pressurized water reactors and in the drywells of boiling water reactors under severe accideat conditions. These simplified formulae were derived by correlation of results of Monte Carlo uncertainty analyses of detailed models of aerosol behavior under accident conditions. Monte Carlo uncertainty analyses of decontamination by natural aerosol processes are reported for $1000,2000,3000$, and $4000 \mathrm{MW}(\mathrm{th})$ pressurized water reactors and for 1500,2500 , and $3500 \mathrm{MW}(\mathrm{th})$ boiling water reactors. Uncertainty distributions for the decontamination factors and decontamination coefficients as functions of time were developed in the Monte Carlo analyses by considering uncertainties in aerosol processes, material properties, reactor geometry, and severe accident progression. Phenomenological uncertainties examined in this work included uncertainties in aerosol coagulation by gravitational collision, Brownian diffusion, turbulent diffusion, and turbulent inertia. Uncertainties in aerosol deposition by gravitational settling, thermophoresis, diffusiophoresis, and turbulent diffusion were examined. Electrostatic charging of aerosol particles in severe accidents is discussed.

Median (50 percentile), 90 , and 10 percentile values of the uncertainty distributions for effective decontamination coefficients were correlated with time and reactor thermal power. These correlations constitute a simplified model that can be used to estimate the decontamination by natural aerosol processes at three levels of conservatism. Example applications of the simplified model are described.

12. KEY WORDS/DESCR!PTORS (List words or phrases that will assist researchers in locating the report.)

aerosol, decontamination, thermophoresis, diffusiophoresis, turbulent deposition, electrostatic charging, severe reactor accidents

\begin{tabular}{l} 
13. AVAILABILITY STATEMENT \\
unlimited \\
\hline \begin{tabular}{l} 
14. SECURITY CLASSIFICATION \\
(This Page) \\
unclassified \\
(This Report) \\
unclas ified \\
\hline 15. NUMBER OF PAGES \\
\hline 16. PRICE
\end{tabular} \\
\hline
\end{tabular}

